Portland State University

PDXScholar

\title{
Uncertainty analysis of runoff estimates from runoff- depth contour maps produced by five automated procedures for the northeastern United States
}

Gary D. Bishop

Portland State University

Follow this and additional works at: https://pdxscholar.library.pdx.edu/open_access_etds

Part of the Geography Commons

Let us know how access to this document benefits you.

\section{Recommended Citation}

Bishop, Gary D., "Uncertainty analysis of runoff estimates from runoff-depth contour maps produced by five automated procedures for the northeastern United States" (1991). Dissertations and Theses. Paper 4313.

https://doi.org/10.15760/etd.6197

This Thesis is brought to you for free and open access. It has been accepted for inclusion in Dissertations and Theses by an authorized administrator of PDXScholar. Please contact us if we can make this document more accessible: pdxscholar@pdx.edu. 
AN ABSTRACT OF THE THESIS OF Gary D. Bishop for the Master of Science in Geography presented September 24, 1991.

Title: Uncertainty Analysis of Runoff Estimates from Runoff-Depth Contour Maps Produced by Five Automated Procedures for the Northeastern United States.

APPROVED BY THE MEMBERS OF THE THESIS COMMITTEE:

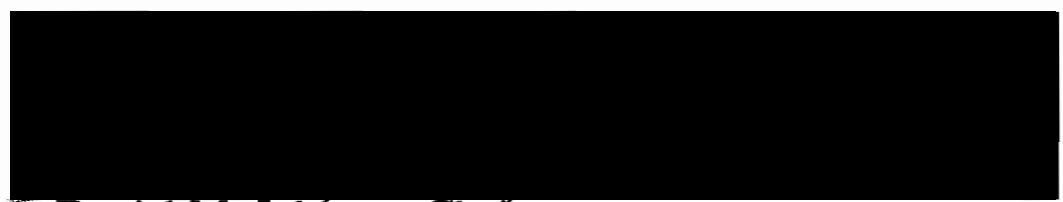

Daniel M. Jornson, Chair
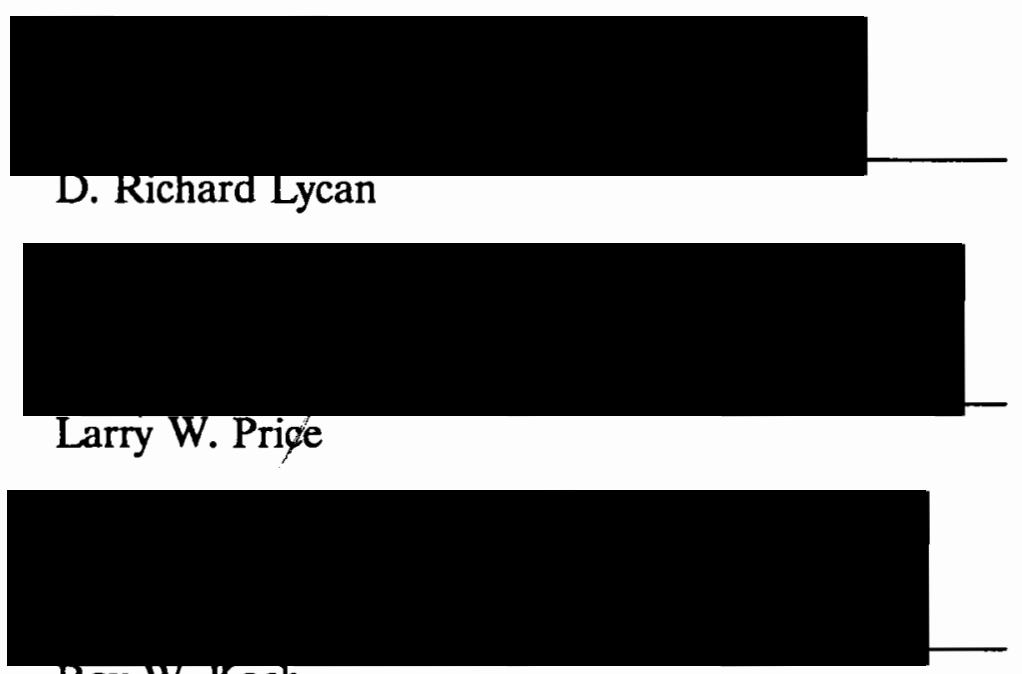

Roy W. Koch

Maps of runoff-depth have been found to be useful tools in a variety of water resource applications. Producing such maps can be a challenging and expensive task. One of the standard methods of producing these maps is to use a manual procedure 
based on gaged runoff data, topographic and past runoff-depth maps, and the expert opinion of hydrologists.

This thesis examined five new automated procedures for producing runoff-depth contour maps to see if the maps produced by these procedures had similar accuracy and characteristics when compared to the manual procedure. An uncertainty analysis was used to determine the accuracy of the automated procedure maps by withholding gaged runoff data from the creation of the contour maps and then interpolating estimated runoff back to these sites from the maps produced. Subtracting gaged runoff from estimated runoff produced interpolation error values. The mean interpolation error was used to define the accuracy of each map and was then compared to a similar study by Rochelle, et al., (1989) conducted on a manual procedure map.

This thesis found that two automated procedures, one based on estimating runoff with mean regional water-year runoff-to-precipitation ratios and the other on a regression formula based on long-term climatic data used to predict water-year 1984 runoff, had the lowest mean interpolation errors. These two procedures produce the most accurate maps on a regional basis of the five tested and compare favorably in regards to accuracy and lack of bias to the manual procedure. These results indicate that simple automated procedures can produce runoff-depth contour maps with regional accuracies roughly equivalent to those produced by the manual procedure. 
UNCERTAINTY ANALYSIS OF RUNOFF ESTIMATES

FROM RUNOFF-DEPTH CONTOUR MAPS

PRODUCED BY FIVE AUTOMATED PROCEDURES

FOR THE NORTHEASTERN UNITED STATES

by

GARY D. BISHOP

A thesis submitted in partial fulfillment of the requirements for the degree of

MASTER OF SCIENCE

in GEOGRAPHY

Portland State University

1991 


\section{TO THE OFFICE OF GRADUATE STUDIES:}

The members of the Committee approve the thesis of Gary D. Bishop presented September 24, 1991.

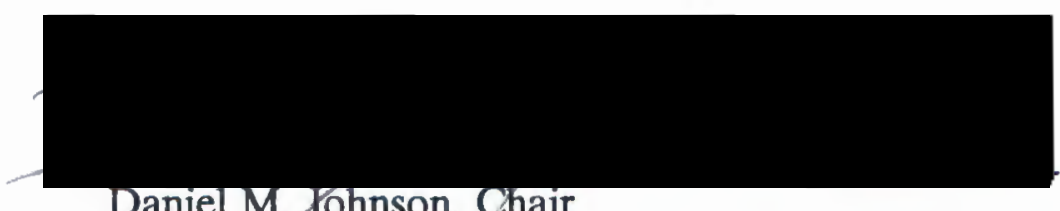

Daniel M. Johnson, Chair

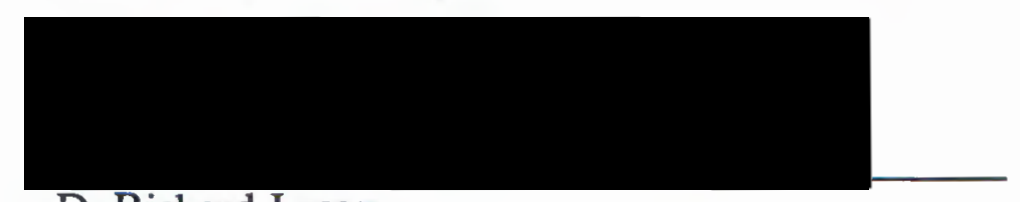

D. Richard Lycan

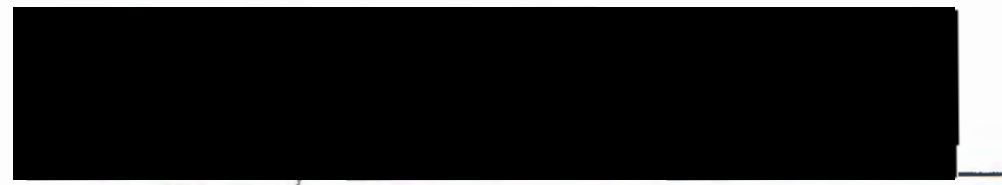

Larry W. Price

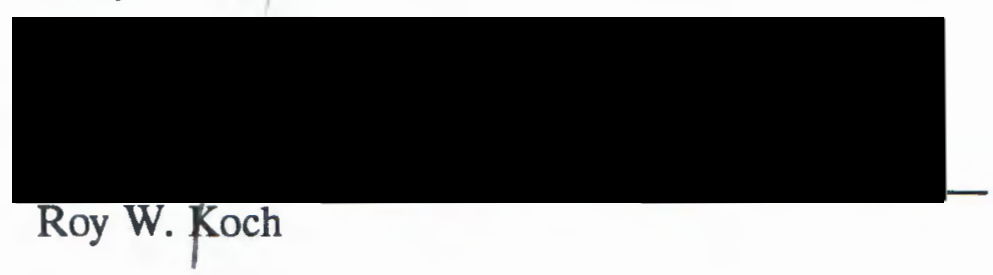

\section{APPROVED:}

Thomas M. Poulsen, Chair, Department of Geography

C. William Savery, Vice Provost for Gradugfe Studies and Research 
TO MY FATHER AND MOTHER 


\section{ACKNOWLEDGEMENTS}

I am grateful to M. Robbins Church of the U.S. Environmental Protection Agency for his inspiration and guidance throughout this project. Without his assistance this thesis would not have been possible. I would like to thank Don Stevens of ManTech Environmental Technology Corporation for his generation of the withheld data set used in the uncertainty analysis, his explanation of the processes and theory involved, and his statistical advice. I greatly appreciate the assistance of David Cassell, also of ManTech, for his ever patient advice on statistical procedures and his computation of the statistical differences between the interpolated and estimated runoff at the water-year 1984 precipitation sites as well as his help in calculating the mean differences between the distance classed long-term and wateryear 1984 runoff-to-precipitation ratios. I would also like to thank Sue Pierson and Bill Campbell of ManTech for there help in the early stages of development of this project and Brenda Huntley of ManTech for her rendering of the flow diagrams used in Figures 9-16.

I am grateful to the Department of Geography, Portland State University, and the American society for Photogrammetry and Remote Sensing, Columbia River Region whose generous endowments helped relieve the financial burden of this research. 
To the faculty, staff, and students of the departments of Geography, Geology, and Urban Studies I extend my gratitude for your support and for what you have taught me. And last but not least, a special thanks to Dr. Dan Johnson and the other members of my committee, Dr. D. Richard Lycan, Dr. Larry Price, and Dr. Roy Koch for their many helpful comments and their assistance in helping me see this project to its completion. 


\section{TABLE OF CONTENTS}

PAGE

ACKNOWLEDGEMENTS. ................... iii

LIST OF TABLES. . . . . . . . $\ldots \ldots \ldots \ldots \ldots \ldots \ldots$ viii

LIST OF FIGURES. $\ldots \ldots \ldots \ldots \ldots \ldots \ldots \ldots \ldots \ldots \ldots, \mathbf{x}$

LIST OF PLATES. $\ldots \ldots \ldots \ldots \ldots \ldots \ldots \ldots \ldots \ldots \ldots \ldots \ldots \ldots$ xiv

\section{CHAPTER}

I INTRODUCTION. $\ldots \ldots \ldots \ldots \ldots \ldots \ldots \ldots \ldots$

Background................ 6

Physical Setting. ............... 10

Data..................... 13

Methodologies. ................. 14

Organization of Thesis.............. 15

Summary.................. 16

II REVIEW OF THE LITERATURE. .......... 17

Introduction. . . . . . . . . . . 17

History. .................. 18

Description of Current Methods of Creating

Runoff-Depth Contour Maps. ............ 19

Discussion of Findings............. 25 
AUTOMATED PROCEDURES USED IN MAPPING

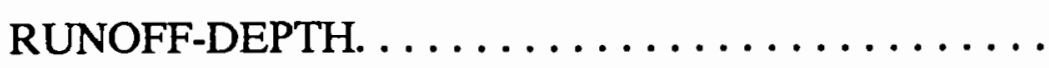

Introduction. . . . . . . . . . . . .

Automated Mapping Methodologies Considered. .

Selection of Five Procedures to be Examined

by an Uncertainty Analysis. . . . . . . . . .

IV UNCERTAINTY ANALYSIS. ........... 61

Introduction. ............... 61

Methodologies. ............... 62

Results and Discussion. ............ 65

Summary of Findings. . . . . . . . . 88

V SUMMARY AND FUTURE AREAS OF RESEARCH. . 92

Summary. . . . . . . . . . . . 92

Future Areas of Research. . . . . . . . . . . . 94

REFERENCES. . . . . . . . . . . . . . . . . . . 95 APPENDICES

A WATER-YEAR 1984 USGS GAGING STATIONS IN THE NORTHEAST UNITED STATES. . . . . . . . . . . 102

B LONG-TERM AND WATER-YEAR 1984 NCDC

PRECIPITATION STATIONS IN THE NORTHEAST

UNITED STATES. . . . . . . . . . . . 
PAGE

C ESTIMATED AND GAGED RUNOFF FOR THE WITHHELD USGS GAGE SITES. . . . . . . . . . . . . . . 134 


\section{LIST OF TABLES}

TABLE

PAGE

I Interpolation Error Descriptive Statistics for Withheld Sites

from a Long-Term Runoff Map................

II Comparison of Long-Term to Water-Year 1984 Gaged Values

at Corresponding Gaged Sites................. 13

III Estimated Errors in Precipitation Measurement from Standard

Rain Gauges......................... $\quad 36$

IV Estimated R/P at Corresponding (Long-Term and WY84)

Precipitation and Runoff Sites. ............... 56

V Estimated Runoff at Water-Year 1984 NCDC Precipitation

Stations............................ $\quad 58$

VI Estimated ET at Corresponding (Long-Term and WY84)

Precipitation and Runoff Sites. $\ldots \ldots \ldots \ldots \ldots \ldots \ldots \ldots, \quad 58$

VII Interpolation Error Descriptive Statistics for the 50 Withheld

Runoff Sites. . . . . . . . . . . . . . . 65

VIII Signed Rank Test for the Difference in Mean Interpolation

Error Being Significantly Different from Zero. ..........

IX Regression Analysis of Gaged Runoff-Depth Versus

Interpolated Runoff-Depth. .................. 
X Correlation Analysis of Gaged Runoff-Depth versus Elevation and Watershed Area. .................. 85

XI Correlation Analysis of Absolute (Cm) Interpolation Error versus Gaged Runoff, Elevation, and Watershed Area. ...... 86

XII Correlation Analysis of Percentage Interpolation Error versus

Gaged Runoff, Elevation, and Watershed Area. . . . . . . 86

XIII F-Test of MLRA Effect on Runoff and Interpolation Error

Values From the Fifty Withheld Sites. . . . . . . . . . 87

XIV Descriptive Statistics of Interpolation Errors for Zones of Greater and Lesser Confidence. . . . . . . . . . . . . 90

XV F-Test of Mean Interpolation Error Values for Zones of Greater and Lesser Confidence. . . . . . . . . . . . . 90 


\section{LIST OF FIGURES}

FIGURE

PAGE

1. Study Area with Major Land Resource Areas. . . . . . . . . . 3

2. Water-Year 1984 USGS Gage Site Centroids and NCDC Precipitation Stations. ................. 4

3. Long-Term (1951-80) Average Annual Runoff-Depth Contour

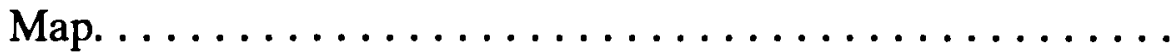

4. Water-Year 1984 Runoff-Depth Contour Map. .......... 8

5. Average Monthly Precipitation and Runoff for Selected Sites in the Northeast. .....................

6. Regression Method Map of Mean Annual Runoff-Depth for West Germany...................... 21

7. Manual Method Map of the Mean Annual Runoff-Depth in the Eastern United States. . . . . . . . . . . . . .

8. Manual Method Map of Mean Annual Runoff-Depth in the Danube Basin. ....................... 26

9. Steps in the Production of a Runoff-Depth Contour Map Using the GAGE84 Procedure. . . . . . . . . . .

10. Steps in the Production of a Runoff-Depth Contour Map

Using the LTET Procedure. . . . . . . . . . . . 
11. Steps in the Production of a Runoff-Depth Contour Map

Using the LTRP Procedure. . . . . . . . . . . . . .

12. Steps in the Production of a Runoff-Depth Contour Map

Using the MNLTET Procedure. . . . . . . . . . . .

13. Steps in the Production of a Runoff-Depth Contour Map

Using the MNLTRP Procedure. . . . . . . . . . .

14. Steps in the Production of a Runoff-Depth Contour Map

Using the REG_ET Procedure. ............. 50

15. Steps in the Production of a Runoff-Depth Contour Map

Using the REG_R Procedure. ............. 51

16. Steps in the Production of a Runoff-Depth Contour Map

Using the MN84RP Procedure. .............. 54

17. Comparison of Eight Procedure Derived Runoff-Depth

Contour Maps in the VT-NH Sub-Area of the Northeast

Region. ......................

18. Uncertainty Analysis Withheld Water-Year 1984 Gaged

Runoff-Depth Sites. . . . . . . . . . . . . . . 63

19. Box-and-Whisker Diagram of Absolute Interpolation Errors (Cm) for the GAGE84, MN84RP, MNLTET, MNLTRP, and REG_R Procedures. . . . . . . . . . . . . . . . . . 
20. Absolute Interpolation Errors (Cm) EDFs for the GAGE84, MNLTET, MNLTRP, REG_R, and MN84RP Procedures. . . . .

21. Cumulative Distribution Function of the Absolute Interpolation Error (Gaged - Estimated Runoff) (Cm) of a Long-Term Manual Method Map of the Eastern U.S.. . . . . . . . .

22. GAGE84 Absolute (Cm) Interpolation Errors at the Withheld Sites.

23. MNLTET Absolute ( $\mathrm{Cm})$ Interpolation Errors at the Withheld Sites.

24. MNLTRP Absolute (Cm) Interpolation Errors at the Withheld Sites. ........................

25. REG_R Absolute $(\mathrm{Cm})$ Interpolation Errors at the Withheld Sites. ........................

26. MN84RP Absolute (Cm) Interpolation Errors at the Withheld Sites. . . . . . . . . . . . . . . . . . . .

27. MAN84 Absolute (Cm) Interpolation Errors at the Withheld Sites.

28. Scatter Plot of GAGE84 Interpolated vs. Gaged Runoff at the 50 Withheld Sites. . . . . . . . . . . . . . .

29. Scatter Plot of MNLTET Interpolated vs. Gaged Runoff at the 50 Withheld Sites. . . . . . . . . . . . . . 
30. Scatter Plot of MNLTRP Interpolated vs. Gaged Runoff at the 50 Withheld Sites. . . . . . . . . . . . . .

31. Scatter Plot of REG_R Interpolated vs. Gaged Runoff at the 50 Withheld Sites. . . . . . . . . . . . . . . 82

32. Scatter Plot of MN84RP Interpolated vs. Gaged Runoff at the 50 Withheld Sites. . . . . . . . . . . . . . . 83

33. Zones of Lesser and Greater Confidence in Runoff Estimates. . 89 


\section{LIST OF PLATES}

\section{PLATE}

1. Long Term Runoff Depth, USGS Manual Map

2. Water-Year 1984 Runoff-Depth, USGS Manual Map

3. Water-Year 1984 Runoff-Depth (GAGE84)

4. Water-Year 1984 Runoff-Depth (LTET)

5. Water-Year 1984 Runoff-Depth (LTRP)

6. Water-Year 1984 Runoff-Depth (MNLTET)

7. Water-Year 1984 Runoff-Depth (MNLTRP)

8. Water-Year 1984 Runoff-Depth (REG_R)

9. Water-Year 1984 Runoff-Depth (REG_ET)

10. Water-Year 1984 Runoff-Depth (MN84RP) 


\section{CHAPTER I}

\section{INTRODUCTION}

The mapping of the distribution of runoff (ie. streamflow) is a task that has been pursued by American geographers and hydrologists since streams were first gaged in this country (Langbein, et al., 1949). The task is made especially difficult by variations in vegetation, geology, land use, precipitation, and other factors over space (Sopper and Lull, 1970, USGS, 1984) which can cause sharp spatial variations in runoff (Rafter, 1903). Nevertheless, reliable runoff estimates are necessary to water resource planning and scientific studies (e.g. Solomon, et al., 1968, Church, et al., 1989) and much effort has been put into creating maps of runoff from which these estimates can be obtained. To show the pattern of runoff unbiased by the size of the watersheds involved, runoff is mapped as runoff-depth; that is, the volume of water that flows off the given area spread proportionately over that area in relation to a location's contribution to runoff (volume of runoff / watershed area) (Miller, et al., 1962).

Geographers and hydrologists have utilized several methods to produce runoffdepth contour maps (Langbein, et al., 1949, Thornthwaite, et al., 1958, Solomon, et al., 1968, Liebscher, 1972, Foyster, 1975, Krug, et al., 1990) but the predominate method of mapping runoff is with manual methods (e.g. Krug, et al., 1990). Automated methods to map runoff-depth have been developed (e.g. Solomon, et al., 1968, Foyster, 1975), but none are widely used. 
This thesis was based on work to find simple automated procedures that duplicate the accuracy of maps produced manually. The accuracy of five new automated procedures for producing water-year runoff-depth contour maps was examined using an uncertainty analysis. The time period considered was water-year 1984 (WY84) (i.e. October 1, 1983 to September 30,1984) with the northeastern United States being the area of study (Figure 1). This time period and region were used because of the availability of a manually produced map for comparison. Major Land Resource Area's (MLRA's) (USDA, 1981) (Figure 1) were utilized for regionalization of certain parameters in some of the automated procedures. MLRA's were used because they were created using both physiographic and land use/cover parameters that can be important to runoff response (Woodruff and Hewlett, 1970, USDA, 1981). The procedures used linear interpolation from point values of runoff to create contours of runoff-depth. To increase the number of sites with runoff values used for interpolation in these procedures, WY84 gaged precipitation stations were used for estimating runoff (Figure 2). All of the procedures except the first listed below used estimated runoff. The five procedures to produce runoff-depth maps are:

1) GAGE84, which uses simple linear interpolation of WY84 gaged runoff data only,

2) MNLTET, which uses a water balance formula method utilizing mean regional evapotranspiration (ET), determined from long-term (i.e. average for 1951-80) precipitation, long-term runoff data, and a long-term runoff-depth 


\section{WATER YEAR 1984 STUDY AREA WITH MAJOR LAND RESOURCE AREAS}

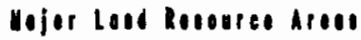

liog erjo fruit and Trage Area

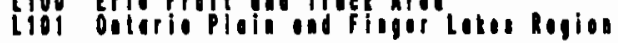

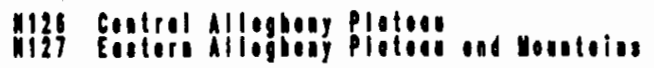

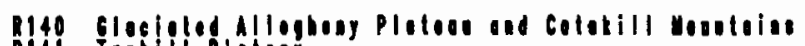

Dit! Iifiliplatiou

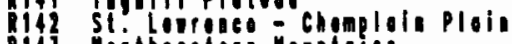

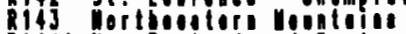

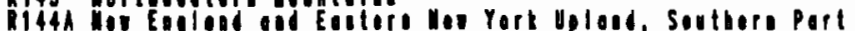

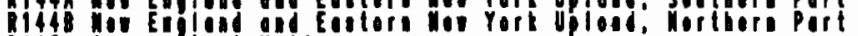

pits conedlent rillor

Ris hrostoct irio

s147 Dorthere Apolochion Ridgo ond Volleys

5148. Horthore pindont

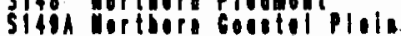

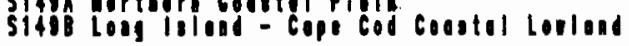

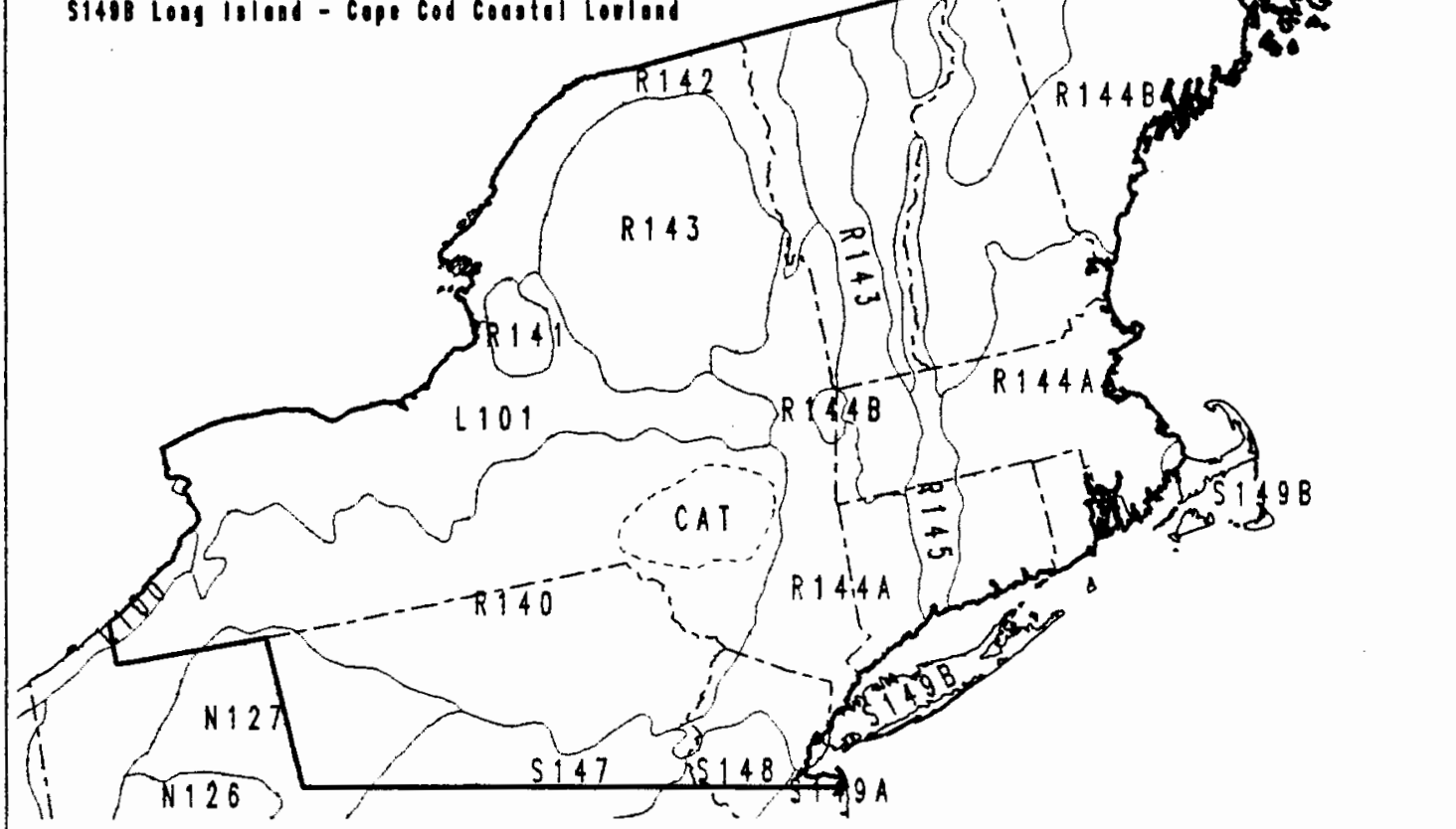

Figure 1. Study Area with Major Land Resource Areas. (MLRA source: USDA, 1981.) 


\section{WATER YEAR 1984 \\ RUNOFF AND PRECIPITATION SITES}

+Precipitolion stotion

- Runoff site centroid

Figure 2. Water-Year 1984 USGS Gage Site Centroids and NCDC Precipitation Stations. 
map, for Major Land Resource Areas (MLRA's) to estimate WY84 runoff at precipitation stations,

3) MNLTRP, which uses the ratio of mean regional long-term runoffto-precipitation ratios (R/P) for MLRA's to calculate WY84 runoff at precipitation stations,

4) REG_R, which uses a regression formula based on long-term data to estimate runoff-depth at WY84 precipitation stations, and 5) MN84RP, which uses mean regional R/P determined from WY84 gaged precipitation and runoff data to calculate WY84 runoff at the precipitation stations.

Three of the procedures (MNLTET, MNLTRP, and REG_R) utilize information (i.e. expert opinion) incorporated in the generation of a long-term (1951-80) runoff depth contour map produced by the U.S. Geological Survey (USGS) (Krug, et al., 1990). One of the questions examined in this thesis is whether utilizing this expert opinion will aide in producing an automated procedure map with an accuracy similar to the manual procedure map.

The five procedures examined are a subset of eight procedures developed in research conducted in conjunction with the U.S. Environmental Protection Agency's (EPA's) Direct/Delayed Response Project (DDRP). The automated procedures have the advantage, since they use computer algorithms, of being reproducible as well as being less expensive and time consuming than the manual method (Church, 1991). 


\section{BACKGROUND}

As part of the EPA's study of the future effects of acidic deposition on surface water chemistry, the DDRP, there arose a need for watershed-specific, average and WY84 runoff-depth estimates for ungaged sites. The USGS, in support of this project, produced an average annual runoff-depth map for the 1951-80 (long-term) period for the eastern United States (Krug, et al., 1990), (Figure 3) (Plate 1), and a WY84 runoff depth map for the northeast United States (Graczyk, et al., 1987), (Figure 4) (Plate 2). These maps were used to manually interpolate runoff estimates for the DDRP watersheds in the northeast United States (Church, et al., 1989). The methods used in the creation of these runoff maps were based on the manual techniques developed by Gannett (1911), Langbein (1949), Knox and Nordenson (1961), Hely, et al. (1961), Schneider, et al. (1965), Busby (1966), and Gebert, et al. (1987). In this thesis this methodology will be referred to as the "manual procedure". In producing the long-term map Krug, et al. (1990) used long-term average runoff values from 1,232 gaging stations, the expert opinion of USGS hydrologists, topography, and past runoff maps. The WY84 map by Graczyk, et al. (1987) used 545 gaging stations and similar methodologies. A more detailed explanation of the methods used by Graczyk, et al. (1987) and Krug, et al. (1990) is presented in Chapter II.

The DDRP required a regional accuracy of site-specific values (i.e., the region as a whole would require a mean percentage accuracy of $X$ ), as opposed to individual site accuracy (i.e., each site would require a percentage accuracy of $\mathrm{X}$ ) due to the regional outlook and scope of the project. The runoff values obtained from the 


\section{LONG-TERM AVERAGE USGS MANUAL RUNOFF-DEPTH CONTOURS}

contoer laternal 2 lechos Bolos 30 loct contore

costore laterval s lactes abore so inch contore

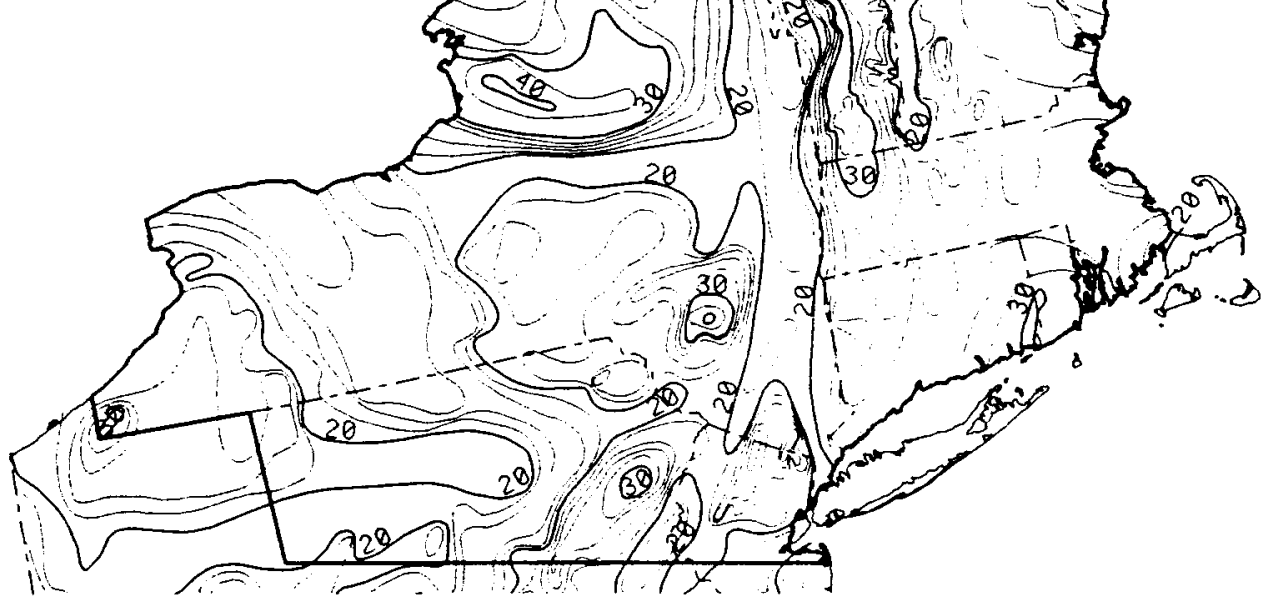

Figure 3. Long-Term (1951-80) Average Annual Runoff-Depth Contour Map. (Krug, et al., 1990.) 


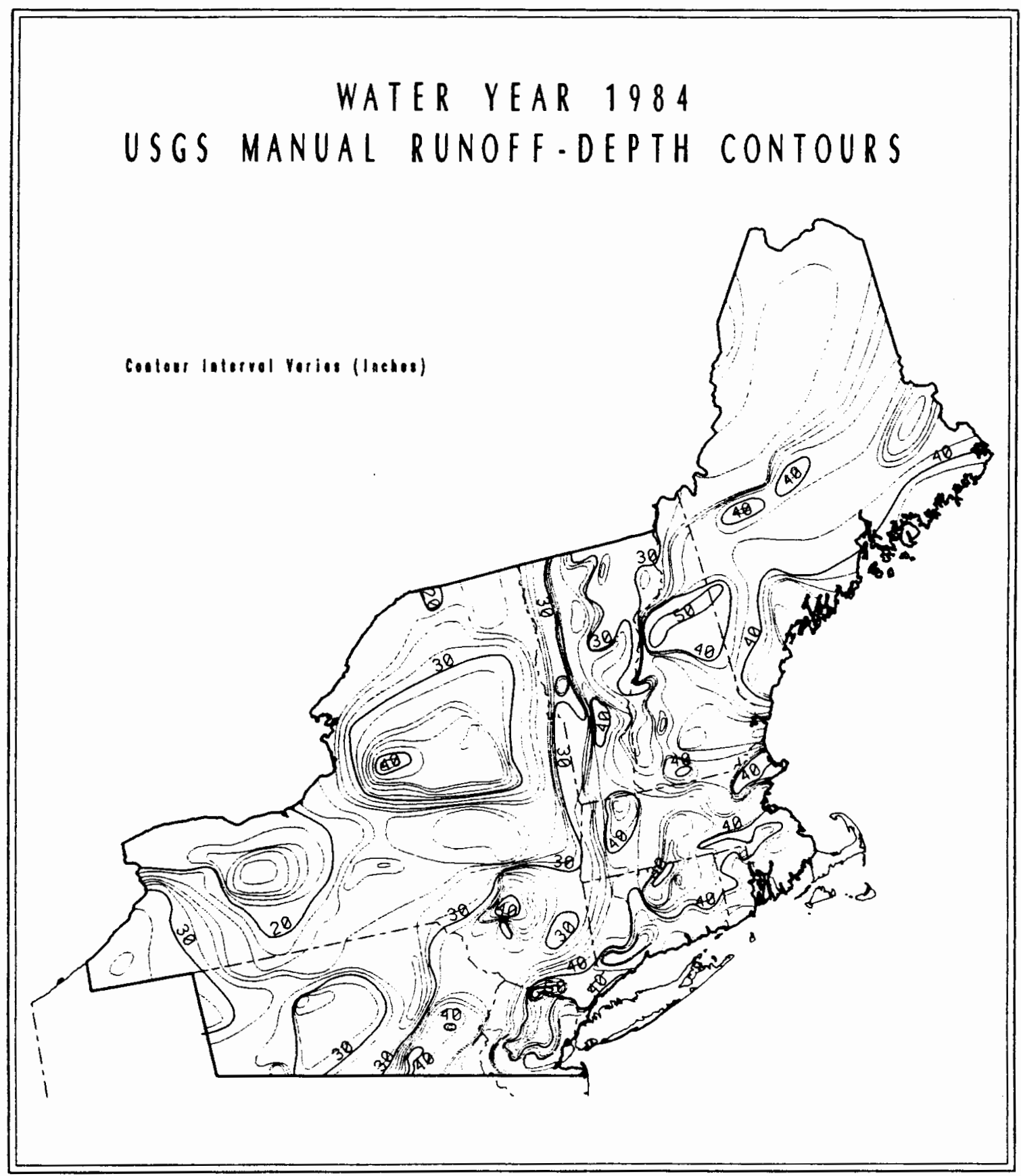

Figure 4. Water-Year 1984 Runoff-Depth Contour Map. (Graczyk, et al., 1987.) 
maps were used as one of the inputs to a watershed sulfur budget model and for sulfur retention estimates (Church, et al., 1989). The errors associated with interpolating runoff values from a manual procedure-derived map for a regional project have been quantified (Table I) and found to be within acceptable limits (Rochelle, et al., 1989). This research assumes that the mean error for the WY84 map produced by Graczyk, et al. (1987) using the manual procedure, is the same as that of the long-term map produced by Krug, et al. (1990).

\section{TABLE I}

INTERPOLATION ERROR DESCRIPTIVE STATISTICS FOR WITHHELD SITES FROM A LONG-TERM RUNOFF MAP

\begin{tabular}{lcccccc} 
& $\begin{array}{c}\text { Standard } \\
\text { Population } \\
\text { Mean }\end{array}$ & $\begin{array}{c}\text { Error of } \\
\text { the Mean }\end{array}$ & $\begin{array}{c}\text { Standard } \\
\text { Deviation }\end{array}$ & $\begin{array}{c}\text { Population } \\
\text { Mean } \\
\text { (Percent) }\end{array}$ & $\begin{array}{c}\text { Standard } \\
\text { Error of } \\
\text { the Mean } \\
\text { (Percent) }\end{array}$ & $\begin{array}{c}\text { Standard } \\
\text { Deviation } \\
\text { (Percent) }\end{array}$ \\
\hline Method & & & & & & \\
Manual(1) & $4.14^{*}$ & 0.92 & $8.91^{*}$ & 5.68 & 1.60 & 15.53 \\
Manual(2) & 1.54 & 0.88 & 8.53 & 0.90 & 1.47 & 14.21 \\
GIS(1) & 4.52 & 0.94 & 9.04 & 6.70 & 1.75 & 16.85 \\
- & & & & & & \\
cm. \\
(1) measured at basin outlet \\
(2) measured at basin centroid
\end{tabular}

Source: Rochelle, et al (1989)

Hypothesis

This thesis hypothesis was that an automated procedure can produce a runoff map for the northeastern United States as accurate as that produced by the manual procedure. The method used in determining accuracy was an "uncertainty analysis". An uncertainty analysis is the withholding of data sites from a runoff map's creation 
for later use in a comparison of the actual withheld data to values obtained by interpolation to these sites from the map generated. The differences between these values, the interpolation error, was then used to quantify the map and the automated procedures accuracy by a comparison of the mean interpolation errors of the automated procedures to the mean interpolation error of the manual procedure.

\section{PHYSICAL SETTING}

The northeastern United States, here defined as the area covered by the WY84 runoff-depth map (Graczyk, et al., 1987) (see Fig. 3), is a temperate region with moderate spatial variations in temperature and precipitation. Most of this variability is due to differences in elevation and distance from the coast. The region is cool and humid consisting of plains, plateaus, and mountains with elevations ranging from sea level along the Atlantic coast to 1,916 meters $(6,288 \mathrm{ft})$ at Mt. Washington. The average annual temperature across the region ranges from 3 to 11 degrees Celsius. Most of the land in the region is forested, especially on the steeper slopes (USDA, 1981).

Average annual precipitation in the Northeast ranges from 70 to over $230 \mathrm{~cm}$ with the general trend being an increase in precipitation with elevation, although distance-from-coast and local rainshadow effects can be significant (Dingman, 1981). The amount of precipitation that falls as snow (based on a forty-year period of record) can range from 75 to over $380 \mathrm{~cm}$ annually (Miller, et al., 1962). In general, precipitation is evenly distributed throughout the year (USDA, 1981) (Figure 5). 

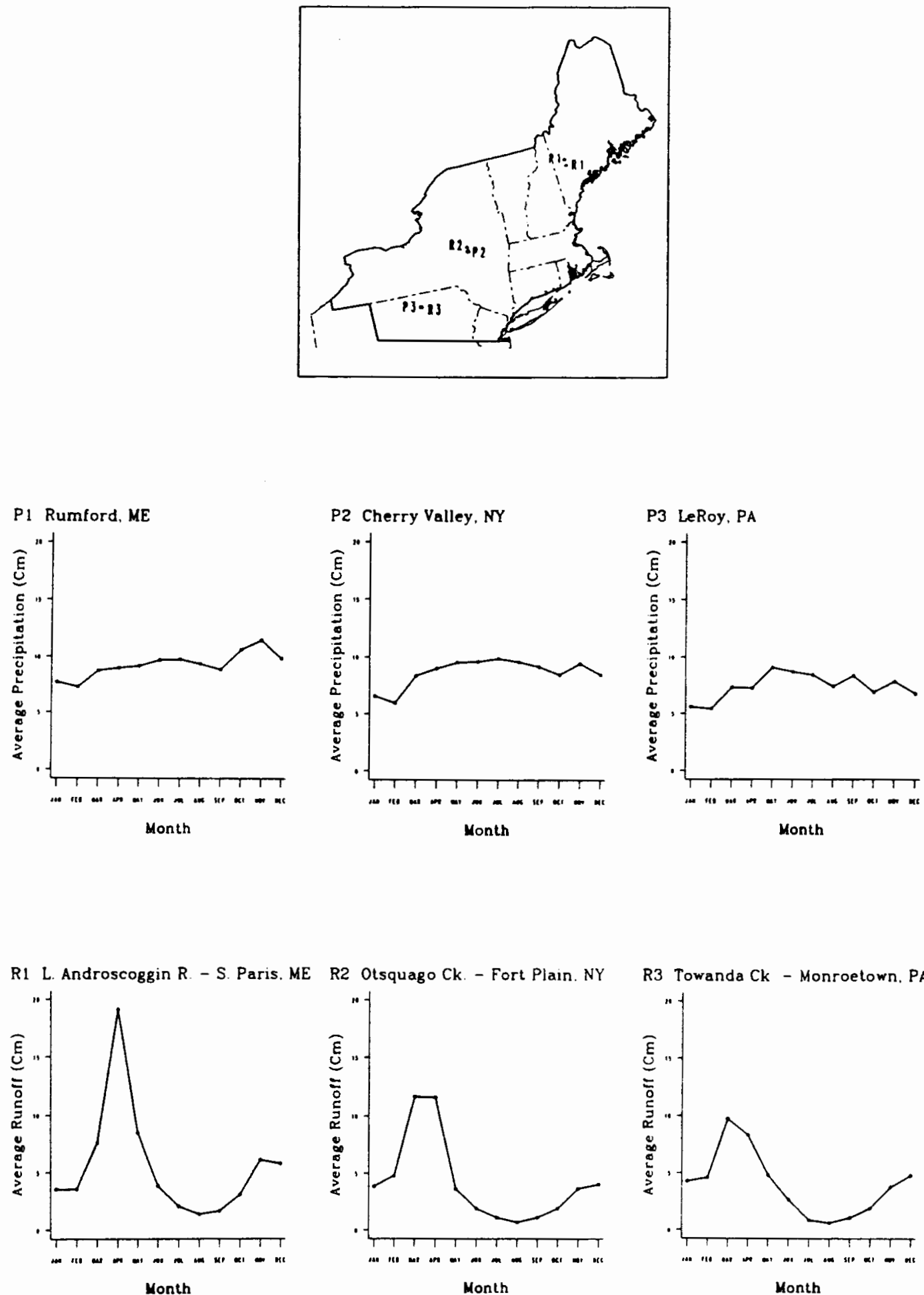

Figure 5. Average Monthly Precipitation and Runoff for Selected Sites in the Northeast. 
Thornthwaite, et al., (1958) estimate that ET varies from 42 to $71 \mathrm{~cm}$ over the Northeast. Hidore (1966) gives a more generalized range of 51 to $89 \mathrm{~cm}$ for the east coast.

With regards to surface runoff, the highest flows occur in March or April due to a combination of snowmelt and rainfall with the lowest flows occurring in August or September (Miller, et al, 1962) (Figure 5). Gebert, et al. (1987) characterized temporal variability of streams in the United States with a coefficient of variation calculated by dividing the standard deviation by the average flow at individual gage sites. Variations of annual values from the long-term mean runoff at gaged sites in the Northeast region were characterized as low or medium (i.e. the lower three quartiles of the coefficient of variation). A few scattered high variation sites are also present and can be found mainly in the southeast portion of the Northeast region.

\section{Water-Year 1984}

WY84 was a wetter than average year for the Northeast. A statistical summary comparing the long-term and WY84 periods is presented in Table II. At the 242 WY84 precipitation stations used in this research that have long-term data available, precipitation averaged $126 \%$ of the long-term average for WY 84 . There is a correlation of 0.88 between the two data sets, showing a linear relationship between the two data sets and little variation from the trend line. Of the 227 runoff gaging sites that have corresponding long-term data runoff on average was $141 \%$ of the normal for WY84 with a correlation of 0.75 . These percentage-above-normal values 
are in general agreement with the National Water Summary for 1984 (USGS, 1985). The statistical distributions of the WY84 and long-term average regional precipitation data sets are not normal.

\section{TABLE II}

COMPARISON OF LONG-TERM TO WATER-YEAR 1984 GAGED VALUES ${ }^{*}$ AT CORRESPONDING GAGED SITES

\begin{tabular}{|c|c|c|c|c|c|}
\hline & Mean & $\begin{array}{l}\text { Standard } \\
\text { Deviation }\end{array}$ & Median & Minimum & Maximu \\
\hline \multicolumn{6}{|c|}{ Precipitation $(n=242)$} \\
\hline Long-Term & 108.58 & 16.16 & 109.16 & 71.96 & 228.40 \\
\hline WY84 & 137.88 & 27.26 & 138.10 & 76.78 & 334.24 \\
\hline \multicolumn{6}{|c|}{ Runoff-Depth (n=227) } \\
\hline Long-Term & 62.04 & 12.03 & 61.72 & 30.48 & 106.68 \\
\hline WY84 & 86.97 & 18.60 & 87.55 & 33.76 & 146.86 \\
\hline
\end{tabular}

"Data in centimeters of depth

\section{DATA}

The data used in this thesis are: 1) USGS long-term and water-year 1984 runoffdepth contour maps, 2) USGS long-term and WY84 stream-flow gaging information, 3) USGS gaging station watershed centroids, and 4) National Climatic Data Center (NCDC) long-term and WY84 climatological data. For the automated procedures 441 WY84 USGS centroid sites (Appendix A) were used with 228 centroids being obtained by matching USGS long-term centroid sites with water-year 1984 sites by the site identification number. The other 213 sites were obtained by manually mapping the gaging site basins on 1:500,000 and 1:250,000 USGS topographic maps and 
determining the centroids using a methodology similar to that used by the USGS. Watershed size ranged from 2 to $17,280 \mathrm{Km}^{2}$ and estimated centroid elevation from 12 to 898 meters. For precipitation, 358 long-term and 405 water-year 1984 NCDC precipitation sites were used in the analysis (Appendix B) whose elevations ranged from 0 to 1908 meters.

\section{METHODOLOGIES}

A literature review was conducted to determine the accuracies obtained, and the methodologies used to obtain these accuracies, from similar runoff-depth contour mapping work. All of the various methods base their accuracy measurements on comparisons of predicted runoff to actual runoff (i.e. predicted runoff - actual runoff $=$ estimation error or accuracy). A wide range in accuracies was noted for the various methodologies. Values of estimated runoff are considered acceptable if they are within $15 \%$ of measured amounts (Shelton, 1985). Based on this review a regional accuracy similar to that obtained from the manual procedure (i.e. a mean error of $0.9 \%$ with a standard deviation of $14.2 \%$ (Rochelle, et al., 1989)) will be considered acceptable for the automated procedures tested in this thesis.

Eight various automated procedures were developed and tested to find an acceptable method of producing a runoff-depth contour map for WY84. A statistical and visual comparison to the manual map for WY84 was conducted. Five of the procedures were chosen for further study with an uncertainty analysis. 
For the uncertainty analysis a contour map was produced for each of the five procedures with a randomly chosen subset of the runoff-depth gaged sites withheld from each process. The withheld sites were chosen with a spatial clustering procedure. This procedure selected a spatially unbiased random sample of 50 of the WY84 runoff sites to be withheld from each of the automated methods (Stevens, 1991). Values were interpolated to the withheld sites from the contour maps produced. The interpolated values minus the actual values were then calculated with the mean difference, i.e. mean interpolation error, defining the accuracy of the maps produced (e.g. Rochelle, et al., 1989).

\section{ORGANIZATION OF THESIS}

This thesis is divided into five chapters. The first has given a general overview of the purpose, data, methods, and the region of study. The second chapter gives a brief history of runoff-depth contour maps and reviews the methodologies currently in use. The third chapter discusses the eight automated methods originally considered for producing runoff-depth maps and the selection of the five automated procedures used in the uncertainty analysis. The fourth presents and discusses the results of the uncertainty analysis of these five procedures. The fifth chapter summarizes the results, states the conclusions of the thesis, and suggests some future areas of research. 


\section{SUMMARY}

Mapping runoff-depth is a difficult, expensive and time consuming task. Research was conducted in conjunction with the DDRP (Direct Delayed Response Project) to find an automated procedure that will provide runoff-depth contour maps with a regional accuracy equivalent to that of maps produced by the manual procedure, but with a lower cost in both time and money. Eight procedures were developed to meet these requirements and five of them were selected for further examination with an uncertainty analysis.

This thesis hypothesized that the manual and five automated procedures examined are equivalent. It tested this hypothesis by comparing the results of an uncertainty analysis of the long-term manual procedure derived runoff-depth contour map (Rochelle, et al., 1989) to the results from the uncertainty analysis of the five maps produced with the automated procedures. The goal of a mean percentage error approximating $0.9 \%$ was set for the automated procedures. 


\section{CHAPTER II}

\section{REVIEW OF THE LITERATURE}

\section{INTRODUCTION}

Runoff-depth contour maps show the amount of surface water flowing from a given area expressed as equivalent water depth. Runoff-depth can be visualized as being the residual of precipitation after the demands of evapotranspiration have been met (assuming that changes in groundwater storage are zero) (Langbein, 1949). The time interval that is mapped varies, but is usually annual (water-year) or long-term average (30 years).

The uses of runoff-depth contour maps include the evaluation of water resources and for scientific and educational purposes (McKay, 1976). Runoff-depth maps can also be useful for estimating the discharge at streams which are not gaged. A research project which could not gage the streams of interest due to the project's size, budget, and time constraints found these maps to be useful (Church, et al., 1989). Estimating average runoff from these maps can be helpful in determining the feasibility of projects such as hydroelectric dams before more detailed studies are done (Solomon, et al., 1968). Users of these maps must keep in mind, however, that local conditions can influence greatly the spatial pattern of runoff, and thus what is shown on a generalized regional map may not reflect specific local conditions (Krug, 
et al., 1990). Runoff can be even more variable over time than precipitation in some areas; so using an annual-mean runoff-depth map to predict a given year's runoff can produce large errors in the estimate (Leopold, et al, 1964).

\section{HISTORY}

In the United States the majority of runoff-depth contour maps are produced by the U.S. Geological Survey (USGS) using stream gage data. Stream gaging started in the United States in about 1890 and in 1892 a runoff-depth map, likely the first in the United States, was produced by F.H. Newell (Langbein, et al., 1949). By 1910 there were 1000 gaging stations in the United States (Thornthwaite, et al., 1958) and in 1911 Gannett produced a map which supplemented gaging data with estimates of runoff in ungaged areas. Estimated "water loss", evapotranspiration (ET), was subtracted from precipitation values in the ungaged areas (Gannett, 1911). In 1934, when there were 3000 gaging stations (Thornthwaite, et al., 1958), the water planning committee of the National Resources Board published a map using similar techniques. A technique using an empirical formula, utilizing temperature and precipitation data, was developed by Thornthwaite and published in 1945 (Langbein, et al, 1949). In 1949, when there were 6000 stations (Thornthwaite, et al., 1958), Langbein produced a map using actual and estimated runoff, along with the expert opinion of hydrologists (i.e. the manual method). This has been the predominant method of mapping runoff-depth in the U.S. ever since. 


\section{DESCRIPTION OF CURRENT METHODS OF CREATING} RUNOFF-DEPTH CONTOUR MAPS

One broad group of methods currently in use are the water-balance methods. This methodology assumes that if all except one element of the water-balance (Formula 1) are known the missing value can be calculated.

Formula 1.

$R=P-E T(+-) S$

$\mathrm{R}=$ Runoff, $\mathrm{P}=$ Precipitation, $\mathrm{ET}=$ Evapotranspiration, $\mathrm{S}=$ Storage

This method is more practical for long periods of time, such as a year or more (e.g. annual mean), where changes in storage can be assumed to be negligible (Kitteredge, 1938, Storr, 1972, Dunne and Leopold, 1978, Lee, 1980, Domokos and Sass, 1990). The methodology most often used is to calculate ET by empirical formulae such as those of Thornthwaite, Penman, or Blaney-Criddle, using data such as temperature and wind speed, collected at or near a precipitation station (Dunne and Leopold, 1978) and then subtracting ET from precipitation to get estimated runoff. Thornthwaite, et al., (1958) stated that their method of estimating runoff, via the water-balance, is superior to direct gaging because the groundwater that seeps past gaging sites, which may be in significant amounts, goes unmeasured. Others have questioned the relative accuracies of the various methods of estimating ET, thus 
casting doubt on which aspect of the water balance (ie. estimated ET or measured runoff) brings with it a larger error (Van Wijk and DeVries, 1954, Dunne and Leopold, 1978, Lee, 1980). The accuracy of the water balance method has not been quantified from maps based on this method, although estimates for individual basins have been calculated with the results "approximating" or in "good agreement" with actual measured values (Thornthwaite, et al., 1958, Mather, 1981).

Regression techniques are another major method of producing runoff-depth contour maps. The technique relates through a formula the dependent variable, runoff or ET, with independent variable(s) such as elevation, precipitation, and temperature, at locations where all these variables are known or can be reasonably estimated. By statistical techniques or intuitional/deductive reasoning a researcher chooses which independent variables best predict the dependent variable at the known sites. The formula generated is then used at other sites where the independent variables are known. A detailed description of the techniques, mathematics, and theory involved can be found in Holder (1985). An example of this technique is the work of Liebscher (1972) who used mean annual precipitation, temperature and the ratio of summer-to-winter precipitation to map average runoff-depth in West Germany (Figure 6). His runoff-depth map was created by hand interpolation from regression-derived estimated runoff and actual runoff values. The map's main purpose is to prepare large area water balances. The strengths of the regression method are that it is reproducible and that the confidence one can place on the regression estimate is quantifiable. Weaknesses include the often subjective 


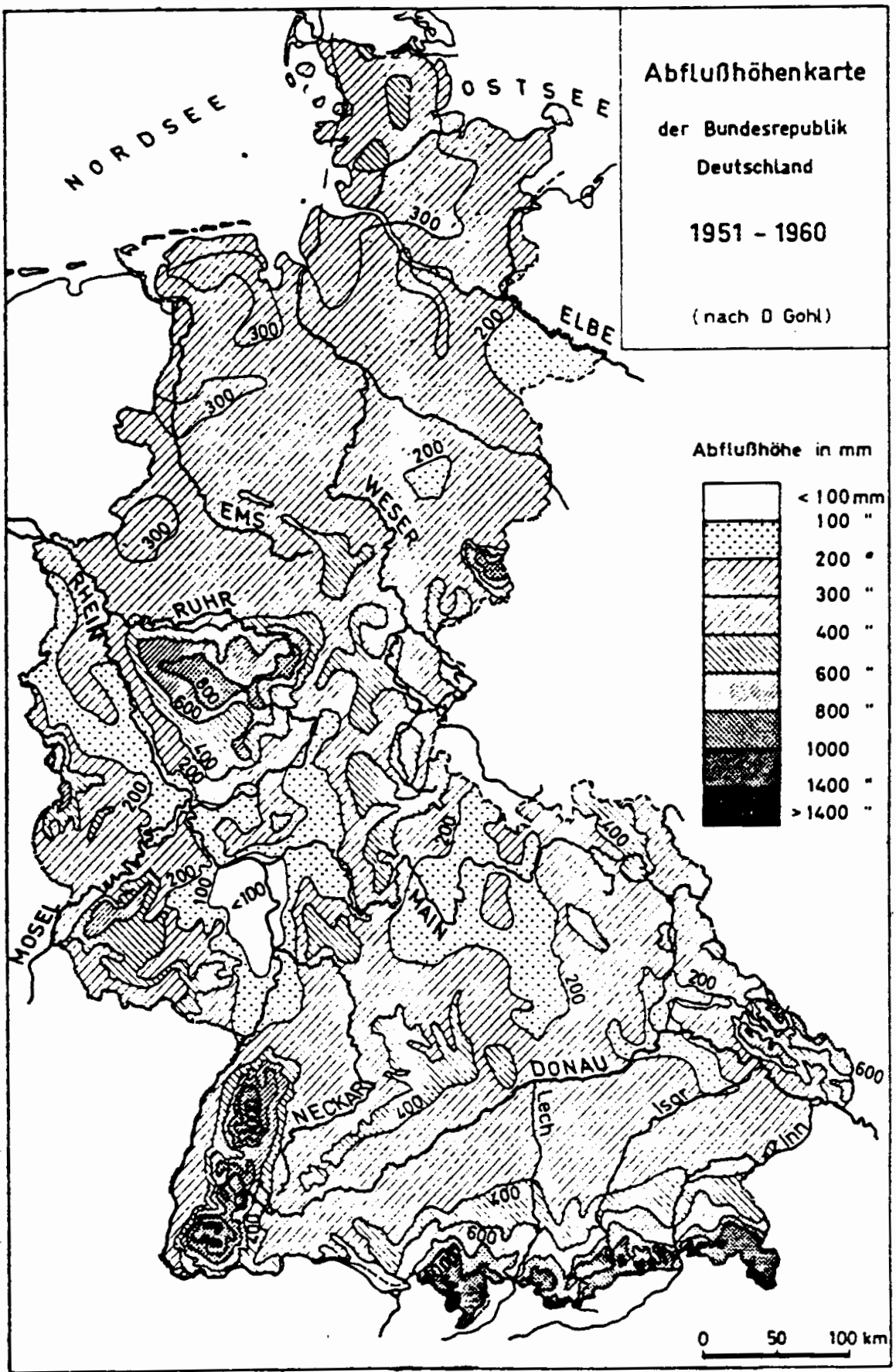

Figure 6. Regression Method Map of Mean Annual Runoff-Depth for West Germany. (Source: Liebscher, 1972.) 
decision as to which independent variables to include in the regression formula. The accuracy of maps produced by this method have not been quantified.

Another broad group of methods can be called the grid square technique. In this method the area of study is divided into a uniform grid, suitable for use in a raster based data system. Various physiographic attributes such as elevation and distance from the coast are calculated for each grid. From grid squares that contain meteorological or gaged sites precipitation, runoff, and ET (from empirical formulae) are calculated or measured and correlated to the physiographic data by regression formulae. Values are then extrapolated to the other grid cell sites and, after minor refinements based on withheld data, a map is produced (Solomon, et al., 1968). A variant method is to use estimated precipitation and ET in a water balance formula developed by Penman that employs a soil moisture component to estimate runoff (Foyster, 1975). The grid square method's main strength is the ease with which estimated discharge of a stream can be calculated by using the estimated runoff for the grid cells in the watershed and the grid size. The weakness of this technique is the generalizations that will occur due to the use of a uniform grid over an amorphous drainage pattern. Calculating from Foyster's (1975) estimated values for five sites in southeast England from one application of this technique, estimated discharge varied from -7 to $+16 \%$ of actual measured discharge with a mean error of $5.43 \%$ and a standard deviation of $9.50 \%$.

The last method to be considered is the creation of runoff-depth contour maps by manual interpolation. The basic hypothesis of this method is that an expert 
hydrologist, using gaged data and taking into account meteorological and physiological factors, can produce a reasonably accurate runoff-depth map. This method has been extensively used by the USGS (Gannett, 1911, Langbein, et al., 1949, Knox and Nordenson, 1957, Schneider, et al., 1965, Busby, 1966, Gebert, et al., 1987, Graczyk, et al., 1987, Krug, et al., 1990). Applications include contributing to scientific knowledge and the estimation of runoff at ungaged streams (Langbein, et al, 1949, Krug, et al., 1990). An advantage of this method is that hydrologists are not constrained by a fixed formula or methodology and thus can take into account local variations or anomalies in the physical environment when creating the contours (UNESCO/WMO, 1977). Conversely, the human element can be considered the weakness of this method since errors in judgment or oversight can occur. Errors of estimates from a long-term map of the eastern U.S. created with this method (Figure 7) were quantified by Rochelle, et al., (1989). The mean error of estimated as compared to actual runoff values was $0.9 \%$ (Rochelle, et al., 1989). Domokos and Sass (1990) gave estimated runoff derived from their manually produced runoff map for 24 large sub-basins in the Danube basin (although it is unclear whether these sites were withheld from the map's creation). From their results a mean error of $0.14 \%$ and a standard deviation of $2.69 \%$ were calculated with errors varying from -4.14 to $+4.79 \%$ of recorded values (Domokos and Sass, 1990). 


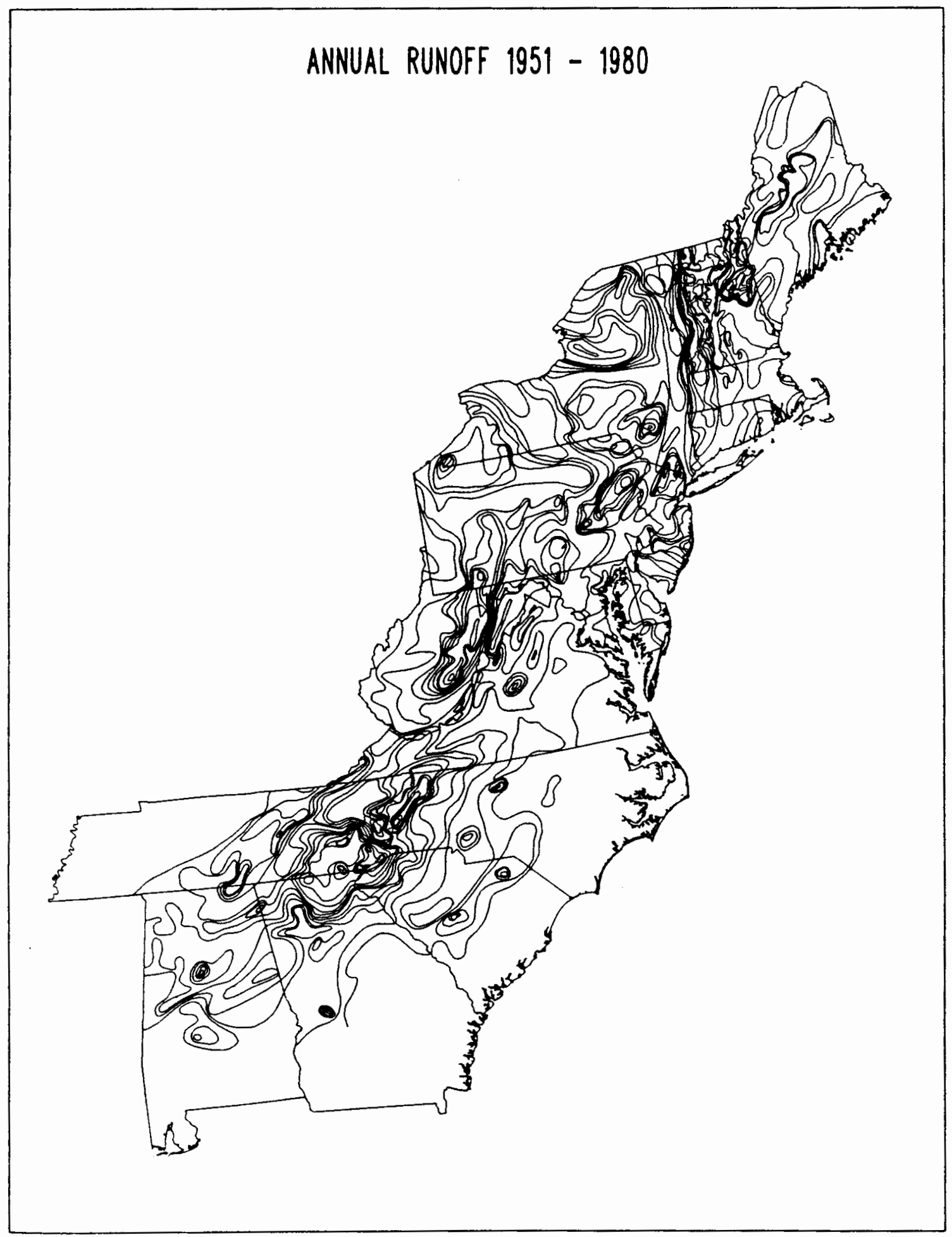

Figure 7. Manual Method Map of the Mean Annual Runoff-Depth in the Eastern United States. (Source: Church, et al., 1989.) 


\section{DISCUSSION OF FINDINGS}

\section{Examples of the Use of Runoff-Depth Contour Maps}

An example of the use of runoff-depth maps is the work of Solomon, et al., (1968) who produced a runoff-depth map of Newfoundland and Labrador to help assess potential hydropower in the region. The project was conducted by the Atlantic Development Board, Government of Canada. Although no specifics of alternative methods considered were discussed in their paper, the authors state the reasons for choosing an automated procedure, the grid square technique, as being the need for moderate accuracy over the large 140,000 square mile area as well as the large amounts of data that needed to be stored, processed and retrieved quickly for the project (Solomon, et al., 1968).

Domokos and Sass (1990) recently reported on a project using runoff-depth contour maps for resource appraisal in the Danube basin. Under international agreement the countries in the basin, using predetermined uniform methodologies, created runoff-depth contour maps using the manual method (Figure 8). The authors do not state why this methodology was chosen but they consider the results to be "acceptable, or even satisfactory". They feel that their results are applicable to future resource planning in the Danube Basin (Domokos and Sass, 1990).

The U.S. Environmental Protection Agency (EPA), in cooperation with other federal agencies, recently completed a study of the potential future effects of sulfur deposition in the eastern U.S., the Direct/Delayed Response Project (DDRP). Estimates of runoff were needed for input-output ion budget models, using long- 

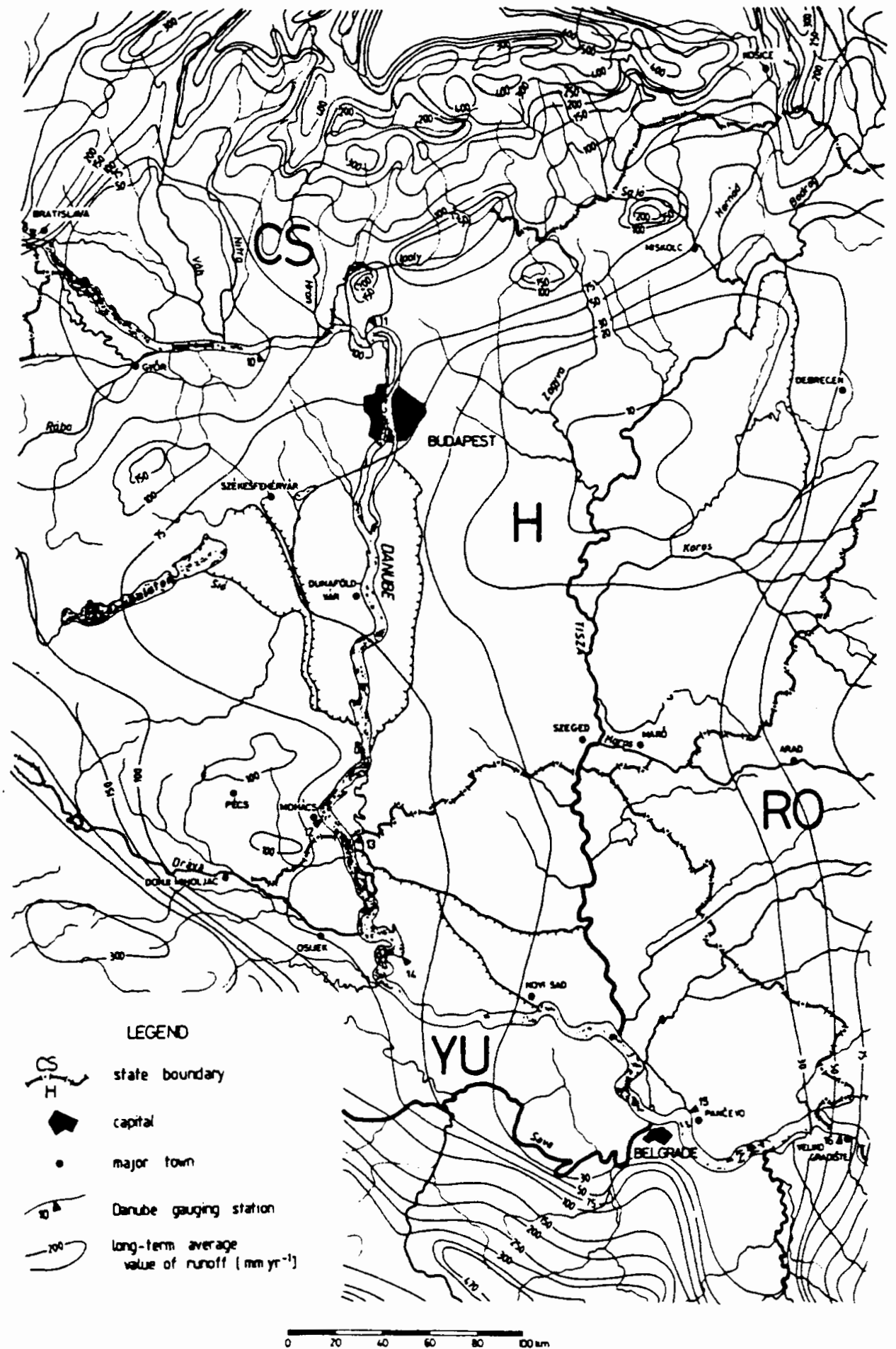

Figure 8. Manual Method Map of Mean Annual Runoff-Depth in the Danube Basin. (Source: Domokos and Sass, 1990.) 
term average values (Krug, et al., 1990), and for sulfur retention estimates for which "typical-year" data were used (i.e. for the northeast United States, WY84) (Graczyk, et al., 1987). The DDRP was faced with three choices for obtaining runoff values: 1) gage the approximately 1800 sites, 2) use an empirical interpolation approach, such as kriging, or 3) interpolate estimated runoff from runoff-depth contour maps produced with existing runoff data and the expert opinion of USGS hydrologists. Budget and time constraints made the first option impractical, while the large variability in topography and other variables that influence runoff across the region was felt to limit the accuracy of the second method. Runoff-depth maps produced by the third option at an appropriate resolution were not available at the time the project started. The USGS was employed to create the necessary maps by the manual method (Graczyk, et al., 1987, Church, et al., 1989, Rochelle, et al, 1989, Krug, et al., 1990). Runoff estimates were interpolated from the maps to the center (i.e. centroid) of each DDRP study watershed. An analysis of the errors associated with the estimates was conducted using an uncertainty analysis and the errors were found to be within acceptable limits (Church, et al., 1989, Rochelle, et al., 1989). The director of the DDRP has noted that if a more precise automated empirical method had been available the project would have utilized it and thereby reduced the considerable expense (e.g. the water-year 1984 map for the northeast United States cost approximately $\$ 25,000$ ) and time spent in having the maps produced manually (Church, 1991). 
Choosing an Appropriate Method of Mapping Runoff-Depth

With the variety of methods of mapping runoff-depth that are available, the question facing researchers is which method of producing a map is best for the situation at hand. There are five interrelated factors that affect the choice of an appropriate method for a given project: scale, desired accuracy, available data, available funding, and available time. The scale of the project under consideration is critical since a large discrepancy between the scale of a project and that at which the map is created can result in large errors or needless accuracy in the estimate of runoff. For example, if one is going to build a small agricultural storage dam on a ten square kilometer watershed one does not use a map of average runoff-depth for the United States. Conversely, if one was examining the general runoff patterns in the Columbia River basin, one would not need to estimate runoff for every square kilometer to get a good idea of the spatial pattern of runoff. Scale becomes less critical in areas of gentle relief were the pattern of runoff tends to be more homogenous. Generalization on smaller scale maps also affect the accuracy of the estimate obtained (UNESCO/WMO, 1977). This brings up the second factor, desired accuracy, which again depends upon the project at hand, as well as available data. Accuracy depends on the spatial density of data as well as variations in topography, geology, etc. (Krug, et al., 1990). Thirdly, the available data can limit the choice of methods used. If only runoff data are available, then a manual method can be the best choice. As climatological and physiographic data become available, the other methodologies become practical. Fourthly, the available funds can influence the 
method chosen. If the appropriate geographic and statistical software are available, an automated procedure (i.e. regression, grid square) is usually the most cost effective. If funds are limited and trained personnel are available, the manual method can be an acceptable short-term, cost-effective method. Lastly, the available time for completion of a project can be critical since manual techniques are often more time consuming than automated procedures.

The five factors are often interrelated with each aspect needing to be weighed carefully against the others, thus complicating the decision process that a person must face. If a project's scale is large (e.g. states to regions) and gaged runoff data, along with physiographic and climatic data are available, then automated procedures might be suitable. In smaller areas, the mapper will have to depend more on expert opinion or interpolative techniques, such as the regression or the grid square method. As the size of the area under consideration shrinks further one will have to extrapolate specific runoff and other information from relatively large distances and one could be forced to rely on manual or simple regression techniques. At all scales it is important that the data be as homogenous and temporally equivalent as possible (UNESCO/WMO, 1977).

\section{Current Status and Future Prospects of Runoff-Depth Contour Maps}

The current status of runoff-depth mapping in the United States is one in which newer, more automated procedures have largely gone unused. Although the manual method is adequate, it is likely that accuracy and efficiency could be improved by using partially or fully automated procedures (UNESCO/WMO, 1977). Some 
preliminary work has been started to merge the advantages of the manual method (i.e. expert opinion), with the advantages of automated procedures (i.e. speed and reproducibility) (Church, 1991); but a full scale research program has not been started. The use of artificial intelligence (expert systems) is an area of great promise for creating runoff-depth maps. Development of a system that uses the thought processes and approaches used in the manual method should be relatively straightforward (Church, 1991).

\section{Summary}

Runoff-depth maps aide the researcher and water manager in taking the first step in managing a resource, i.e. appraisal. These maps can be useful for estimating runoff at ungaged sites, in hydroelectric planning, and in providing general knowledge of runoff patterns. Researchers should keep in mind the relative scale of a project versus the map to be used, the accuracy needed for the task at hand, as well as the data used in creating the map. Due to the generalizations inherent in such maps, the map user needs to be cognizant of possible effects that local conditions might have on runoff-depth estimates at the site(s) of interest if these maps are to be used effectively. Research should be encouraged in the development of artificial intelligence methodologies for producing runoff-depth contour maps. These methodologies offer the best hope of improving the accuracy and availability of runoff-depth contour maps (Church, 1991). 


\section{CHAPTER III}

\section{AUTOMATED PROCEDURES USED IN MAPPING RUNOFF-DEPTH}

\section{INTRODUCTION}

In conjunction with research for the Environmental Protection Agency's (EPA) Direct/Delayed Response Project (DDRP) a study was conducted to find simple automated procedure(s) for producing annual (water-year) runoff-depth contour maps. The goal was for the procedure(s) to have a regional accuracy similar to that of the manual procedure maps produced by the U.S. Geological Survey (USGS) as quantified by Rochelle, et al. (1989). From several general methodologies eight specific procedures were examined to find a method that met these criteria.

Part of the underlying strategy of the methods tested is to densify the network of known runoff-depth value sites by using climatological data from National Climatic Data Center (NCDC) precipitation stations in the region of study, (i.e. the northeast United States) to estimate runoff at these stations.

The WY84 map produced by Graczyk, et al. (1987) was chosen as the runoffdepth map to be produced by the automated procedures to be examined. This map was chosen because: 1) it was produced by the same methodology as the long-term map produced by Krug, et al. (1990) whose accuracy was quantified by Rochelle, et al. (1989), 2) the WY84 USGS runoff gaging site data were readily available, 3) the 
precipitation data for WY84 were readily available, and 4) WY84 was a wetter than average year following a normal year in the northeast United States (USGS, 1984, 1985), thus minimizing the effects of ground and surface water storage changes on the analysis. Eight different procedures were compared with statistical and visual techniques to the manual method. Based on this comparison procedures for further testing with an uncertainty analysis were chosen.

\section{Rationale for Automation}

Automated procedures have many advantages: lower cost and time as compared to manual procedures, ease of data handling, and reproducibility. Automated methods have been found to be an effective means of mapping runoff (e.g. Foyster, 1975). Automated procedures have disadvantages though: being unable to handle unforeseen or local influences on the phenomena being mapped, difficulty in accurately mapping non-homogeneous data or source networks, and handling the influences of mountainous terrain (McKay and Thomas, 1971, UNESCO/WMO, 1977, Dingman, et al., 1988). In this thesis these disadvantages were felt to be largely overcome by the use of estimated runoff at precipitation stations densifying the known runoff sites used for interpolation. This densification, along with the uniformity of data used and the regional scale of accuracy desired, was felt to make the automated procedures comparable to the manual methods. 


\section{Simplifications at the Regional Scale}

One of the assumptions of this research is that due to the broad regional scale being utilized, a relatively unsophisticated methodology will be appropriate. As noted by Palmer and Havens (1958), "Although ease of application is not a suitable criterion of adequacy, it is often a primary consideration of use" (p. 123). As part of the philosophy of simplification the use of simple water-balance, rainfall-toprecipitation ratio $(\mathrm{R} / \mathrm{P})$, and regression techniques were explored. Contours were generated by linear interpolation also for the sake of simplicity.

At the scale of this study the area of the watershed compared to the study area is small and thus it was felt appropriate to treat the areal runoff values as points (Foyster, 1975). The runoff sites are placed in the center of their appropriate drainage basin, as opposed to the actual gage site, in accordance with standard USGS runoff-depth mapping policy (Graczyk, et al., 1987, Rochelle, et al., 1989, Krug, et al., 1990).

At the regional scale the use of a water balance approach was felt to be suitable (Foyster, 1975). The longer time periods considered (i.e. water-year and long-term average) preclude the need to consider change in storage although local conditions, such as geology, may cause these assumptions to be invalid in some areas (Kitteredge, 1938, Storr, 1972, Dunne and Leopold, 1978, Lee, 1980). When accurate measurements of precipitation $(\mathrm{P})$ and runoff $(\mathrm{R})$ are available the calculation of evapotranspiration $(E T)$ is straightforward $(E T=P-R)$, although the concept of "accurate measurement" can be a major problem (Munson, 1966). Even if the 
assumption of zero change in storage is false the possible errors in the measurement and estimation of runoff and precipitation values could override this usually small amount.

Another simplifying concept in the use of a regional scale is that averages or integrals of factors affecting runoff process at a more local scale can be generalized (Klemes, 1983). Things that might appear anti-intuitive at the large scale, e.g. the storage component of the water balance being ignored, can be assumed to hold true at the regional scale over longer time periods (McKay and Thomas, 1971).

\section{Underlying Assumptions with Principal Data Used}

For this research long-term runoff-depth values were obtained by interpolation from the long-term runoff-depth map (Krug, et al., 1990). These values were used because of the quantifiable nature (Rochelle, et al., 1989) of the interpolated values at ungaged sites and because they are more accurate than interpolations from gaged sites alone. It has been found that estimates of runoff-depth obtained from the longterm runoff-depth map are not regionally or spatially biased or biased due to the local density of sites used in the map's creation (Rochelle, et al., 1989). There also is no bias in estimates due to basin size from the long-term runoff map (Rochelle, $e$ t al. 1988). The gaged and interpolated values of runoff-depth used in this research do not take into account the errors in stream gaging which have been estimated to range from $0-5 \%$ (Winter, 1981) to $10-15 \%$ (Mather, 1981).

An underlying assumption of the long-term precipitation and runoff data used in this research is that they define a climatic normal and that, through various methods, 
a prediction for a given year's runoff, outside of the time frame used in determining long-term average precipitation and runoff, can be made. Work by Drozdov, et al. (1965) and Court (1967) has found that the 30-year period used to define climatic normals for precipitation is without scientific foundation. Court (1967) found that for precipitation estimates the longer the year to be predicted is from the base period (i.e. the period defining climatic normal) the shorter the climatic normal time period needs to be. It is unknown whether this also applies for runoff. The 30-year base period was used in this research because of the ease of data acquisition, its widely held acceptance, and because it was the time period used in the generation of the long-term runoff map, not due to any inherent superiority to this time length.

\section{Definitions of Elements of the Water-Balance}

Precipitation will be defined as the water depth collected and recorded at standard rain gauges. An attempt was made to locate an expertly drawn long-term precipitation contour map at the same resolution and scale as the long-term runoff map, but none were available. This limited the research to using gaged precipitation data. Estimates of errors in precipitation measurement vary (Table III) and no attempt was made to correct for these errors, which overall have a negative bias (Rasmusson, 1968), in this research. The reasons for these errors include operator error, wind (Neff, 1977, DeAngelis, et al., 1984), snow (Dingman, et al., 1988), and occult precipitation (e.g. fog drip, rime) (Dingman, 1981). Dingman (1981) notes that occult precipitation can be significant in higher forested watersheds. Work by Yoxall (1980) and others has shown the importance of having an adequately dense 
precipitation station network to show the spatial pattern of precipitation and to accurately estimate this element of the water balance. No studies describing the required density of precipitation sites for a study at the regional scale are available in the literature, although a study by Dingman, et al. (1988) in West Virginia had an average error of $7.5 \%$ for estimating precipitation in a mountainous terrain were station density was $900 \mathrm{~km}^{2} /$ gage. Precipitation site density for the study region in this research was $929 \mathrm{~km}^{2} /$ gage for the long-term sites and $821 \mathrm{~km}^{2} /$ gage for the WY84 sites.

\section{TABLE III}

ESTIMATED ERRORS IN PRECIPITATION MEASUREMENT FROM STANDARD RAIN GAUGES

\begin{tabular}{llll} 
\% Error & Time Frame & Study & Source \\
\hline $5-50$ & Annual & Struzer, et al. $(1965)$ & Rasmusson (1968) \\
$5-15$ & 4-5 Years & Neff & Neff (1977) \\
$0-30$ & Annual & Rodda (1985) & Dingman, et al. (1988)
\end{tabular}

Runoff will be defined as the amount of surface-water measured at a gaging site by the USGS. Runoff-depth is this measured volume spread over the upstream watershed area (volume of runoff/area).

Evapotranspiration is defined here as the remainder of precipitation once runoffdepth is subtracted. This is assumed to be equivalent to the amount of water evaporated and transpired for a given location. This definition would not be valid if variations in deep or surface storage were significant; but due to the longer time periods and large areas involved in this research it is felt that these variations are 
negligible at best. The longer time periods considered will also tend to reduce the cumulative errors caused by inaccuracies in the measurement of runoff and precipitation (UNESCO/WMO, 1977).

\section{AUTOMATED MAPPING METHODOLOGIES CONSIDERED}

To create a runoff-depth contour map as accurate as that produced by the USGS manual procedure for WY84 with a simple automated procedure several general methodologies were considered: 1) a linear interpolation method employing known gaged runoff data only; 2) a water-balance approach in which ET, determined from long-term data, is assumed to be constant; 3) a method which assumes that $R / P$, determined from long-term data, remains constant over time; 4) a regional mean approach to 2) and 3); 5) a regression formula approach which uses long-term data to create a formula to predict runoff or ET in WY84; and 6) a regional mean approach utilizing R/P based on WY84 data only. From these general methodologies eight specific procedures were formulated. For all of the procedures to be described here an ARC/INFO* GIS was utilized on a mainframe platform. Interpolations were based on Triangular Irregular Networks (TIN's) representing the given surface by a series of points of known values interconnected by triangles (ESRI, 1986). All interpolations and contours were visually checked against actual and estimated values plotted on the same map.

Mention of brand names or commercial products does not constitute endorsement or recommendation for use by the author, Portland State University, or the U.S. Environmental Protection Agency. 
The first methodology is a map created from the linear interpolation of gaged WY84 runoff-depth data. This methodology was utilized to test whether any benefit was derived from the use of the above methodologies to follow when compared to this simple procedure. The steps involved in this procedure are: 1) Create a TIN for the gaged WY84 runoff values; and 2) produce a contour map, by linear interpolation, for WY84 runoff using the TIN created in 1). This method is diagramed in Figure 9 and will be referred to as the GAGE84 procedure.

The second methodology assumes that ET is constant over time. ET has been found to be conservative in space and time (Leopold, et al, 1964, Likens, et al., 1977, Lee, 1980, Saxton, 1981). This simplification (assuming ET is constant over time) was felt to be reasonable considering the other possible errors in the water-balance calculation (e.g. measurement errors). The steps involved in this procedure are: 1) create a TIN for long-term runoff from the long-term manual map; 2) interpolate long-term runoff to the long-term precipitation stations using the TIN produced in 1); 3) calculate, from the interpolated runoff and measured precipitation, the longterm ET value for each precipitation station; 4) create a TIN from the long-term ET values calculated in 3); 5) interpolate long-term ET to the WY84 stations using the TIN created in 4); 6) calculate estimated runoff using precipitation and ET values at each precipitation station (estimated $\mathrm{R}=\mathrm{P}-\mathrm{ET}$ ); 7) create a TIN using both the estimated runoff at the precipitation stations and the gaged runoff; 8) generate a contour map, by linear interpolation, for WY84 runoff using the TIN created in 7). This methodology will be referred to as the LTET procedure (Figure 10). 


\section{GAGE84}

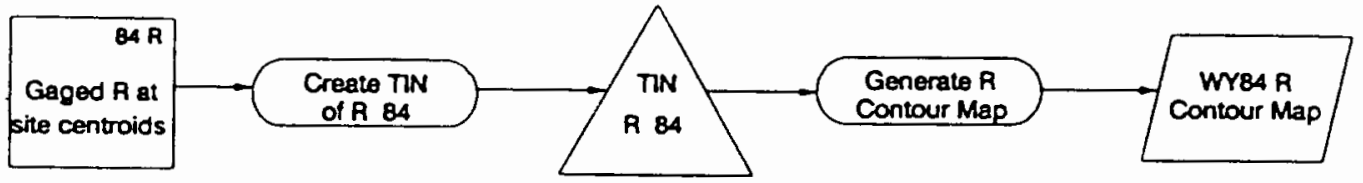

Figure 9. Steps in the Production of a Runoff-Depth Contour Map Using the GAGE84 Procedure. 


\section{LTET}

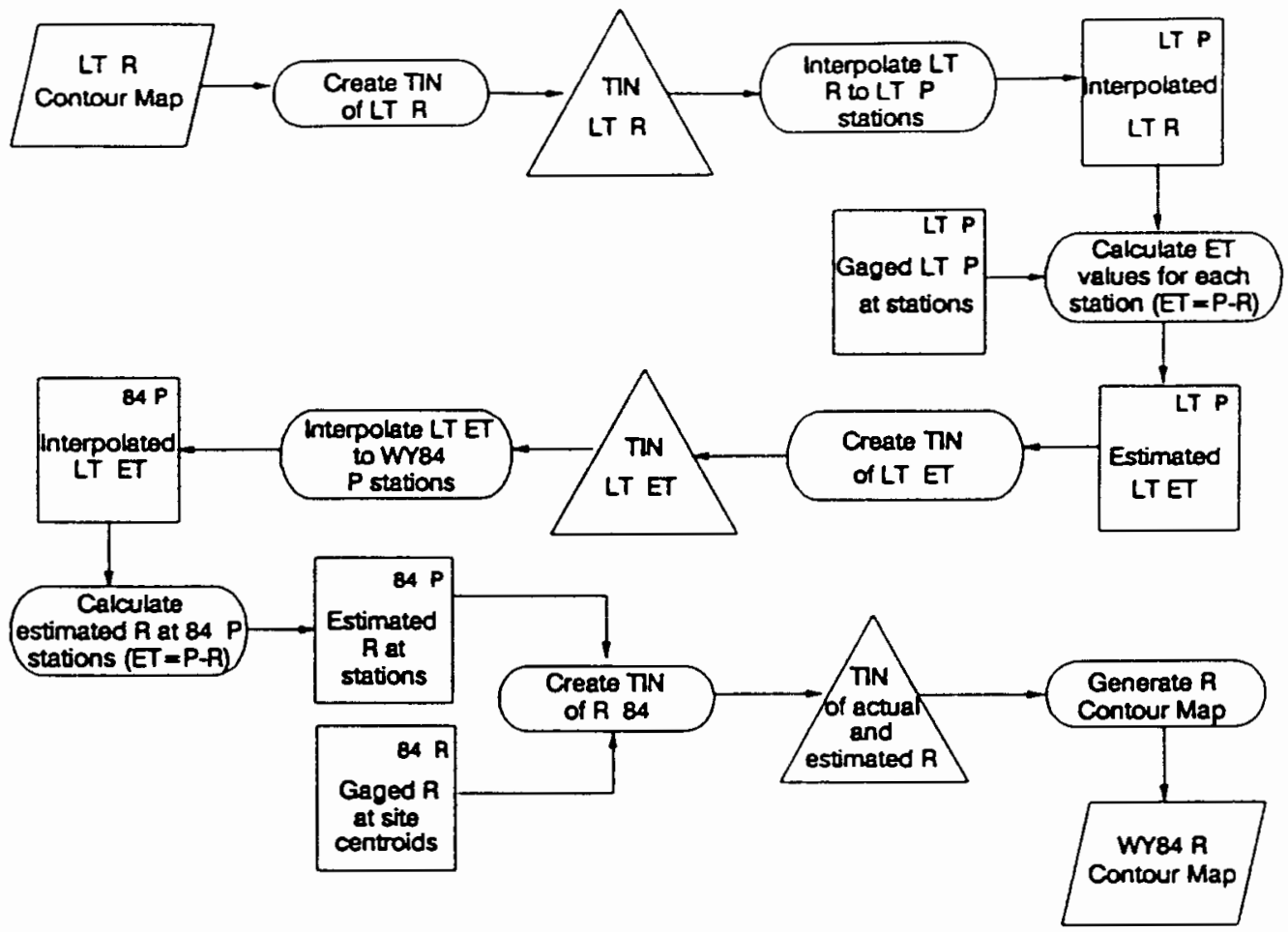

Figure 10. Steps in the production of a Runoff-Depth Contour Map using the LTET Procedure. 
The third methodology assumes that R/P remains constant over time. Although the literature does not support this hypothesis either for individual watersheds having a constant $\mathrm{R} / \mathrm{P}$ or as a predictor for other ungaged streams (Rafter, 1903, Hidore, 1966), it was felt that this approach met the criteria of simplicity, and at the regional scale it was assumed that the errors introduced would be tolerable. The steps involved in this procedure are: 1) create a TIN for long-term runoff from the longterm manual map; 2) interpolate long-term runoff to the long-term precipitation stations using the TIN produced in 1); 3) calculate, from the interpolated runoff and measured precipitation, the long-term R/P value for each station; 4) create a TIN from the long-term R/P values calculated in 3); 5) interpolate long-term R/P to the WY84 precipitation stations using the TIN created in 4); 6) calculate estimated runoff using precipitation and $R / P$ values at each precipitation station (estimated $R$ $\mathrm{P}(\mathrm{R} / \mathrm{P})$ ); 7) create a TIN using both the estimated runoff at precipitation stations and the gaged runoff; 8) generate a contour map, by linear interpolation, for WY84 runoff using the TIN created in 7). This methodology will be referred to as the LTRP procedure (Figure 11).

The fourth methodology uses the MLRA regional mean values of methods two and three to predict WY84 runoff. Due to the inherent noise in the results from individual sites, caused by measurement errors or local conditions as compared to the region as a whole, it was felt that using a regional mean of the ET and R/P values might give a more generalized and regionally correct result. The use of regional means as hydrologic predictors is supported by the work of Sopper and Lull 


\section{LTRP}
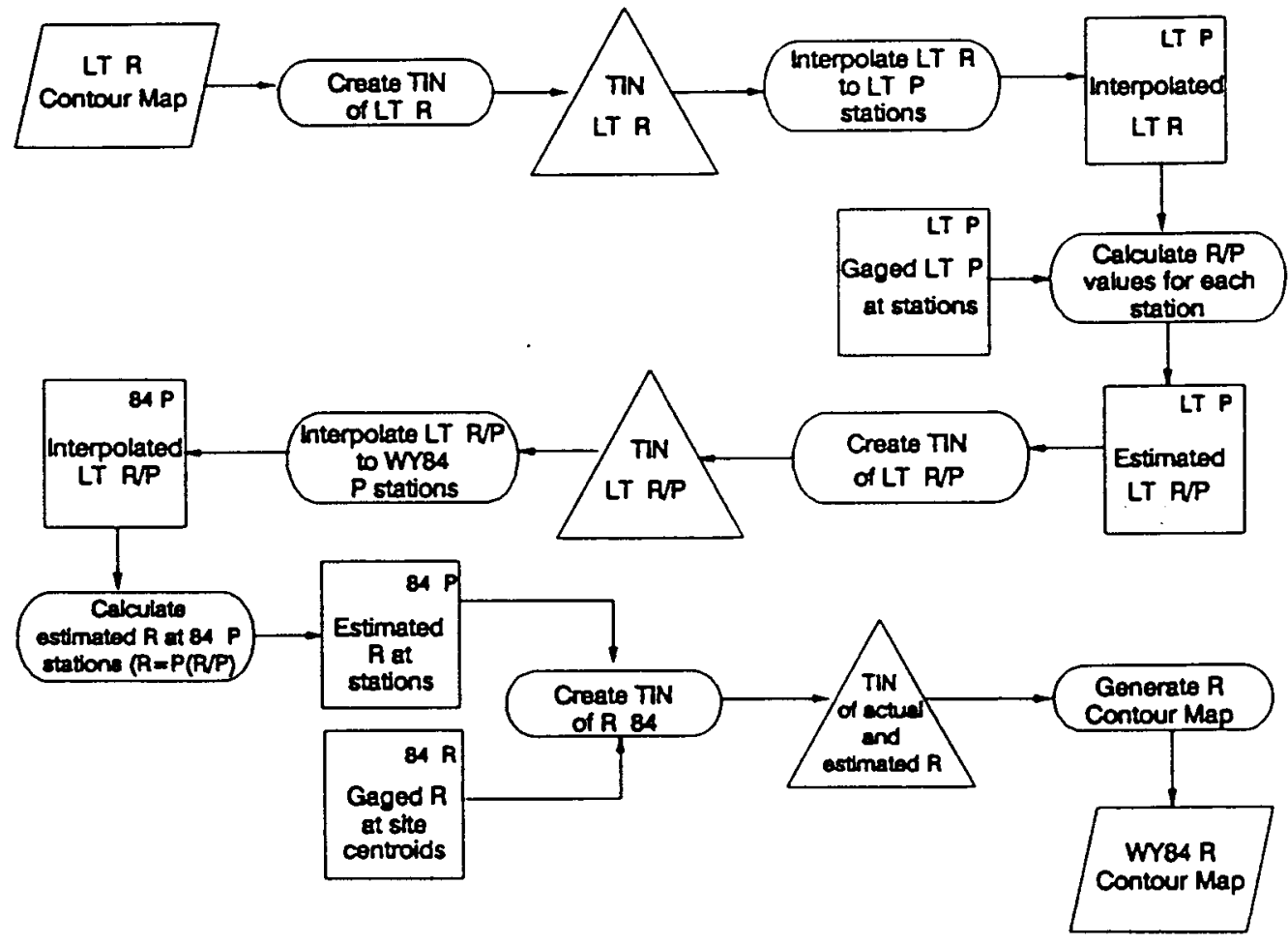

Figure 11. Steps in the Production of a Runoff-Depth Contour Map Using the LTRP Procedure. 
$(1965,1970)$ who found that experimental watershed runoff was in relatively close agreement to regional averages and Moss and Dawdy (1973) who found that regional values are valid for interpolating to ungaged sites. In producing the long-term $R / P$ and ET values two methods were used. One was interpolating long-term runoff from the manual USGS map to long-term precipitation stations; the other interpolates long-term precipitation to the long-term runoff centroids. Between the two methods for determining R/P there was a statistically significant difference between the means of the two data sets $(Z=4.90 P<0.001$ (The $P$ statistic gives the smallest level of significance that would have allowed the rejection of the null hypothesis (Iman and Conover, 1983))) but hydrologically it is insignificant, 0.54 versus 0.56 . For ET there also is a significant difference between the means of the two data sets $(\mathrm{Z}=4.01 \mathrm{P}$ $<0.001$ ) but the difference in the means, 50.2 versus $47.1 \mathrm{~cm}$, is also not likely to be hydrologically significant.

For mean ET values the steps involved are: 1) create a TIN for (a) the long-term runoff values from the manual map, and (b) the long-term precipitation at the precipitation stations; 2) interpolate long-term precipitation values to the long-term runoff sites and long-term runoff values to the long-term precipitation stations using the TIN's created in 1); 3) calculate, from the interpolated and measured values, an ET value for each of the precipitation stations and runoff sites; 4) sort the runoff and precipitation sites by their MLRA and calculate a mean ET for each MLRA; 5) assign the mean ET values to WY84 precipitation stations based on the MLRA's in which the station occurs; 6) calculate estimated runoff using precipitation values and 
the mean ET values at each station (estimated $\mathrm{R}=\mathrm{P}-\mathrm{ET}$ ); 7) create a TIN using both the estimated runoff at precipitation stations and the gaged runoff; 8) generate a contour map, by linear interpolation, for WY84 runoff using the TIN created in 7). This methodology is diagramed in Figure 12 and will be referred to as the MNLTET procedure. For the mean R/P method the steps involved are: 1) create a TIN for (a) the long-term runoff values from the manual map, and (b) the long-term precipitation at the precipitation stations; 2) interpolate long-term precipitation values to the longterm runoff sites and long-term runoff values to the long-term precipitation stations using the TIN's created in 1); 3) calculate, from the interpolated and measured values, an $\mathrm{R} / \mathrm{P}$ value for each of the precipitation stations and runoff sites; 4) sort the runoff and precipitation sites by their MLRA and calculate a mean R/P for each MLRA; 5) assign the mean R/P values to WY84 precipitation stations based on the MLRA's in which the station occurs; 6) calculate estimated runoff using precipitation values and the mean $R / P$ values at each station (estimated $R=P(R / P)$ ); 7) create a TIN using both the estimated runoff at precipitation stations and the gaged runoff; 8) generate a contour map, by linear interpolation, for WY84 runoff using the TIN created in 7).This methodology is diagramed in Figure 13 and will be referred to as the MNLTRP procedure.

The fifth methodology uses linear regression formulae to predict runoff or ET at precipitation stations. These formulae are based on the relationship between various climatic and physiographic variables and the long-term values of runoff, interpolated from the long-term manual map, and ET, estimated by the water-balance method at 


\section{MNLTET}

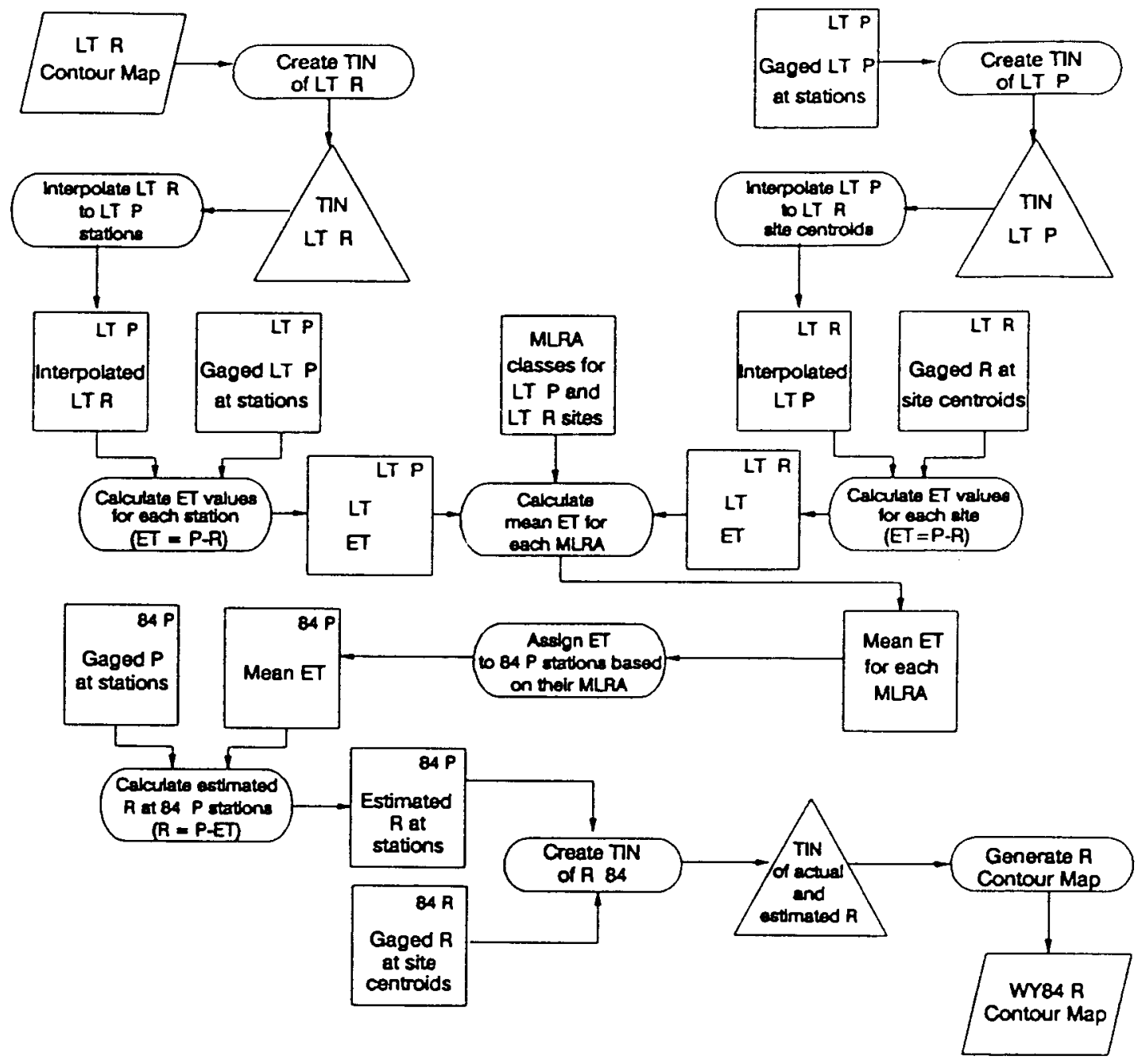

Figure 12. Steps in the Production of a Runoff-Depth Contour Map Using the MNLTET Procedure. 


\section{MNLTRP}

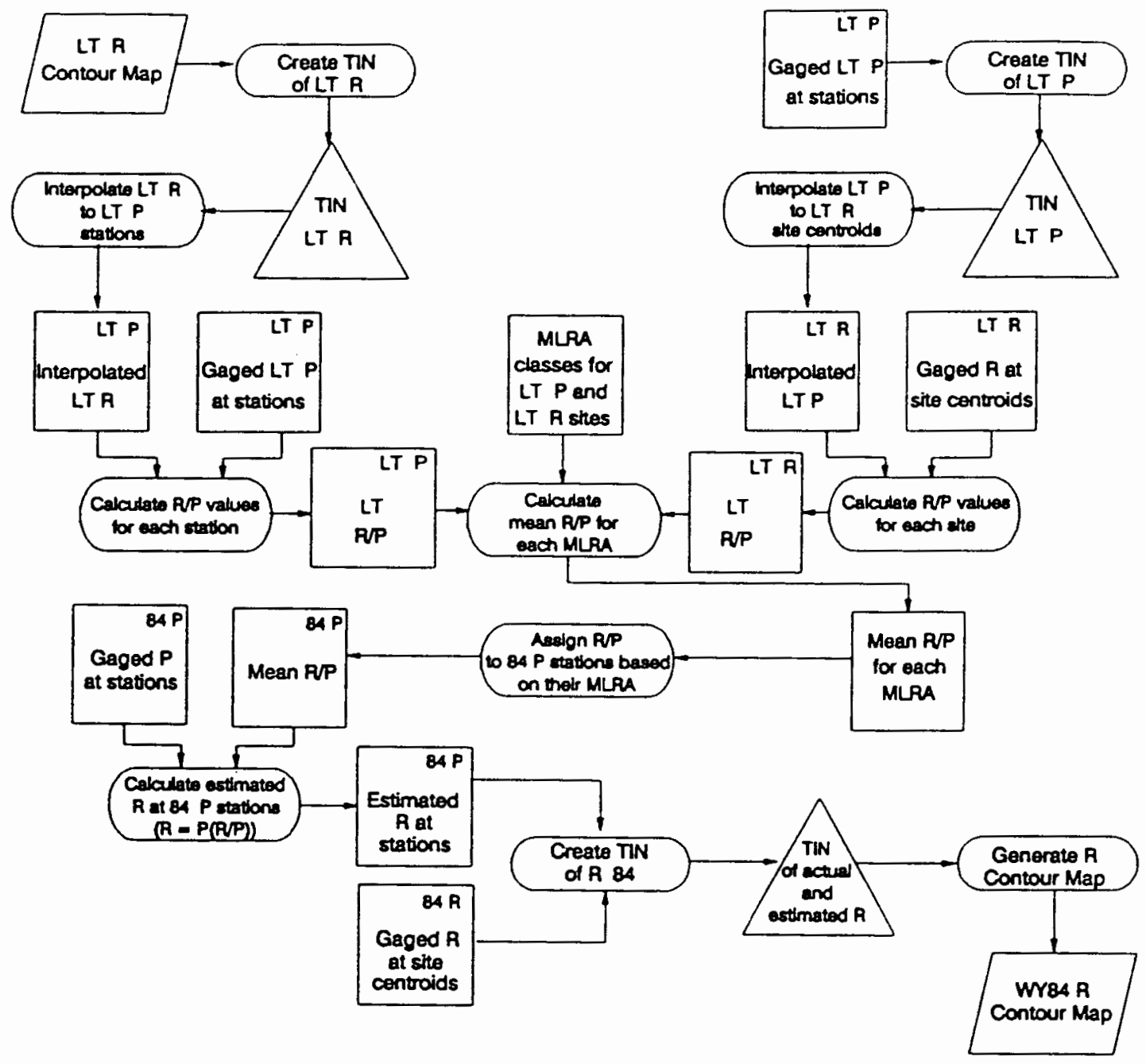

Figure 13. Steps in the Production of a Runoff-Depth Contour Map Using the MNLTRP Procedure. 
the long-term precipitation stations. Regression formulae have been used in the past to interpolate runoff values within the time and geographic framework in which the formulae were developed (Lull and Sopper, 1967, Sopper and Lull, 1970, Liebscher, 1972, Dingman, 1981), but no examples of extrapolating a regression formula temporally with runoff data was found in the literature. Regression equations have been used to predict storm runoff (Lee and Bray, 1969), temperature (Lee, 1969) and other climatic variables (Dingman, 1981). Deangelis, et al., (1984) found for a watershed in the Northeast that a single linear relationship exists between precipitation and runoff, even when very wet and dry years were examined. This implies that a relationship defined for a normal period in a region may have validity in wet or dry years. A single regression formula for the region was deemed to be appropriate due to the general regional scale approach of the research, a desire to avoid over-fitting of the regression model produced (Klemes, 1983) and the need for a broad range of data in which to fit the desired estimates (Lee, 1980). Critiques of the use of regression formulae in hydrology include Linsley's (1967) questioning of the ability of the formulae to adequately represent the phenomena especially in mountainous terrain (Mckay and Thomas, 1971, UNESCO/WMO, 1977). These reservations aside, the success of Liebscher (1972) with this methodology and the findings of Deangelis, et al., (1984) warranted its investigation.

For predicting runoff-depth the independent variables used by Liebscher (1972) (i.e. annual precipitation, mean annual temperature, and the ratio of summer to winter precipitation) were used because of the availability of the needed data and the 
variables taking into account the seasonal differences in runoff's response to precipitation (Shelton, 1985). The variables met the 0.15 significance level (i.e. a 15\% chance of rejecting a variable that would contribute to the predictive power of the model (SAS Institute, Inc., 1985)) to be included in the model which has an $R^{2}$ of 0.758. A graph of regression derived and estimated runoff showed no bias or outliers. Plots of studentized residuals also showed no bias. For ET no suitable regression formula was found that used the available data so all available variables that might influence ET were included in a stepwise regression procedure. Five variables (February and April precipitation, May mean temperature, April maximum temperature, and the ratio of summer to winter precipitation) met the 0.15 significance level and were determined to make significant improvements to the model by their F values. The model's $R^{2}$ is 0.699 . A graph of regression derived and estimated ET showed no bias or outliers. Plots of studentized residuals also showed no bias. For both of the regression analyses the Mt. Washington precipitation site was not included in determining the regression formula after an examination of scatter plots showed the site to be an outlier.

The steps in the ET regression are: 1) create a TIN for the long-term manual runoff map; 2) interpolate long-term runoff to the long-term precipitation stations using the TIN created in 1); 3) calculate long-term ET from the interpolated and measured values; 4) generate a regression formula to predict long-term ET estimated in 3), using long-term climatic data at precipitation stations in a stepwise regression procedure; 5) calculate estimated ET, using the regression formula developed in 4) 
and the WY84 climatic data at each precipitation station; 6) calculate estimated runoff using precipitation values and the estimated ET at each station (estimated $R$ $=\mathrm{P}-\mathrm{ET}$ ); 7) create a TIN using both the estimated runoff at precipitation stations and the gaged runoff; 8) generate a contour map, by linear interpolation, for WY84 runoff using the TIN created in 7). This method is diagramed in Figure 14 and will be referred to as the REG_ET procedure. The steps involved in the runoff regression method are: 1) create a TIN for the long-term manual runoff map; 2) interpolate long-term runoff to the long-term precipitation stations using the TIN created in 1); 3) generate a regression formula to predict long-term runoff estimated in 2), using long-term climatic data at precipitation stations and the relationship developed by Liebscher (1972) (i.e. runoff is a function of mean annual temperature, mean annual precipitation, and the ratio of summer to winter precipitation); 4) calculate estimated runoff, using the regression formula developed in 3) and the WY84 climatic data at each precipitation station; 5) create a TIN using both the estimated runoff at precipitation stations and the gaged runoff; 6) generate a contour map, by linear interpolation, for WY84 runoff using the TIN created in 5). This method is diagramed in Figure 15 and will be referred to as the REG_R procedure.

The sixth methodology uses the mean MLRA values of WY84 R/P ratios determined by interpolating WY84 runoff from gaged centroid sites to the precipitation stations and WY84 precipitation from the stations to the runoff centroids. No statistical difference was found between the means using the two methods $(0.605$ vs. $0.604, Z=.10 P=.92)$. Lull and Sopper $(1966)$ noted a marked 
REG_ET

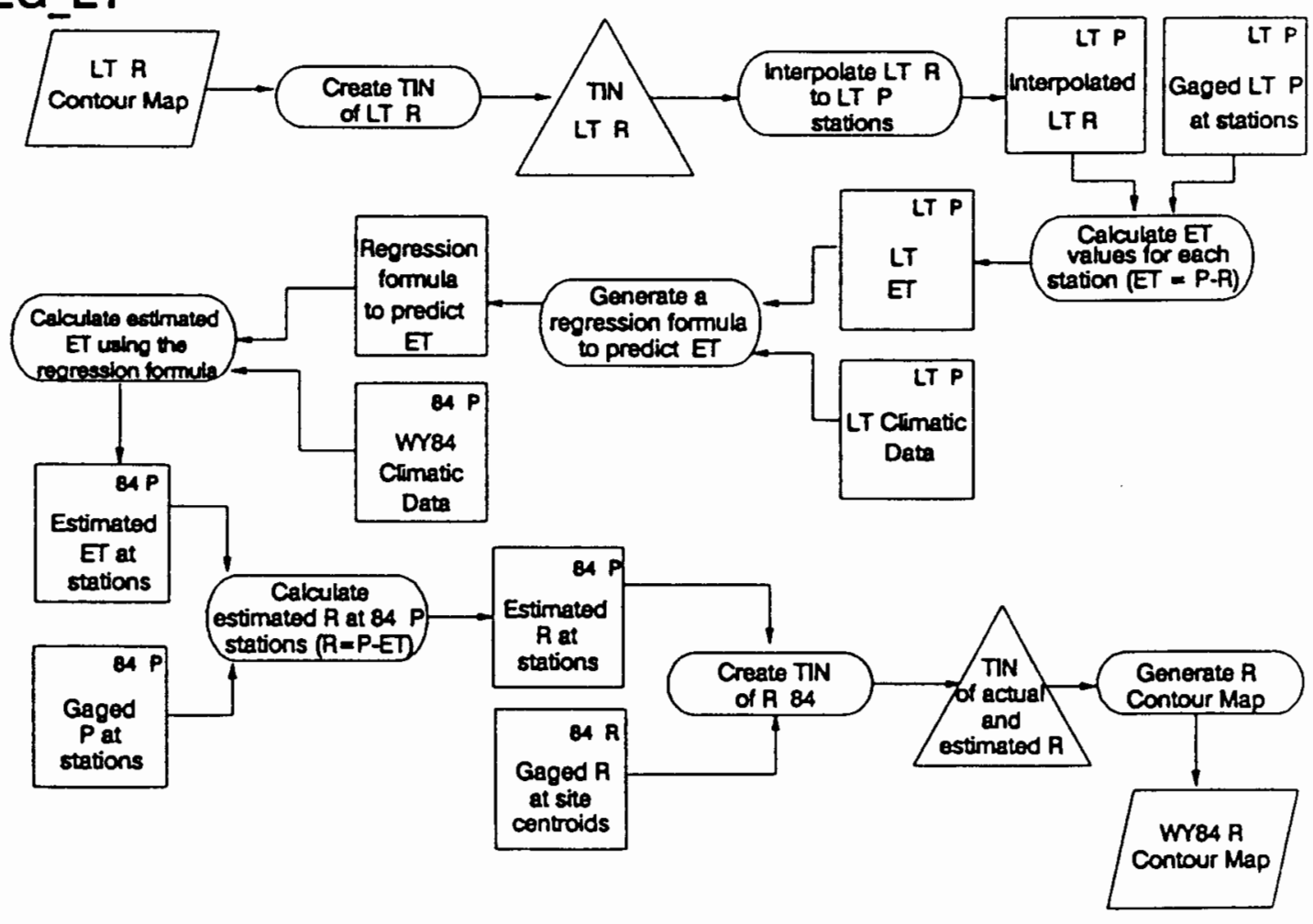

Figure 14. Steps in the Production of a Runoff-Depth Contour Map Using the REG_ET Procedure. 


\section{REG $R$}

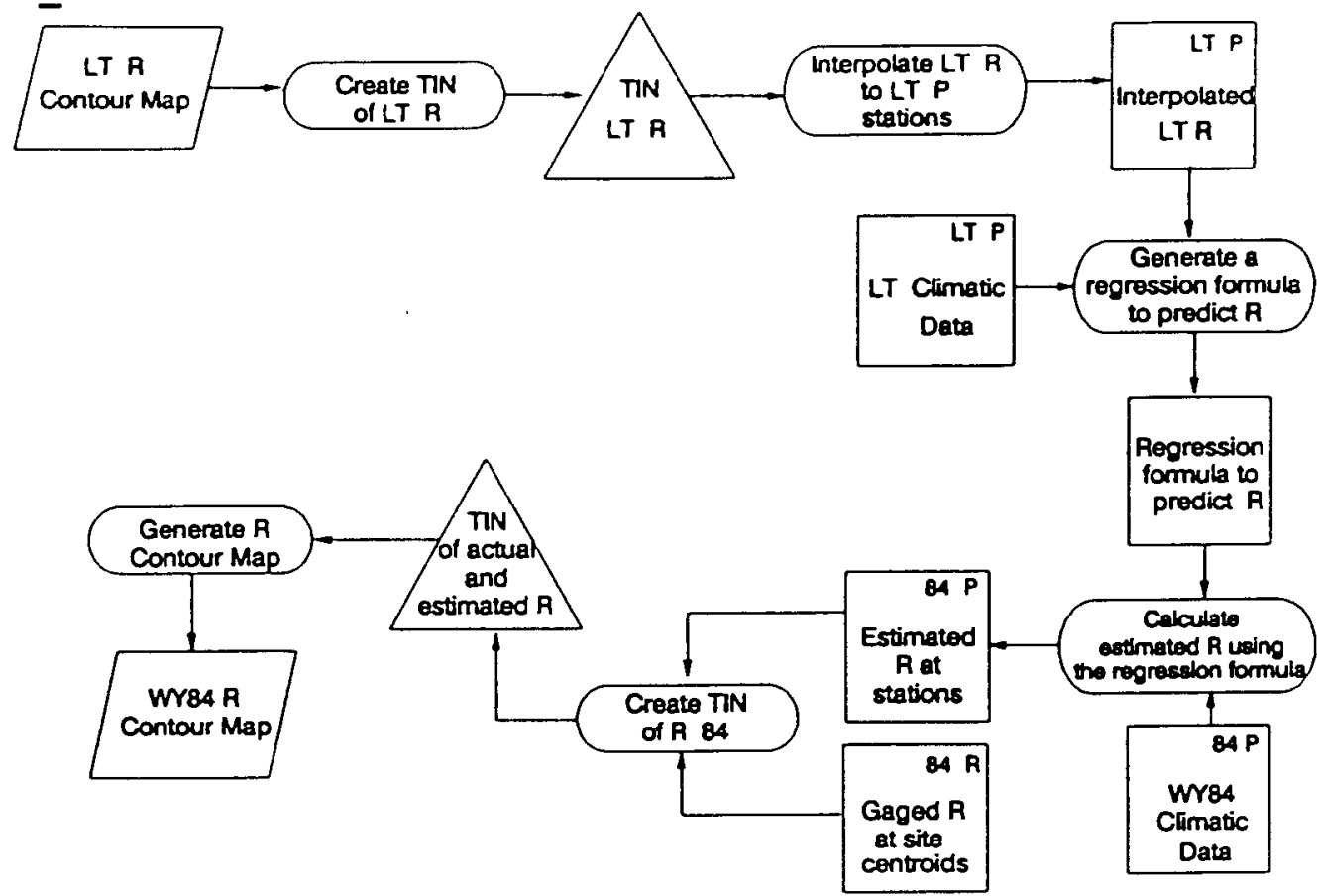

Figure 15. Steps in the Production of a Runoff-Depth Contour Map Using the REG_R Procedure. 
decrease in the correlation of runoff to precipitation in the NE when paired sites (precipitation:runoff) are more than $13 \mathrm{~km}$ (8 miles) apart. However scatter-plots of the $\mathrm{R} / \mathrm{P}$ values versus distance to the nearest gage of the opposing type showed no trends and no differences between the two methods (i.e. runoff to precipitation stations, precipitation to runoff sites). For WY84 precipitation values interpolated to runoff sites a statistically significant difference $(Z=2.26 P=.024)$ was found between the mean R/P of sites less than $13 \mathrm{~km}(0.595)$ and those greater than $13 \mathrm{~km}$ (.619); but these values are not hydrologically significant. For WY84 runoff interpolations to precipitation stations no statistical difference $(\mathrm{Z}=0.636 \mathrm{P}=.52)$ was found between the two groups (less-than $13 \mathrm{~km} .602$, greater-than $13 \mathrm{~km} \mathrm{.608).}$

The steps involved in this procedure are: 1) create a TIN for (a) the WY84 runoff values from the gaged runoff (as assigned to the centroid of the basin in which the basin occurs), and (b) WY84 precipitation at the precipitation stations; 2) interpolate WY84 precipitation values to WY84 runoff sites and WY84 runoff values to WY84 precipitation stations from the TIN's created in 1); 3) calculate, from the interpolated and measured values, $\mathrm{R} / \mathrm{P}$ for each of the precipitation stations and runoff sites; 4) sort the runoff and precipitation sites by their MLRA and calculate a mean R/P for each MLRA; assign the mean R/P values to the WY84 precipitation stations based on the MLRA in which the station occur; 6) calculate estimated runoff using precipitation values and the mean $R / P$ values at each station (estimated $R=$ $\mathrm{P}(\mathrm{R} / \mathrm{P})$ ); 7) produce a TIN using both the estimated runoff at precipitation stations and the gaged runoff; 8) produce a contour map, by linear interpolation, for WY84 
runoff using the TIN created in 7). This method is diagramed in Figure 16 and will be referred to as the MN84RP procedure.

\section{SELECTION OF FIVE PROCEDURES TO BE EXAMINED BY AN UNCERTAINTY ANALYSIS}

\section{Visual Comparison}

Eight maps were produced by the eight different procedures described above (Plates 3-10). The maps were first visually compared to the expertly drawn runoffdepth map produced by Graczyk, et al. (1987) (MAN84) (Plate 2) to note any general patterns or agreement/disagreement in the procedure maps as compared to the MAN84 map. The first general trend noted was the lack of strong variations among the automated procedures as far as the general pattern of runoff-depth depicted (Figure 17). This is probably due to the use of the same gaged runoff sites in all the procedures.

Upon closer examination a spikier, less generalized surface became apparent when comparing the LTET and LTRP maps to the MAN84, MNLTET, and MNLTRP maps. Both the LTRP and MNLTRP maps appear to underestimate runoff, especially along the Atlantic coast. This is probably due to the much higher than average precipitation experienced by this area in WY84 (USGS, 1985). This suggests that the assumption, (i.e. $\mathrm{R} / \mathrm{P}$ is constant over time) that the LTRP and MNLTRP maps are based on is false. This was supported by a comparison of longterm and WY84 R/P values at precipitation and runoff sites that contain values for both time periods $(n=460)$. The runoff-to-precipitation ratio was calculated for the 


\section{MN84RP}

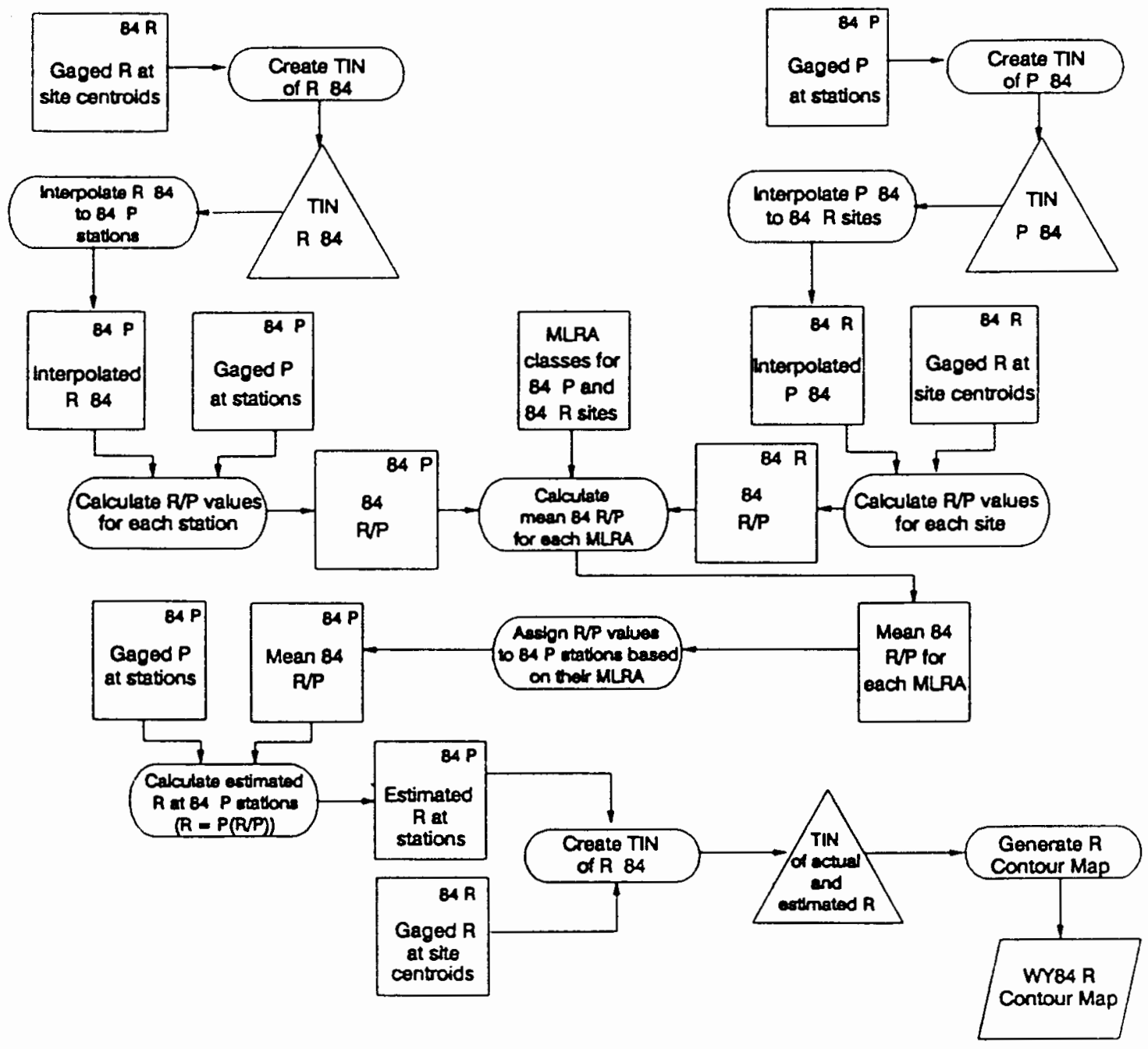

Figure 16. Steps in the Production of a Runoff-Depth Contour Map Using the MN84RP Procedure. 


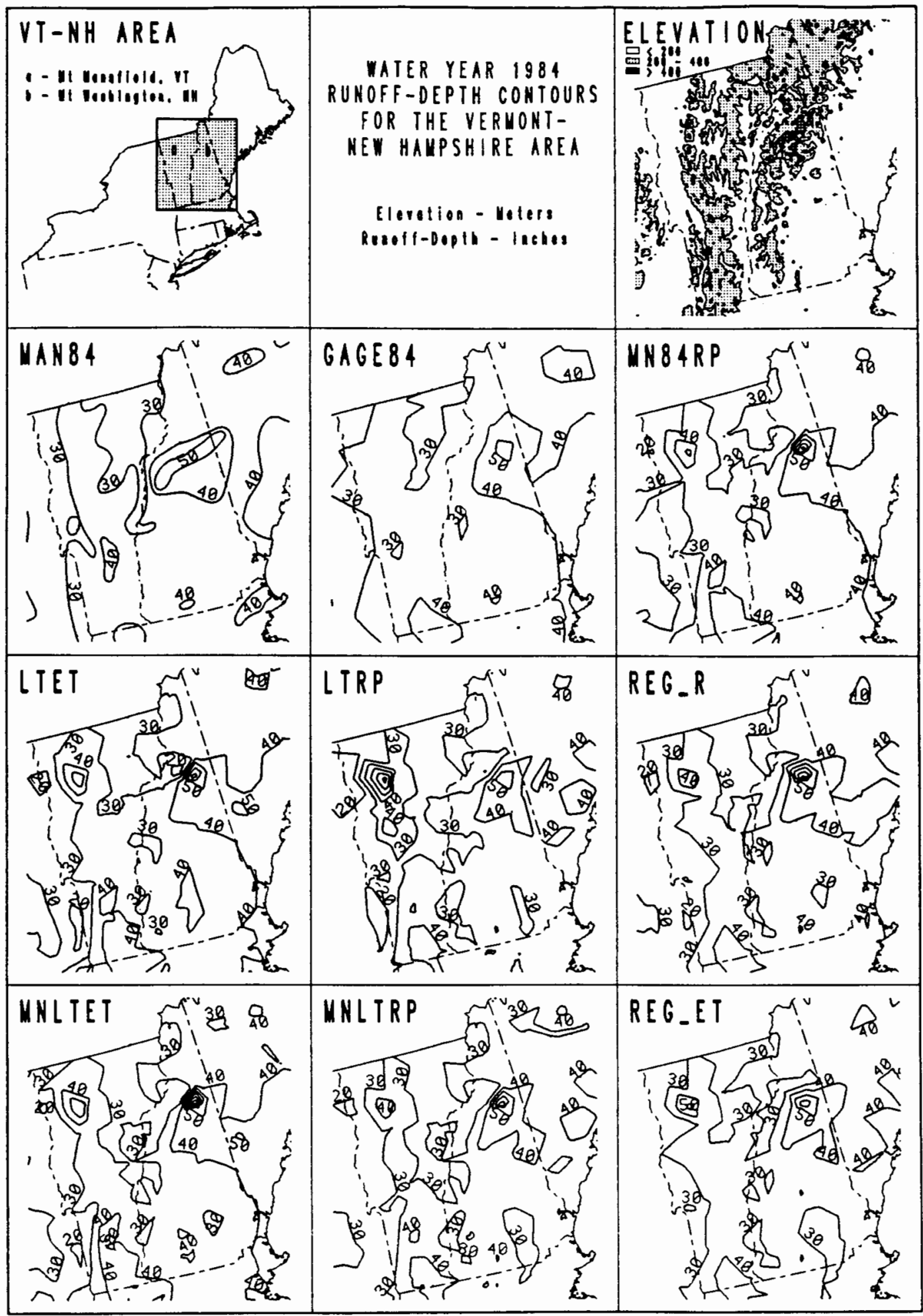

Figure 17. Comparison of Eight Procedure Derived Runoff-Depth Contour Maps in the VT-NH Sub-Area of the Northeast Region. 
precipitation stations by interpolation from the given time periods manual method map while for runoff sites precipitation values were interpolated from precipitation stations (Table IV). The difference in the means was found to be significant at the .0001 level by both a T-test and a signed rank test. The differences are also hydrologically significant. The REG_R and REG_ET maps also appear to underestimate runoff over the region. This may be due to the inadequacies of the regression models, inappropriateness of temporal extrapolation, or biases in the climatological or gaged data. Random errors in the measurement of the climatological data inputs could also explain the noted bias (Weber, et al., 1973). The GAGE84 map follows the general trend of the MAN84 map, but lacks the detail of the MAN84 map, especially in the mountainous areas. The MN84RP map is a fairly close match to the MAN84 map, both in general pattern and values. For all the procedures there are some minor variations from the MAN84 map which may be due to the increased resolution or noise caused by using estimated runoff values.

\section{TABLE IV}

\section{ESTIMATED R/P AT CORRESPONDING (LONG-TERM AND WY84) PRECIPITATION AND RUNOFF SITES*}

\begin{tabular}{lcc} 
& Mean & $\begin{array}{c}\text { Standard } \\
\text { Deviation }\end{array}$ \\
\hline long-term R/P & .548 & .080 \\
WY84 R/P & .614 & .091 \\
WY84 R/P - long-term R/P & .065 & .079 \\
& & \\
n $=460$ & &
\end{tabular}




\section{$\underline{\text { Statistical Comparison }}$}

A statistical comparison of the methods was also conducted by comparing estimated and interpolated values of runoff at the WY84 precipitation sites. These values are summarized in Table V. The general trend of underestimation by LTRP, MNLTRP, REG_ET, and REG_R are confirmed by the statistical analysis. A trend of overestimation by the LTET and MNLTET procedures is also apparent. This suggests that the simplifying assumption (i.e. ET is constant over time) that the LTET and MNLTET procedures are based on may be inappropriate. This was confirmed by comparing long-term and WY84 ET at precipitation and runoff sites that correspond between the two time periods $(n=460)$. ET was calculated by interpolating runoff from the appropriate runoff-depth maps, long-term and WY84, to the precipitation sites and then subtracting the runoff value from the precipitation value. For the runoff sites precipitation values were interpolated from the precipitation stations and a similar calculation made (Table VI). The difference in means are significantly different at the .001 level with both the T-test and the signed rank test. The GAGE84 and MN84RP methods give the closest approximation to the MAN84 map using this analysis. A comparison of the means of the estimated runoff at precipitation stations and interpolated values from MAN84 was conducted. All of the procedures means were significantly different at the .001 level except for GAGE84 $(\mathrm{P}(\mathrm{T})=.92 \mathrm{P}(\mathrm{S})=.65)$ and MN84RP $(\mathrm{P}(\mathrm{T})=.35 \mathrm{P}(\mathrm{S})=.38)$. 


\section{TABLE V}

ESTIMATED RUNOFF AT WATER-YEAR 1984

NCDC PRECIPITATION STATIONS

\begin{tabular}{|c|c|c|c|c|c|c|}
\hline Method & $\mathrm{n}$ & Mean & $\begin{array}{l}\text { Standard } \\
\text { Deviation }\end{array}$ & Minimum & Maximum & $\begin{array}{l}\text { Standard } \\
\text { Error of } \\
\text { the Mean }\end{array}$ \\
\hline \multicolumn{7}{|c|}{ Interpolated Values: } \\
\hline MAN84 & 394 & $83.82^{*}$ & $18.06^{*}$ & $30.13^{*}$ & $127.00^{*}$ & 0.91 \\
\hline GAGE84 & 381 & 83.59 & 18.52 & 30.56 & 146.70 & 0.95 \\
\hline \multicolumn{7}{|c|}{ Estimated Values: } \\
\hline LTET & 396 & 86.87 & 21.41 & 33.14 & 207.44 & 1.08 \\
\hline MNLTET & 405 & 87.37 & 24.24 & 32.95 & 293.34 & 1.20 \\
\hline LTRP & 396 & 73.32 & 16.45 & 35.73 & 148.63 & 0.83 \\
\hline MNLTRP & 405 & 74.10 & 15.87 & 38.32 & 209.70 & 0.79 \\
\hline REG_ET & 225 & 74.67 & 17.84 & 37.82 & 181.36 & 1.19 \\
\hline REG_R & 217 & 76.60 & 18.54 & 34.97 & 225.37 & 1.26 \\
\hline MN84̄RP & 397 & 84.00 & 20.70 & 37.50 & 229.29 & 1.04 \\
\hline
\end{tabular}

\section{TABLE VI}

ESTIMATED ET*

AT CORRESPONDING (LONG-TERM AND WY84)

PRECIPITATION AND RUNOFF SITES ${ }^{* *}$

\begin{tabular}{llc} 
& Mean & \multicolumn{1}{c}{$\begin{array}{c}\text { Standard } \\
\text { Deviation }\end{array}$} \\
\hline long-term ET & 49.44 & 10.80 \\
WY84 ET & 54.49 & 18.81 \\
WY84 ET - long-term ET & 5.05 & 14.67 \\
${ }^{*} \mathrm{Cm}$ & & \\
${ }_{\mathrm{n}=460}$ &
\end{tabular}

The rejection of the R/P and ET being constant assumptions are not conclusive at this point since unknown biases from the use of the manual maps may be involved. 
These conclusions will be further tested in Chapter IV with the comparison of estimates made from maps created based on these assumptions to actual gaged values with an uncertainty analysis.

\section{Choice of Procedures Used in the Uncertainty Analysis}

To reduce the amount of work involved in the uncertainty analysis a representative subset of the eight procedures was chosen. Five procedures were selected to conduct the uncertainty analysis on using the above visual and statistical comparisons. The GAGE84 method was chosen to represent the simplest and most straightforward automated procedure available. MNLTET and MNLTRP were chosen over LTET and LTRP mainly due to the better visual fit to the MAN84 map. REG_R was chosen as the regression method to be tested because of the simpler formula used and its slightly better visual and statistical fit to the MAN84 map as compared to REG_ET.MN84RP was chosen because of its close visual and statistical match to MAN84.

\section{Summary of Findings}

A statistical comparison of the means of the estimated runoff-depth at WY84 precipitation stations shows the GAGE84 and MN84RP methods having the closest approximation to the values interpolated from MAN84. This indicates that the working hypothesis that using information gained from a long-term expert map would improve the accuracy of a given water-year's map is inappropriate since visually and statistically none of the maps using the long-term data appear to be superior to those 
using only WY84 data. This conclusion will be further tested in Chapter IV with an uncertainty analysis. Depending on the accuracy desired for the project at hand all of the procedures above could be considered acceptable. The MN84RP method visually and statistically appears to give the closest approximation to the manually produced map for WY84. 


\section{CHAPTER IV}

\section{UNCERTAINTY ANALYSIS}

\section{INTRODUCTION}

A subset of the automated procedures described in Chapter III (GAGE84, MNLTET, MNLTRP, REG_R, and MN84RP) was compared to the manual method using an uncertainty analysis of runoff estimates. An uncertainty analysis is the withholding of data sites from a runoff map's creation for later use in a comparison of values obtained by interpolation from the generated maps to the actual gaged data. The results of an uncertainty analysis conducted on a long-term average runoffdepth map conducted by Rochelle, et al. (1989) will define the accuracy of the manual procedures. The uncertainty analysis of the automated procedures consisted of four steps. The first step was the selection of the data sites to be withheld from the contour map generation. The second was the generation of the contour maps. The third step was the interpolation of runoff-depth from the maps generated to the withheld sites. The fourth was the calculation of the interpolation errors by subtracting interpolated (estimated) runoff from gaged runoff at each site. A statistical summary and analysis was then conducted on these results as well as an examination for possible biases in estimated runoff and interpolation errors. 


\section{METHODOLOGIES}

The first step in the uncertainty analysis was the choice of the sites to be withheld. Of the 441 U.S. Geological Survey (USGS) Water-Year 1984 (WY84) runoff sites in the region of study 50 sites were withheld. This number approximates the number of sites used by Rochelle, et al. (1989) in the Northeast (NE) portion of their study of the eastern U.S. (approximately 40). Results using a withheld-site set of 50 are comparable to the results from the 97 sites used in Rochelle, et al. (1989) (Stevens, 1991).

In selecting the 50 withheld sites (Figure 18) it was desirable to have the sample reflect the spatial properties of the gaged site population; that is being sparse where stations are sparse and dense were stations are dense. Although in the long run strict random sampling will have this property, individual samples tend towards being poor representations of the spatial distribution. Some restrictions were therefore placed on the selection of the withheld sites. This was done with the use of a spatially systematic random sample (e.g. Bickford, et al., 1963) (Stevens, 1991, Stevens, et al., 1991). The sampling procedure used was based on spatial clustering similar to that used in the National Lake Survey (NLS) (Overton, 1987), except that sites were selected with an algorithm rather than subjectively as the NLS did. The spatial extent of the resource (gaged sites) was divided into compact clusters of points such that approximately an equal number of samples (i.e. withheld sites) were taken from each cluster. Clusters were formed by an algorithm that selects a point in the population that is furthest from the spatial center of the population. The points near this cluster 


\section{WATER YEAR 1984 RUNOFF SITES UNCERTAINTY ANALYSIS WITHHELD SITES}

YYQ 4 SITE CENTROIOS

- Vithida

+ Not Withheld 
seed that have not been selected were assigned to this cluster until the desired cluster size was reached. The process was then repeated with the spatial extent of the populations reduced by the exclusion of the points already selected (Stevens, 1991).

Due to statistical considerations (i.e. spatial restrictions, problems in variance estimation) the sample size per cluster is best when it is approximately two. Two sites therefore were selected from each of 25 clusters comprised of roughly 18 sites each. Due to 441 not being divisible by 18 some clusters had fewer than 18 sites, but this moderate variation in cluster size was deemed to be of little consequence as long as the target size was near two (Stevens, 1991, Stevens, et al., 1991).

After the site selection the next step was the generation of the contour maps for each of the procedures (GAGE84, MNLTET, MNLTRP, REG_R, MN84RP) without using the 50 withheld sites. This included withholding the WY84 runoff data from the generation of the mean regional $\mathrm{R} / \mathrm{P}$ values used in the MN84RP procedure. For all of the procedures the 50 sites were withheld from the generation of the TIN (i.e. Triangulated Irregular Network (ESRI, 1986)) created from estimated and actual runoff-depth values, used to create the runoff-depth contours. In the third step a TIN was created from these contours and estimated runoff-depth values were linearly interpolated to the withheld sites. The fourth step was the calculation of interpolation error values by subtracting gaged from estimated runoff at each withheld site. These values are presented in Appendix C. 


\section{RESULTS AND DISCUSSION}

\section{Interpolation Errors}

Summary statistics (i.e. mean, standard deviation, etc.) were generated from the interpolation error values calculated in the uncertainty analysis. These were then compared to the results of Rochelle, et al. (1989) (Table VII). Rochelle, et al. (1989) 'CNTR' method, a manual method which interpolates to the gaged sites centroid, is equivalent to the GIS driven linear interpolation used in this thesis. The mean error for the REG_R and MN84RP procedures, both for absolute and percentage interpolation errors, yielded the best results and the closest equivalence to the manual procedure and also showed a marked improvement over the simple interpolation procedure (GAGE84).

\section{TABLE VII}

INTERPOLATION ERROR DESCRIPTIVE STATISTICS FOR THE 50 WITHHELD RUNOFF SITES

\begin{tabular}{lcccccc} 
Method & $\begin{array}{c}\text { Standard } \\
\text { Mean }\end{array}$ & $\begin{array}{c}\text { Error of } \\
\text { the Mean }\end{array}$ & $\begin{array}{c}\text { Standard } \\
\text { Deviation }\end{array}$ & $\begin{array}{c}\text { Population } \\
\text { Mean } \\
\text { (Percent) }\end{array}$ & $\begin{array}{c}\text { Standard } \\
\text { Error of } \\
\text { the Mean } \\
\text { (Percent) }\end{array}$ & $\begin{array}{c}\text { Standard } \\
\text { Deviation } \\
\text { (Percent) }\end{array}$ \\
\hline Manual & $1.54^{*}$ & $0.88^{*}$ & 8.53 & 0.90 & 1.47 & 14.21 \\
GAGE84 & -1.60 & 1.60 & 11.33 & -3.23 & 2.06 & 14.57 \\
MNLTET & -4.45 & 2.43 & 17.22 & -6.34 & 2.72 & 19.22 \\
MNLTRP & 4.20 & 1.74 & 12.31 & 3.32 & 1.95 & 13.82 \\
REG_R & 0.48 & 1.82 & 12.87 & -0.74 & 2.08 & 14.72 \\
MN84RP & -0.37 & 1.67 & 11.83 & -1.76 & 1.96 & 13.83
\end{tabular}

: $\mathrm{Cm}$.

"Manual(CNTR) method, Source: Rochelle, et al, (1989) 
A box-and-whisker diagram of the interpolation errors is presented in Figure 19. The REG_R, MN84RP, and GAGE84 methods show the best grouping of values near zero. A bias towards overestimation by the MNLTET method and underestimation by the MNLTRP method is also apparent.

Empirical distribution function (EDF) graphs are commonly used to display the cumulative relative frequency of a sample (Iman and Conover (1983)). These graphs display the portion of the sample values, on the vertical axis, that are less than or equal to the sample value presented on the horizontal axis. EDF's of interpolation error values for the five procedures are presented in Figure 20. REG_R, MN84RP, and GAGE84 have the steepest slopes centered on an error of zero of the five tested showing a large number of sites with an error near zero. A bias towards overestimation using MNLTET is apparent in the graph from its being off-center of the zero value. All of the procedures show a marked increase in absolute error towards the tails of their distributions. This pattern may be due to the general regionalization algorithms used by the procedures. Watersheds that are atypical for a region will not be handled as well by the algorithms used and thus will have larger interpolation errors (Church, 1991). The general pattern of the EDF's is similar to that found by Rochelle, et al. (1989) (Figure 21) for the long-term runoff-depth map of the eastern United States, although the absolute errors are greater for WY84 than the long-term error's found by Rochelle, et al. (1989). This is probably due to the increase in runoff-depth in WY84 (i.e. a mean of 141\%) as compared to the long- 


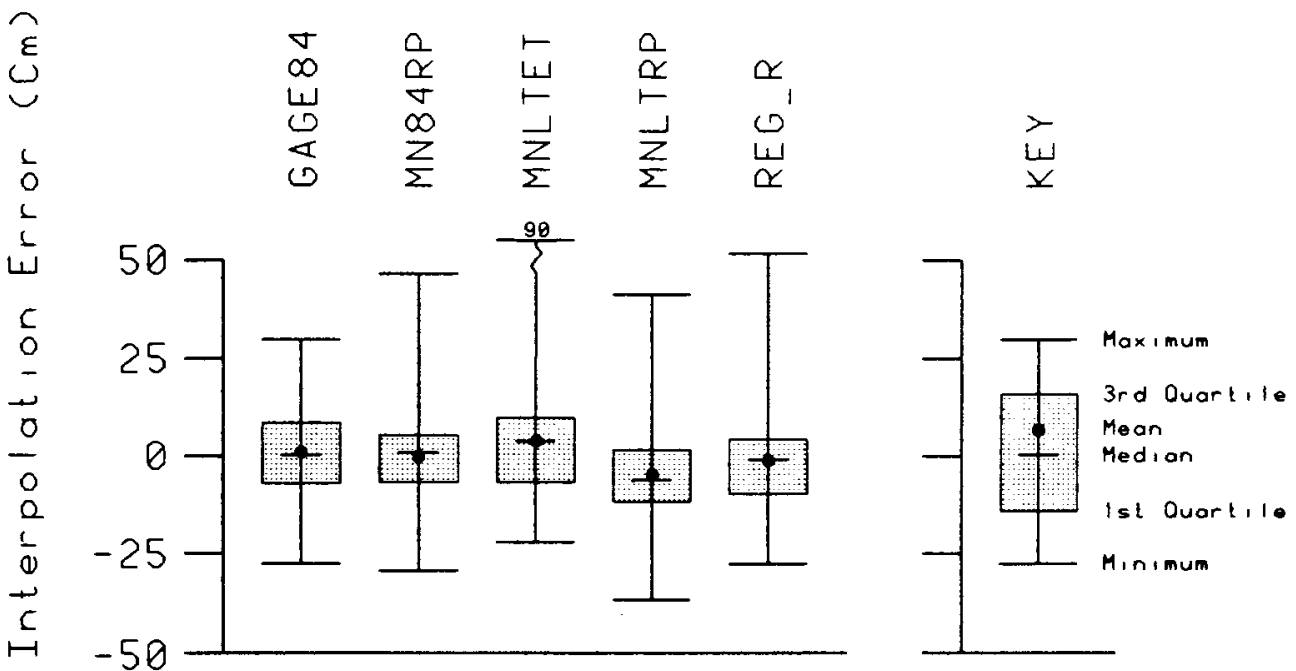

Figure 19. Box-and-Whisker Diagram of Absolute Interpolation Errors (Cm) for the GAGE84, MN84RP, MNLTET, MNLTRP, and REG_R Procedures. 


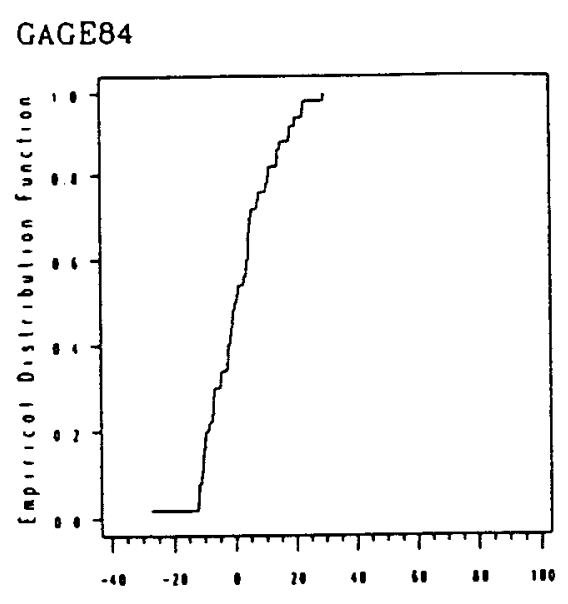

lalerpololion Error (Ca)

MNLTRP

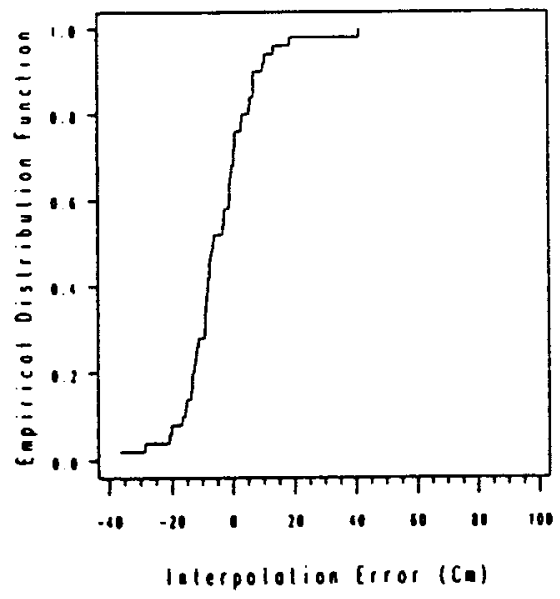

MN84RP

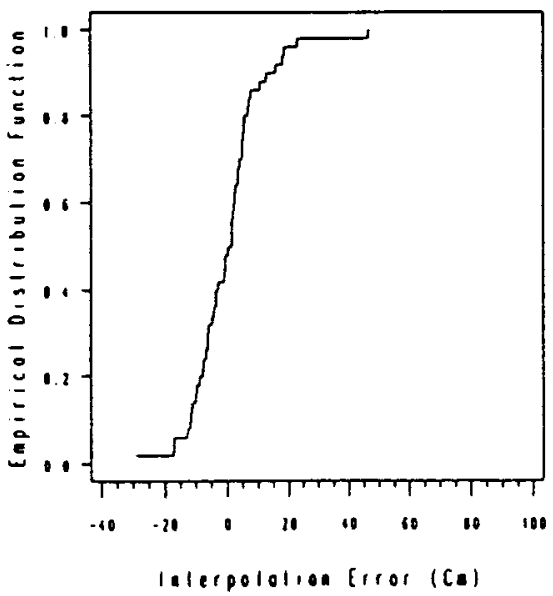

MNLTET

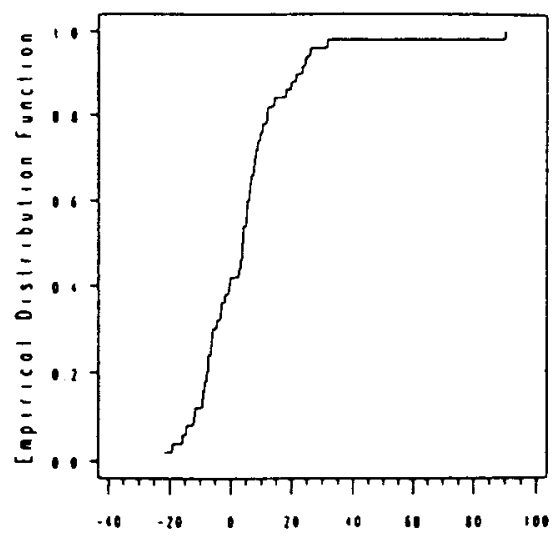

Inlerpololion troe (Ca)

REG_R

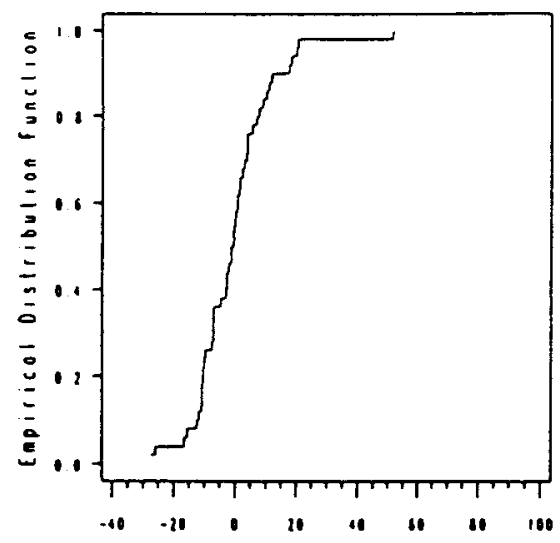

lelerpololion feror (Ca)

Figure 20. Absolute Interpolation Error (Cm) EDFs for the GAGE84, MNLTET, MNLTRP, REG_R, and MN84RP Procedures. 


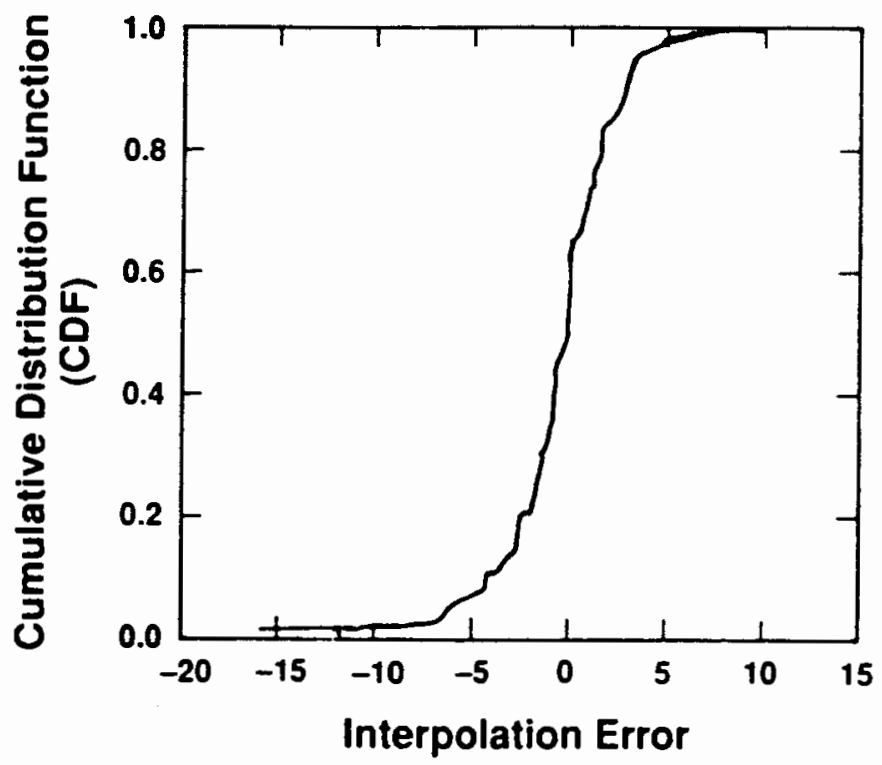

Figure 21. Cumulative Distribution Function of the Absolute Interpolation Error (Gaged - Estimated Runoff) (Cm) of a Long-Term Manual Method Map of the Eastern U.S.. (Source: Rochelle, et al., 1989.) 
term average, although other factors including possible defects in the procedures may be contributing to this effect.

Interpolation error values were tested for the significance of their means from zero (Table VIII). A T-test, which requires that the distribution of the variable to be tested is normal, is the test usually used for this purpose (Iman and Conover 1983). A signed rank test, which does not require a normal distribution (Iman and Conover, 1983), was used since none of the distributions of the procedures interpolation errors were normal. MNLTRP was the only method whose mean interpolation error, both absolute and percentage, was shown by the signed rank test to be significantly different from zero. The bias is probably due to this procedure being based on the apparently false assumption that $\mathrm{R} / \mathrm{P}$ remains constant over time.

\section{TABLE VIII}

SIGNED RANK TEST FOR THE DIFFERENCE IN MEAN INTERPOLATION ERROR BEING SIGNIFICANTLY DIFFERENT FROM ZERO

\begin{tabular}{lcccc} 
& \multicolumn{2}{c}{ Absolute } & \multicolumn{2}{c}{ Percentage } \\
Method & Interpolation Error & \multicolumn{2}{c}{ Interpolation Error } \\
Sgn Rank & $\mathrm{P}(\mathrm{S})$ & Sgn Rank & P(S) \\
\hline GAGE84 & 70.5 & 0.50 & 78.5 & 0.45 \\
MNLTET & 153.5 & 0.14 & 177.5 & 0.09 \\
MNLTRP & -294.5 & $<.01$ & -246.5 & 0.02 \\
REG_R & -80.5 & 0.44 & -56.5 & 0.59 \\
MN84RP & -20.5 & 0.85 & 18.5 & 0.86
\end{tabular}

A visual inspection of mapped absolute interpolation errors (Figures 22-27) was conducted to examine if a relationship exists between high interpolation error withheld sites and sites where the manual procedure map generalized the contours. 


\section{INTERPOLATION ERRORS $(\mathrm{Cm})$ GAGED - GAGE84 RUNOFF}

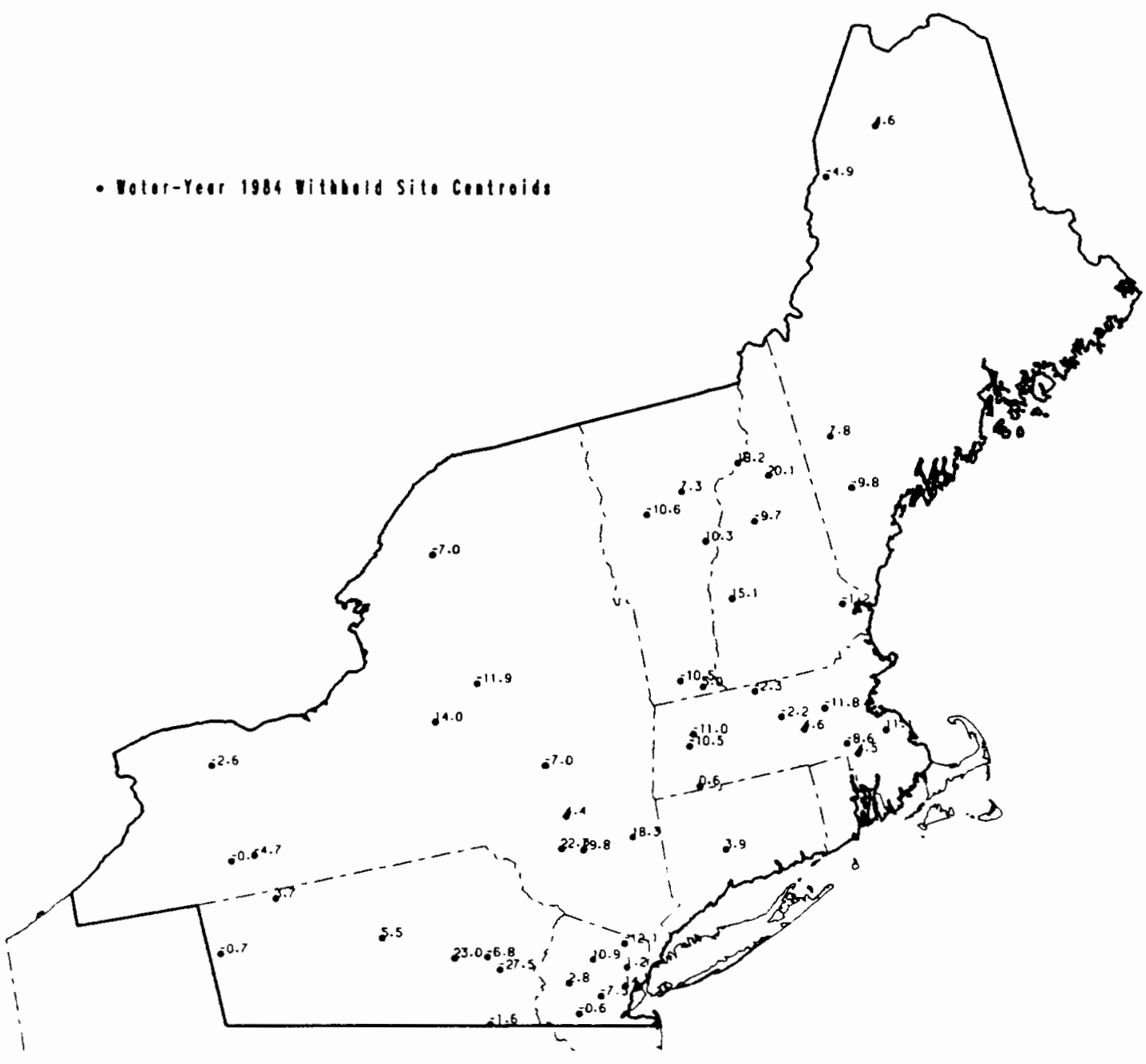

Figure 22. GAGE84 Absolute (Cm) Interpolation Errors at the Withheld Sites. 


\section{INTERPOLATION ERRORS (Cm)} GAGED. MNLTET RUNOFF

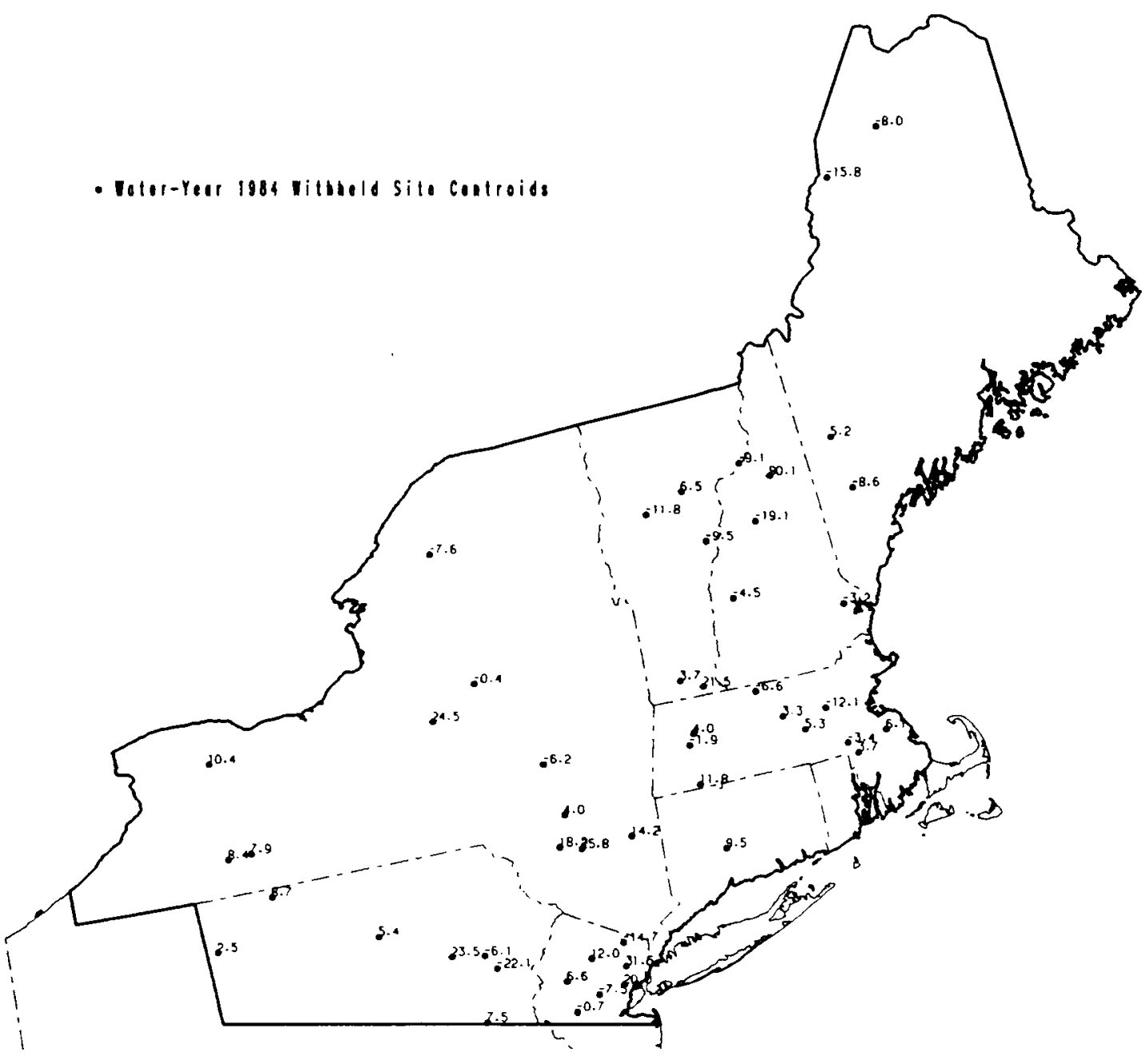

Figure 23. MNLTET Absolute $(\mathrm{Cm})$ Interpolation Errors at the Withheld Sites. 
INTERPOLATION ERRORS (Cm) GAGED - MNLTRP RUNOFF

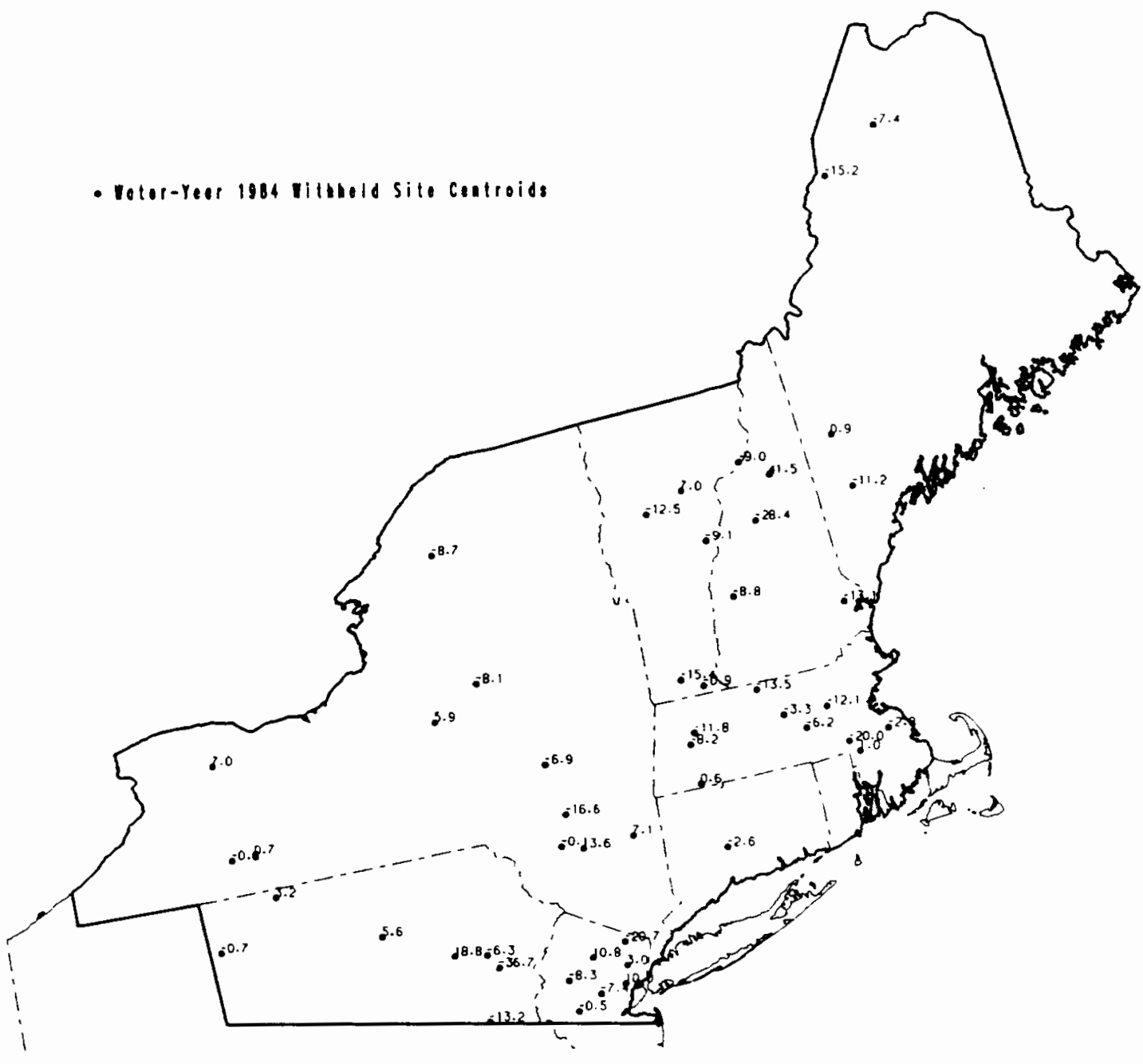

Figure 24. MNLTRP Absolute $(\mathrm{Cm})$ Interpolation Errors at the Withheld Sites. 


\section{INTERPOLATION ERRORS (Cm) GAGED-REG-R RUNOFF}

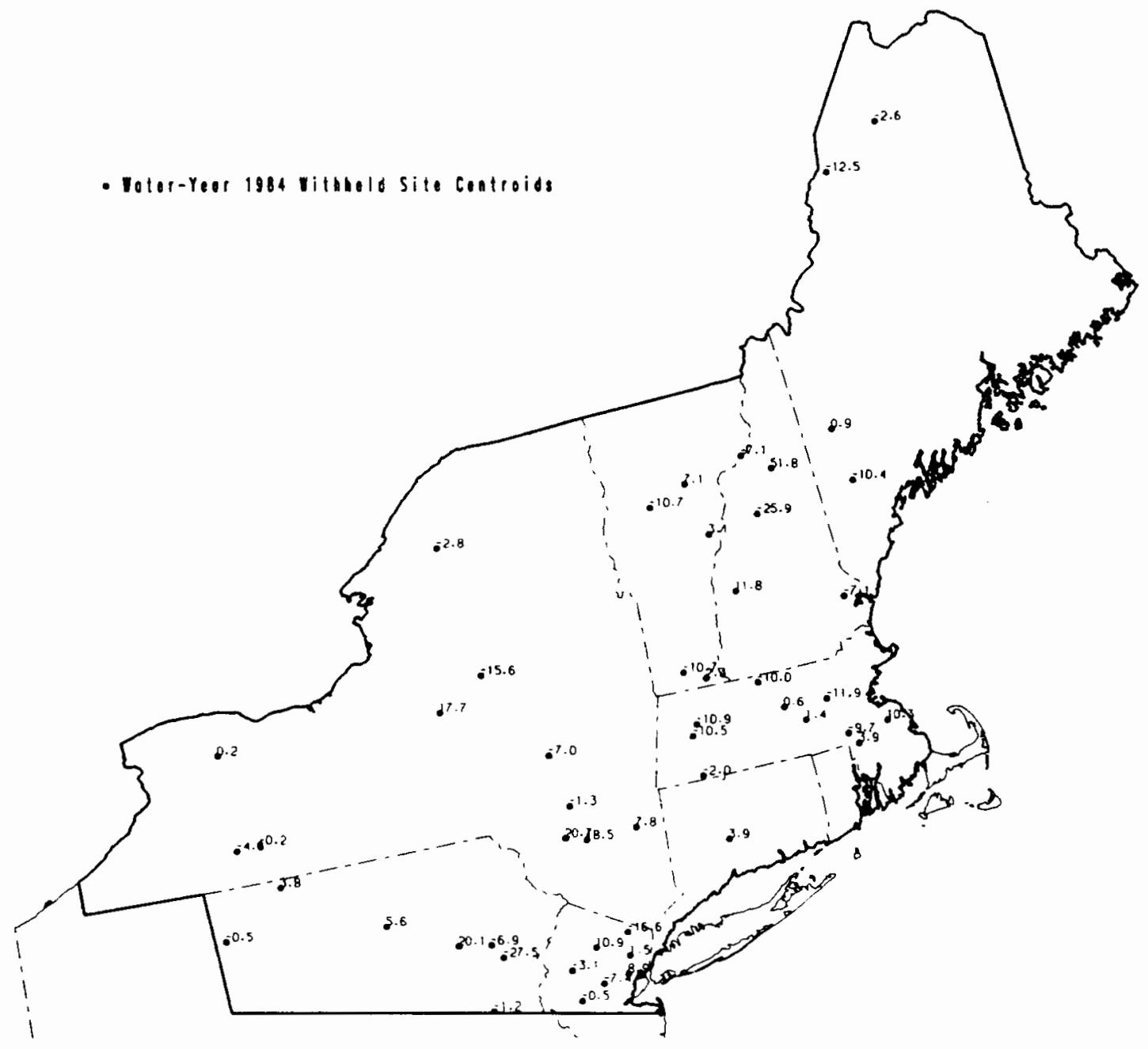

Figure 25. REG_R Absolute $(\mathrm{Cm})$ Interpolation Errors at the Withheld Sites. 


\section{INTERPOLATION ERRORS (Cm) GAGED. MN $84 R P$ RUNOFF}

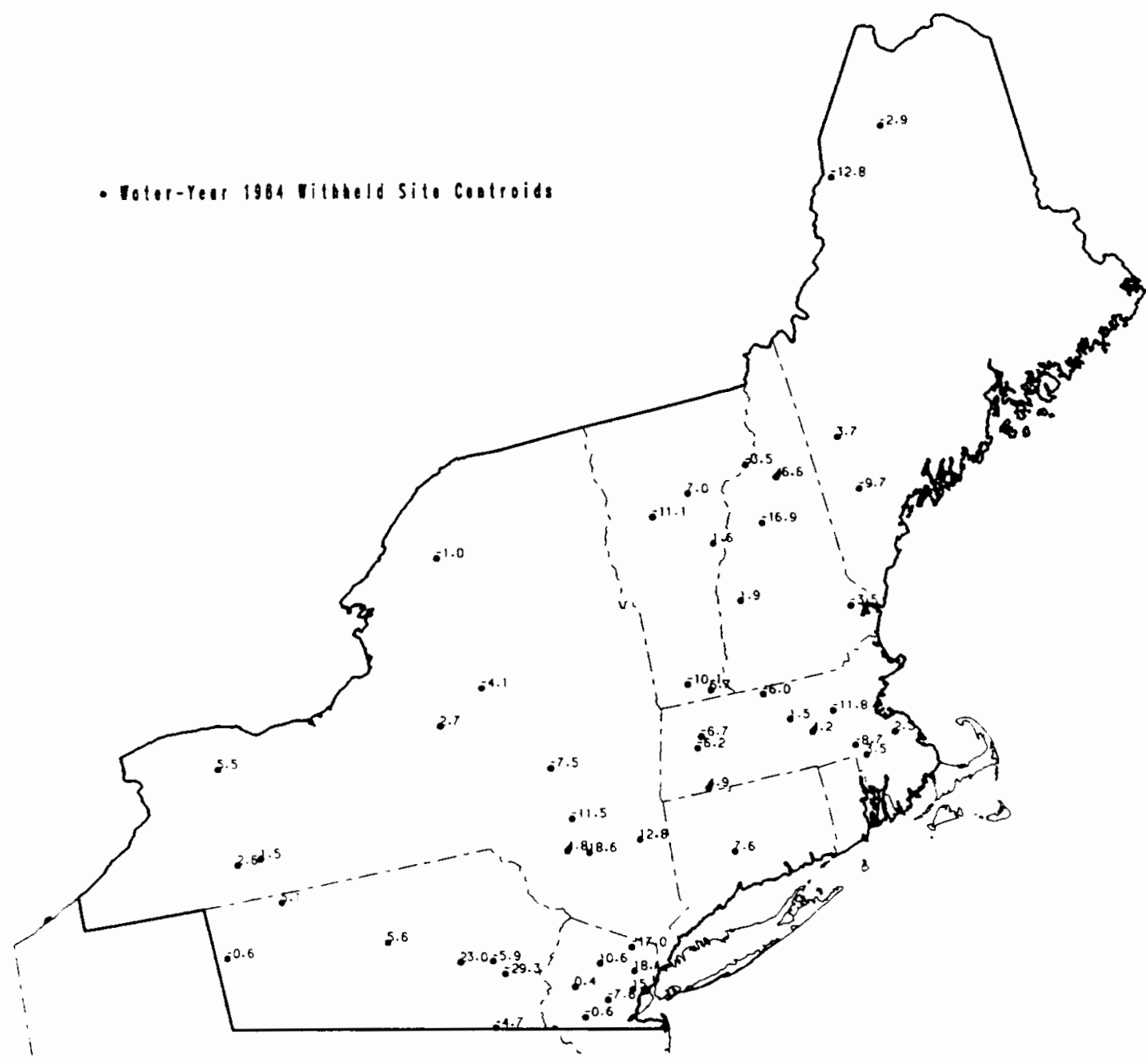

Figure 26. MN84RP Absolute $(\mathrm{Cm})$ Interpolation Errors at the Withheld Sites. 
INTERPOLATION ERRORS (Cm) GAGED. MAN84 RUNOFF

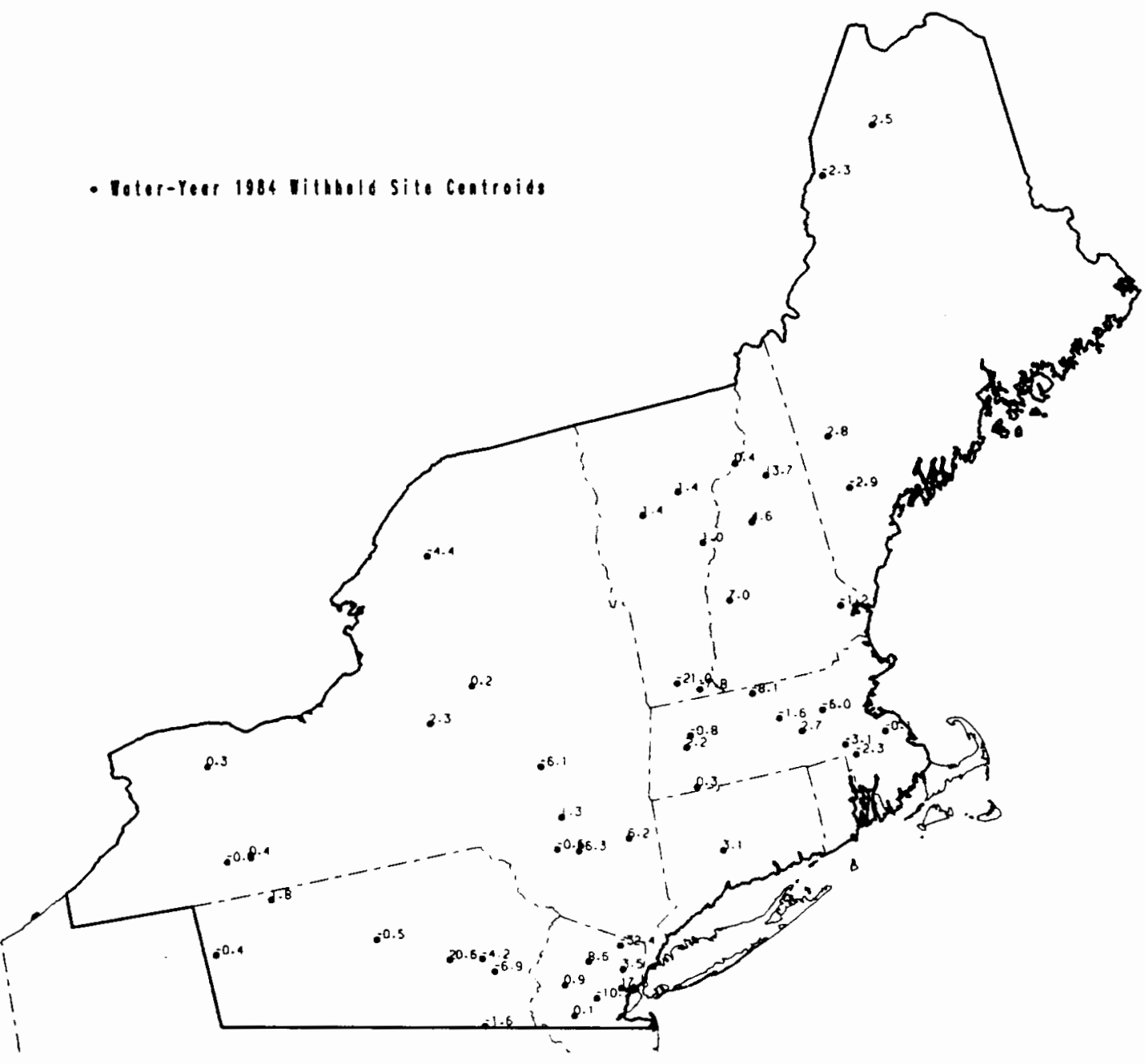

Figure 27. MAN84 Absolute (Cm) Interpolation Errors at the Withheld Sites. 
For the manual procedure estimated runoff was interpolated to the withheld sites from the MAN84 map. Differences in the MAN84 interpolated values and the gaged values are the result of the "expert opinion" used by the USGS in creating this map. Most of the errors are due to generalizations in areas of complex hydrology. Several of the high error sites found in the MAN84 error map (Figure 27) correspond to sites with high errors in the automated procedure maps. Thus several areas where the automated procedures had high errors are also not handled well by the manual procedure. One of the sites (1137500 Ammonoosuc River at Bethlehem Junction, NH near Mt. Washington) is an example of the generalization and complex hydrology problem. Estimates from the MAN84 map would overestimate by $13.7 \mathrm{~cm}$ the measured runoff-depth at this site while estimates from the automated procedures would be even higher. This is due to the large influence the Mt. Washington precipitation station has on the estimated runoff at this site. This demonstrates one of the weaknesses in the automated procedures in that topographic effects that would temper the influence of the Mt. Washington precipitation site at the Ammonoosuc River gage site are not incorporated into the procedure. A general trend of equivalency or improvement in the results of MNLTET, MNLTRP, REG_R, and MN84RP over GAGE84 was also noted.

$\underline{\text { Regression Analysis for Bias in Estimated Runoff }}$

A regression analysis was conducted to examine if any bias exists in estimated runoff as compared to actual runoff at the fifty withheld sites. The interpolated runoff was treated as the independent or predictor variable of gaged runoff, the dependent 
variable. A lack of bias is shown by an intercept that is not significantly different from zero and a slope statistically equivalent to one. The results of the analysis are shown in Table IX. Using a combined hypothesis test that the slope equals one and the intercept equals zero GAGE84, MN84RP, and to a lesser degree REG_R show results consistent with unbiased estimates at the five percent level. The MNLTET and MNLTRP procedures show results consistent with biased estimates with this analysis. As another check on these conclusions scatter plots of interpolated versus gaged runoff (Figure 28-32) were produced. They show the underestimation trend in MNLTRP and overestimation of the MNLTET procedure. No strong bias due to runoff was noted in the plots. This will be further tested with a residual analysis later in this chapter.

\section{TABLE IX}

\section{REGRESSION ANALYSIS OF GAGED RUNOFF-DEPTH VERSUS INTERPOLATED RUNOFF-DEPTH*}

\begin{tabular}{|c|c|c|c|c|c|c|}
\hline & \multicolumn{3}{|c|}{ Standard Error } & \multirow{2}{*}{$\begin{array}{c}\text { Standard Error } \\
\text { of Intercept }\end{array}$} & \multirow[b]{2}{*}{$\mathrm{p}^{* *}$} & \multirow[b]{2}{*}{$\mathrm{R}^{2}$} \\
\hline Method & Slope & of Slope & Intercept & & & \\
\hline$\overline{\text { GAGE84 }}$ & 0.887 & .094 & $8.55^{t * *}$ & $8.70^{\circ * *}$ & .307 & .65 \\
\hline MNLTET & 0.551 & .085 & 37.28 & 8.15 & $<.001$ & .47 \\
\hline MNLTRP & 0.836 & .100 & 17.99 & 8.62 & .019 & .59 \\
\hline REG_R & 0.769 & .094 & 20.80 & 8.47 & .057 & .58 \\
\hline MN84̄RP & 0.824 & .091 & 15.20 & 8.26 & .165 & .63 \\
\hline
\end{tabular}




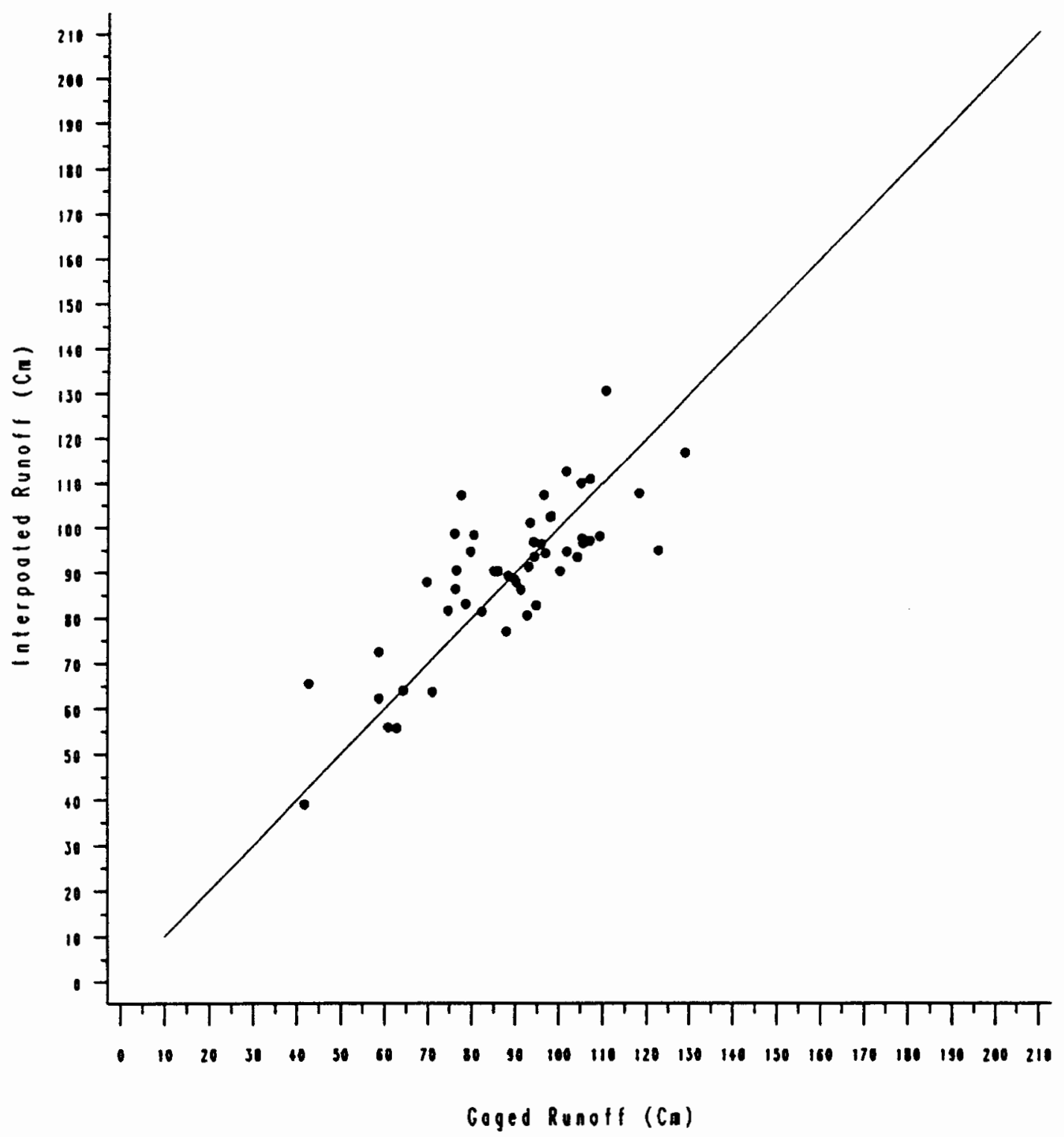

Figure 28. Scatter Plot of GAGE84 Interpolated vs. Gaged Runoff at the 50 Withheld Sites. 


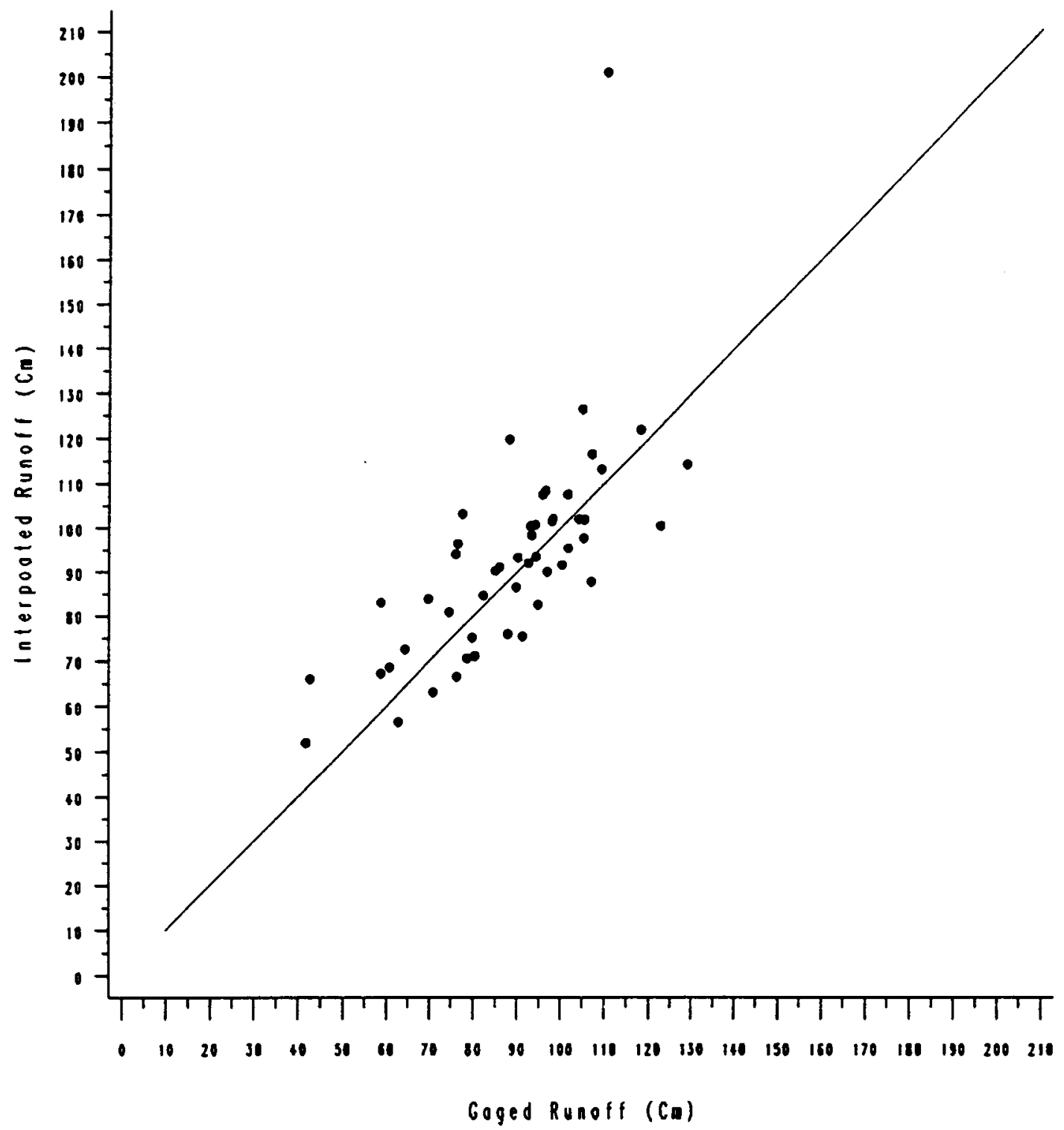

Figure 29. Scatter Plot of MNLTET Interpolated vs. Gaged Runoff at the 50 Withheld Sites. 


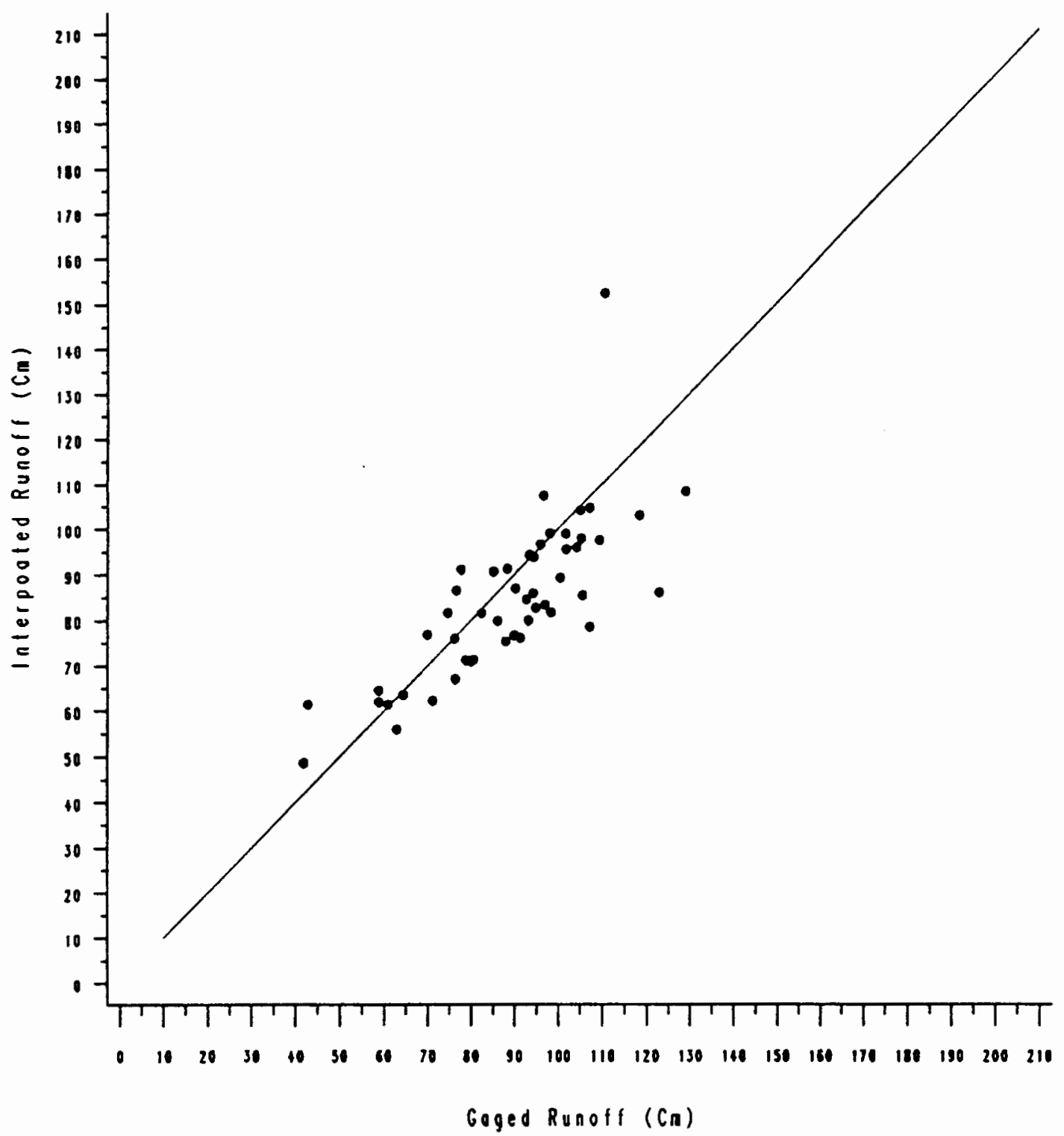

Figure 30. Scatter Plot of MNLTRP Interpolated vs. Gaged Runoff at the 50 Withheld Sites. 


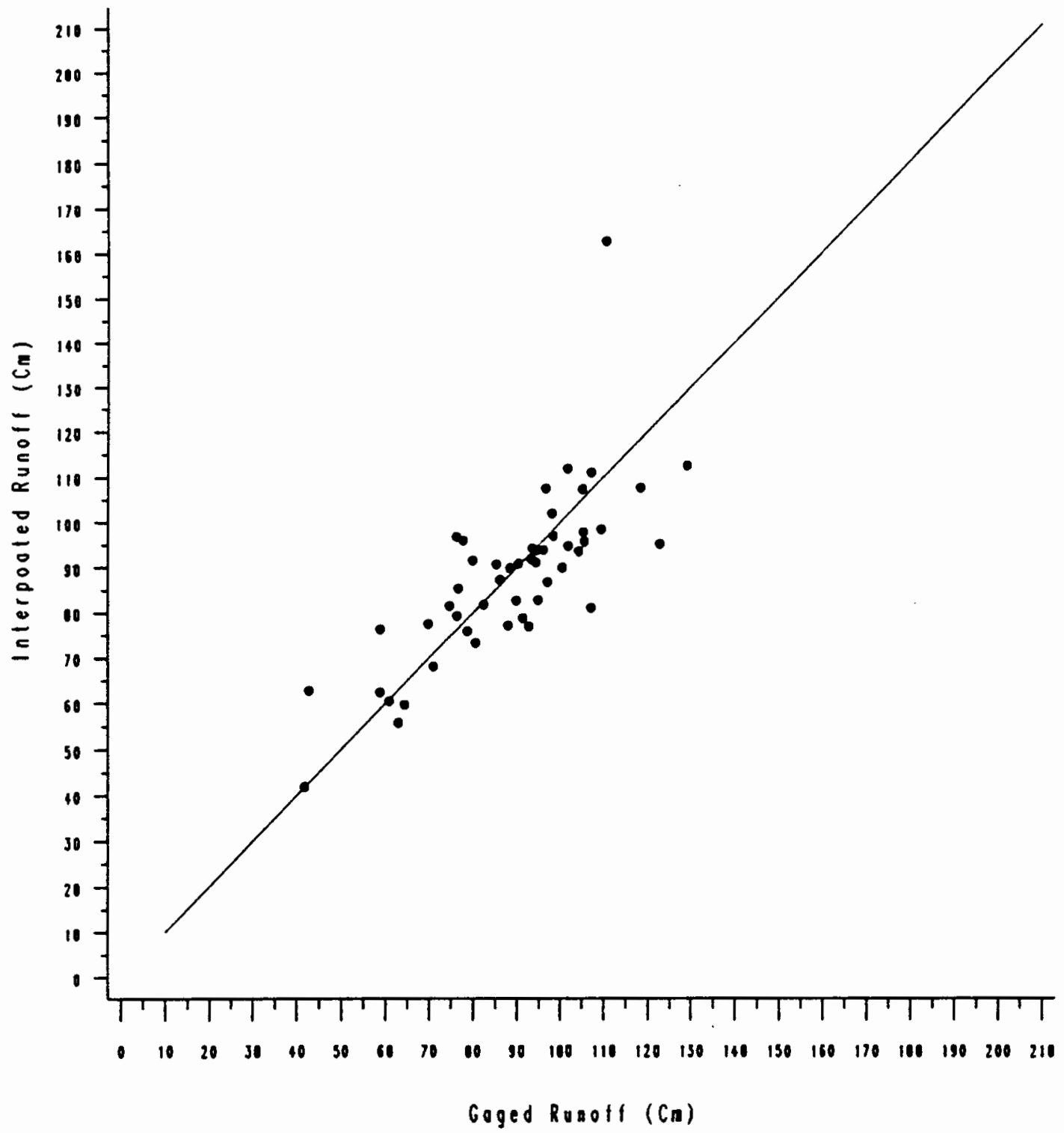

Figure 31. Scatter Plot of REG_R Interpolated vs. Gaged Runoff at the 50 Withheld Sites. 


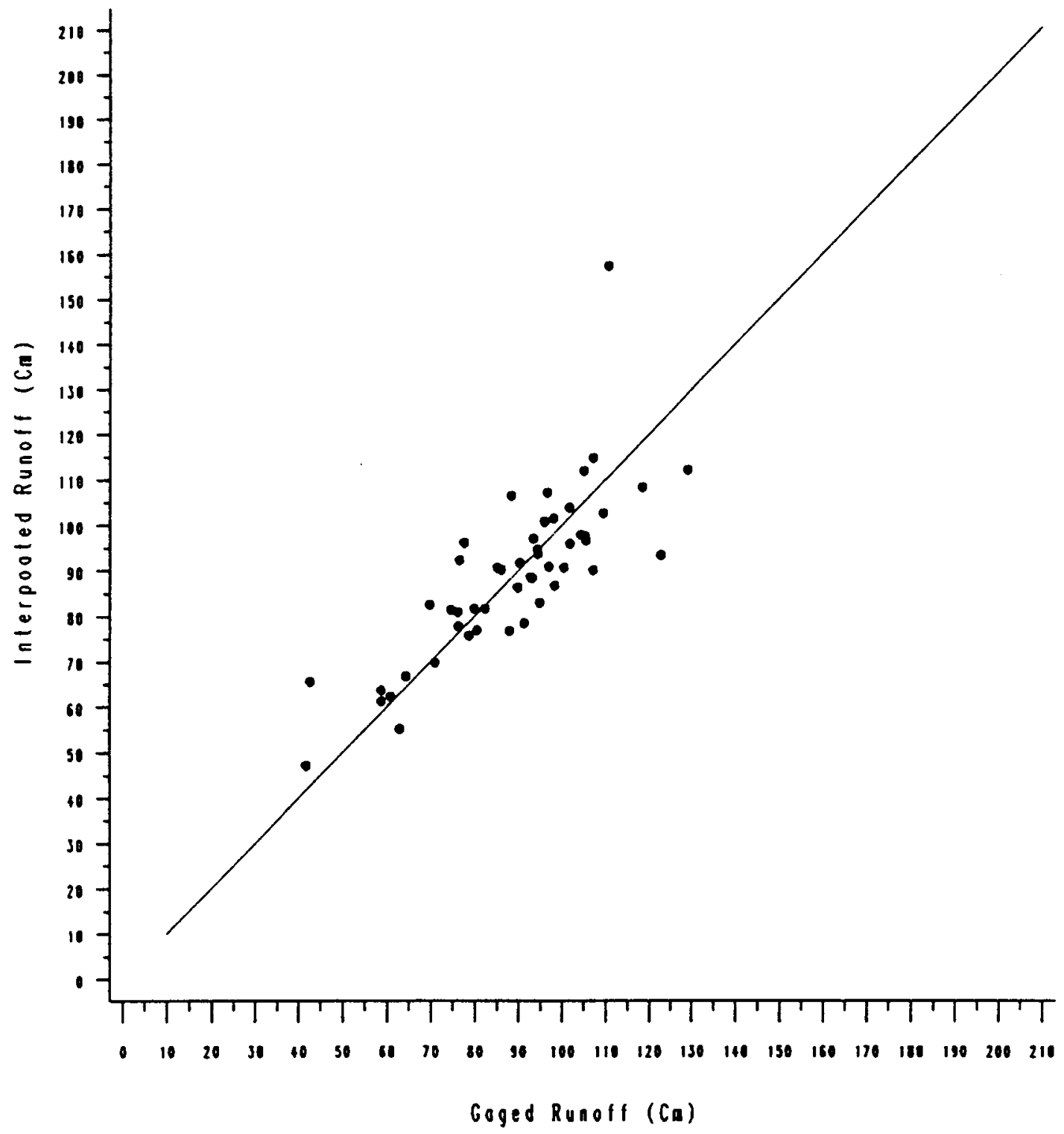

Figure 32. Scatter Plot of MN84RP Interpolated vs. Gaged Runoff at the 50 Withheld Sites. 
Biases Due to Elevation, Watershed Area, and Runoff

To examine if there are biases in the runoff estimates or the interpolation errors due to factors such as elevation estimated at the centroid or watershed area a correlation analysis was conducted. Both a Pearson, which assumes a linear relationship between the variables, and a Spearman, which assumes a non-linear relationship, correlation analysis were utilized. Scatterplots were also produced. First, the characteristics of the gaged runoff used in this thesis were examined with the correlation analysis. No correlation was found between runoff-depth and watershed area or elevation from this statistical analysis (Table $\mathrm{X}$ ). This confirms the findings of Rochelle, et al. (1988) who found no relationship between watershed area and runoff-depth for a similar data set from the same area and time period. A visual examination of the scatter plot of runoff vs watershed area shows the variability of runoff-depth to be greater for smaller watersheds thus confirming the findings of Rochelle, et al. (1988) and Garbrecht (1991).

Next, interpolation errors were examined for correlations with elevation, watershed area, and runoff. Interpolation errors for all procedures were consistently correlated to gaged runoff except for the Pearson analysis of MNLTET (Table XI and XII). These correlations may be influenced by the non-independence of the interpolation error (estimated - gaged runoff and estimated - gaged / gaged runoff) and the gaged runoff values (Kite, 1989). A likely cause is that due to the regional means and generalizations being used in the procedures, in general a higher than 
TABLE X

\section{CORRELATION ANALYSIS OF \\ GAGED RUNOFF-DEPTH VERSUS \\ ELEVATION AND WATERSHED AREA*}

$\begin{array}{llc}\text { Pearson } & & \\ \text { Elevation } & \mathrm{r}_{\mathrm{p}}{ }^{* *} & -0.20 \\ & \mathrm{P}\left(\mathrm{r}_{\mathrm{p}}\right) & <.01 \\ \text { Watershed Area } & \mathrm{r}_{\mathrm{p}} & -0.05 \\ & \mathrm{P}\left(\mathrm{r}_{\mathrm{p}}\right) & 0.26 \\ \text { Spearman } & & \\ \text { Elevation } & \mathrm{r}_{\mathrm{s}} & -0.27 \\ & \mathrm{P}\left(\mathrm{r}_{\mathrm{s}}\right) & <.01 \\ \text { Watershed Area } & \mathrm{r}_{\mathrm{s}} & -0.20 \\ & \mathrm{P}\left(\mathrm{r}_{\mathrm{s}}\right) & <.01\end{array}$

$\mathrm{n}=441$

"* $\left(r_{p}=\right.$ correlation using a Pearson analysis, $r_{s}=$ correlation using a Spearman analysis, $\mathrm{P}=$ the smallest level of significance that would allow the rejection of the null hypothesis (Iman and Conover, 1983).)

average runoff-depth area for the region would be underestimated while a lower than average runoff-depth area for the region will be overestimated (Church, 1991). There is no apparent bias in interpolation errors due to elevation. There is an apparent bias due to watershed size in the MNLTET procedure according to the Spearman analysis but an examination of the scatter plot showed no apparent trend. No other procedure showed any significant bias due to watershed size.

\section{$\underline{\text { Regional Effects }}$}

To examine if any MLRA regional effects on runoff or interpolation errors exist an F-test was conducted. The results are summarized in Table XIII. Regional effects 
TABLE XI

CORRELATION ANALYSIS OF

ABSOLUTE (Cm) INTERPOLATION ERROR VERSUS

GAGED RUNOFF, ELEVATION, AND WATERSHED AREA

\begin{tabular}{|c|c|c|c|c|c|c|}
\hline \multirow{2}{*}{\multicolumn{7}{|c|}{ MNLTRP }} \\
\hline & & & & & & \\
\hline \multirow{2}{*}{ Gaged Runoff } & $r_{p}$ & -0.45 & -0.17 & -0.44 & -0.35 & -0.37 \\
\hline & $P\left(r_{p}\right)$ & $<.01$ & 0.25 & $<.01$ & 0.01 & $<.01$ \\
\hline \multirow[t]{2}{*}{ Elevation } & $r_{p}$ & -0.12 & 0.02 & -0.06 & -0.04 & -0.12 \\
\hline & $P\left(r_{p}\right)$ & 0.39 & 0.90 & 0.70 & 0.79 & 0.40 \\
\hline \multirow{2}{*}{$\begin{array}{l}\text { Watershed } \\
\text { Area }\end{array}$} & $r_{p}$ & 0.14 & -0.20 & -0.08 & -0.14 & -0.09 \\
\hline & $P\left(r_{p}\right)$ & 0.33 & 0.17 & 0.59 & 0.32 & 0.52 \\
\hline \multicolumn{7}{|l|}{ Spearman } \\
\hline \multirow[t]{2}{*}{ Gaged Runoff } & $r_{s}$ & -0.44 & -0.30 & -0.49 & -0.45 & -0.44 \\
\hline & $P\left(r_{s}\right)$ & $<.01$ & 0.03 & $<.01$ & $<.01$ & $<.01$ \\
\hline \multirow[t]{2}{*}{ Elevation } & $r_{s}$ & -0.11 & -0.10 & -0.11 & -0.14 & -0.18 \\
\hline & $P\left(r_{s}\right)$ & 0.44 & 0.50 & 0.44 & 0.33 & 0.20 \\
\hline Watershed & $\mathbf{r}_{s}$ & -0.07 & -0.32 & -0.18 & -0.25 & -0.20 \\
\hline Area & $P\left(r_{s}\right)$ & 0.60 & 0.02 & 0.19 & 0.07 & 0.17 \\
\hline
\end{tabular}

TABLE XII

CORRELATION ANALYSIS OF

PERCENTAGE INTERPOLATION ERROR VERSUS

GAGED RUNOFF, ELEVATION, AND WATERSHED AREA

GAGE84

\begin{tabular}{lcccccc}
\multicolumn{1}{c}{} & GAGE84 & MNLTET & MNLTRP & REG R & MN84RP \\
\hline Pearson & & & & & & \\
Gaged Runoff & $\mathrm{r}_{\mathrm{p}}$ & -0.47 & -0.33 & -0.49 & -0.42 & -0.46 \\
& $\mathrm{P}\left(\mathrm{r}_{\mathrm{p}}\right)$ & $<.01$ & 0.02 & $<.01$ & 0.01 & $<.01$ \\
Elevation & $\mathrm{r}_{\mathrm{p}}$ & -0.13 & -0.03 & -0.08 & -0.07 & -0.15 \\
& $\mathrm{P}\left(\mathrm{r}_{\mathrm{p}}\right)$ & 0.37 & 0.81 & 0.55 & 0.65 & 0.30 \\
Watershed & $\mathrm{r}_{\mathrm{p}}$ & 0.10 & -0.23 & -0.12 & -0.18 & -0.12 \\
Area & $\mathrm{P}\left(\mathrm{r}_{\mathrm{p}}\right)$ & 0.47 & 0.11 & 0.39 & 0.22 & 0.39 \\
& & & & & & \\
Spearman & & & & & & \\
Gaged Runoff & $\mathrm{r}_{\mathrm{s}}$ & -0.41 & -0.33 & -0.44 & -0.42 & -0.47 \\
& $\mathrm{P}\left(\mathrm{r}_{\mathrm{s}}\right)$ & $<.01$ & 0.02 & $<.01$ & $<.01$ & $<.01$ \\
Elevation & $\mathrm{r}_{\mathrm{s}}$ & -0.13 & -0.10 & -0.11 & -0.14 & -0.18 \\
& $\mathrm{P}\left(\mathrm{r}_{\mathrm{s}}\right)$ & 0.37 & 0.50 & 0.44 & 0.32 & 0.21 \\
Watershed & $\mathrm{r}_{\mathrm{s}}$ & -0.08 & -0.30 & -0.19 & -0.26 & -0.20 \\
Area & $\mathrm{P}\left(\mathrm{r}_{\mathrm{s}}\right)$ & 0.59 & 0.03 & 0.18 & 0.07 & 0.16
\end{tabular}


were significant at the one percent level for gaged runoff and at the five percent level for GAGE84 and MN84RP runoff. The significant regional variations in gaged runoff support the use of MLRA's as the regionalization scheme used in MNLTET, MNLTRP, and MN84RP. There were no significant regional effects on interpolation error. REG_R shows no regional differences for runoff. This is probably due to the region-wide nature of the regression formula used.

\section{TABLE XIII}

F-TEST OF MLRA EFFECT

ON RUNOFF AND INTERPOLATION ERROR VALUES FROM THE FIFTY WITHHELD SITES

\begin{tabular}{|c|c|c|c|c|c|c|}
\hline \multirow[b]{2}{*}{ Runoff } & \multicolumn{2}{|c|}{ Runoff } & \multicolumn{2}{|c|}{$\begin{array}{c}\text { Interpolation } \\
\text { Error }(\mathrm{Cm})\end{array}$} & \multicolumn{2}{|c|}{$\begin{array}{c}\text { Interpolation } \\
\text { Error (\%) }\end{array}$} \\
\hline & $\mathrm{F}$ & $\mathrm{P}(\mathrm{F})$ & $\mathrm{F}$ & $\mathrm{P}(\mathrm{F})$ & & $P(F)$ \\
\hline Gaged Values & 4.50 & $<.001$ & 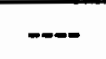 & $\ldots$ & $\ldots$ & $\ldots$ \\
\hline GAGE84 & 2.65 & .016 & 1.25 & .293 & 1.12 & .372 \\
\hline MNLTET & 1.12 & .372 & 0.40 & .928 & 1.02 & . 444 \\
\hline MNLTRP & 1.82 & .094 & 1.44 & .206 & 1.65 & 135 \\
\hline REG_R & 1.63 & .140 & 0.71 & .698 & 0.96 & .490 \\
\hline MN84̄RP & 2.71 & .014 & 0.90 & .532 & 0.99 & .466 \\
\hline
\end{tabular}

\section{Topographic and Site Density Effects}

An analysis was also conducted to determine if interpolation errors were greater in mountainous versus non-mountainous terrain or in areas of low runoff site density. Graczyk, et al. (1987) and Krug, et al. (1990) state that estimates of runoff-depth from manual procedure maps maybe less accurate in areas of high relief and lower site density although Rochelle, et al. (1989) concluded that no such correlation exists due to site density. Generalized mountainous zones were created for this analysis 
based on areas of higher elevation (greater than 400 meters) and/or steeper slopes (generally greater than $15 \%$ ). Higher site density zones were based on areas within $13 \mathrm{Km}$ of WY84 runoff sites (Figure 33 ). The $13 \mathrm{Km}$ distance was based on work by Sopper and Lull $(1966,1970)$ who found a marked decrease in correlation between runoff and precipitation sites (used to estimate runoff in the automated procedures) in the Northeast greater than this distance. The withheld sites were related to these zones of lesser (i.e. mountainous and/or low site density) and greater confidence. Since the lower site density zones are based on WY84 runoff sites none of the withheld sites were in this zone and thus no statistical analysis was possible. Nine of the withheld sites were in the mountainous (lower confidence in estimates) zone. An examination of the means and standard deviations of the two groups (Table XIV) shows higher absolute mean errors and greater standard deviations for the lesser confidence zones. No statistically significant difference was found between the two zones using an F-test (Table XV). The use of this map for gaging relative confidence in the estimates of runoff from these maps, though not proven statistically, may still be a useful tool for applications requiring site specific estimates.

\section{SUMMARY OF FINDINGS}

The REG_R and MN84RP procedures were found to have mean errors equivalent to those of the manual procedure as defined by Rochelle, et al. (1989) by the uncertainty analysis. No regional biases in the interpolation errors were found which shows equivalence to the results found for the manual procedure by Rochelle, 


\section{WY84 RUNOFF-DEPTH CONTOUR CONFIDENCE REGIONS}

Regions of Confidence

[8] Lesser Confidence (Topogrophy)

Lesser Confidence (Site Density)

$\square$ Greoler contidence

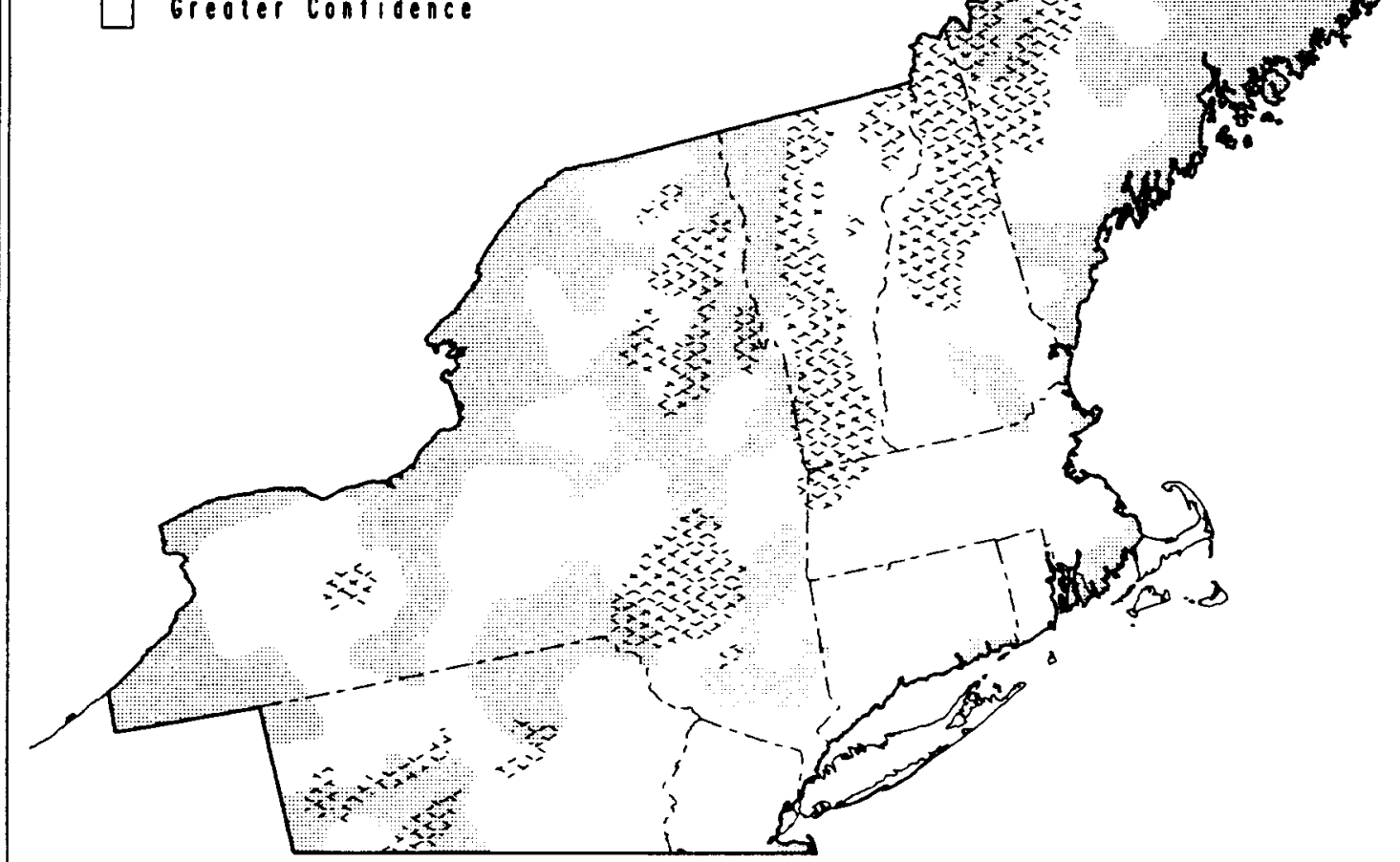

Figure 33. Zones of Lesser and Greater Confidence in Runoff Estimates. 


\section{TABLE XIV}

DESCRIPTIVE STATISTICS OF INTERPOLATION ERRORS FOR ZONES OF GREATER* AND LESSER** CONFIDENCE

\begin{tabular}{|c|c|c|c|c|}
\hline \multirow[b]{2}{*}{ Method } & \multicolumn{2}{|c|}{$\begin{array}{c}\text { Interpolation Error }(\mathrm{Cm}) \\
\text { Standard }\end{array}$} & \multicolumn{2}{|c|}{$\begin{array}{r}\text { Interpolation Error (\%) } \\
\text { Standard }\end{array}$} \\
\hline & Mean & Deviation & Mean & Deviation \\
\hline \multicolumn{5}{|c|}{$>$ Confidence Zone } \\
\hline GAGE84 & 1.41 & 11.12 & 3.35 & 14.76 \\
\hline MNLTET & 2.86 & 11.93 & 5.37 & 16.34 \\
\hline MNLTRP & -4.18 & 10.43 & -2.97 & 12.91 \\
\hline REG_R & -1.08 & 10.01 & 0.44 & 13.00 \\
\hline 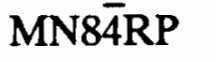 & 0.34 & 9.88 & 2.19 & 12.95 \\
\hline \multicolumn{5}{|c|}{$<$ Confidence Zone } \\
\hline GAGE84 & 2.47 & 12.92 & 2.71 & 14.55 \\
\hline MNLTET & 11.72 & 32.15 & 10.81 & 30.04 \\
\hline MNLTRP & -4.28 & 19.63 & -4.92 & 18.28 \\
\hline REG_R & 2.23 & 22.44 & 2.14 & 21.92 \\
\hline MN84̄RP & 0.52 & 19.23 & -0.20 & 18.16 \\
\hline
\end{tabular}

\section{TABLE XV}

F-TEST OF MEAN INTERPOLATION ERROR VALUES FOR ZONES OF GREATER* AND LESSER"* CONFIDENCE

\begin{tabular}{lcccc} 
& \multicolumn{2}{c}{ Interpolation Error $(\mathrm{Cm})$} & \multicolumn{2}{c}{ Interpolation } \\
Method & $\mathrm{F}$ & $\mathrm{P}(\mathrm{F})$ & $\mathrm{F}$ & $\mathrm{P}(\mathrm{F})$ \\
\hline GAGE84 & 0.06 & .804 & 0.01 & .907 \\
MNLTET & 1.99 & .165 & 0.59 & .448 \\
MNLTRP & 0.00 & .983 & 0.15 & .705 \\
REG_R & 0.48 & .490 & 0.10 & .757 \\
MN84RP & 0.00 & .967 & 0.22 & .644
\end{tabular}

\footnotetext{
Non-Mountainous $(\mathrm{n}=41)$

"Mountainous $(n=9)$
} 
et al. (1989). Bias in interpolation errors when compared to gaged runoff was found for all methods. The non-independence of the variables and/or the regional generalizations in the procedures used are possible explanations. Since this bias was not tested for with the manual procedure it cannot be assumed that this is a weakness found only in the automated procedures. No biases in interpolation errors were found due to elevation or watershed area, other than a statistically significant bias for watershed area for the MNLTET procedure which was not supported by a visual inspection of the related scatter plot. A regression analysis between actual and estimated runoff showed that GAGE84, MN84RP (at the five percent level) and REG_R (at the one percent level) showed results consistent with unbiased estimates. No statistically significant bias was found for interpolation errors in mountainous terrain. 


\section{CHAPTER V}

\section{SUMMARY AND FUTURE AREAS OF RESEARCH}

\section{SUMMARY}

This thesis hypothesized that a simple automated procedure can produce as accurate a water-year runoff-depth contour map as that produced by the manual procedure currently used by the U.S. Geological Survey (USGS). Five (GAGE84, MNLTET, MNLTRP, REG_R, and MN84RP) maps for WY84 derived from automated procedures were tested with an uncertainty analysis to see if actual runoff values matched those predicted from the contour maps produced by the procedures. Two of the procedures, REG_R and MN84RP with mean percentage errors of -0.74 and $-1.76 \%$ respectively, were found to be equivalent to the mean percentage error noted for the manual method, $0.9 \%$ determined by Rochelle, et al. (1989). No biases in interpolation error by Major Land Resource Area (MLRA) were found and no biases were found in predicted runoff due to elevation or watershed size. This lack of bias was also noted for the manual procedure (Rochelle, et al., 1988,1989). Bias in the interpolation error due to runoff-depth was found for the automated procedures with larger interpolation errors occurring at watersheds with greater runoff-depth. It is not known whether this bias exists in the manual procedure maps. 
The simplifying assumption that $\mathrm{R} / \mathrm{P}$ remains constant over time was shown to be inappropriate by the results of this thesis. The success of the MN84RP method indicates that regionalization of $\mathrm{R} / \mathrm{P}$ values to predict runoff at precipitation stations is appropriate if data for the given water-year is used and a mean regional accuracy is required. The assumption that ET remains constant over time was shown to be statistically appropriate by the results of the uncertainty analysis although the accuracy of the results obtained was lower than the other methods examined. The use of long-term data was shown to be useful by the positive results of the REG_R procedure, but is not required as evidenced by the results of the MN84RP procedure.

The two methodologies, REG_R and MN84RP, are put forth as acceptable methods for producing runoff-depth contour maps for projects requiring a mean regional accuracy of about $1 \%$. Caution should be used if estimates of runoff for individual sites are needed from one of these maps. As with all estimations from runoff-depth contour maps, large differences from actual values may occur due to local conditions. Individual site estimation errors of $15 \%$ or greater are not to be unexpected with maps generated by the automated procedures. Until better methodologies are perfected these two procedures should provide an adequate, inexpensive means of producing a water-year specific map for wetter than normal water-years in the Northeast. 


\section{FUTURE AREAS OF RESEARCH}

The procedures tested in this thesis are not intended to be the final solution to the problem of automating the production of runoff-depth contour maps. Even in their present form there is a need for further testing of the automated procedures on water-years with below normal and normal precipitation as well as for other regions. Further refinement of the REG_R procedure with the use of regression formulas created for MLRA or MLRA groupings would also be worth investigation.

Research into the use of artificial intelligence for producing runoff-depth maps is an area that might also yield worthwhile results. The incorporation of the decision making processes used by the expert hydrologists at the USGS into an automated procedure could greatly improve the results of automated mapping of runoff-depth.

With further research into automated methods the time-consuming and expensive manual procedure in use by the USGS can be replaced. The advantages of lower costs, reproduceability, and standardization of methods, especially in regards to known accuracy, will make the time and cost involved in researching these new methods worthwhile. 


\section{REFERENCES}

Bickford, C.A., C.E. Mayer, and K.D. Ware. 1963. An Efficient Sampling Design for Forest Inventory; the Northeast Forest Resurvey. Journal of Forestry $61: 826$ 33.

Busby, M.W. 1966. Annual Runoff in Conterminous United States. U.S. Geological Survey Hydrologic Report HA-212.

Church, M.R., K.W. Thornton, P.W. Shaffer, D.L. Stevens, B.P. Rochelle, G.R. Holdren, M.G. Johnson, J.J. Lee, R.S. Turner, D.L. Cassell, D.A. Lammers, W.G. Campbell, C.I. Liff, C.C. Brandt, L.H. Liegel, G.D. Bishop, D.C. Mortenson, S.M. Pierson, and D.D. Schmoyer. 1989. Direct/Delayed Response Project: Future Effects of Long-Term Sulfur Deposition on Surface Water Chemistry in the Northeast and Southern Blue Ridge Province. EPA/600/389/061a-d, Washington, D.C.: U.S. Environmental Protection Agency.

Church, M.R.. 1991. Technical Director Direct/Delayed Response Project, Personal Communication.

Court, Arnold. 1967. Climatic Normals as Predictors, Report No. 67-82-1. Northridge, California : San Fernando Valley State College Foundation.

DeAngelis, R.J., J.B. Urban, W.J. Gburek, and M.A. Contirio. 1984. Precipitation and Runoff on Eight New England Basins During Extreme Wet and Dry Periods. Hydrological Sciences Journal, 29(1) : 13-28.

Dingman, S. Lawrence. 1981. Elevation: A Major Influence on the Hydrology of New Hampshire and Vermont, U.S.A.. Hydrological Sciences Journal. 26(4) : 399413.

Dingman, S. Lawrence, Diana M. Seely-Reynolds, and Robert C. Reynolds III. 1988. Application of Kriging to Estimating Mean Annual Precipitation in a Region of Orographic Influence. Water Resources Bulletin 24(2) : 329-39.

Domokos, Miklos, and Jeno Sass. 1990. Long-Term Water Balances for Subcatchments and Partial National Areas in the Danube Basin. Journal of Hydrology 112: 267-92. 
Drozdov, O.A., V.V. Orlov, and T.S.A. Shver. 1965. The Optimal Length of Period for Climatic Averages, in Climatic Normals as Predictors, Report No. 67-82-1, ed. Arnold Court, Trans. George S. Mitchell. Northridge, California : San Fernando Valley State College Foundation.

Dunne, Thomas and Luna B. Leopold. 1978. Water in Environmental Planning. New York : W.H. Freeman and Company.

Environmental Systems Research Institute, Inc. (ESRI). 1986. TIN Users Manual, Version 3.2.

Foyster, A.M. 1975. Mapping Runoff by the Grid Square Technique. Nordic Hydrology $6: 207-21$.

Gannett, H. 1911. Map of the United States Showing Mean Annual Runoff. Surface Water Supply of the United States, U.S. Geological Survey, Water Supply Papers.

Garbrecht, Jurgen. 1991. Effects of Spatial Accumulation of Runoff on Watershed Response. Journal of Environmental Quality $20: 31-35$.

Gebert, Warren A., David J. Graczyk, and William R. Krug. 1987. Average Annual Runoff in the United States 1951-80. Hydrologic Investigations Atlas HA-710. Reston, Virginia: U.S. Geological Survey.

Graczyk, D.J., W.A. Gebert, W.R. Krug, and G.J. Allord. 1987. Maps of Runoff in the Northeastern Region and the Southern Blue Ridge Province of the United States During Selected Periods in 1983-85. U.S. Geological Survey Open-File Report 87-106.

Hely, A.J., T.J. Nordenson, et al.. 1961. Precipitation Water Loss and Runoff in the Delaware River Basin and New Jersey. U.S. Geological Survey Hydrologic Report HA-11.

Hidore, John. 1966. Regional Variations in Natural Water Consumption in the Conterminous United States. Journal of Hydrology 4 : 79-90.

Holder, R.L.. 1985. Multiple Regression in Hydrology. Wallingford, Oxfordshire: Institute of Hydrology.

Iman, Ronald L. and W.J. Conover. 1983. A Modern Approach to Statistics. New York : John Wiley and Sons. 
Kite, Geoff. 1989. Some Statistical Observations. Water Resources Bulletin 25(3) : 483-90.

Kitteredge, Joseph, Jr.. 1938. The Magnitude and Regional Distribution of Water Losses Influenced by Vegetation. Journal of Forestry $36(8): 775-78$.

Klemes, Vit. 1983. Conceptualization and Scale in Hydrology. Journal of Hydrology $65: 1-23$.

Knox, C.E. and T.J. Nordenson. 1957. Average Annual Runoff and Precipitation in the New England - New York Area. U.S. Geological Survey Hydrologic Report HA-7.

Krug, W.R., W.A. Gebert, D.J. Graczyk, D.L. Stevens, B.P. Rochelle, and M.R. Church. 1990. Map of Mean Annual Runoff for the Northeastern, Southeastern and Mid-Atlantic United States, Water Years 1951-1980. U.S. Geological Survey Water Resources Investigation Report 88-4904.

Langbein, Walter B., et al.. 1949. Annual Runoff in the United States. U.S. Geological Survey Circular 52. Washington, D.C. : Department of the Interior.

Lee, J. and D.K. Bray. 1969. The Estimation of Runoff from Rainfall for New Brunswick Watersheds. Journal of Hydrology 9 : 427-37.

Lee, R.. 1969. Latitude, Elevation, and Mean Temperature in the Northeast. Professional Geographer 21(4) : 227-31.

Lee, Richard. 1980. Forest Hydrology. New York, N.Y.: Columbia University Press.

Leopold, L.B., M.G. Wolman, and J.P. Miller. 1964. Fluvial Processes in Geomorphology. San Francisco, Ca.: W.H. Freeman and Company.

Liebscher, H. 1972. A Method for Runoff-Mapping from Precipitation and Air Temperature Data. In World Water Balance: Proceedings of the Reading Symposium, July 1970, Vol. 1. 115-21. Gentbrugge, Belgium: UNESCO/IASH/WMO.

Likens, G.E., F.E. Bormann, R.S. Pierce, J.S. Eaton, and N.M. Johnson. 1977. Biogeochemistry of a Forested Ecosystem. New York, N.Y. : Springer-Verlag New York Inc..

Linsley, Ray K. 1967. The Relation Between Rainfall and Runoff. Journal of Hydrology $5: 297-311$. 
Lull, Howard W. and William E. Sopper. 1966. Factors that Influence Streamflow in the Northeast. Water Resources Research 2(3) : 371-9.

Lull, Howard W. and William E. Sopper. 1967. Prediction of Average Annual and Seasonal Streamflow of Physiographic Units in the Northeast. In Forest Hydrology, Ed. William E. Sopper and Howard W. Lull. Oxford : Pergamon Press.

Mather, John R.. 1981. Using Computed Stream Flow in Watershed Analysis. Water Resources Bulletin 17(3) : 474-82.

Mckay, G.A. and M.K. Thomas. 1971. Mapping of Climatological Elements. The Canadian Cartographer 8(1) : 27-40.

Mckay, Gordon A.. 1976. Hydrological Mapping. In Facets of Hydrology, ed. John C. Rodda. London: John Wiley and Sons.

Miller, David W., James J. Geraghty, and Robert S. Collins. 1962. Water Atlas of the United States: Basic Facts About the Nations Water Resources. Port Washington, New York: Water Information Center, Inc.

Moss, M.E. and D.R. Dawdy. 1973. Stochastic Simulation for Basin with Short or no Records of Streamflow, in Design of Water Resource Projects with Inadequate Data. Proceedings of the Madrid Symposium, June 1973. UNESCO-WMOIAHS. Madrid : UNESCO-WMO-IAHS.

Munson, Wendell C.. 1966. Estimating Consumptive Use by the Munson P.E. Method, In Methods for Estimating Evapotranspiration. Irrigation and Drainage Specialty Conference, Las Vegas, Nevada, November 2-4, 1966. New York, N.Y. : ASCE.

Neff, Earl L.. 1977. How Much Does a Rain Gage Gage? Journal of Hydrology 35 :213-20.

Overton, W.S.. 1987. Phase II Analysis Plan, National Lake Survey -- Working Draft. April 1987. Technical Report 115, Dept of Statistics, Oregon State University, Corvallis, Oregon.

Palmer, Wayne C. and A. Vaughn Havens. 1958. A graphical Technique for Determining Evapotranspiration by the Thornthwaite Method. Monthly Weather Review 86(4) : 123-28. 
Rafter, George W.. 1903. The Relation of Rainfall to Runoff. Water Supply and Irrigation Paper No. 80, U.S. Geological Survey. Washington D.C. : Government Printing Office.

Rasmusson, Eugene M.. 1968. Atmospheric Water Vapor Transport and the Water Balance of North America : II, Large-Scale Water Balance Investigations. Monthly Weather Review 96(10) : 720-34.

Rochelle, Barry P., M. Robbins Church, Warren A. Gebert, David J. Graczyk, and William R. Krug. 1988. Relationship Between Annual Runoff and Watershed Area for the Eastern United States. Water Resources Bulletin 24(1) : 35-41.

Rochelle, Barry P., Donald L. Stevens, Jr., and M. Robbins Church. 1989. Uncertainty Analysis of Runoff Estimates from a Runoff Contour Map. Water Resources Bulletin 25(3) : 491-98.

Rodda, J.C.. 1985. Precipitation Research. EOS 66(2) : 10.

SAS Institute Inc.. 1985. SAS User's Guide: Statistics, Version 5 Edition. Cary, N.C. : SAS Institute Inc..

Saxton, Keith E.. 1981. Mathematical Modeling of Evapotranspiration on Agricultural Watersheds, in Modeling Components of the Hydrologic Cycle. Proceedings of the International Symposium on Rainfall Runoff Modeling held May 18-21, 1981 at Mississippi State University, U.S.A.. ed. Vijay P. Singh.

Schneider, W.J., et al. 1965. Water Resources of the Appalachian Region, Pennsylvania to Alabama: Patterns of Runoff in the Region. U.S. Geological Survey Hydrological Report HA-198.

Shelton, M.L.. 1985. Modeling Hydroclimatic Processes in Large Watersheds. Annals of the Association of American Geographers 75 : 185-202.

Solomon, S.I., J.P. Denouvilliez, E.J. Chant, J.A. Woolley, and C. Cadou. 1968. The Use of a Square Grid System for Computer Estimation of Precipitation, Temperature, and Runoff. Water Resources Research 4 : 919-29.

Sopper, William E. and Howard W. Lull. 1965. Streamflow Characteristics of Physiographic Units in the Northeast. Water Resources Research 1(1) : 11524.

Sopper, William E. and Howard W. Lull. 1970. Streamflow Characteristics of the Northeastern United States. Pennsylvania State University Agricultural Experiment Station Bulletin 766. 
Stevens, Donald L., Jr.. 1991. Statistician, ManTech Environmental Technology, Inc., Corvallis, Oregon, Personal Communication.

Stevens, Donald L., Jr., Anthony R. Olsen, Denis White. 1991. Integrated Sampling Design for the Environmental Monitoring and Assessment Program. Draft in Review.

Storr, D.. 1972. A Survey of Water Balance Problems, Projects and Progress in Alberta, in World Water Balance : Proceedings of the Reading Symposium. July 1970, Vol. 2. Gentbrugge, Belgium : UNESCO/IASH/WMO.

Struzer, L. R., I.N. Nechaev, and E.G. Bogdanova. 1965. Sistematicheskie Pogreshnosti Izmereniia Atmosfernykh Osadkov (Systematic Errors in Precipitation measurements) . Meteorologiya $\mathrm{i}$ Gidrologiya (Studies in Meteorology and Hydrology) $10: 50-4$ Clearing House for Federal and Technical Information, Washington, D.C..

Thornthwaite, C.W., J.R. Mather, and D.B. Carter. 1958. 3 Water Balance Maps of Eastern North America. With a Forward by Edward A. Ackerman. Washington, D.C. : Resources for the Future.

United States Department of Agriculture (USDA). 1981. Land Resource Regions and Major Land Resource Areas of the United States. Soil Conservation Service Agricultural Handbook, No. 296. Washington, D.C. : U.S. Government Printing Office.

UNESCO/WMO. 1977. Hydrological Maps: A Contribution to the International Hydrological Decade. Studies and Reports in Hydrology 20. Geneva : UNESCO/WMO.

U.S. Geological Survey. 1984. National Water Summary 1983 - Hydrological Events and Issues. USGS Water-Supply Paper 2250. Washington, D.C. : U.S. Government Printing Office.

U.S. Geological Survey. 1985. National Water Summary 1984: Hydrologic Events, Selected Water-Quality Trends, and Ground-Water Resources. USGS WaterSupply Paper 2275. Washington, D.C. : U.S. Government Printing Office.

Van Wijk, W.R., and D.A. DeVries. 1954. Evapotranspiration. Netherlands Journal of Agricultural Science 2(2): 105-19.

Weber, Jean E., Chester C. Kisiel, and Lucien Duckstein. 1973. On the Mismatch Between Data and Models of Hydrologic and Water Resources Systems. Water Resources Bulletin 9(6) : 1075-88. 
Winter, Thomas C.. 1981. Uncertainties in Estimating the Water Balance of Lakes. Water Resources Bulletin 17(1) : 82-115.

Woodruff, James F. and John D. Hewlett. 1970. Predicting and Mapping the Average Hydrologic Response for the Eastern United States. Water Resources research 6(5) : 1312-26.

Yoxall, W.H.. 1980. The Water Balance in Newfoundland. Water Resources Bulletin $16(6): 1030-33$. 
APPENDIX A

WATER-YEAR 1984 USGS GAGING STATIONS

IN THE NORTHEAST UNITED STATES 
[1 $\quad$ IN

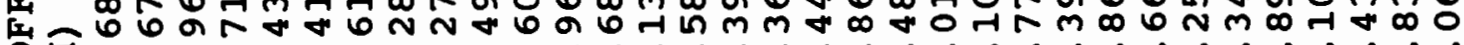

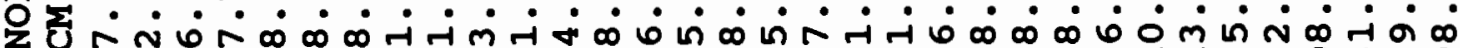

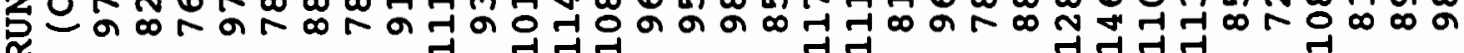

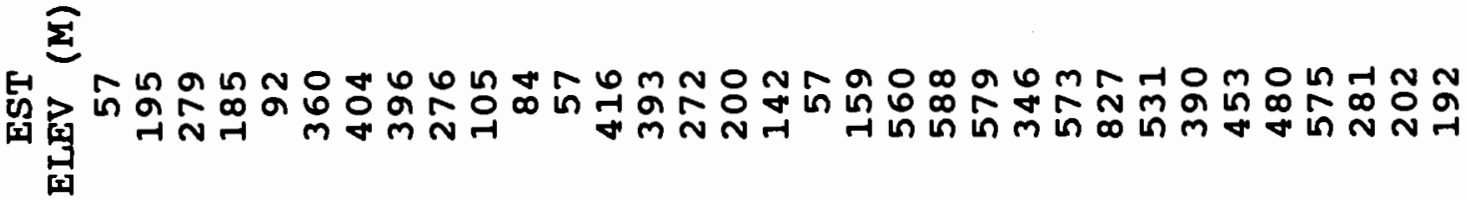

포롤

要

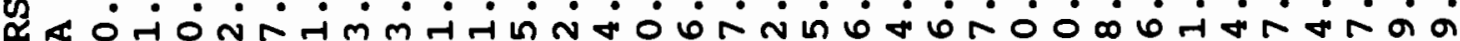

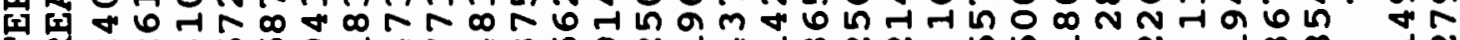

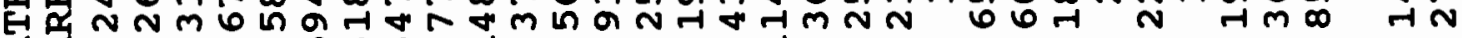
द $N$ N

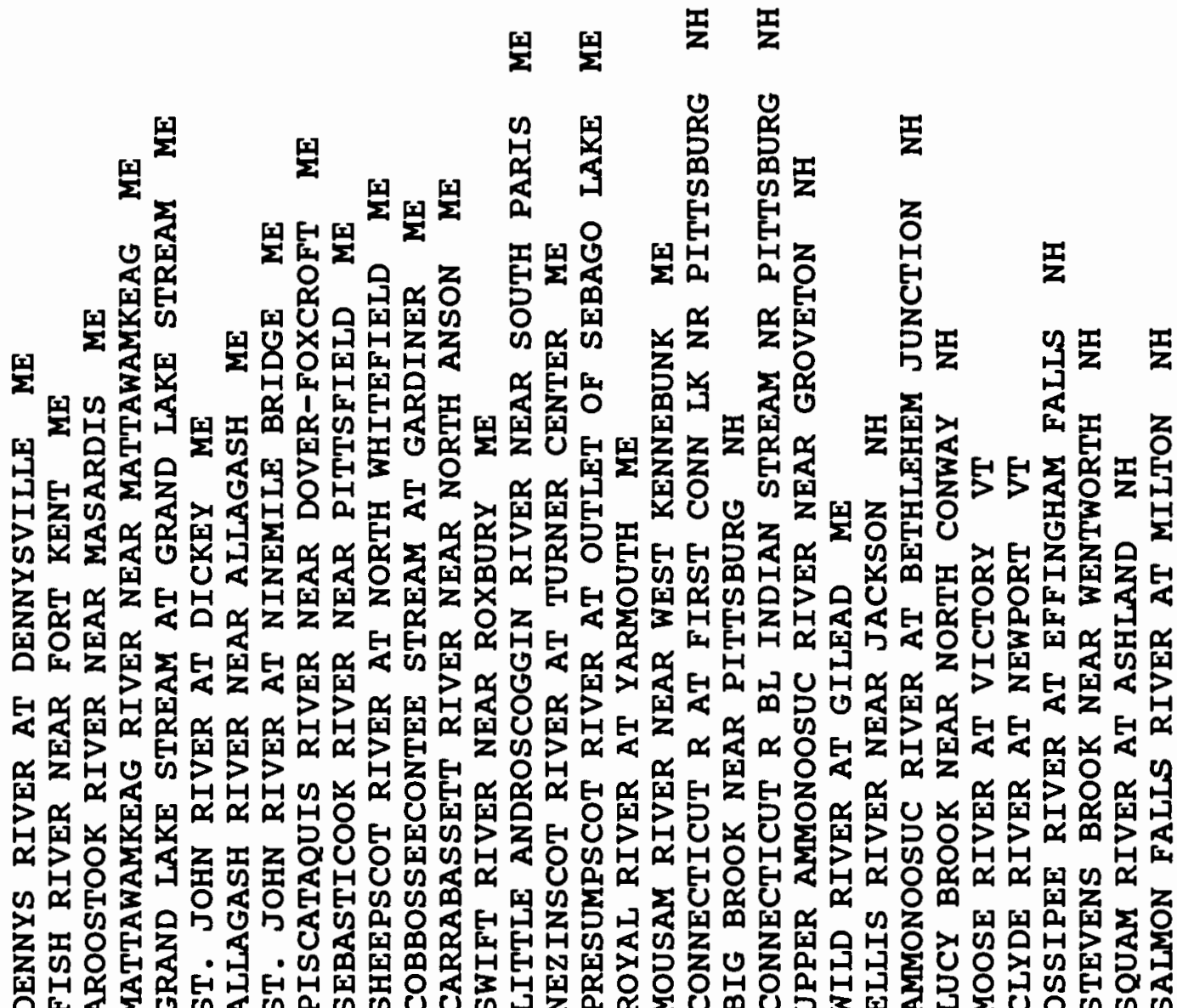

0 0 0 0 0 0 0 0 0 0 0 0 0 0 0 0000000000000 ○ 0000000000000000000 0 0 0 0 0 0 00000000

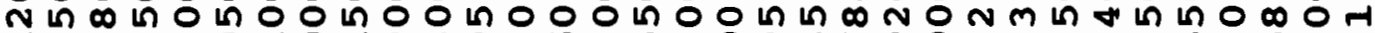
N

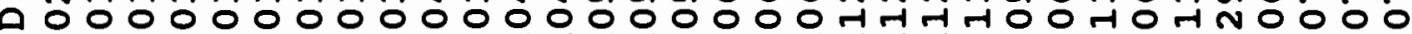

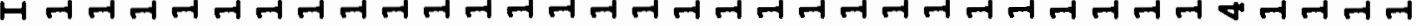


[4 II $=0$ \% o

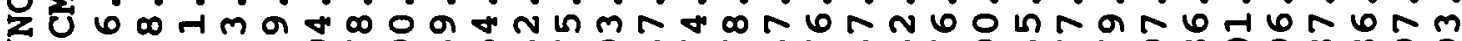

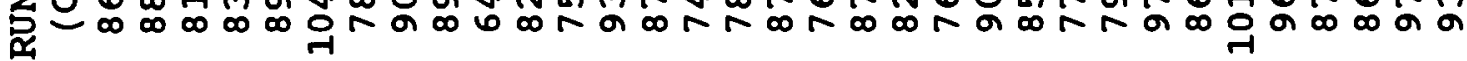

\footnotetext{
武

E

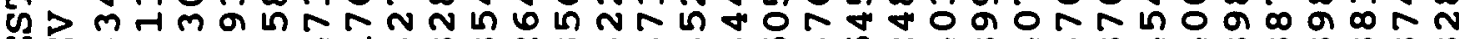
[घ]

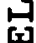

国实

(2) NH⿻

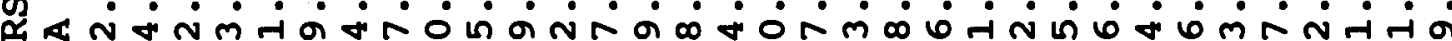

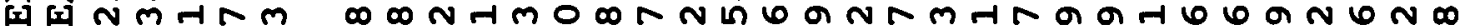

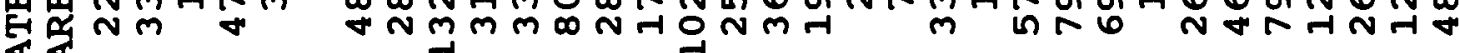
4

E-1<smiles>[CH]1[CH-]C1</smiles>

要

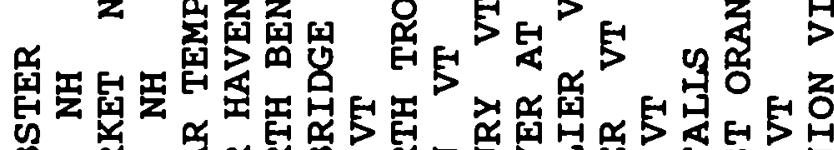

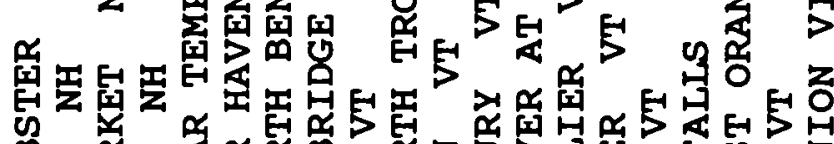

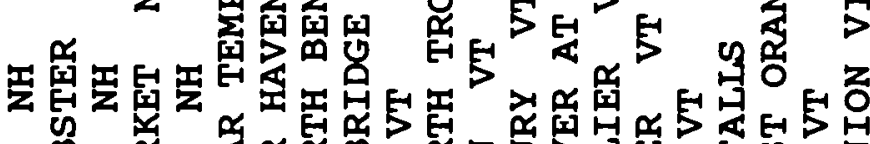

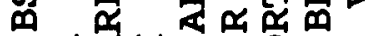

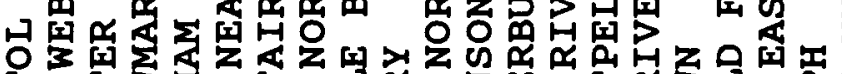

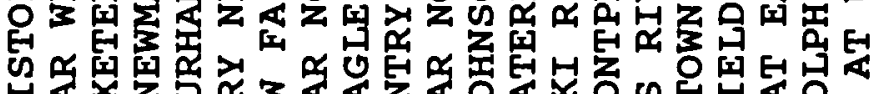

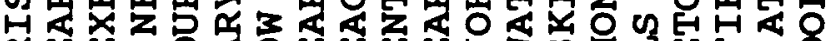

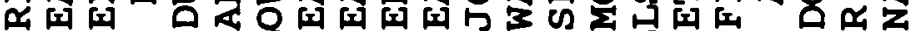

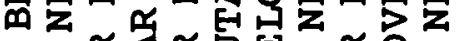

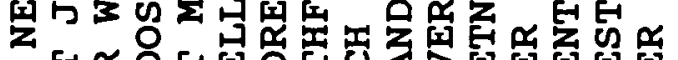

눌

는

(x)

[a]

[1

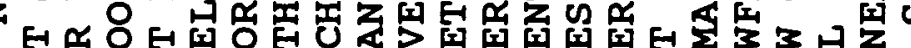

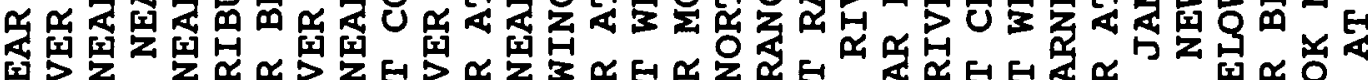

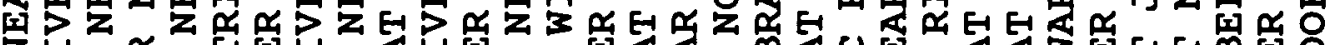
$z H$ 只

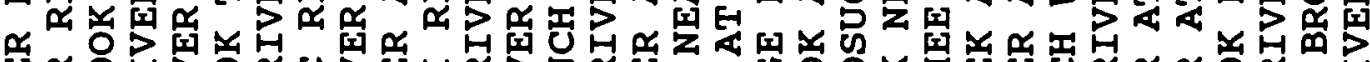

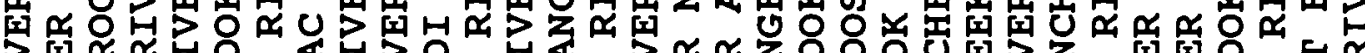

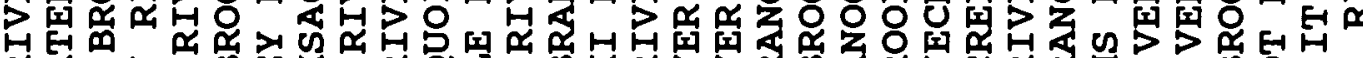

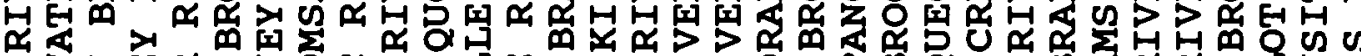

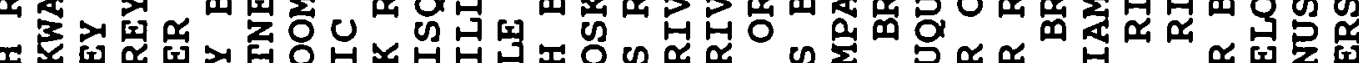

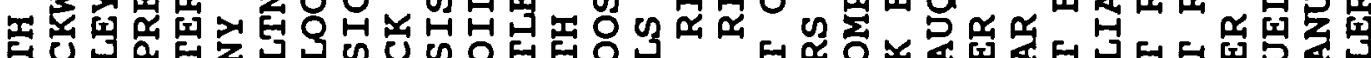

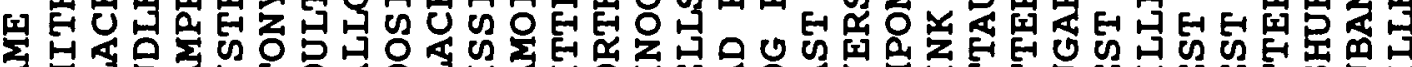

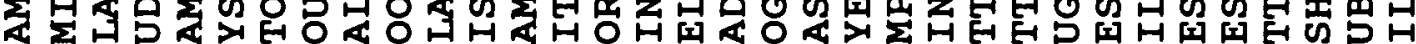

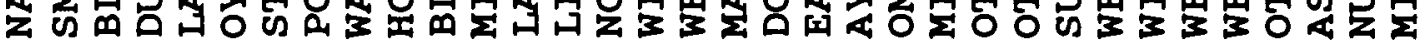

옹ㅇㅇㅇㅇㅇㅇㅇㅇㅇㅇㅇㅇㅇㅇㅇㅇㅇㅇㅇㅇㅇㅇㅇㅇㅇㅇㅇㅇㅇㅇㅇㅇㅇㅇㅇㅇㅇㅇㅇㅇㅇㅇㅇㅇㅇㅡ

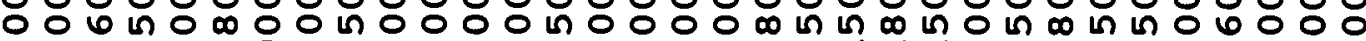
$\infty \pi m m m m o$ d

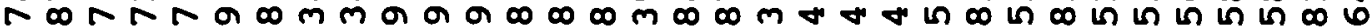

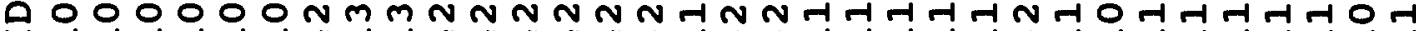
Hન $ન$ ન 


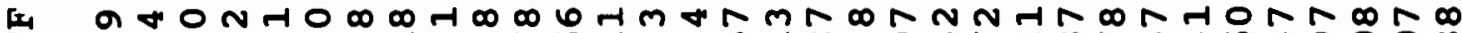
I

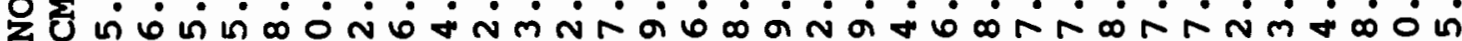

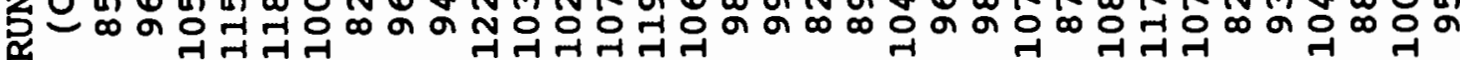

\section{$\bar{\Sigma}$}

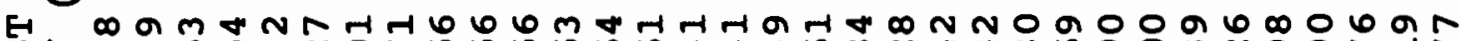

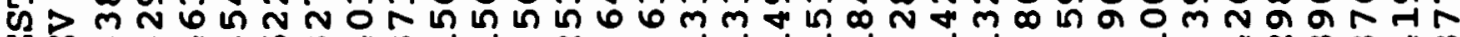
国同m 国

Qty

[ᄑ NNN

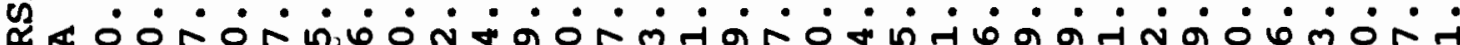

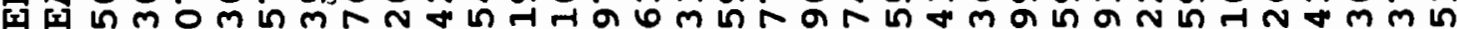

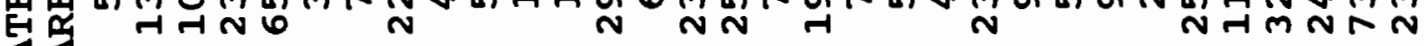
4

3

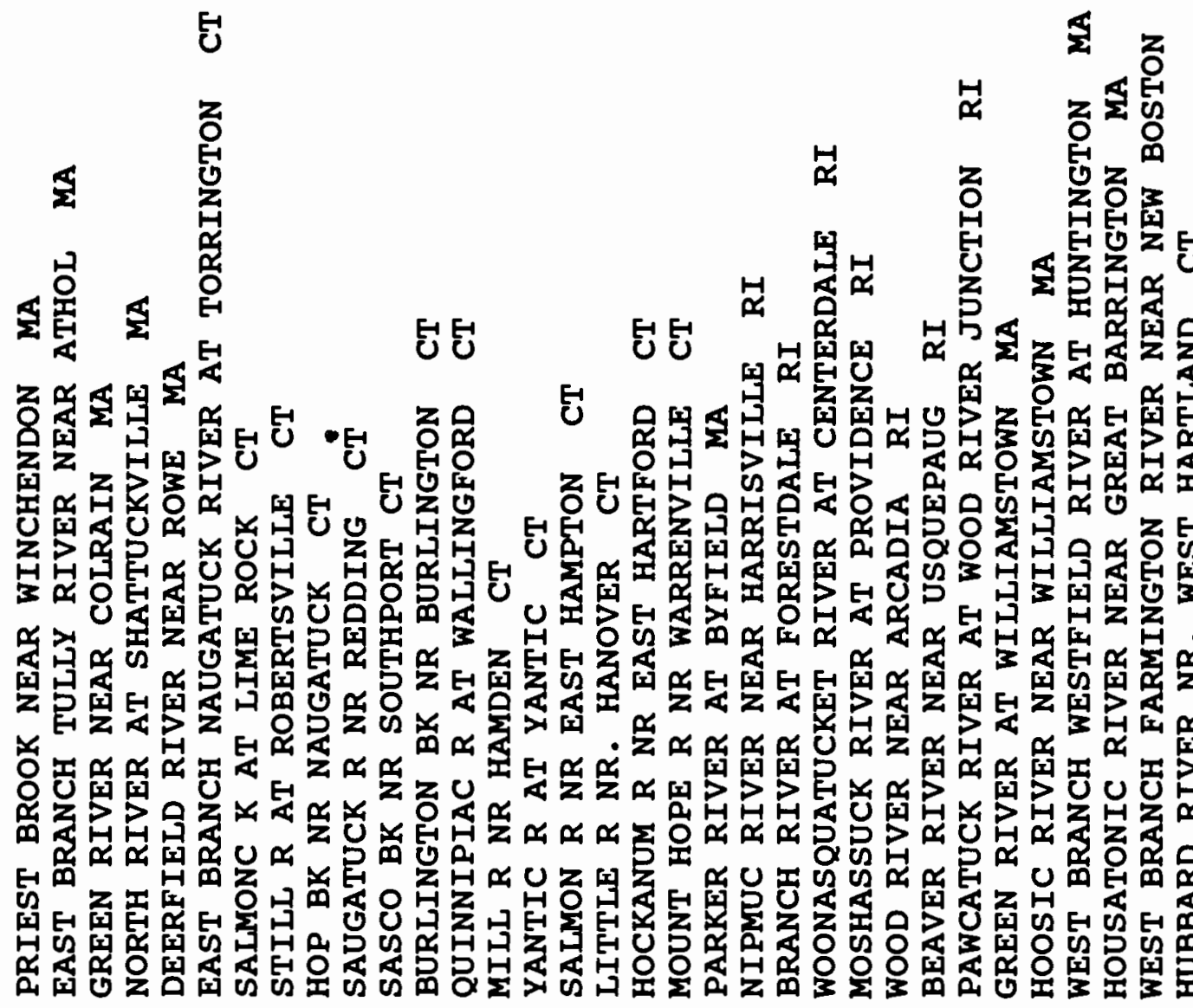

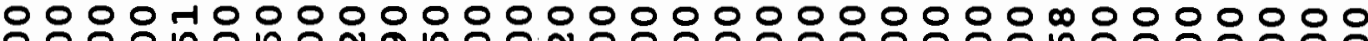
이이 no

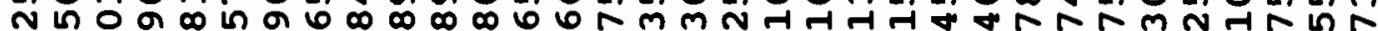
b 6 N

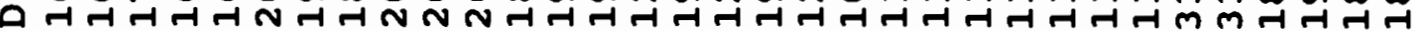

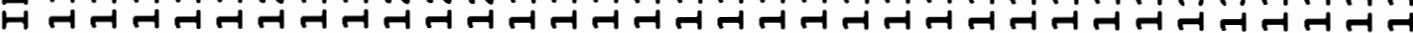


[4 $\quad$ a 9 क I $=0$ N OE. Z U

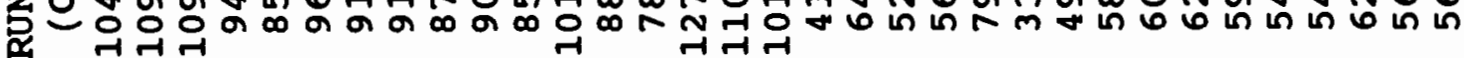

\footnotetext{
2

E N Us $>0$ G

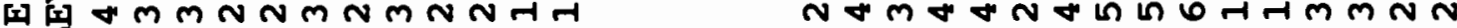
[1]
}

Q

至

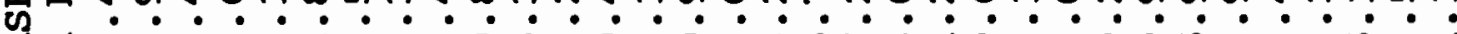
\&

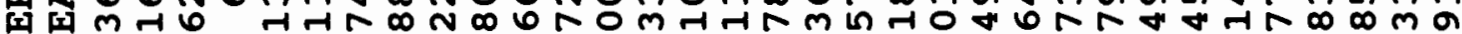
Eम नNA 舟

3

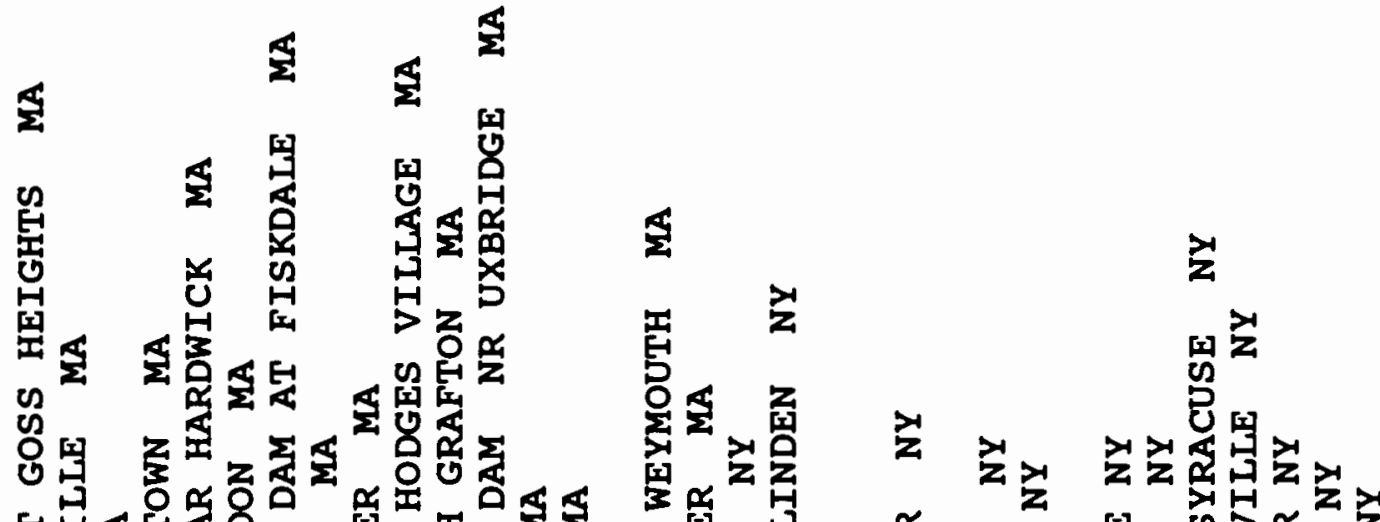

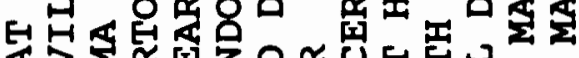

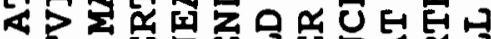
$\alpha$ 焉

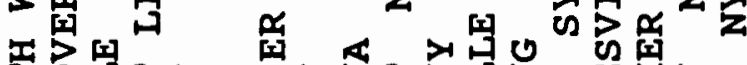

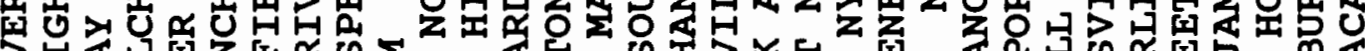

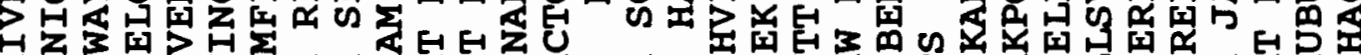

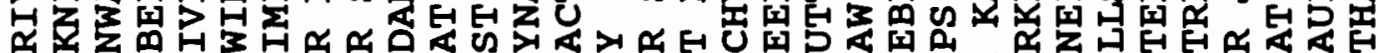

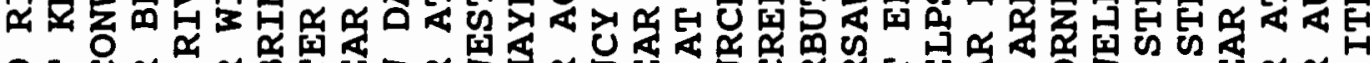

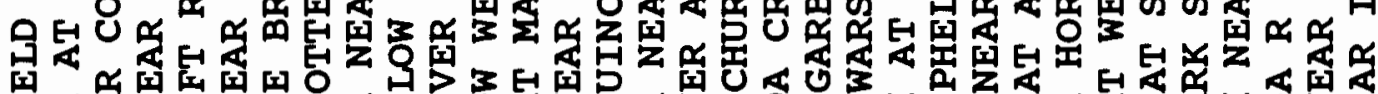

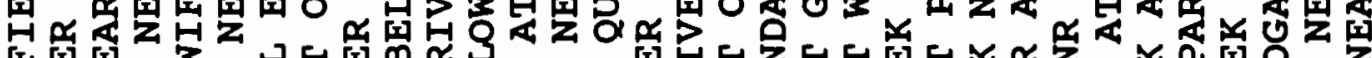

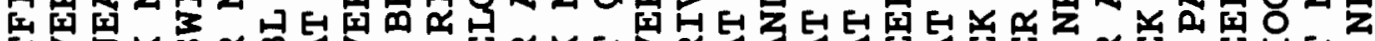

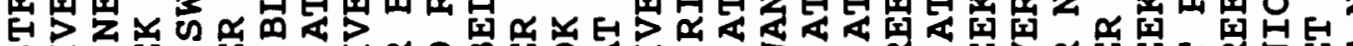
ขै $\alpha$ 国

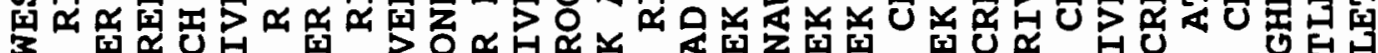

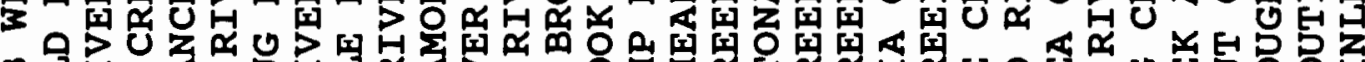

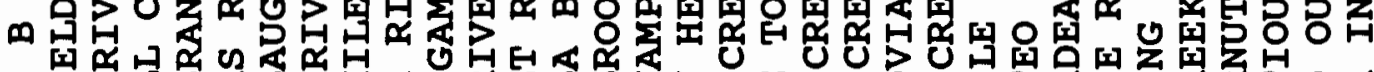

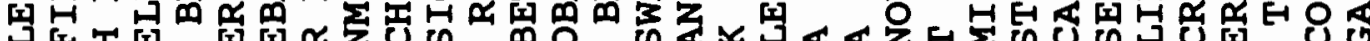

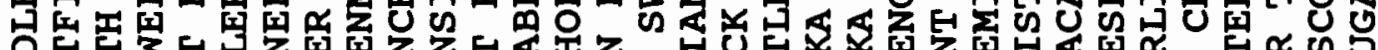

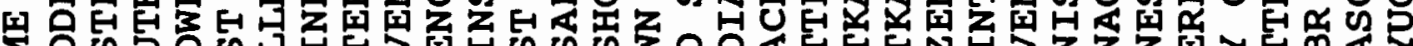

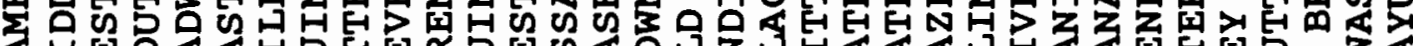

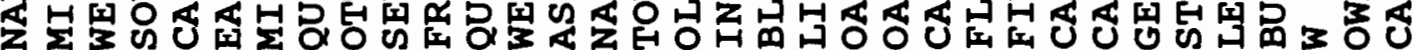

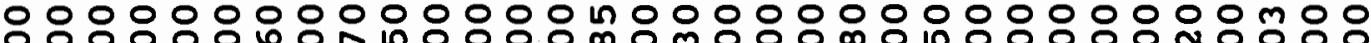
n

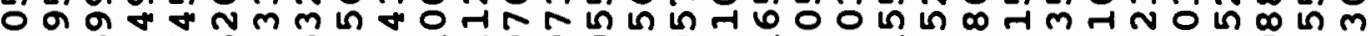
क N

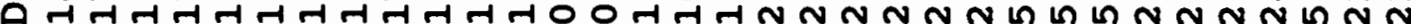
मન 


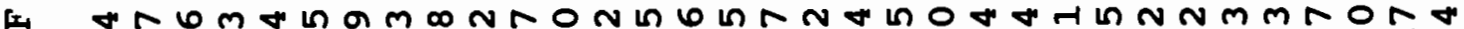

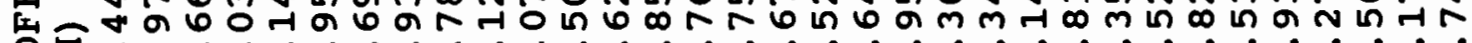
o

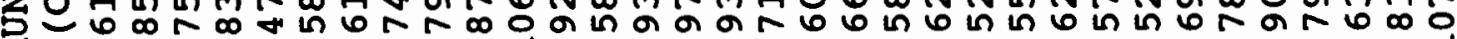
P

$\underline{\Sigma}$

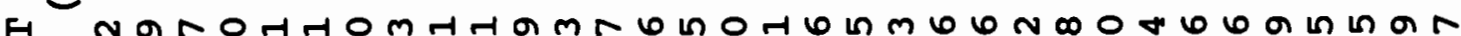
U $>$ o d

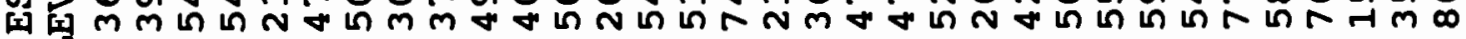
[1]

空运

至

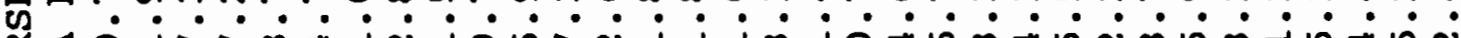
幽

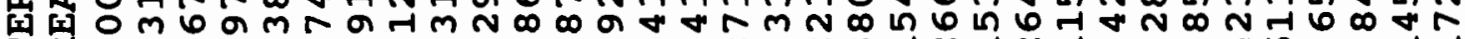

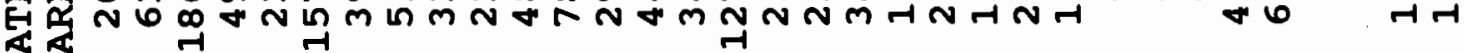

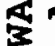
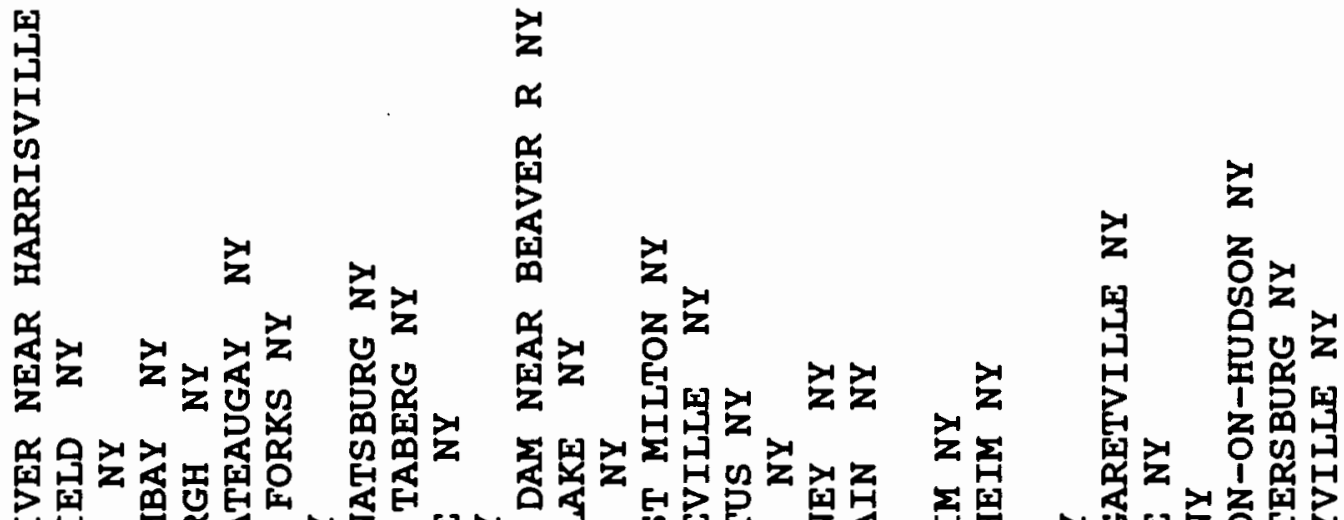

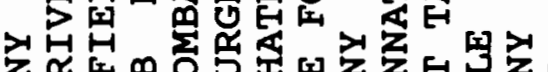

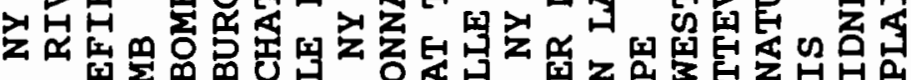

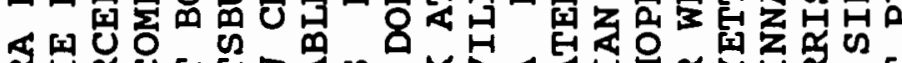

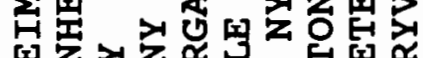

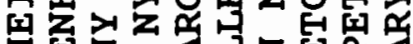

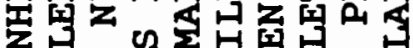

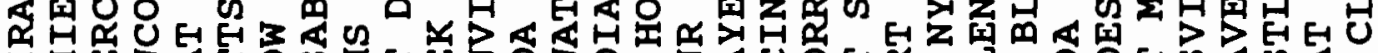

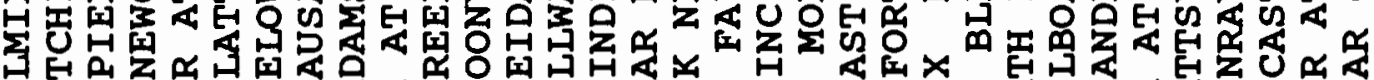
国 4 国 터요

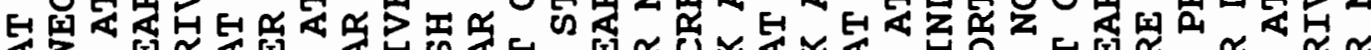

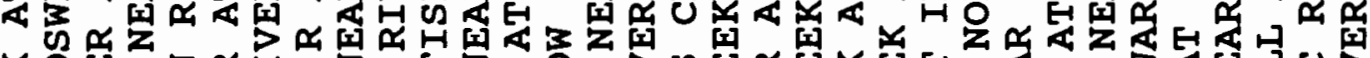
의

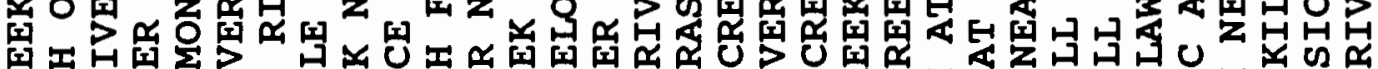

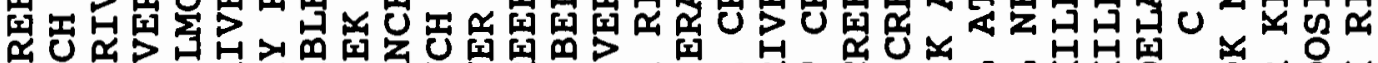

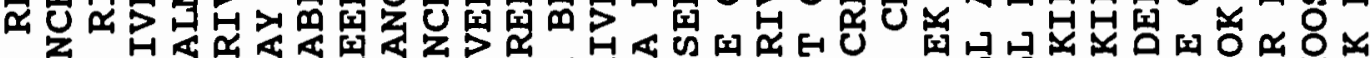

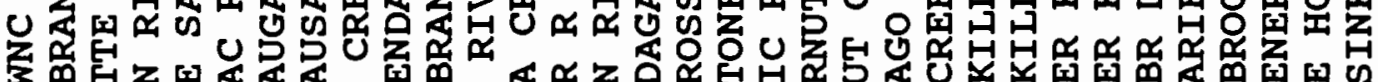

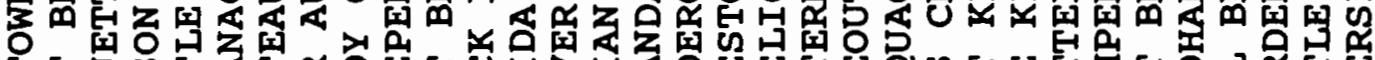

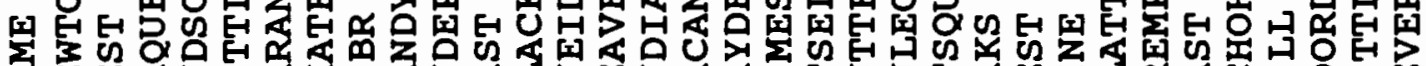

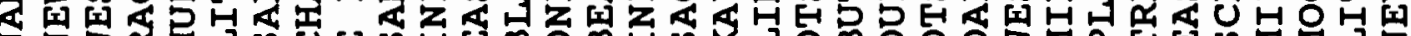

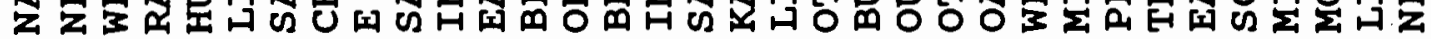

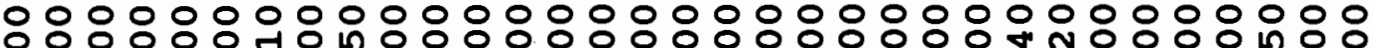

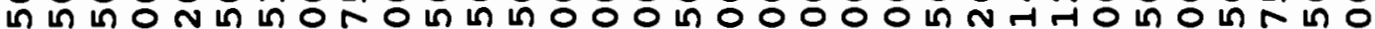

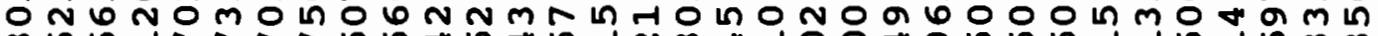
m $06 \mathrm{H}$ -

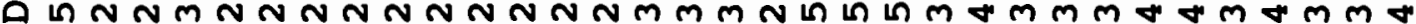
H 


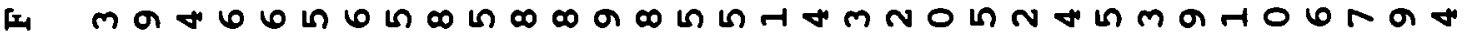

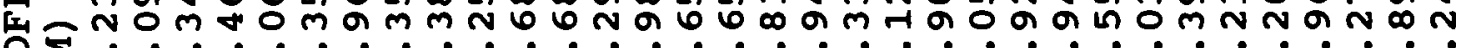
O z J

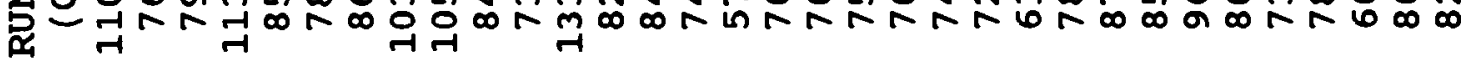

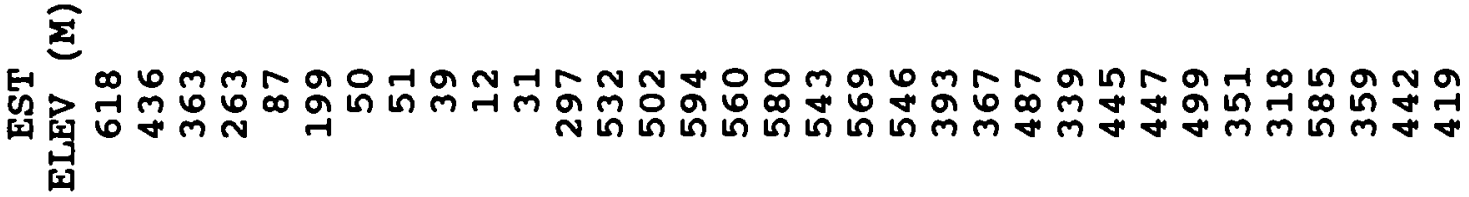

Q

焉NAO U ⿷匚丿

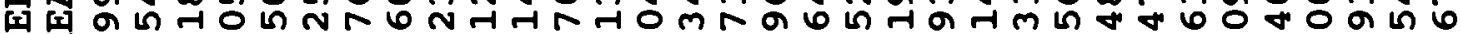

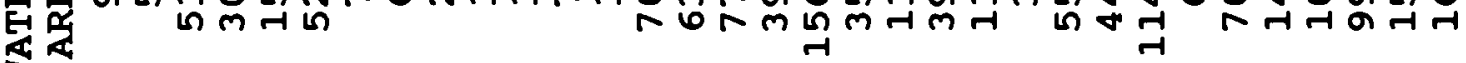
3

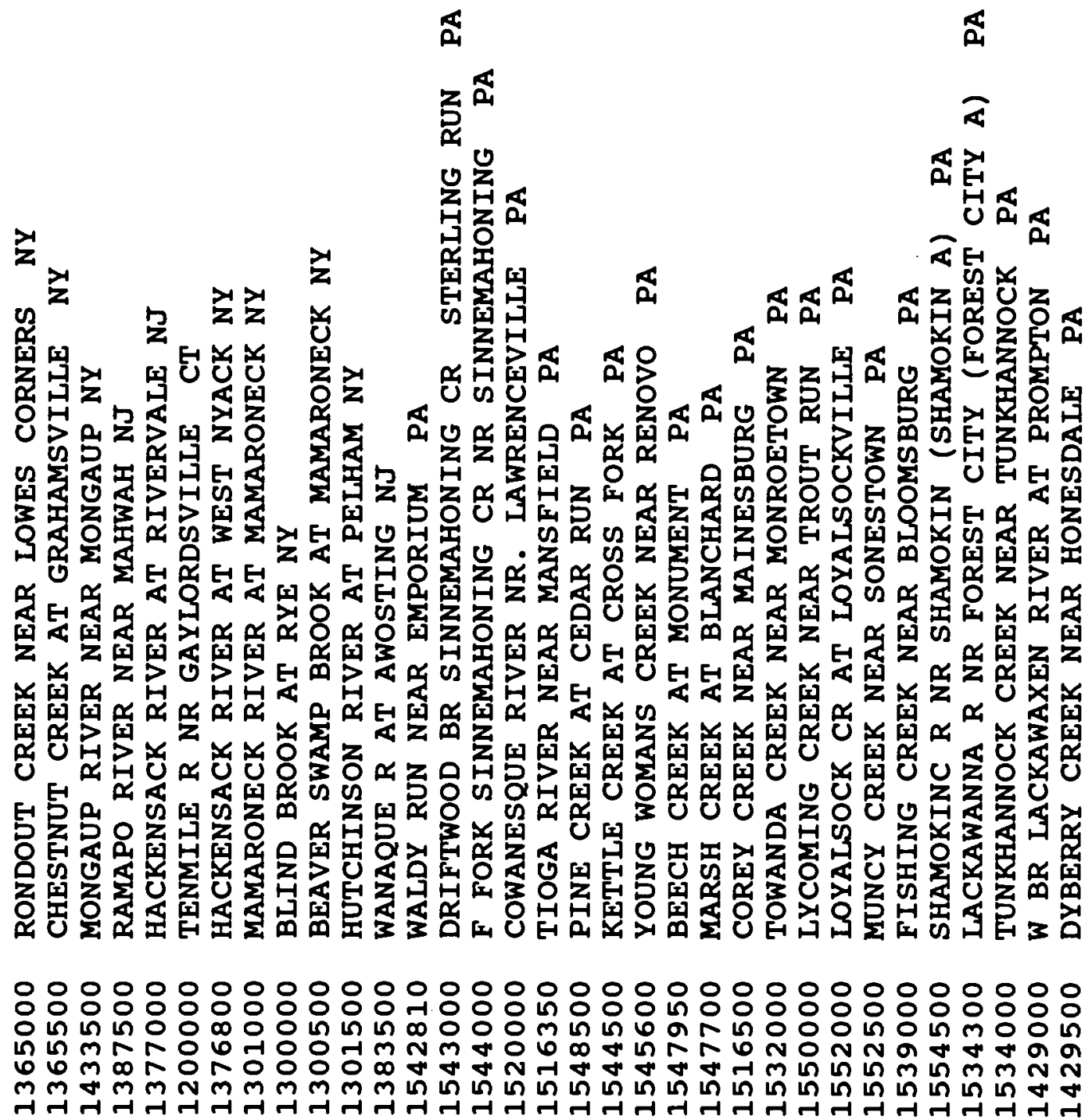


[4 I

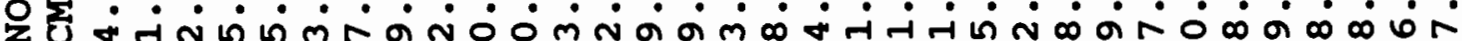

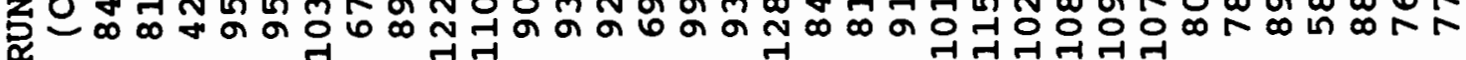

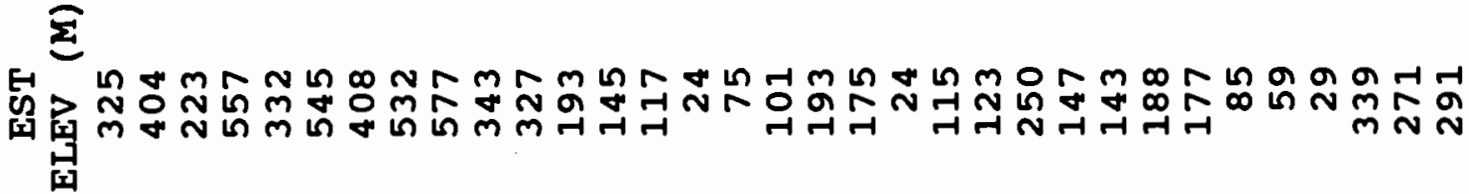

[x.

[द्य

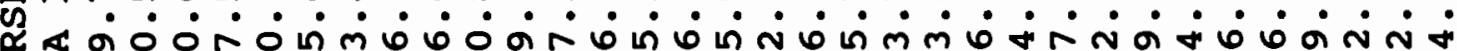
[n Eब 0 N < 3

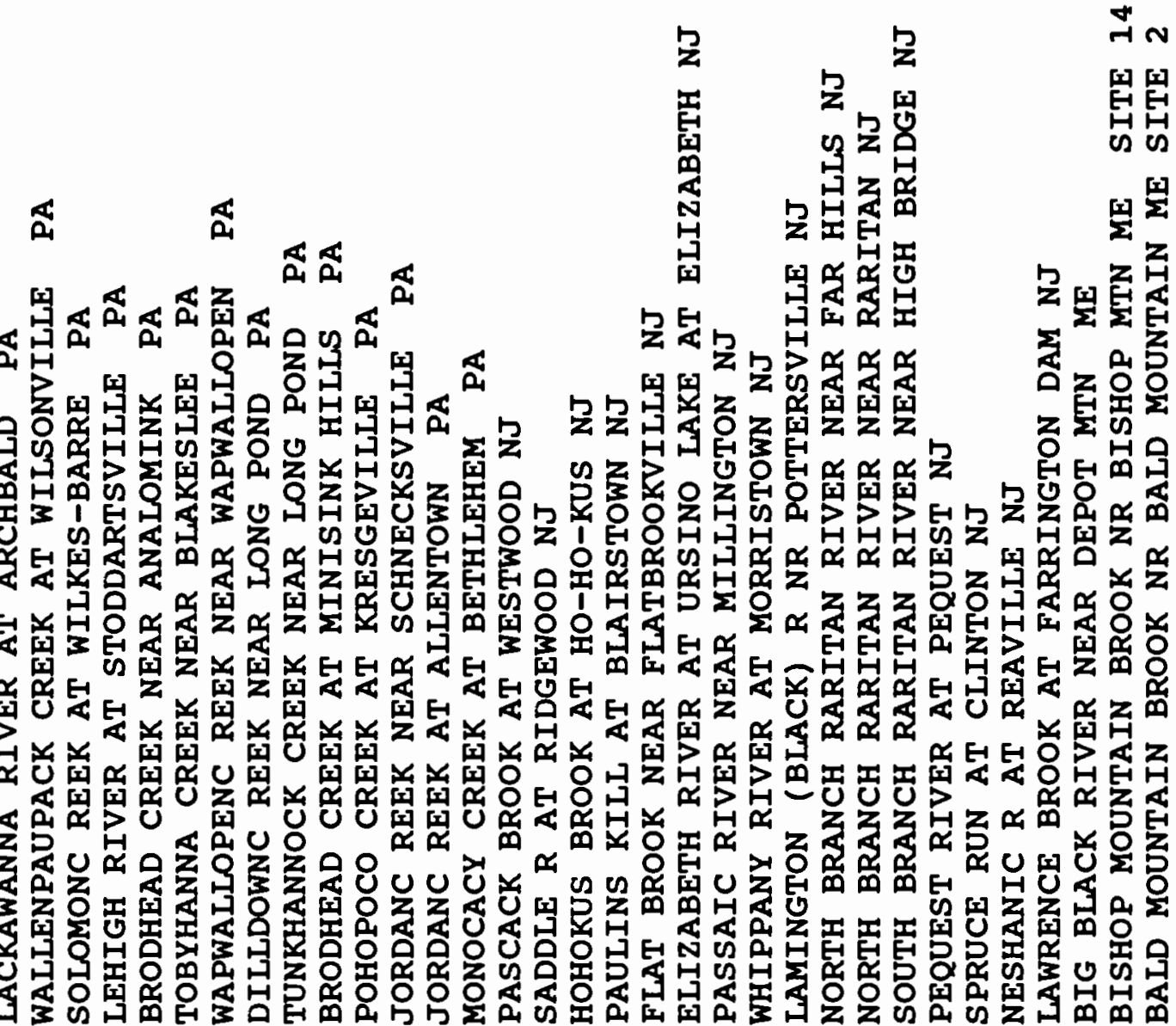

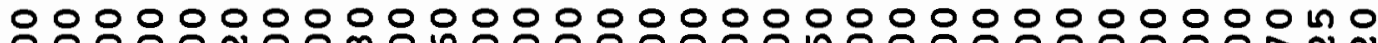

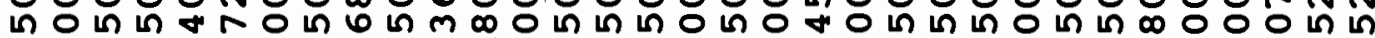
* N

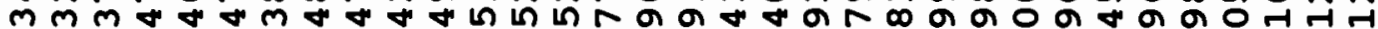
ด

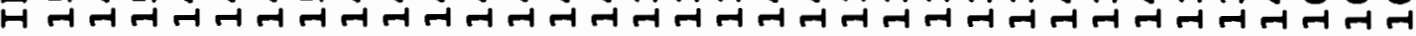




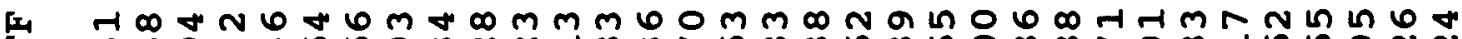

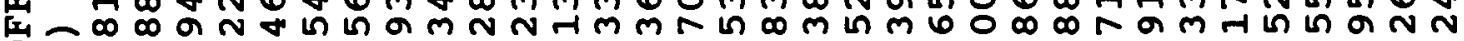
z

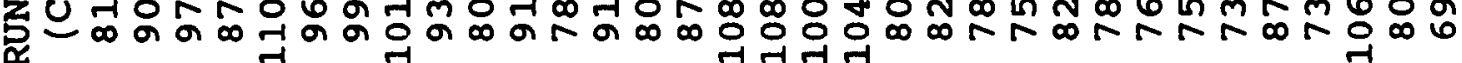

Zit

E OmmnNma

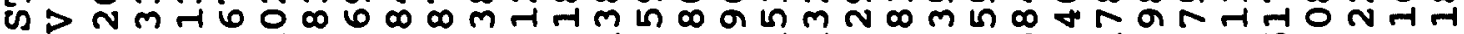
[1 1

国

I 0 ㅂ.

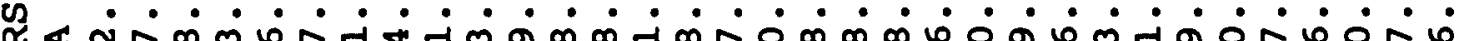

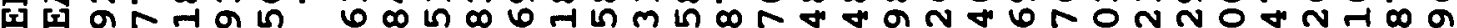

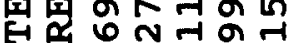
य $\infty \mathrm{m}$

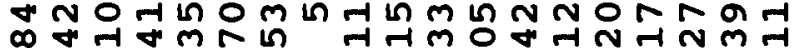
$\infty 60 \wedge m$ ב. $\infty+\pi)$ H

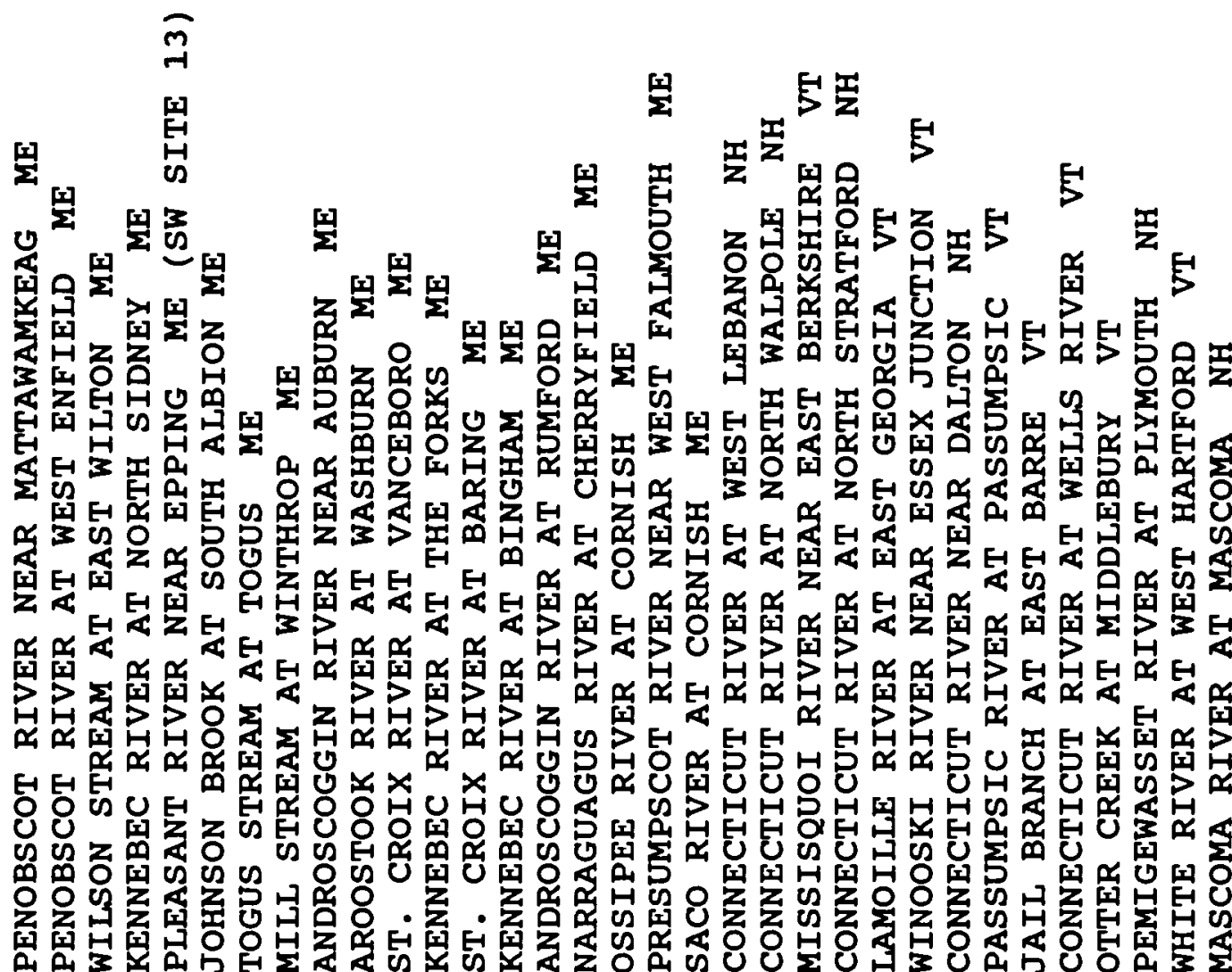

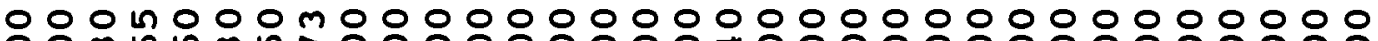
o n $M N$ N - +

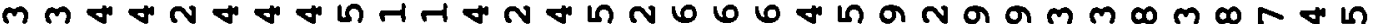

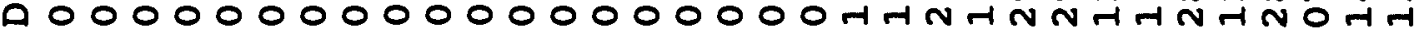
म 
[4 HNANNNMNOO m li 0 o

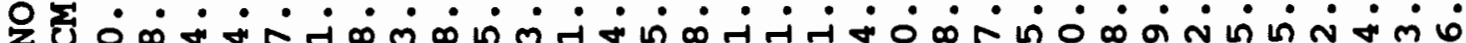
旁U 西 $+\rightarrow$

2

E $n m-N$ n U $\rightarrow$ L घ $\rightarrow$

ar.

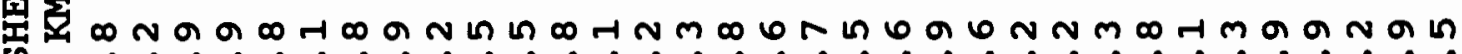

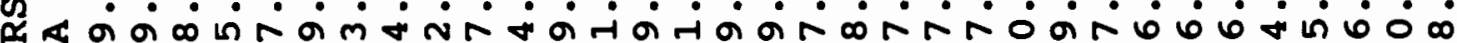

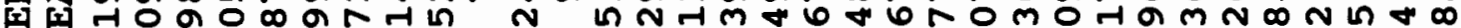

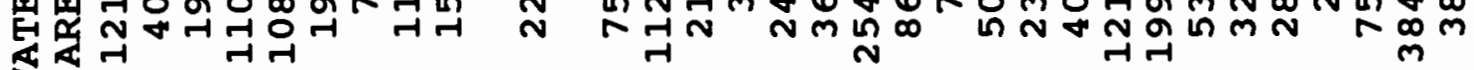
3

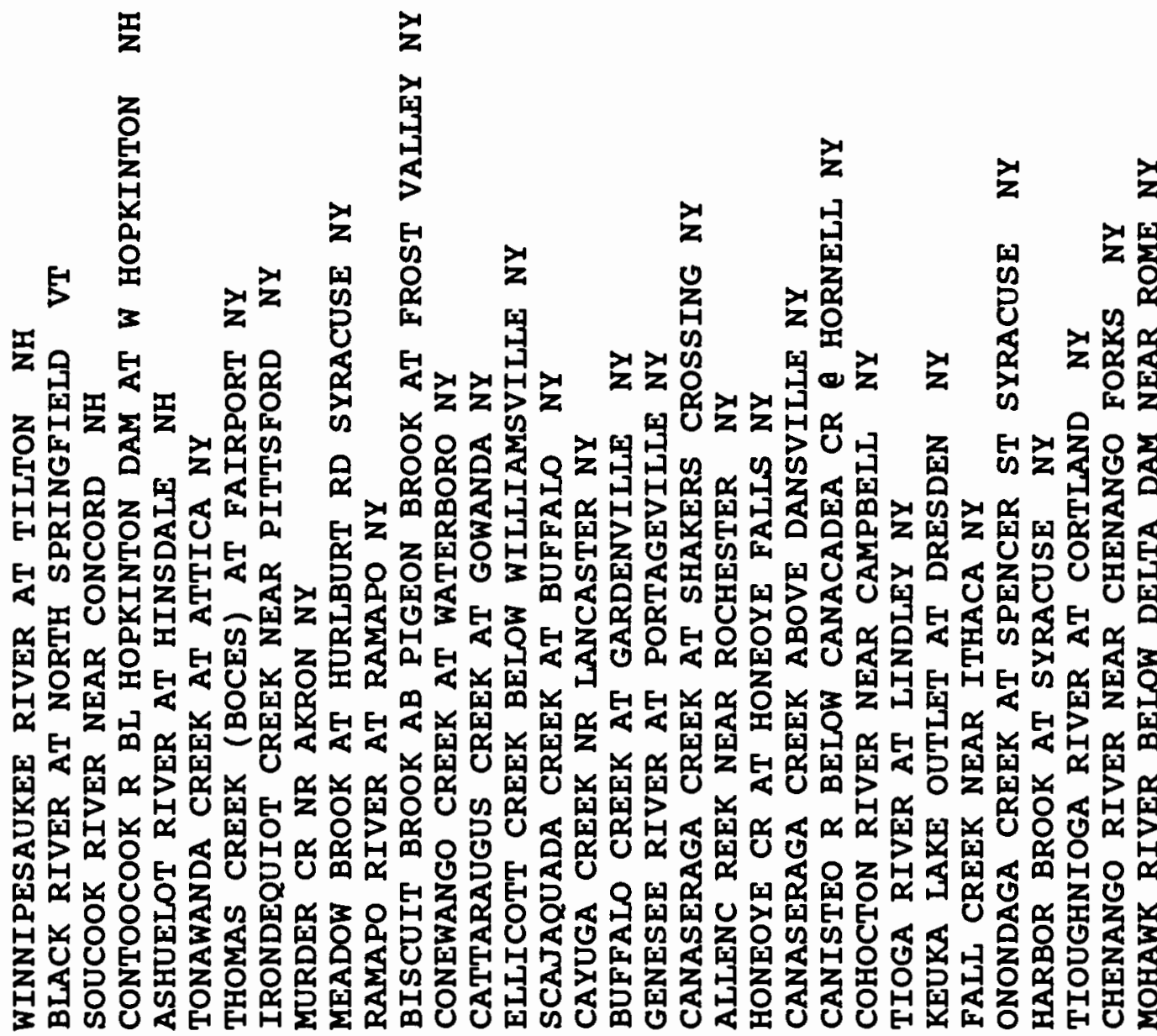

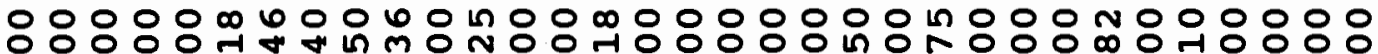

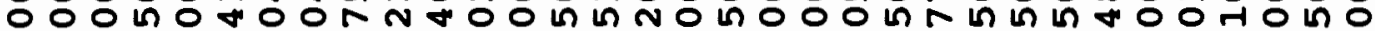
न

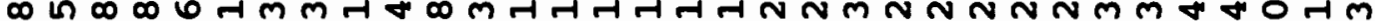

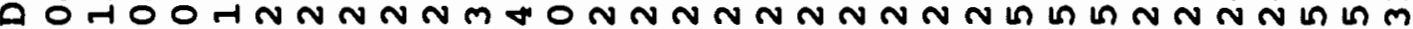
म न 


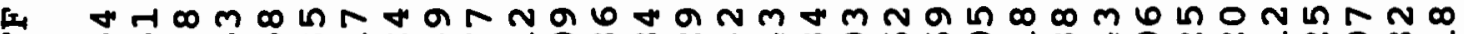

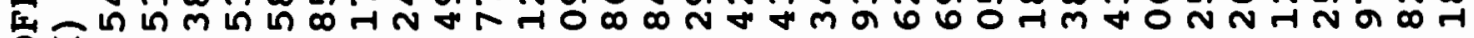

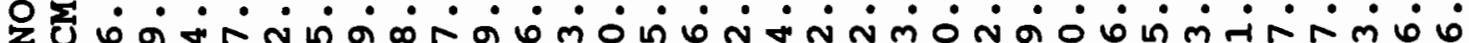

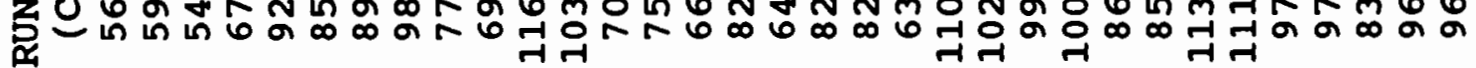

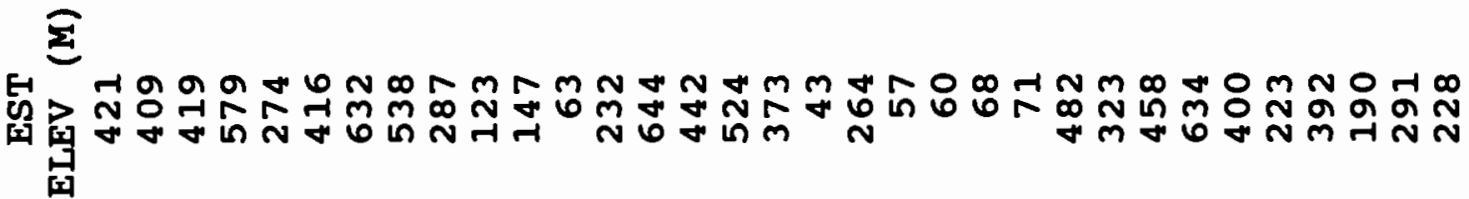

国

플

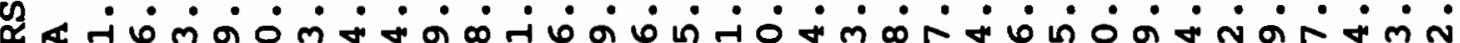

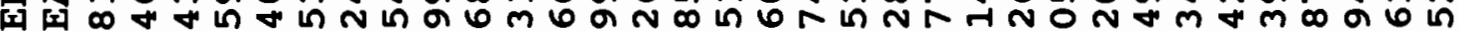

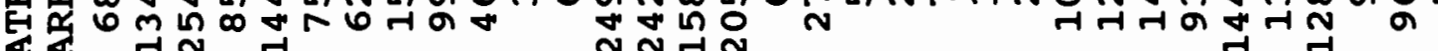

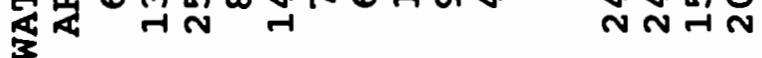

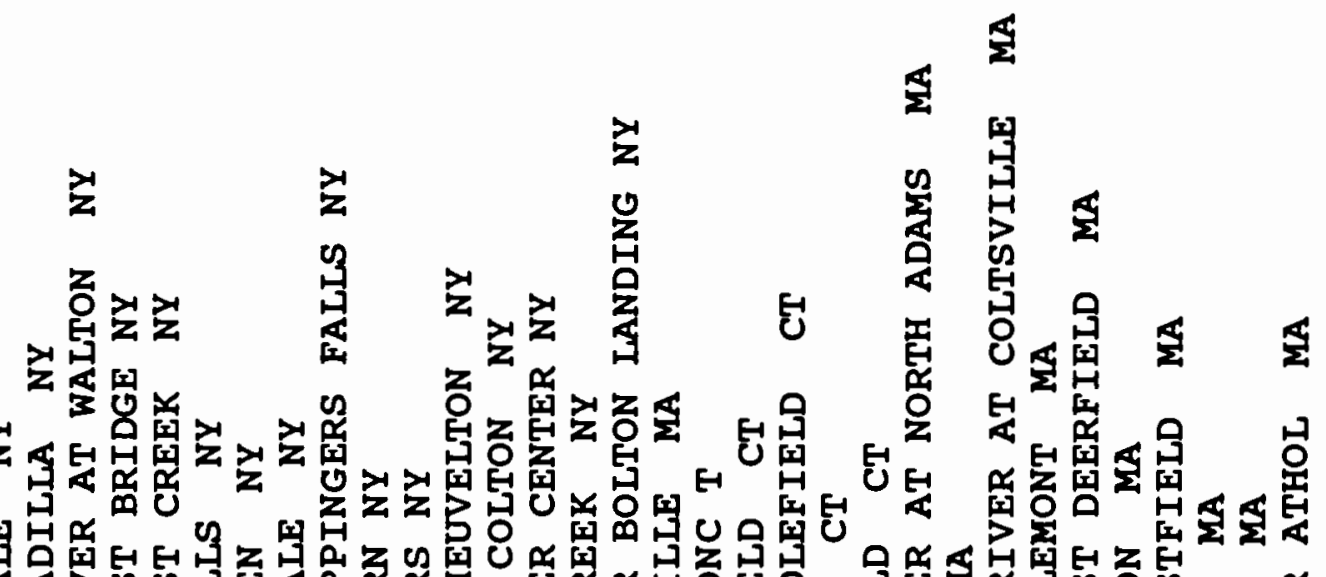

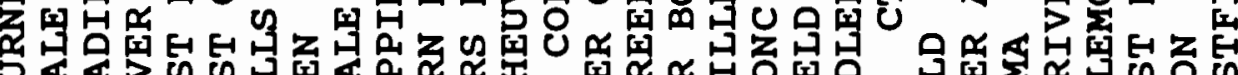

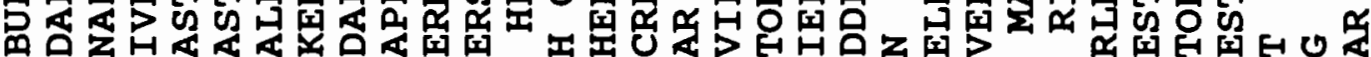

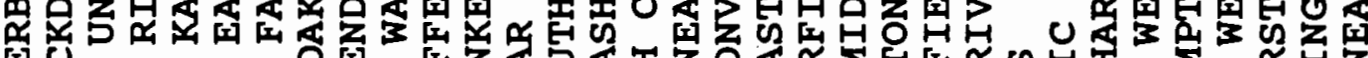

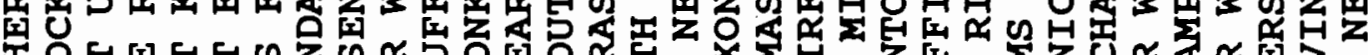

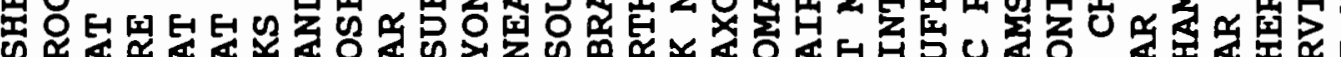

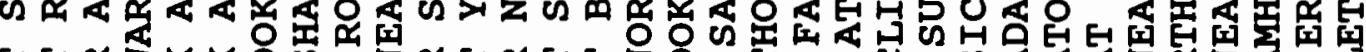
EE

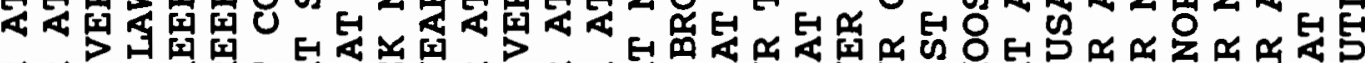

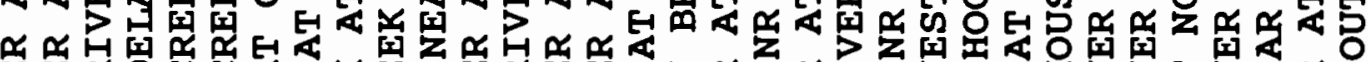

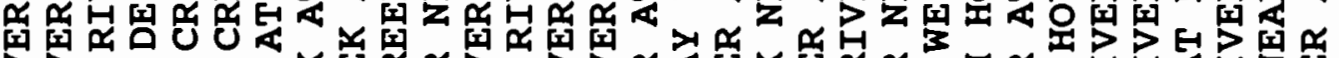

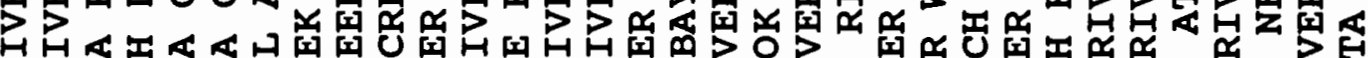

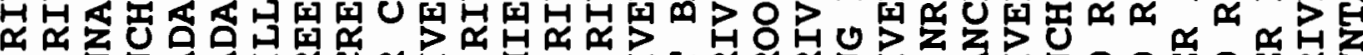

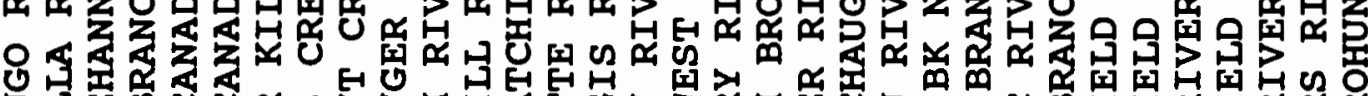

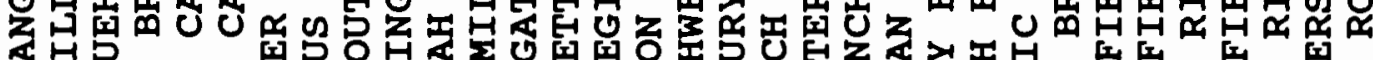

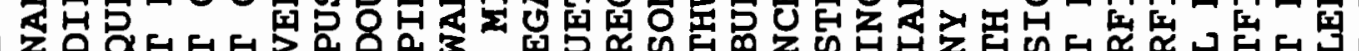

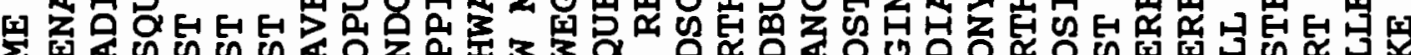

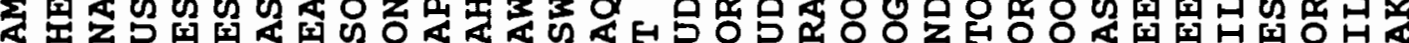

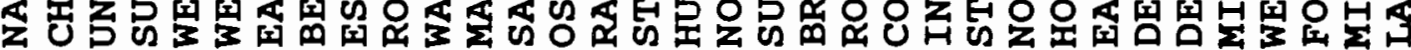

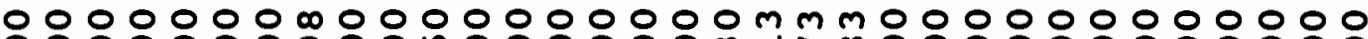

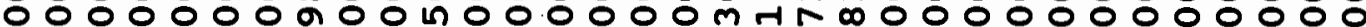

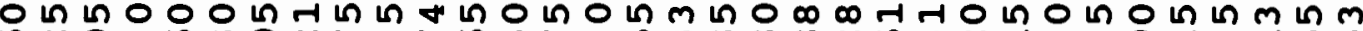

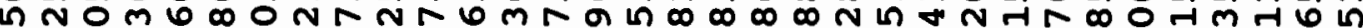

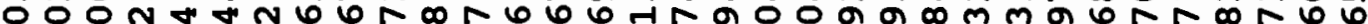
ด $n$ n मનન 


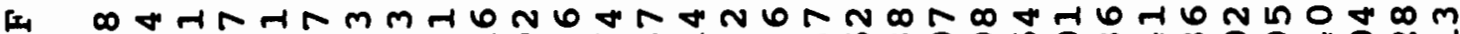
I

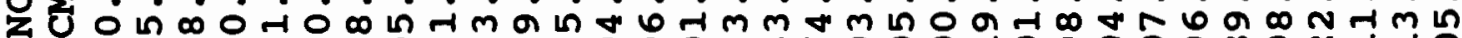
s.

\footnotetext{
ב1

E d RN

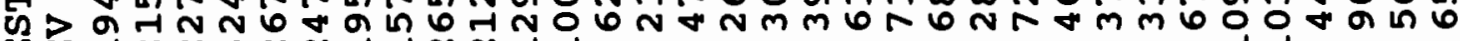

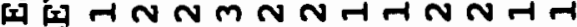

(1)
}

ay

焉 (3)

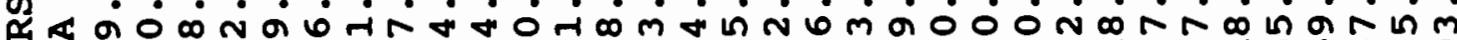

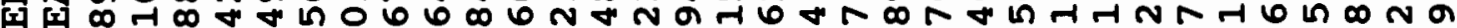
Ex 3
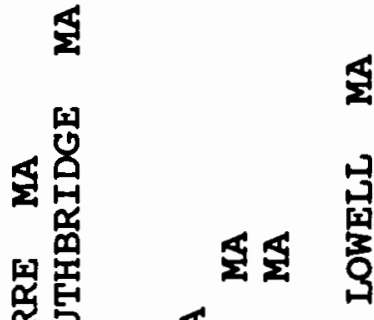

5

$\stackrel{1-1}{1}$

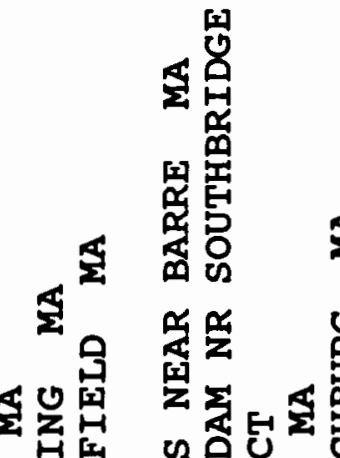

o 12

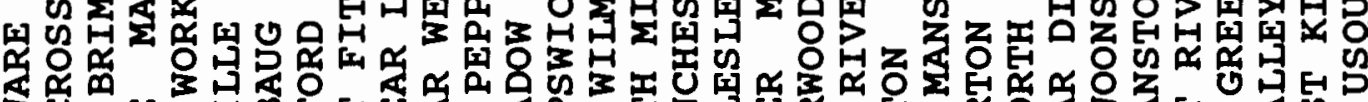

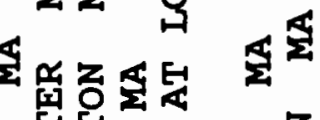

过是

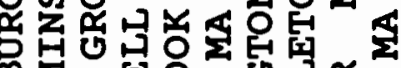

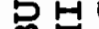

됭

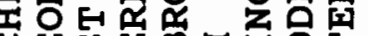

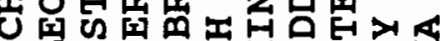

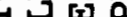

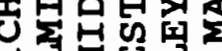

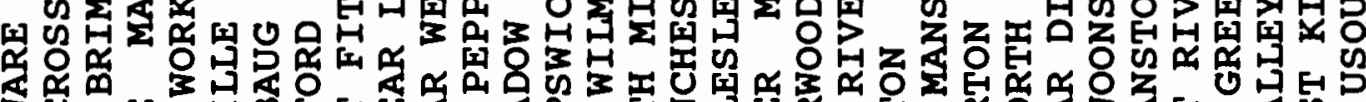

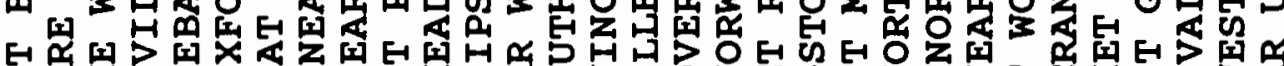

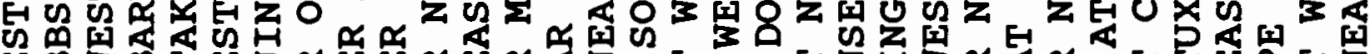

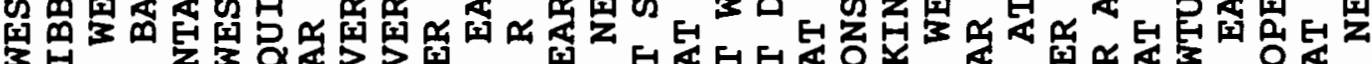

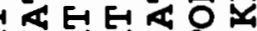
4 [x 14

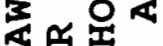

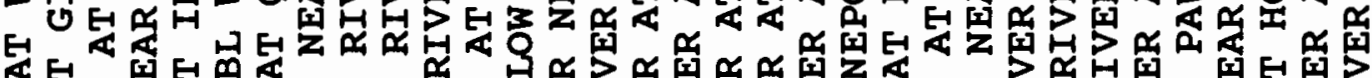

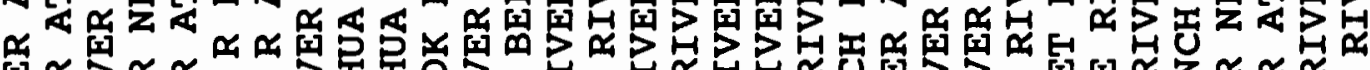

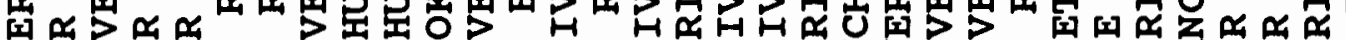

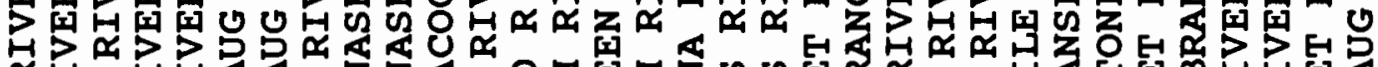

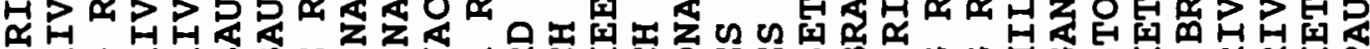

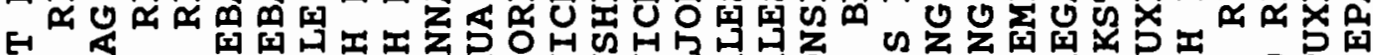

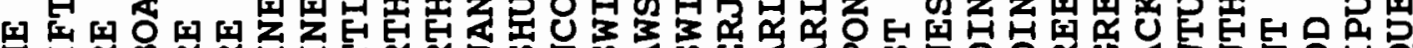

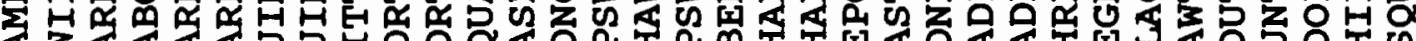

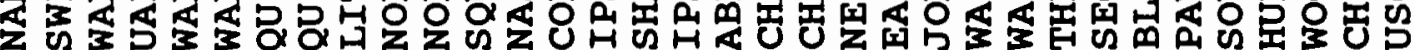

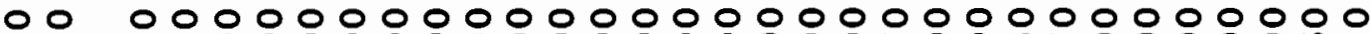

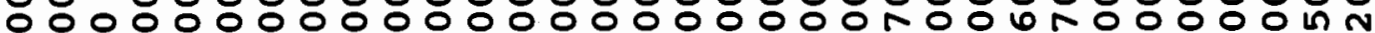
in

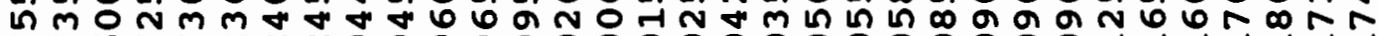
NA

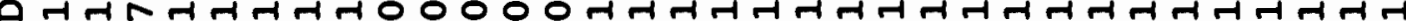

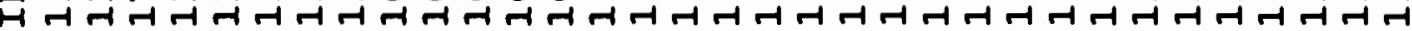


[4 س

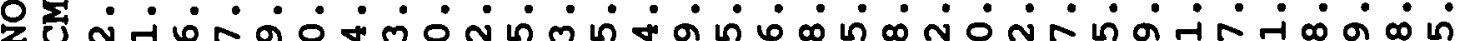

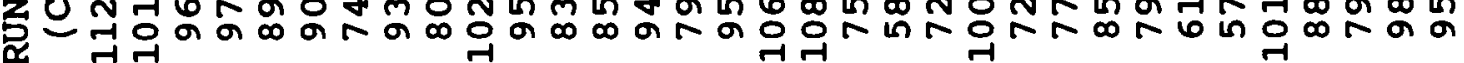

\section{$\underline{Z}$}

E m U $>$ A घ 1

in

刍

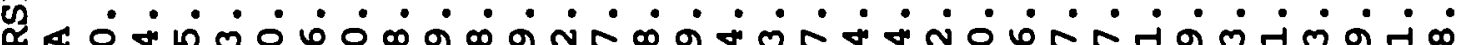
[I I

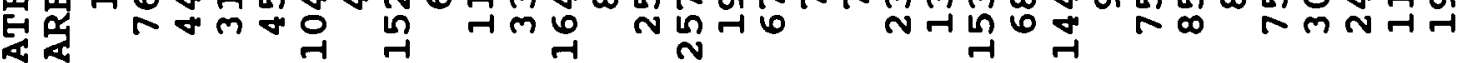
3

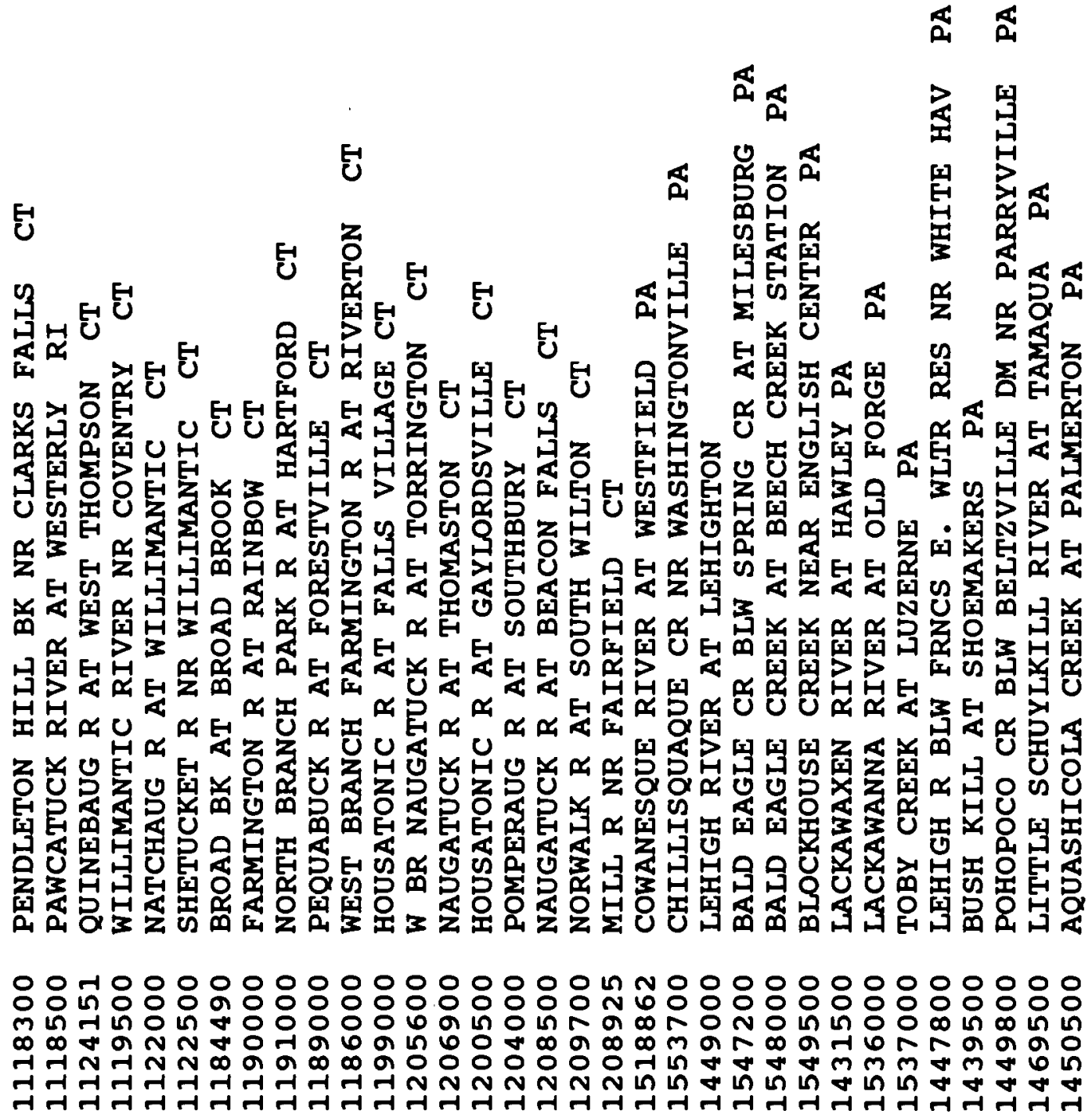




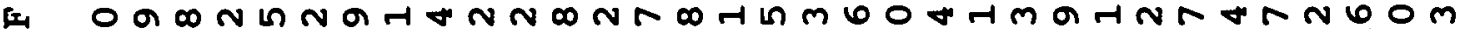

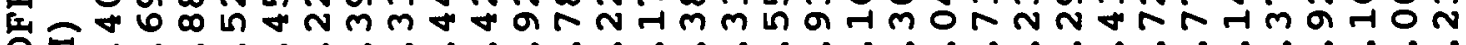

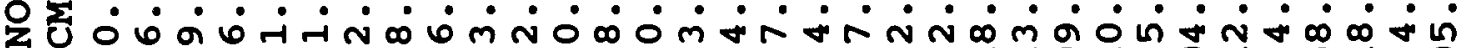
质엄

$\underline{\Sigma}$

E is $>$ N $\infty$ in

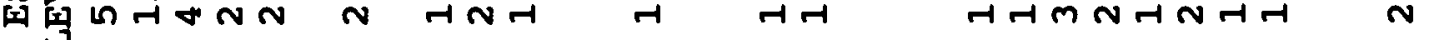
H

An

至

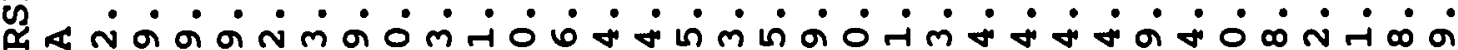

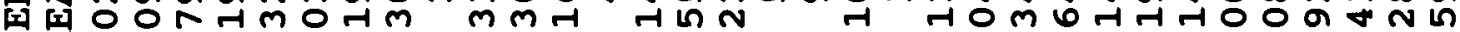

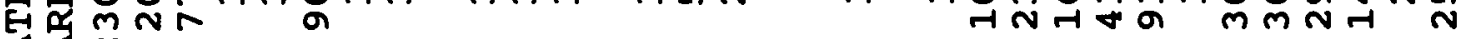

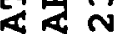

3

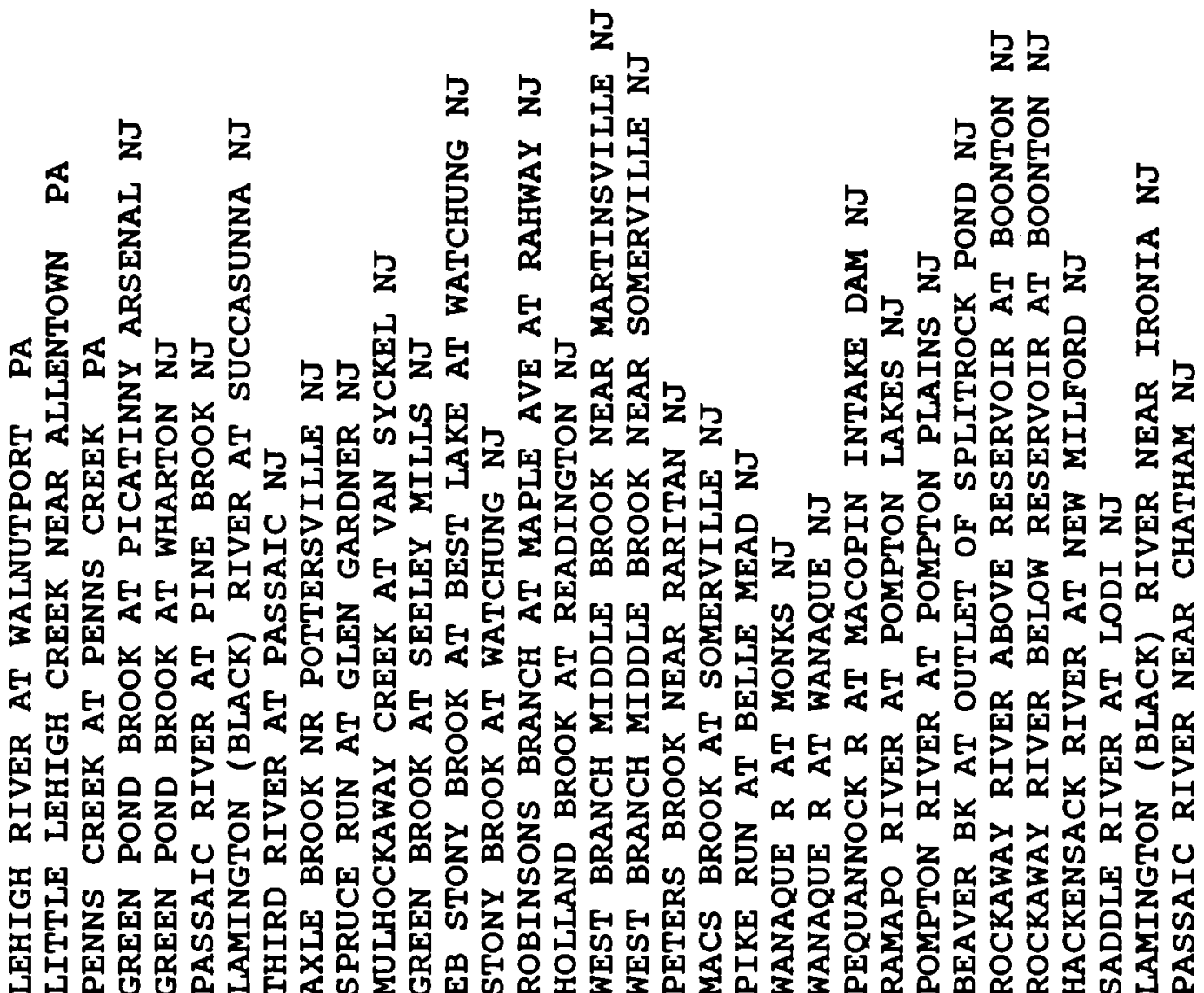

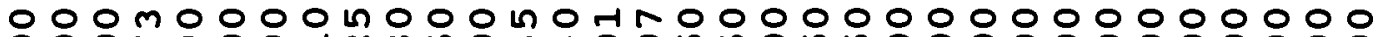
이이에

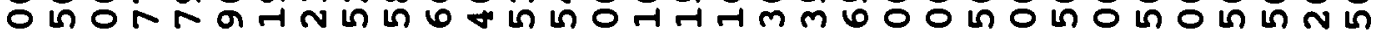

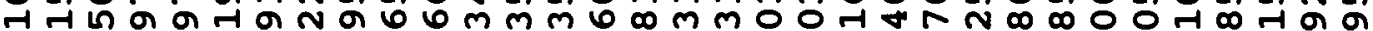

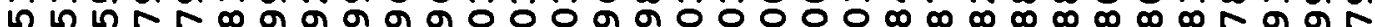

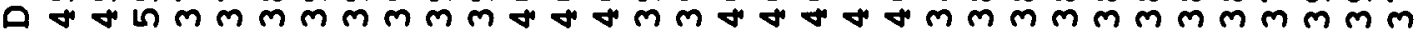

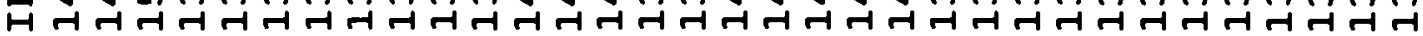




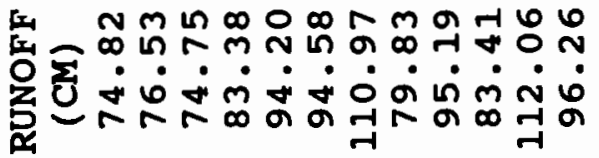

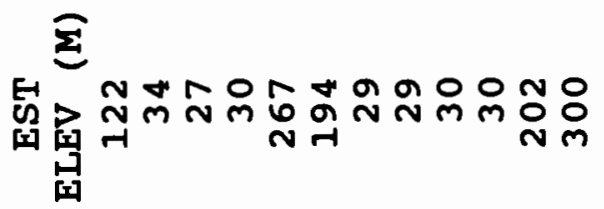
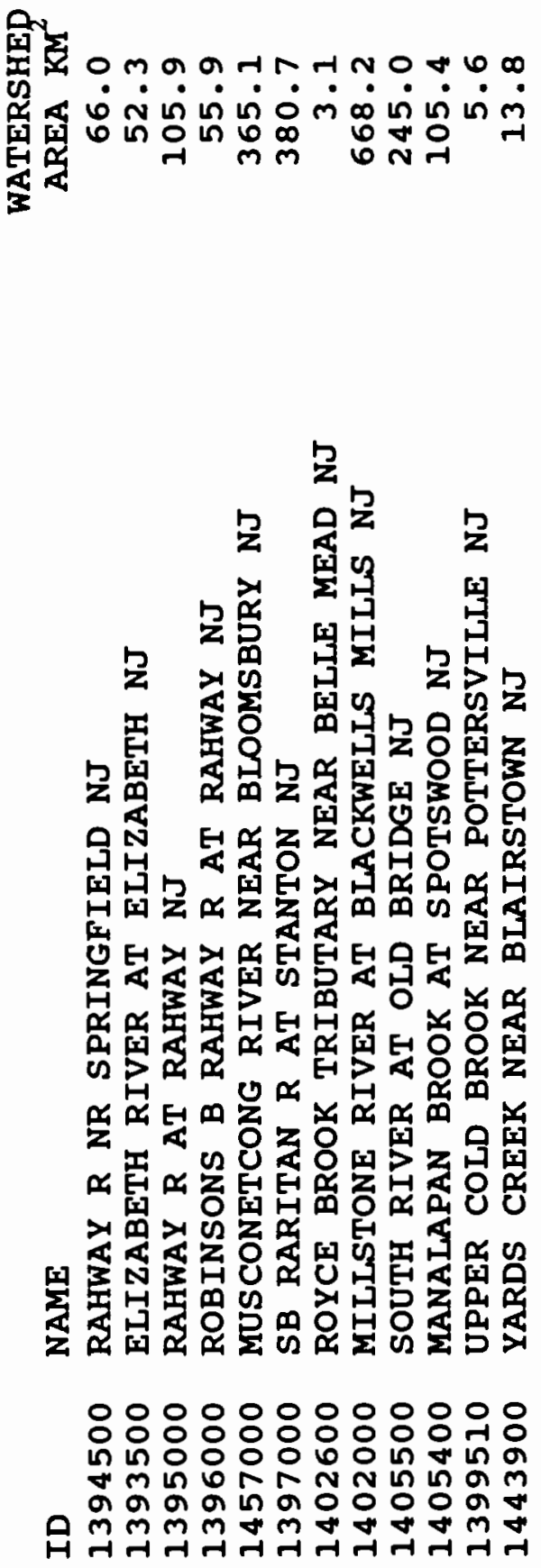
APPENDIX B

LONG-TERM AND WATER-YEAR 1984

NCDC PRECIPITATION STATIONS

IN THE NORTHEAST UNITED STATES 


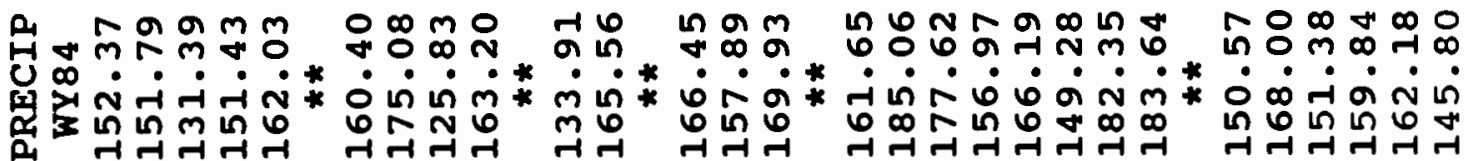

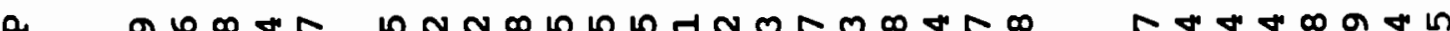
U

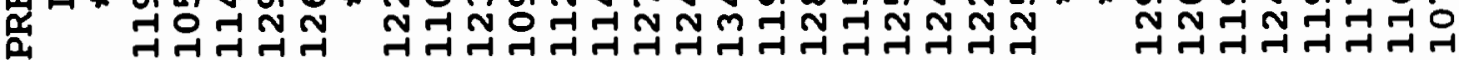

Z

H E[

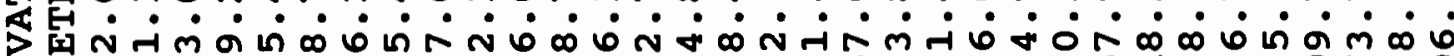

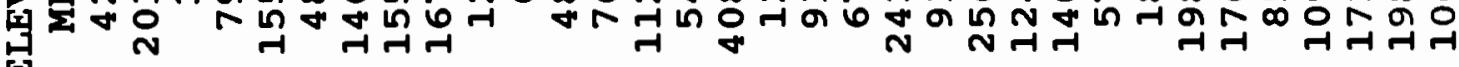
[-1]

H

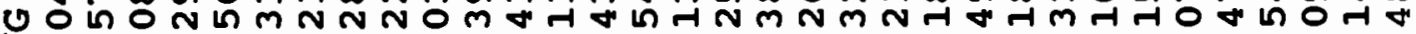
Z

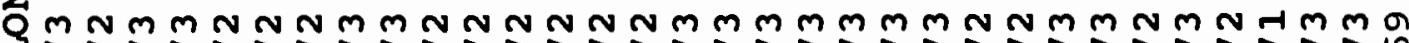

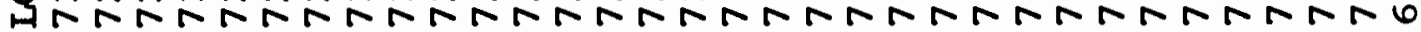

H

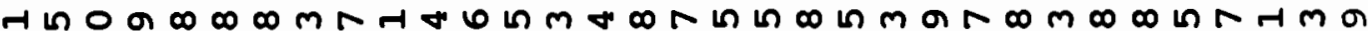
(1)

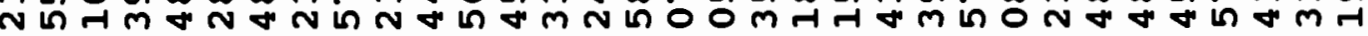

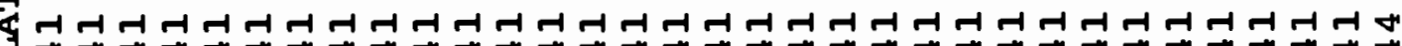

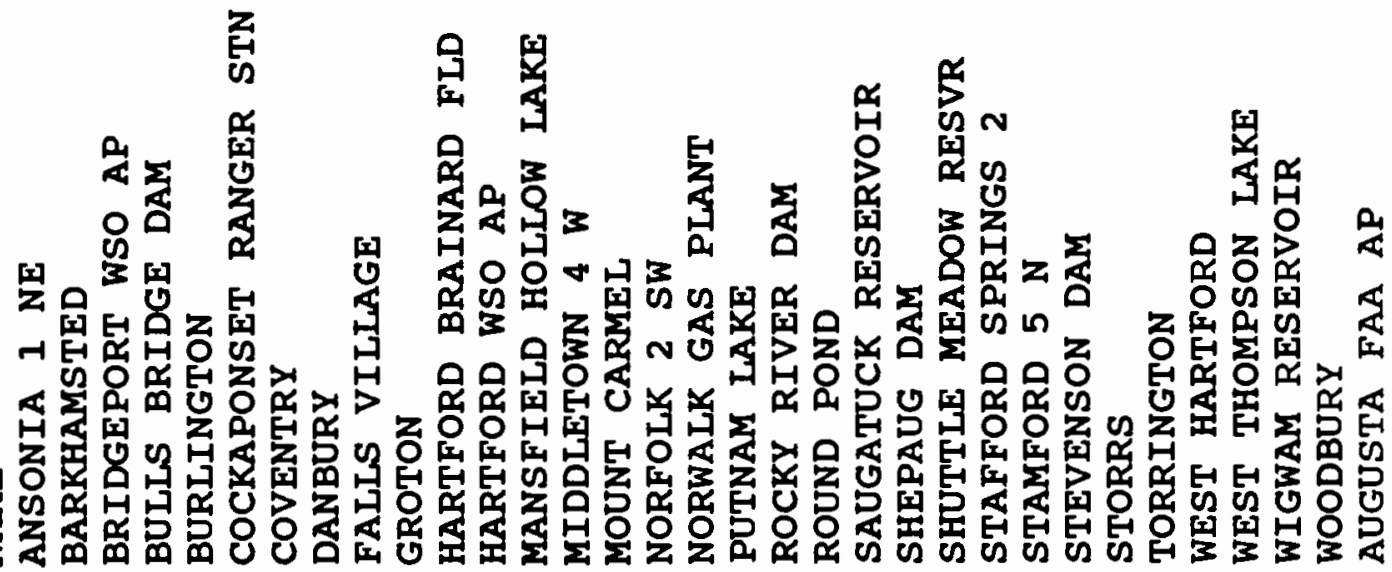

$\infty$ a

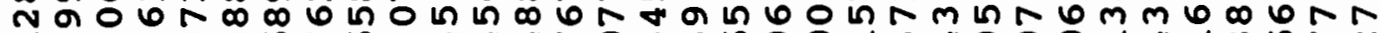

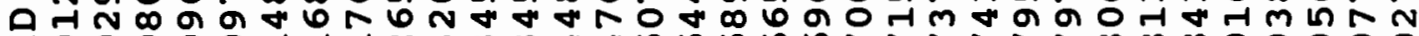

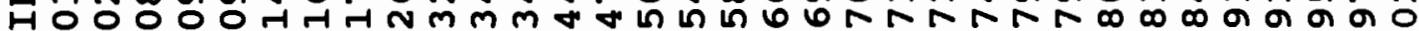

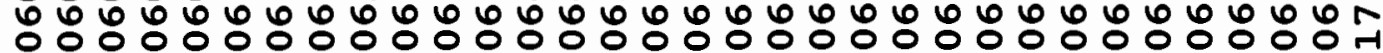




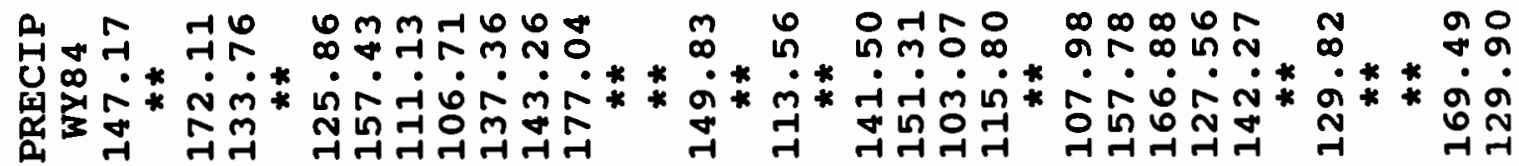

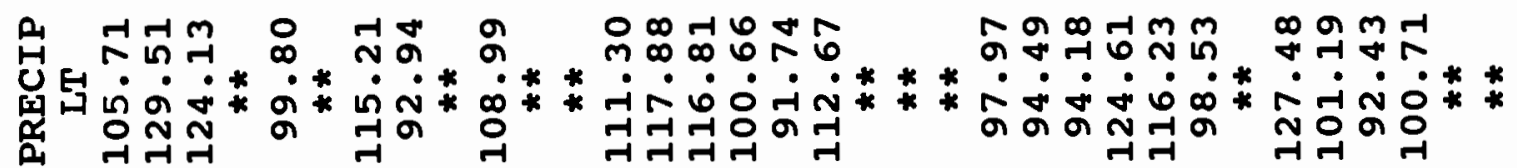

Z

H E

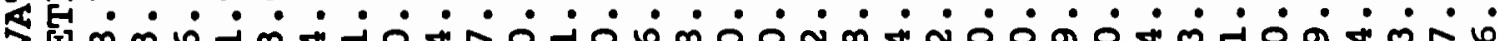

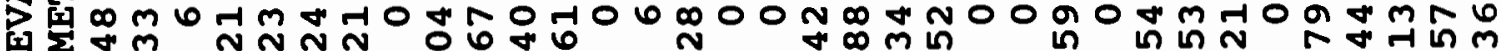
H

ब U Q

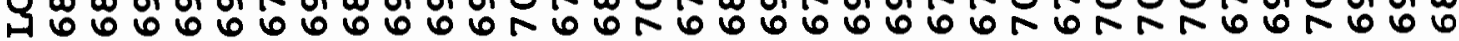

$\infty$ n E-1 * N NO

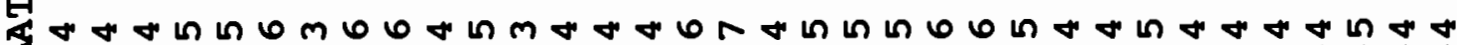

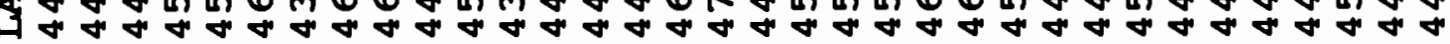

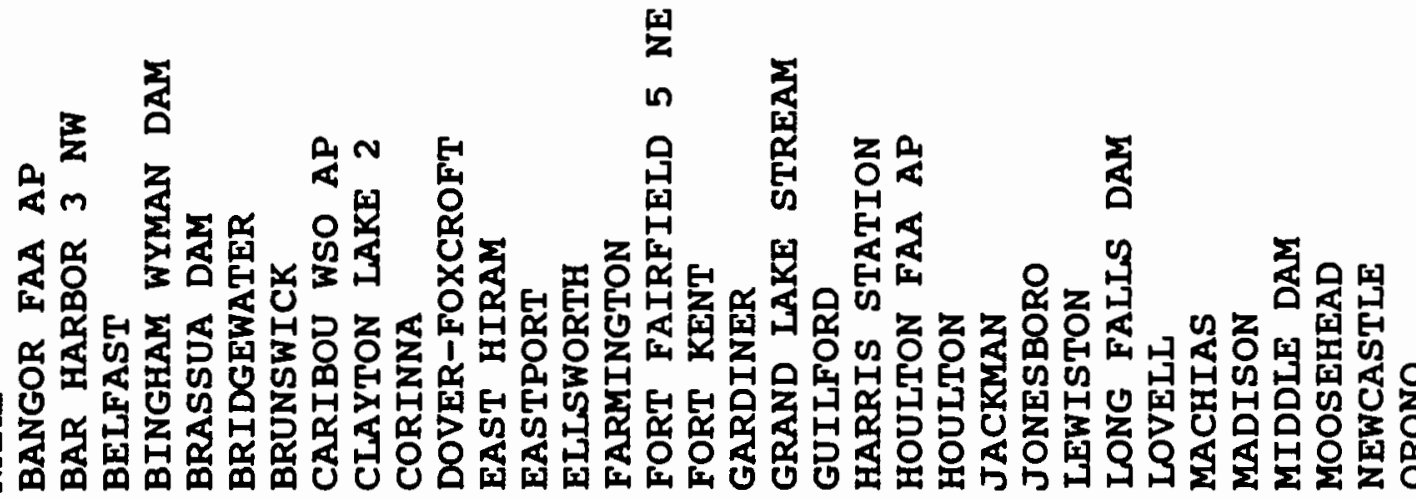

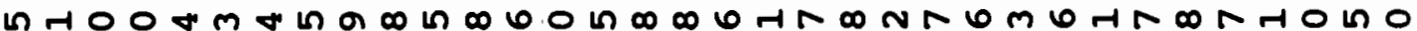

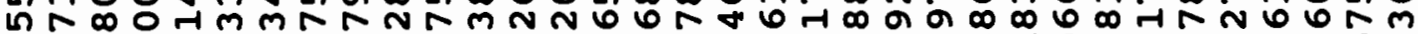

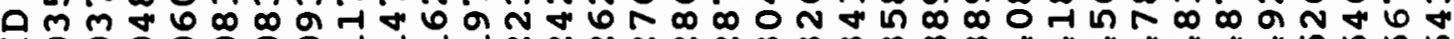

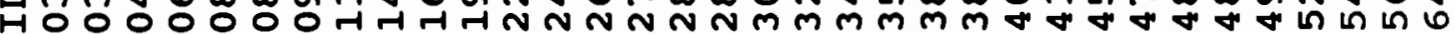

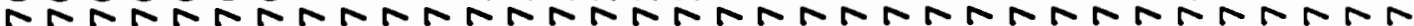

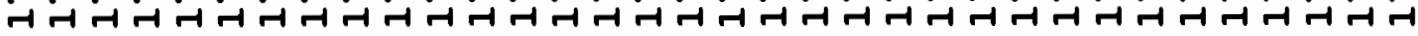




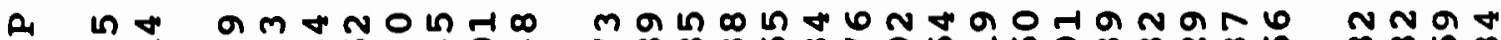
H ن

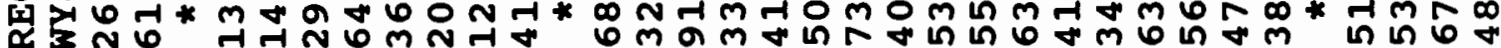

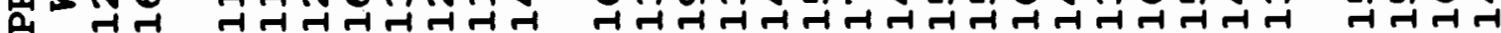

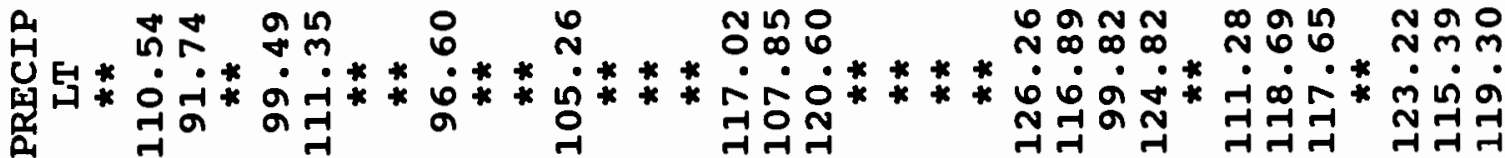

Z

H E[

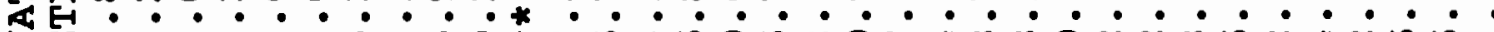
> [n

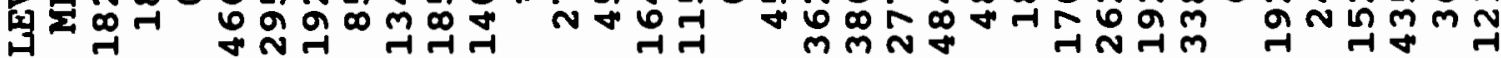
[1]

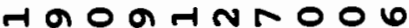
UN

an $N$ a z

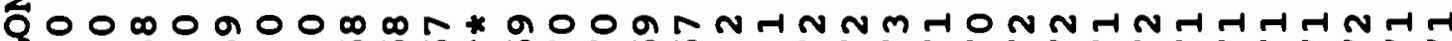
ar E-1

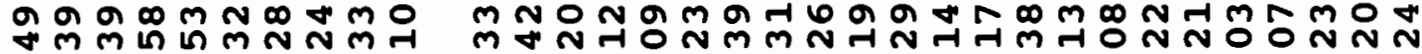
cam

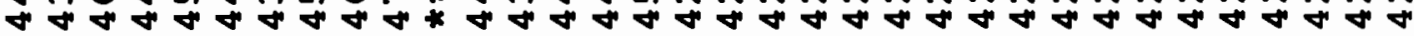

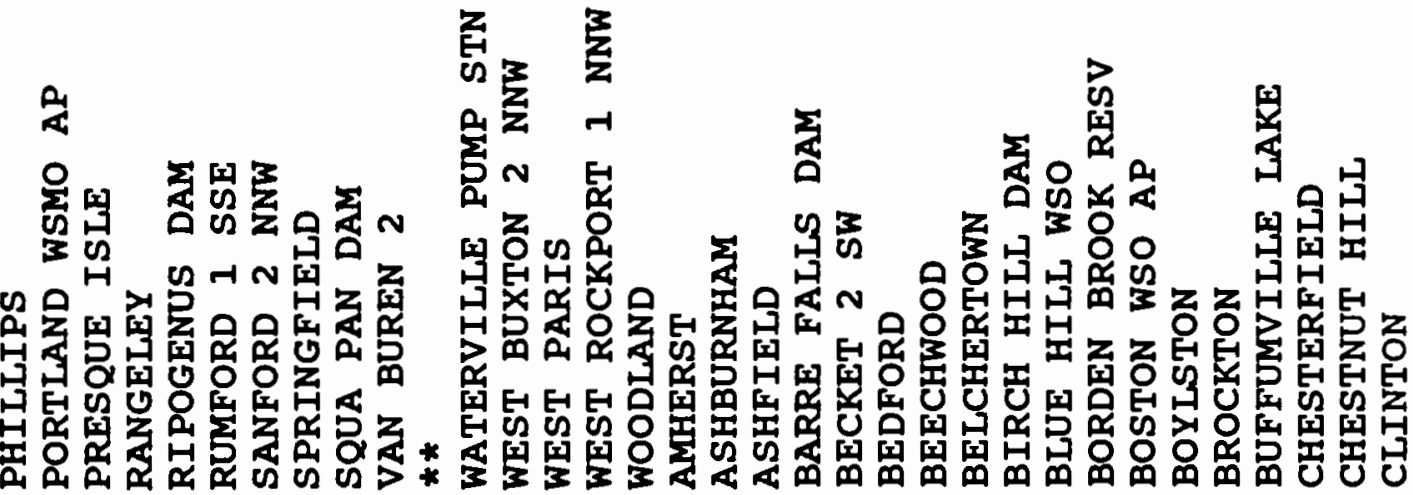

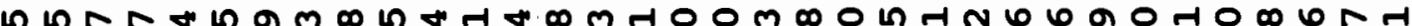

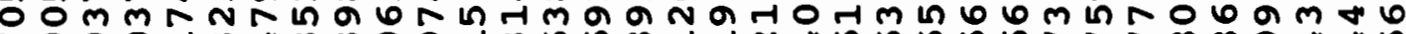
D H

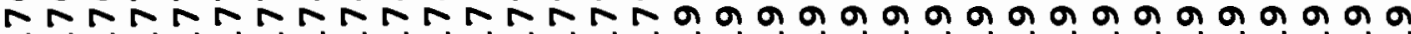

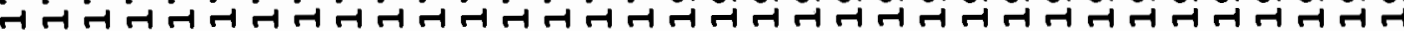




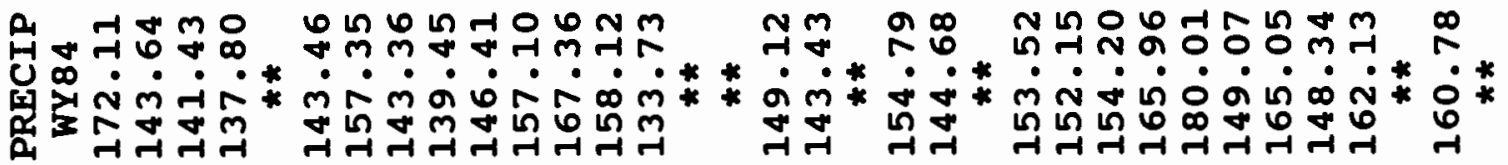

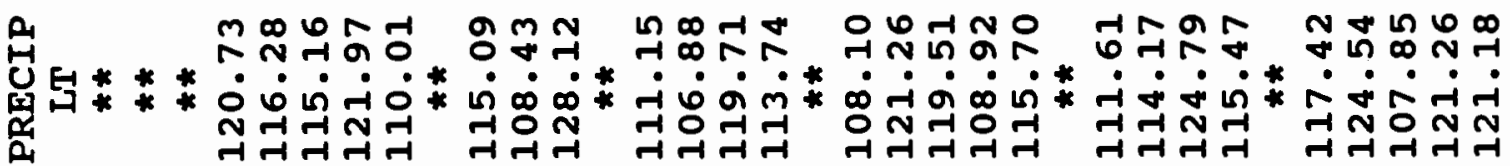

Z

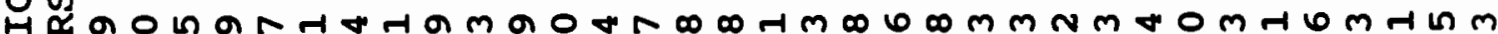

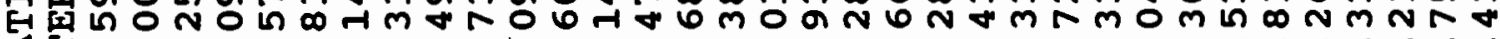

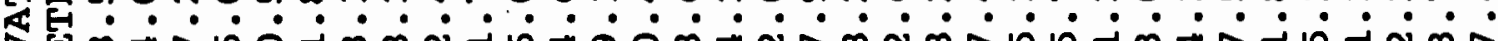
B

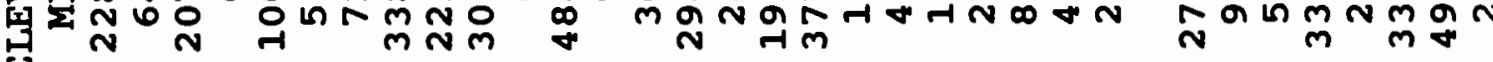

[aI

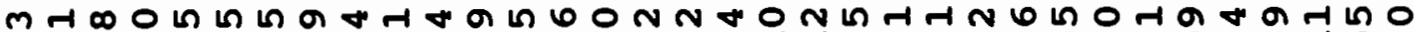
U

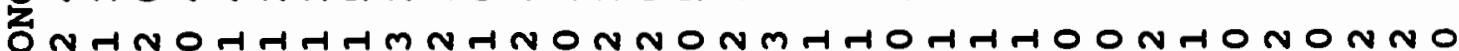

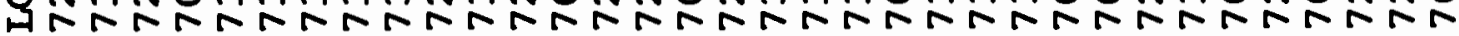

ton E

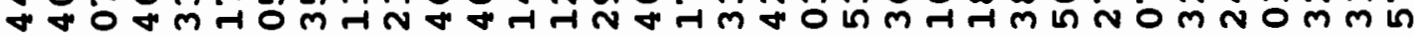

AN N N

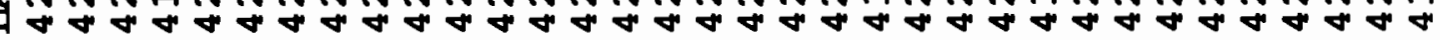

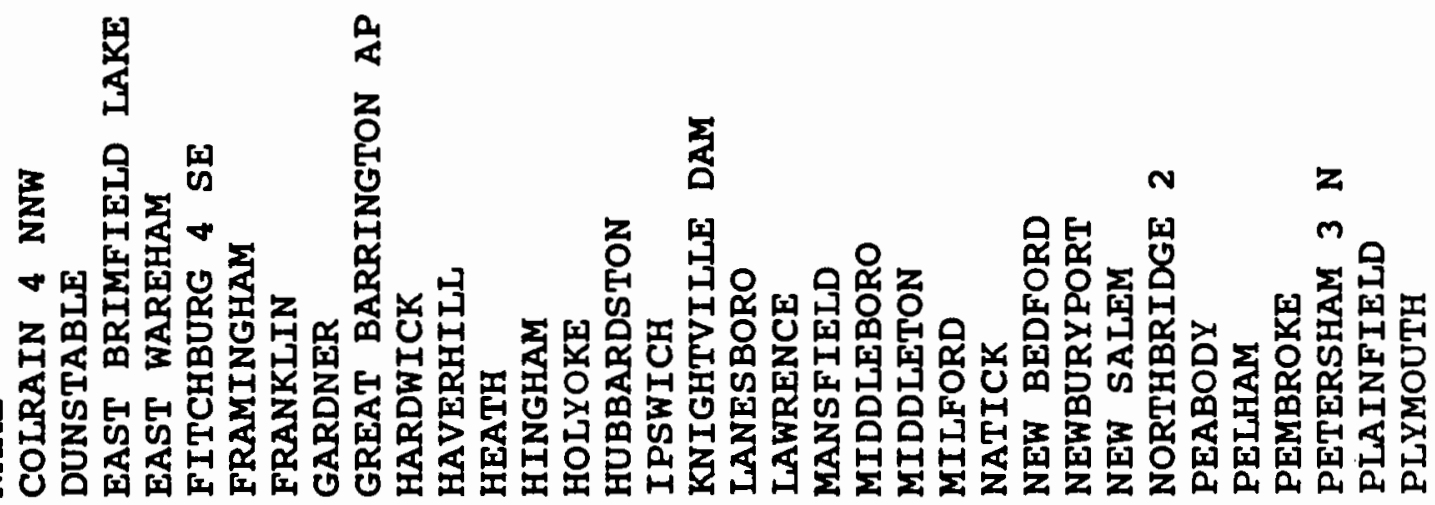

a 60 -

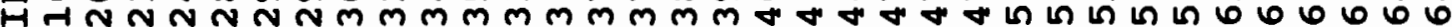

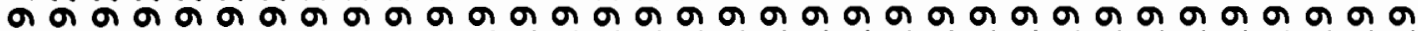

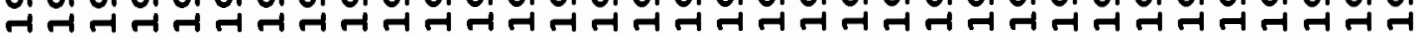




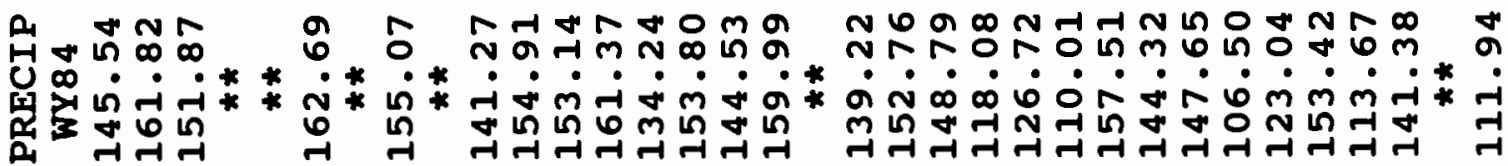

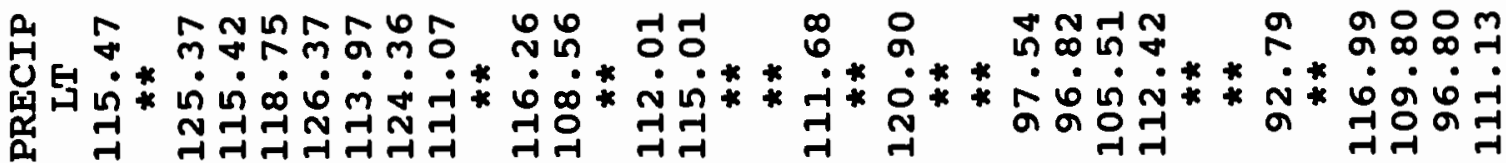

Z

Hamm $m$ m $m+0$ a E[ 4 E - : - : - :

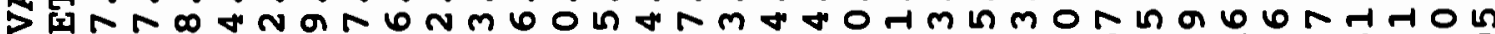
贸 [-1

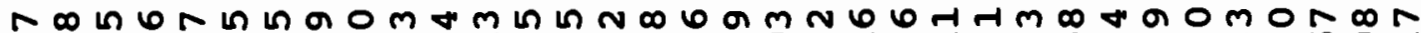
U $z$ d N

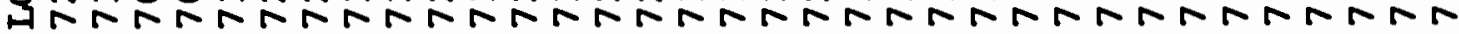
E-1

NANG Om Nm

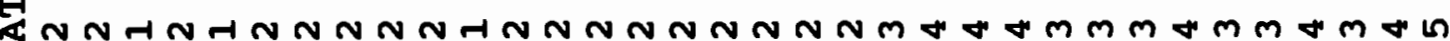

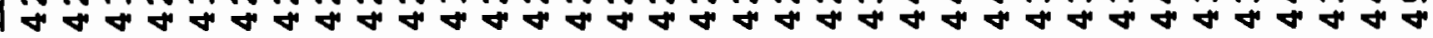

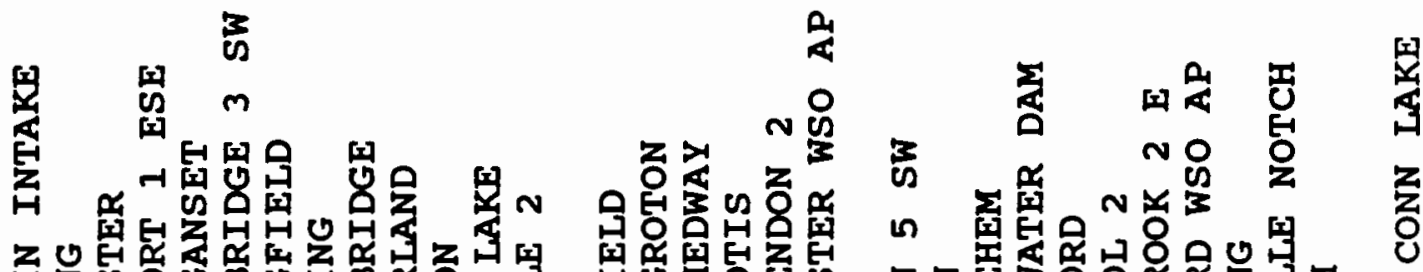

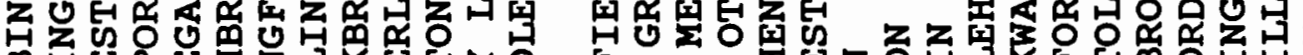

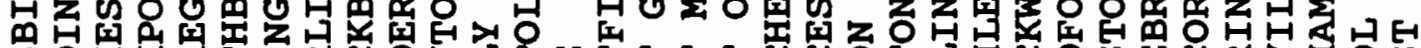

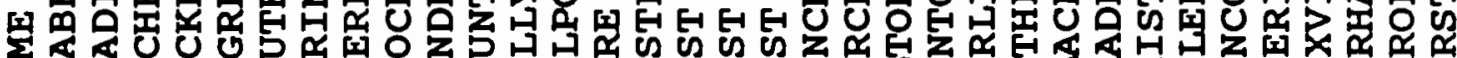

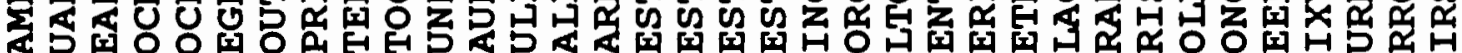

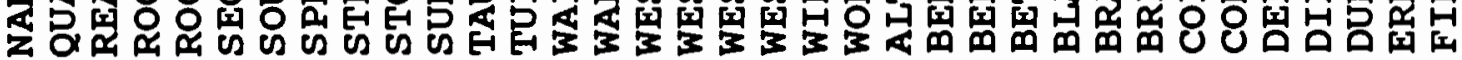

am $m$ NmN

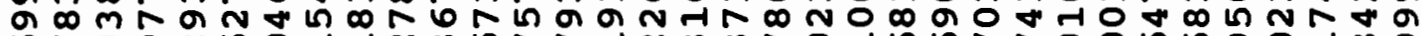

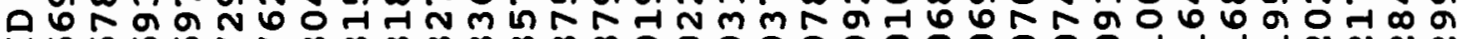
H 6 \% 6 \%

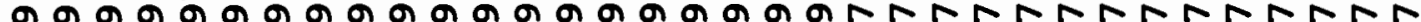

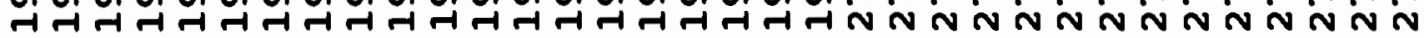




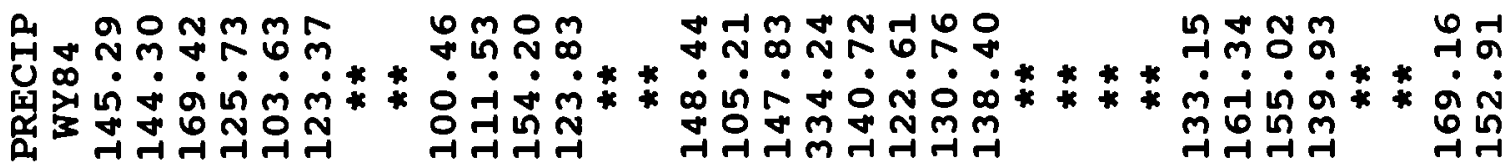

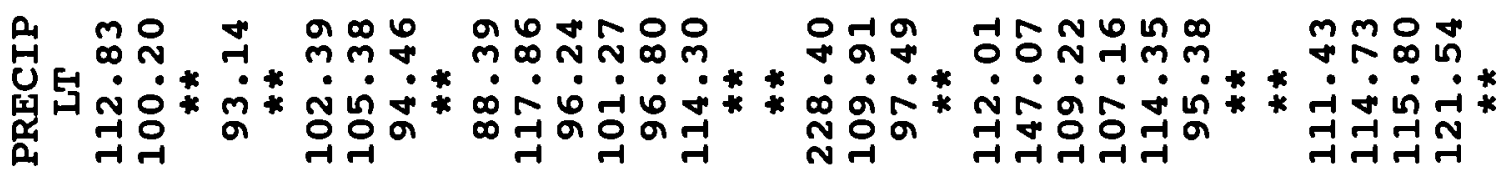

蛋

Ha n E[

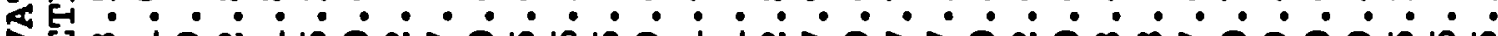
B Im $\mathrm{m}$ a N

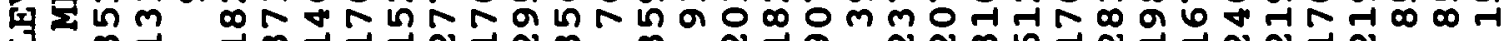
舀 $m$ H

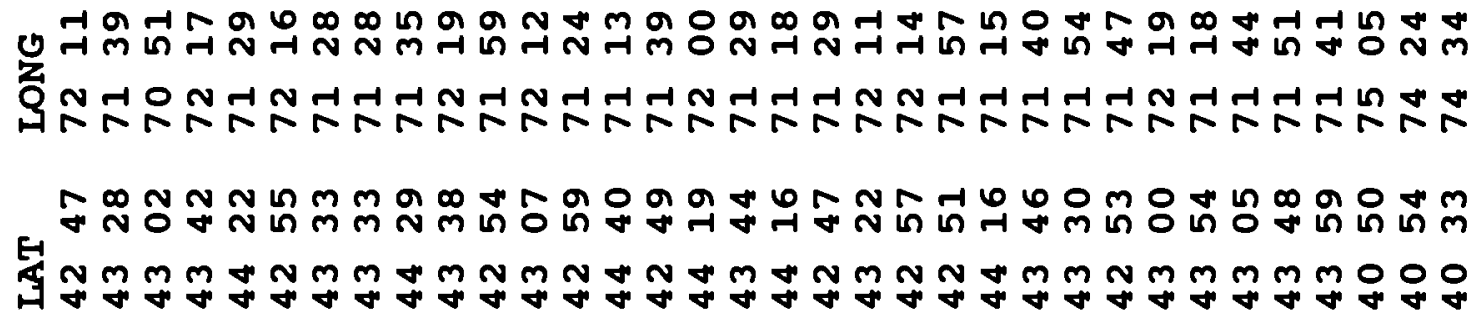

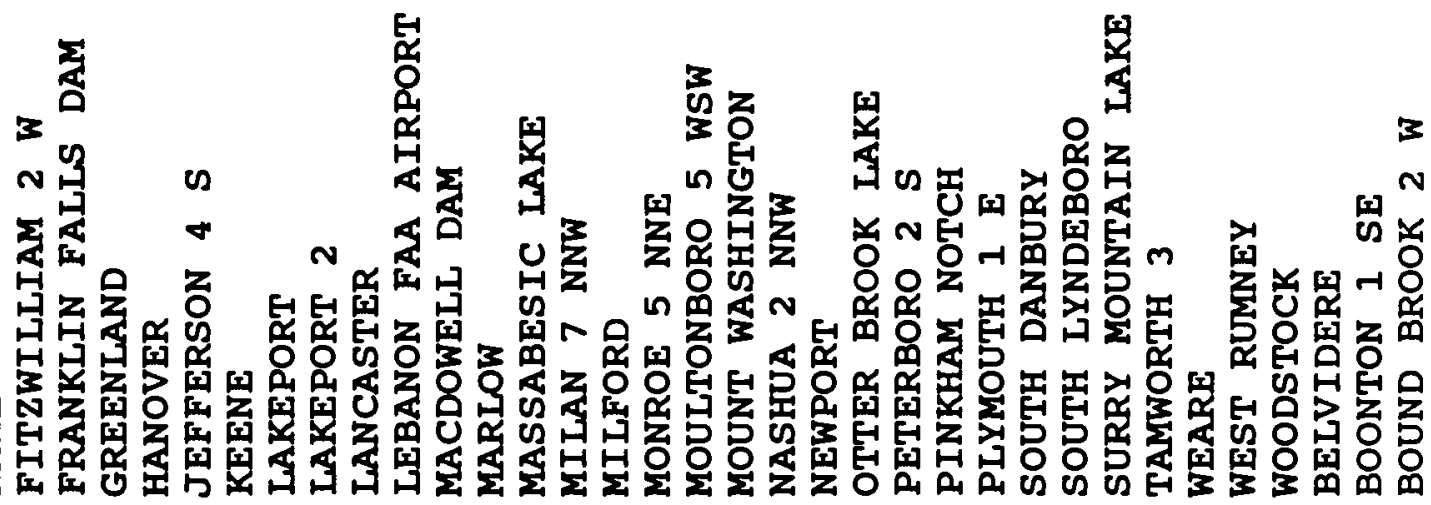

+ N

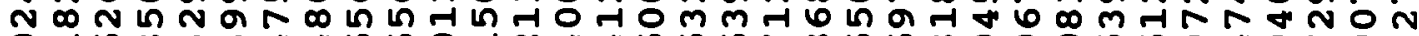

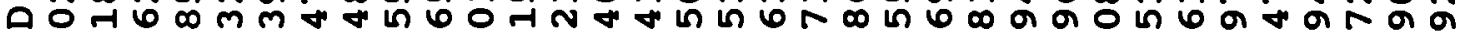

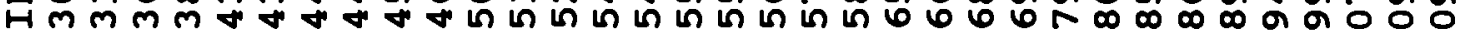

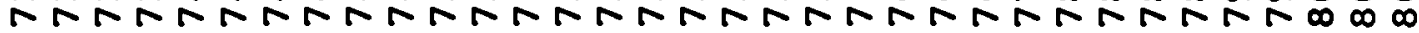
N N N N N N N N N N N U N N N N N N N N N N N N N 


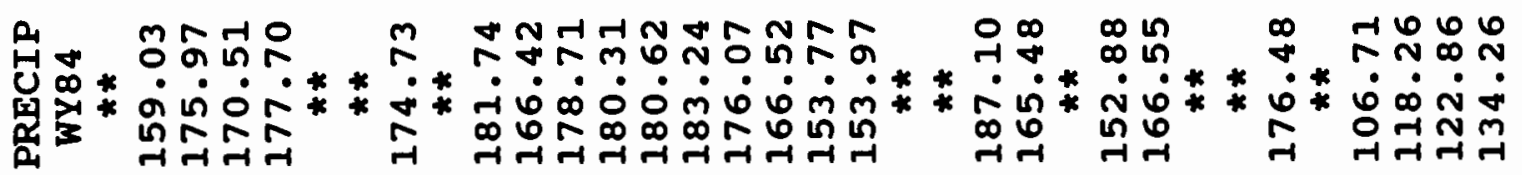

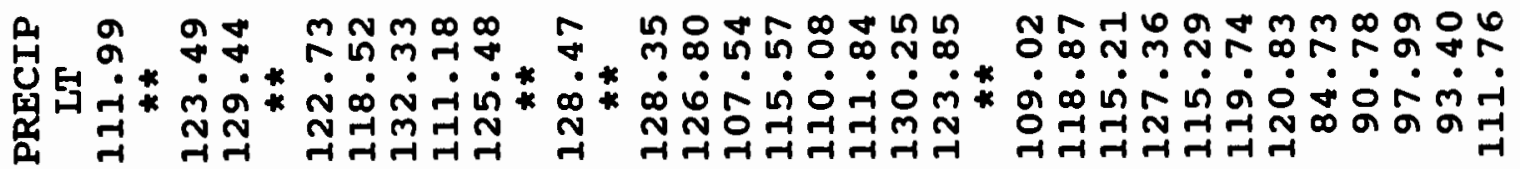

Z

H留 EM G $>$ I

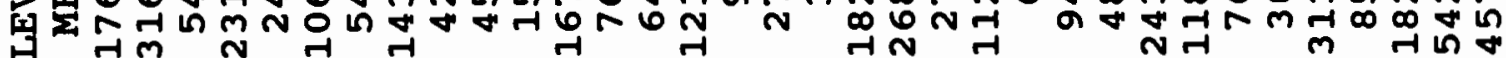
(r)

nO U $z$

S.

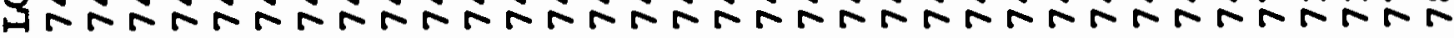

an $\mathrm{d}$ ( E.

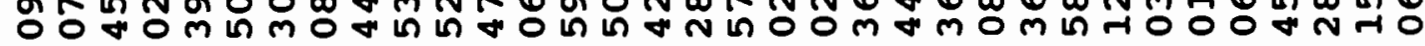

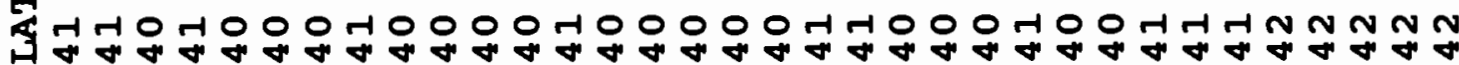

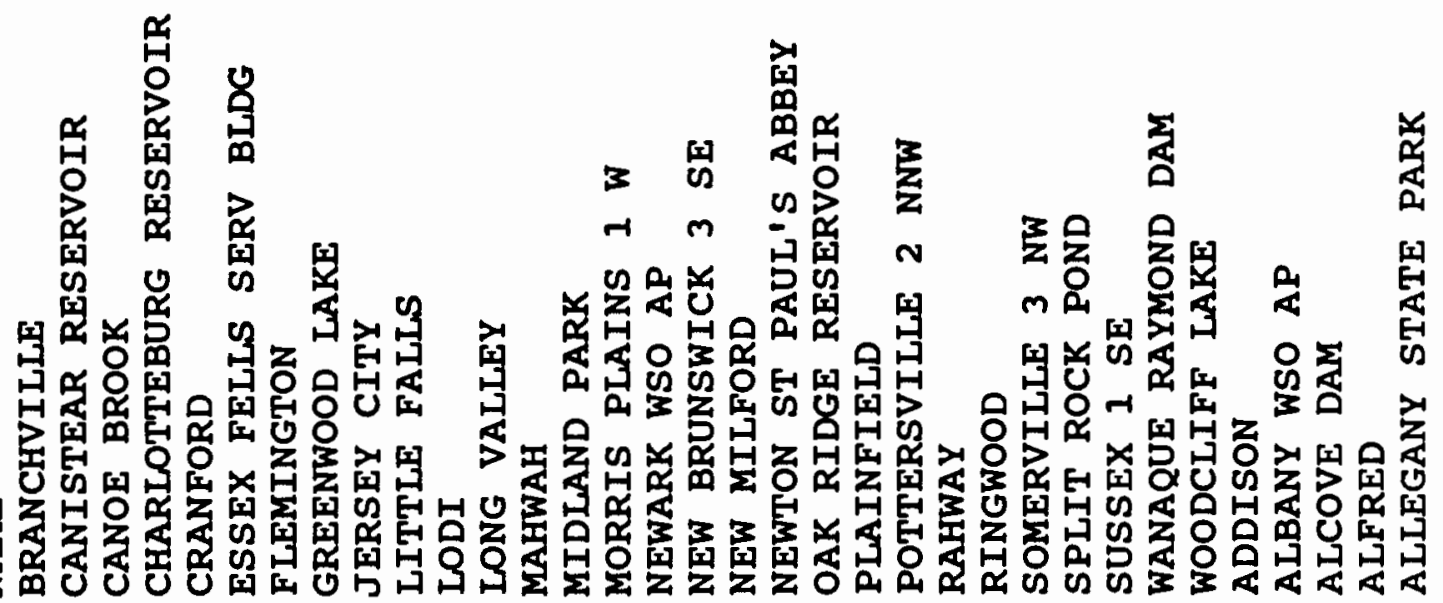

क

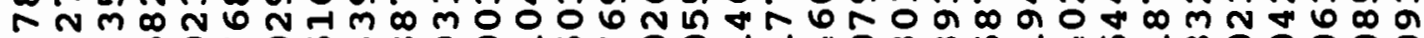
A HO

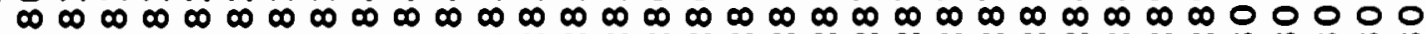
N N N N N N N N N N N N N N N N N N N N N N N m m m 


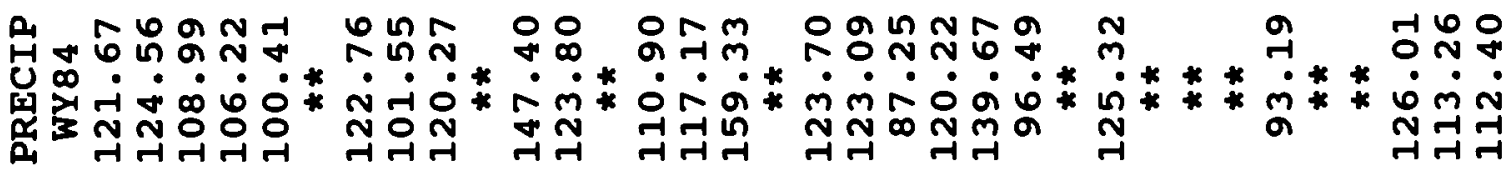

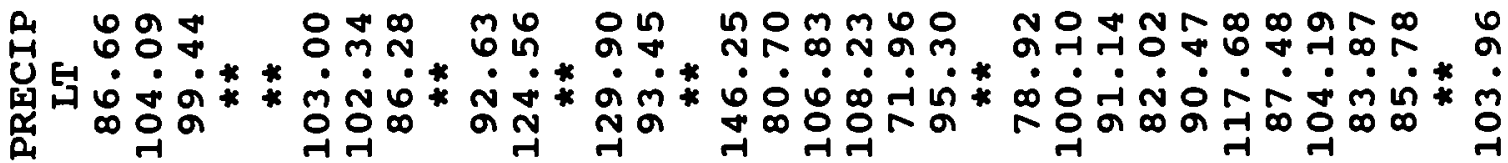

䒹约

茛a 00 D n

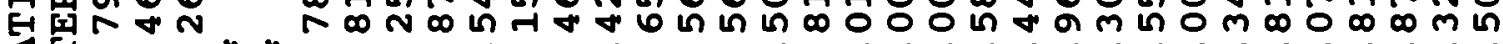

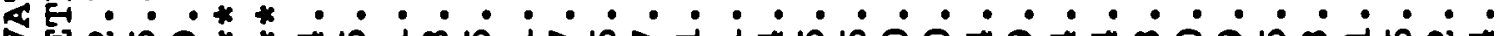

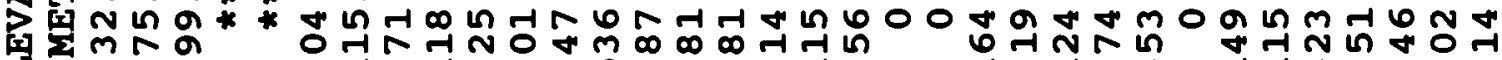

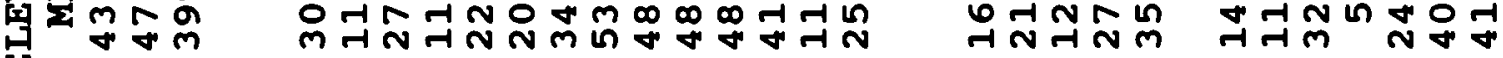
回

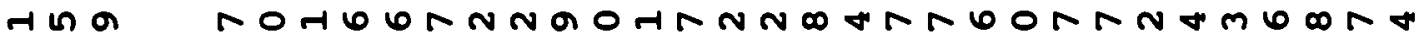

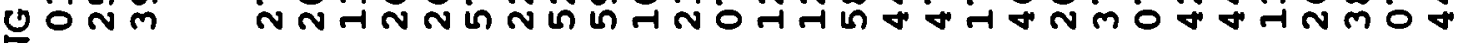

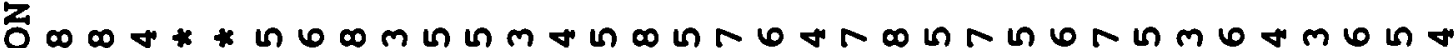
arkr.

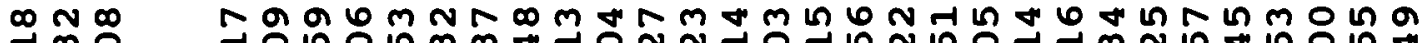
E

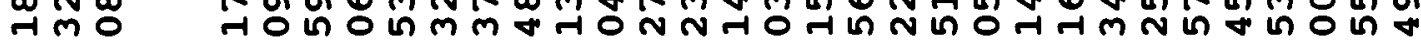

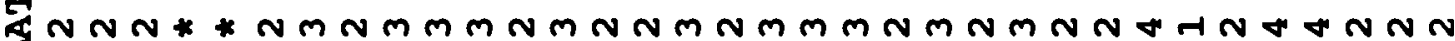

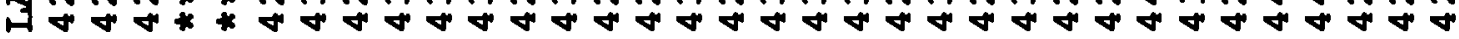

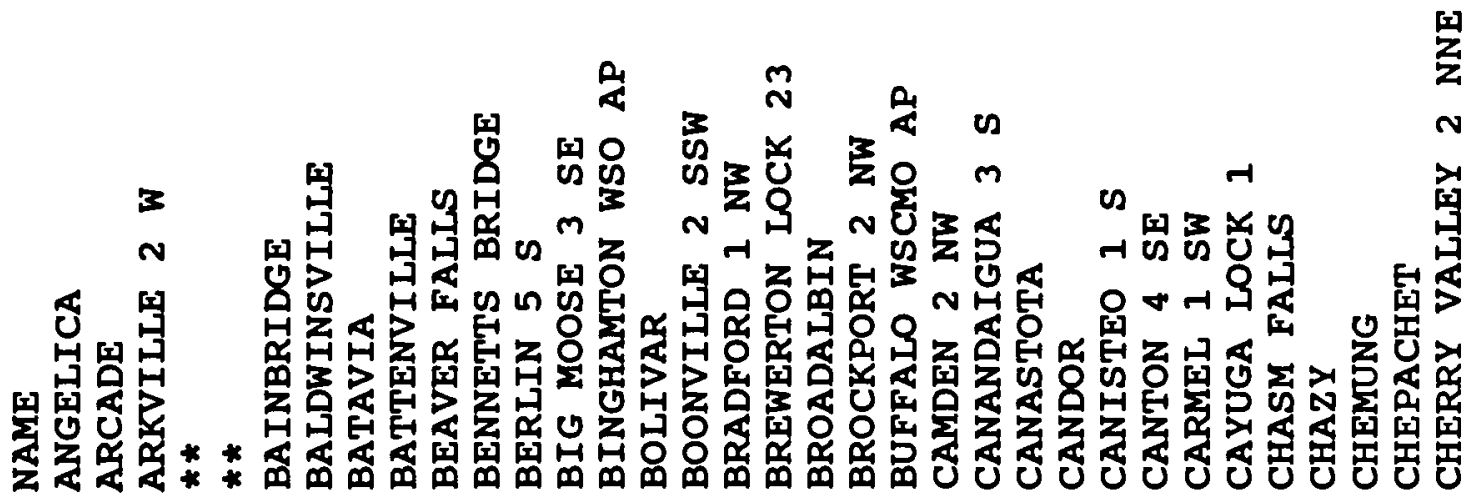

mo $\infty N$ n ด

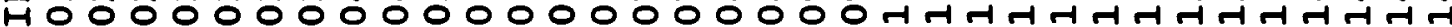

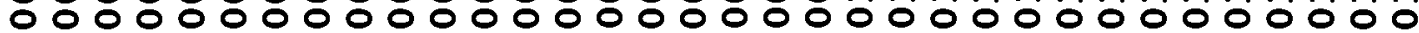
$m m m m m m m m m m m m m m m m m m m m m m m m m m m m m m m m m$ 


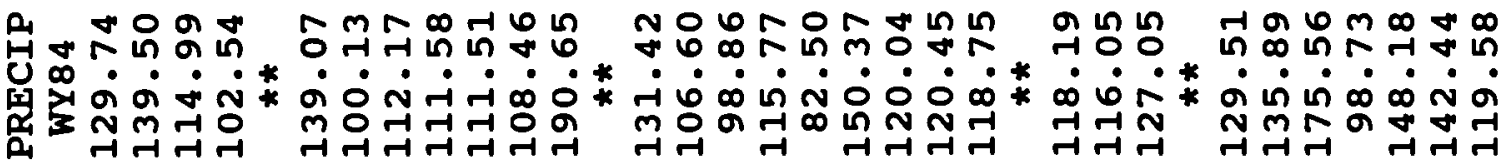

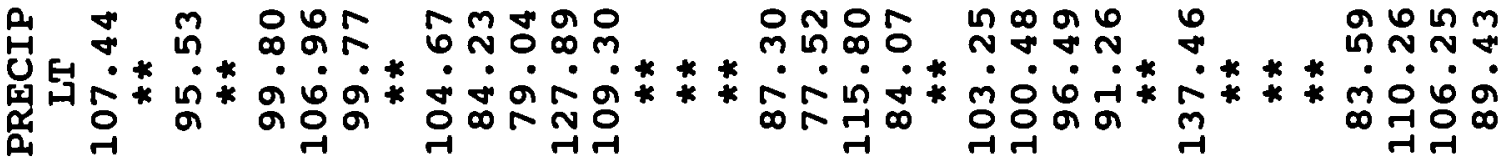

苗

H

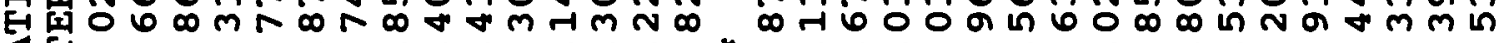
4

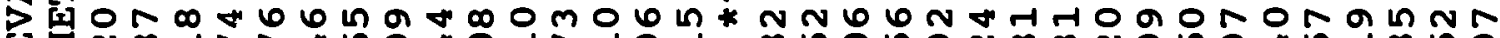

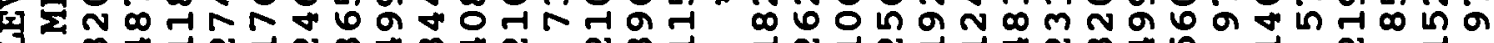
(a)

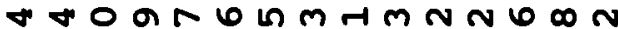

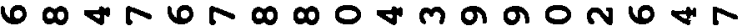
U 之

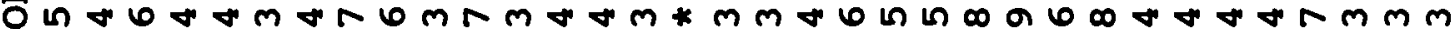

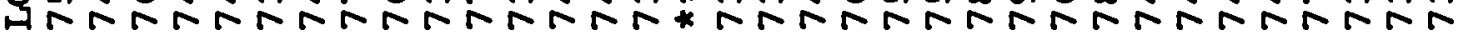

N n\$ El

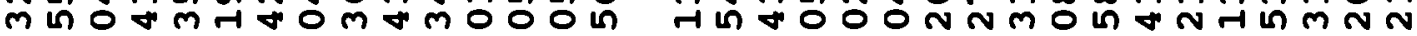

द

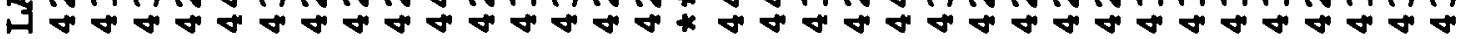

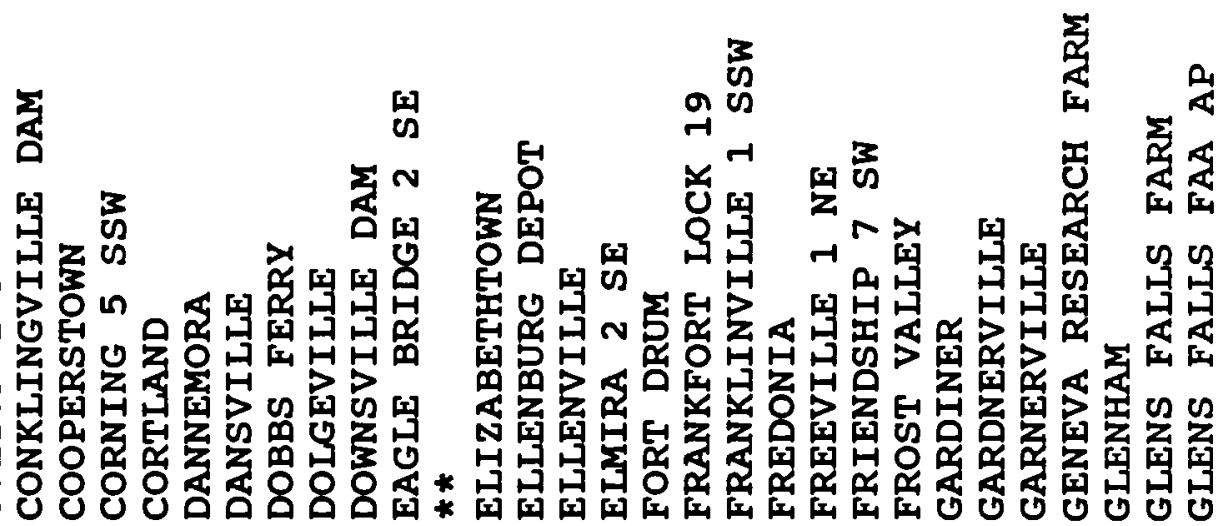

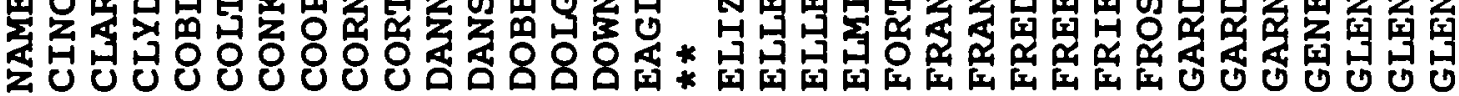

N

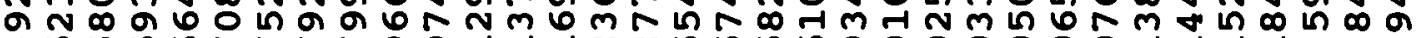
Q

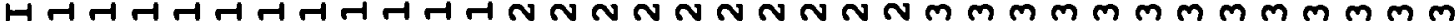
0000000000000000000000000000000000 $m m m m m m m m m m m m m m m m m m m m m m m m m m m m m m m m m m$ 


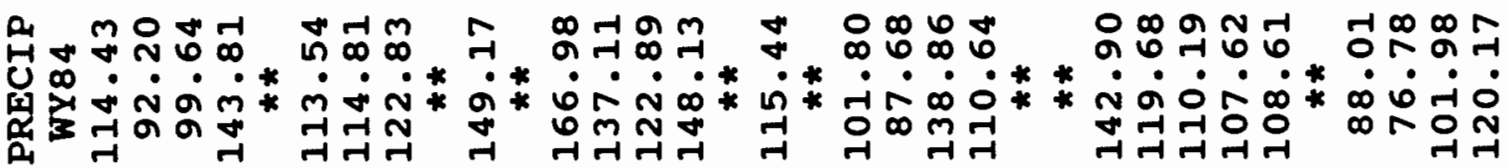

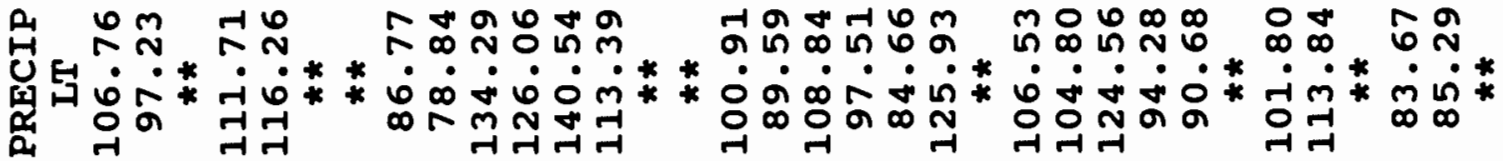

$\overbrace{0}^{Z}$

Hák E[x

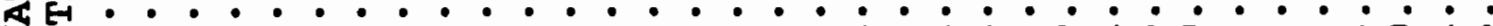
P

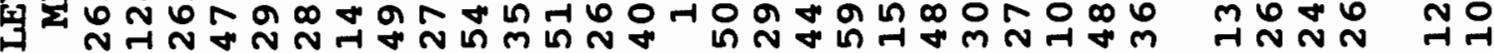
[x]

O

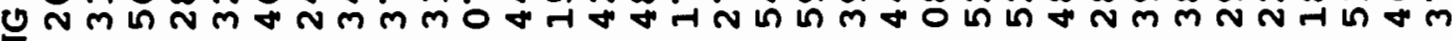

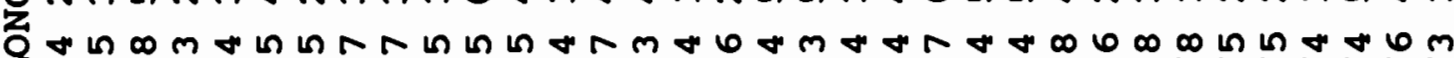

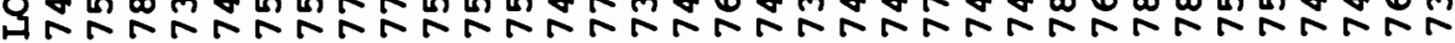
E.

m

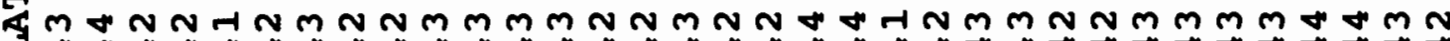

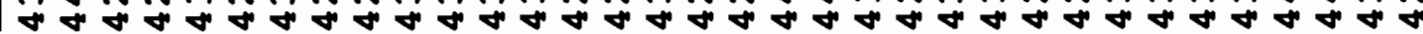

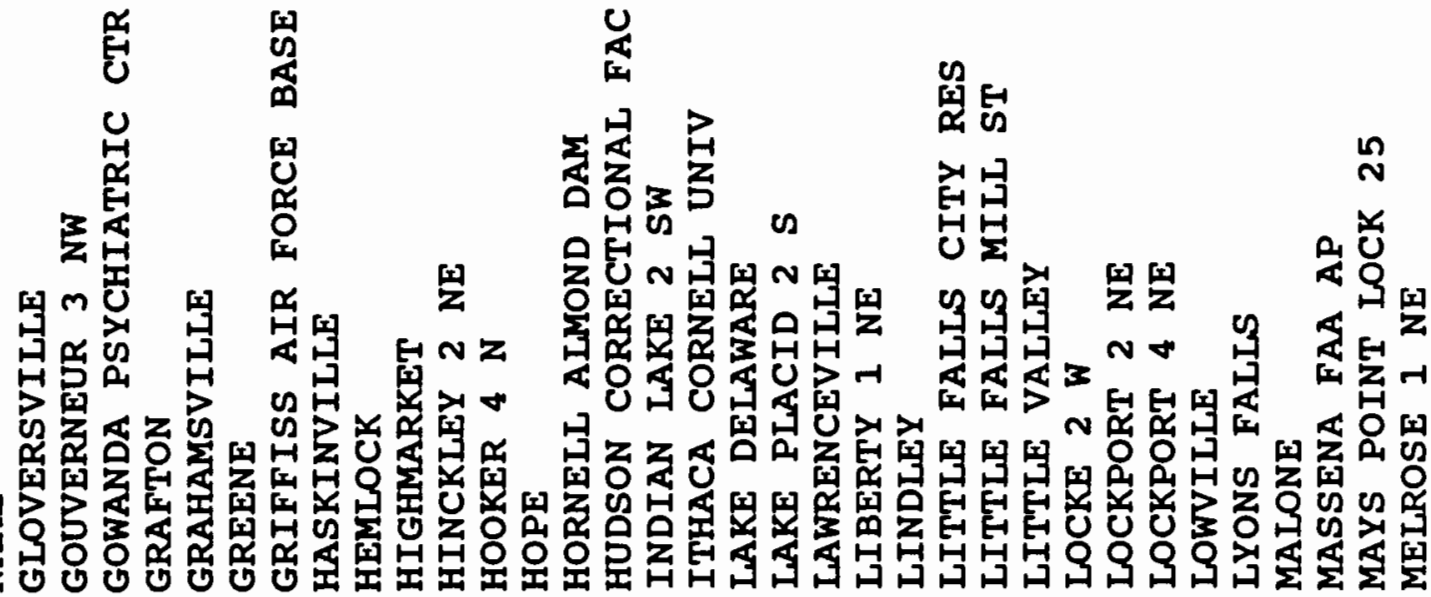

ब H

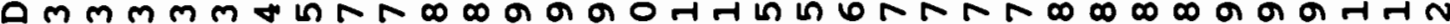
Hmmmm m m m m m m mm m

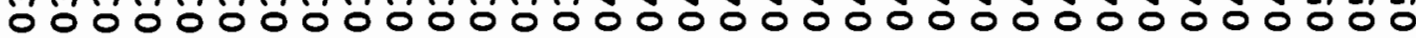

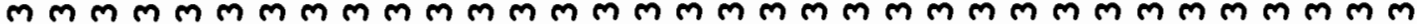




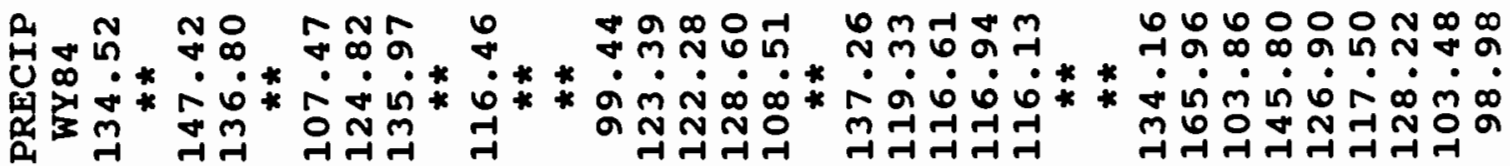

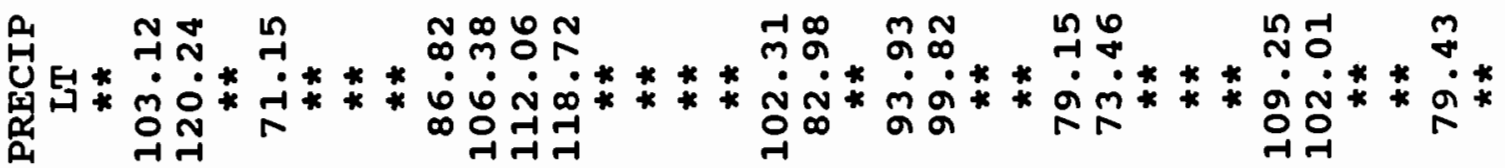

Z゙

H

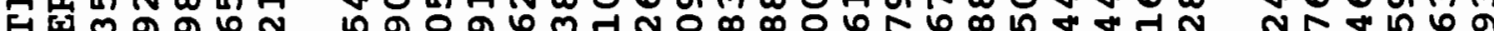
E! $\rightarrow$ स 四 (n)

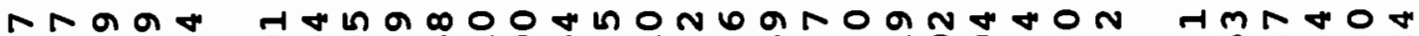

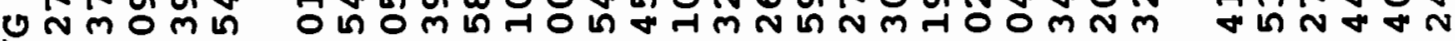
Z⿱一兀㇒m

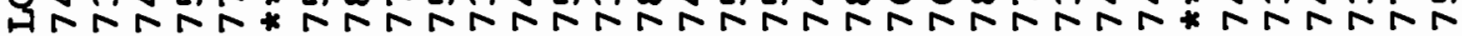

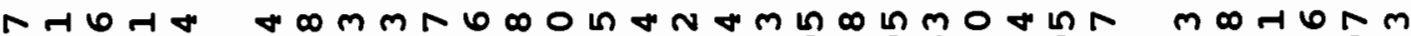

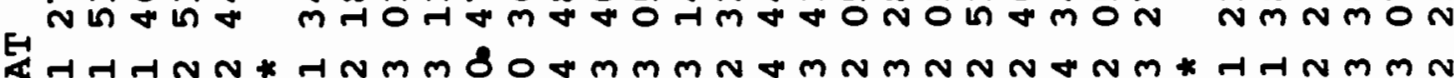
E-

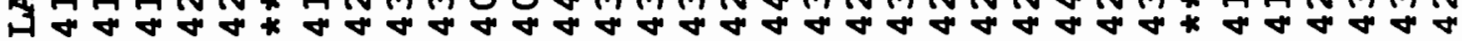

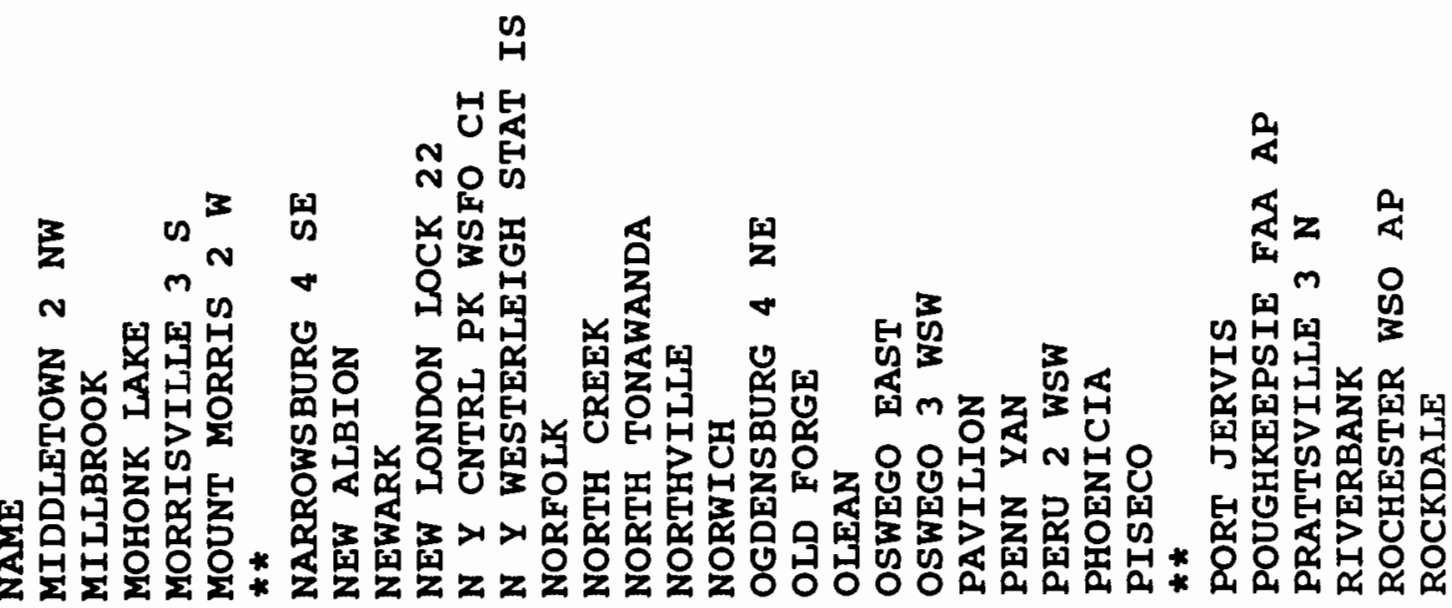

O

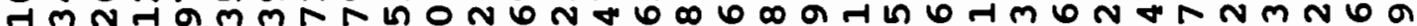

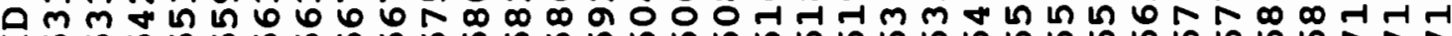

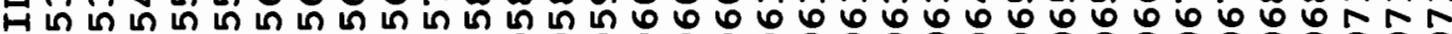

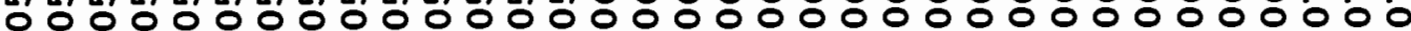

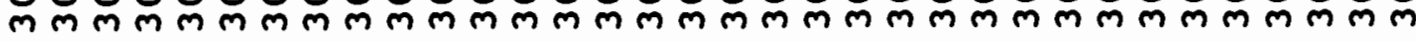




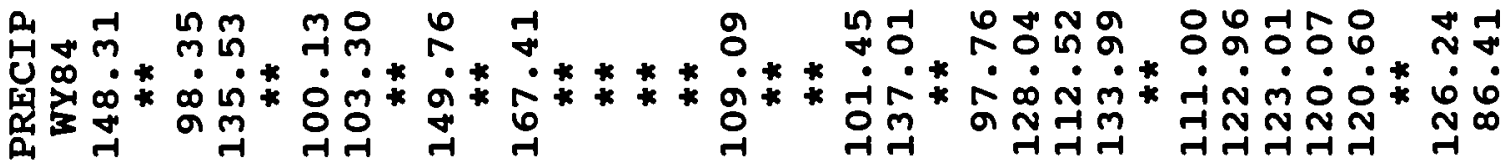

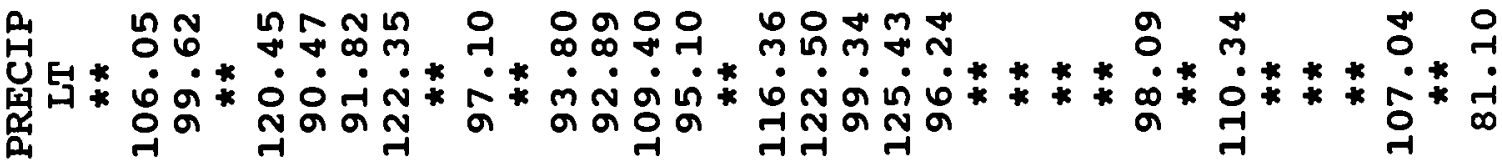

乙е

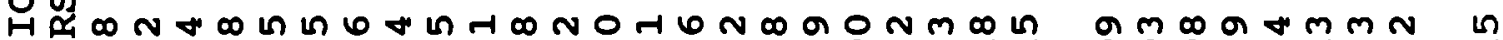

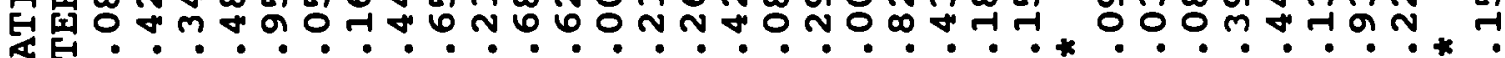
«

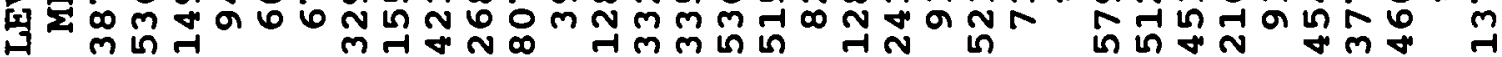
[x]

No a a

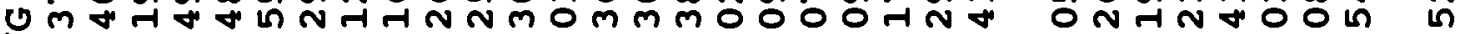
Z

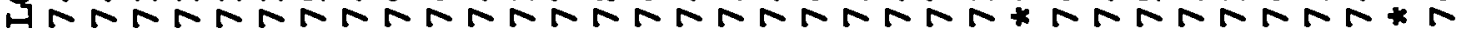

แ E.

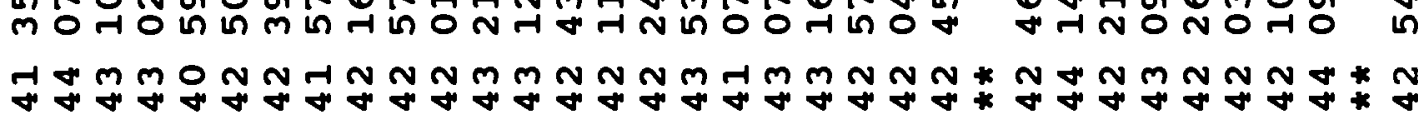

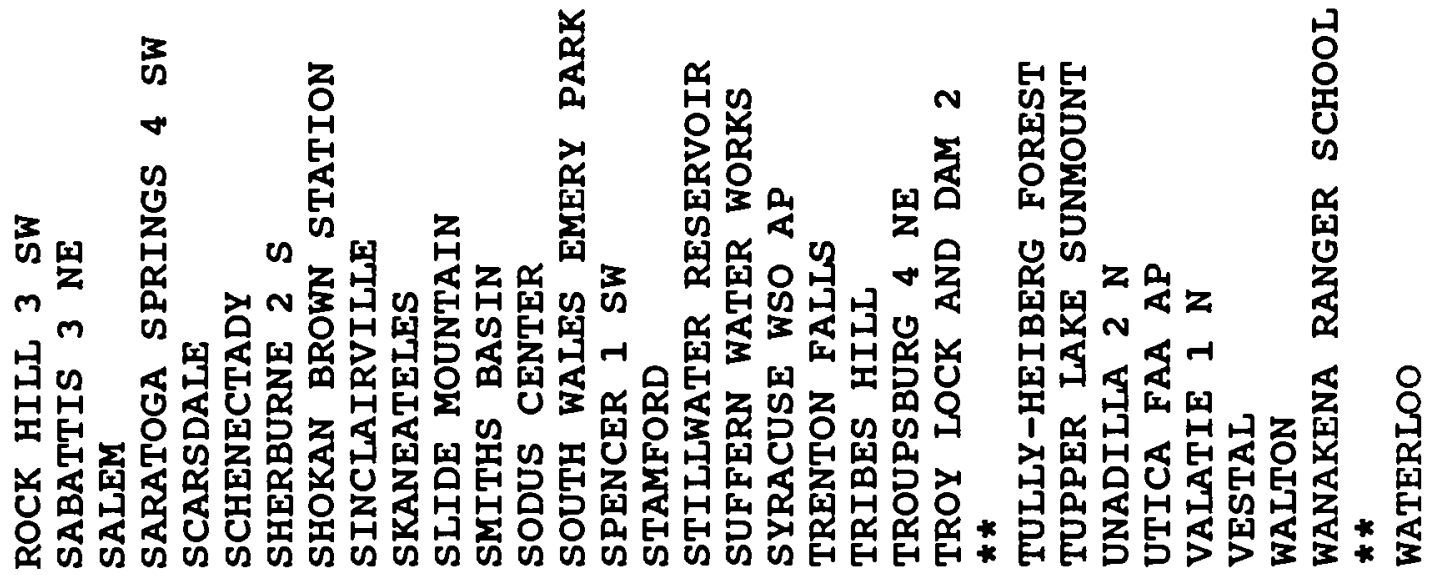

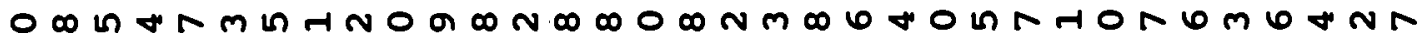

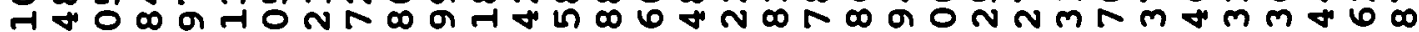

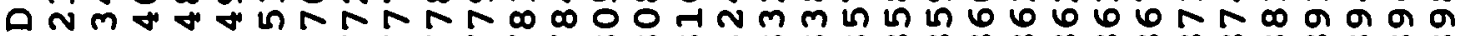
HNANRNRNRNRNRN

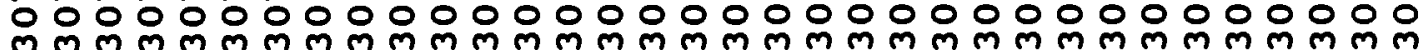




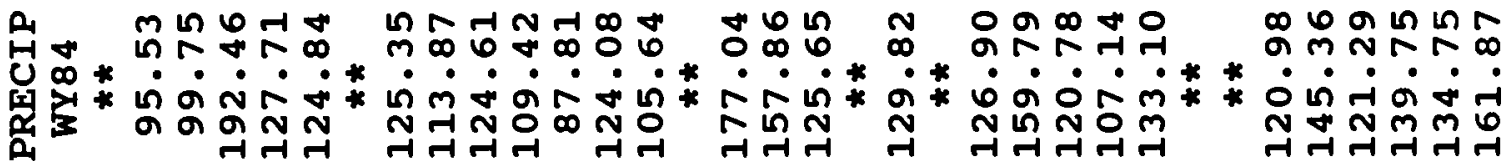

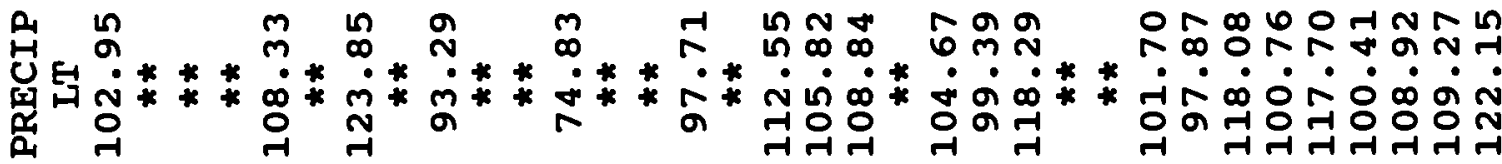

Z es

Ha

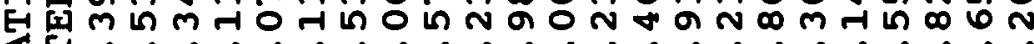

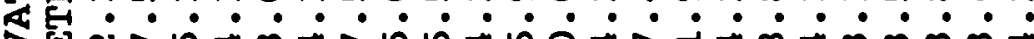
四

NOA

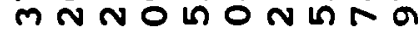
$\therefore \dot{0} \cdot \dot{0} \dot{0} \cdot \dot{0}$

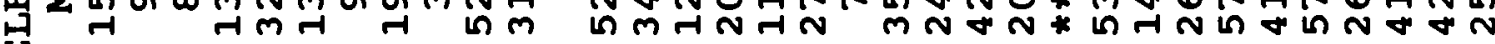
[-1]

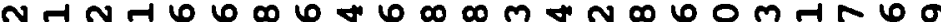
U

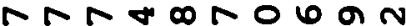
Q⿱艹

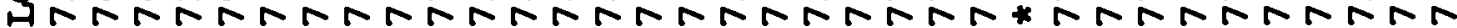

mom E

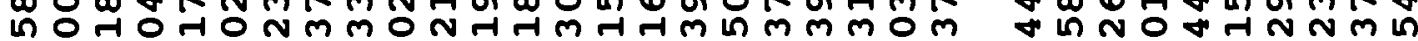

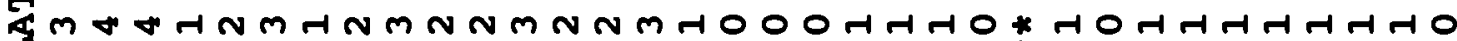

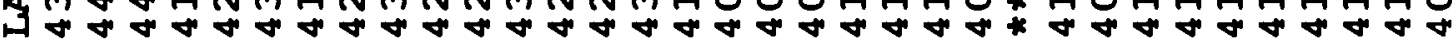

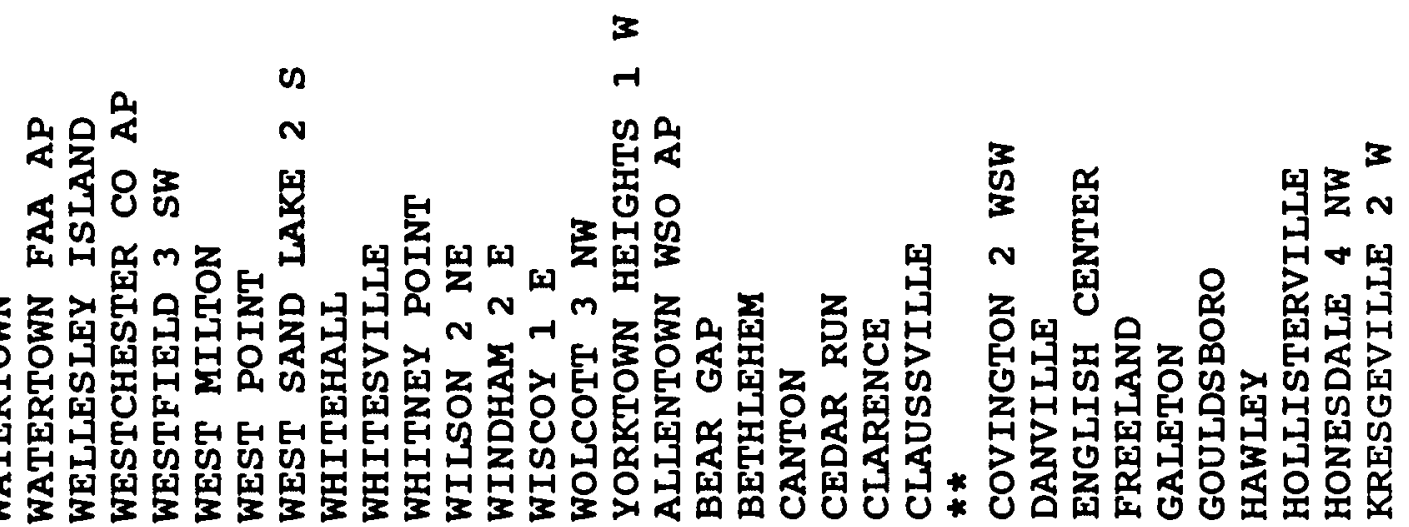

응

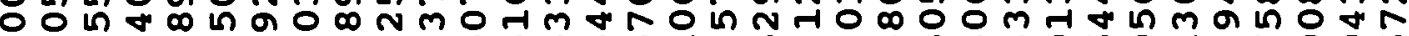

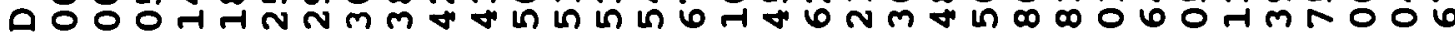

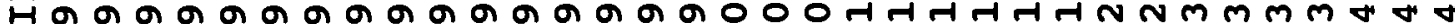

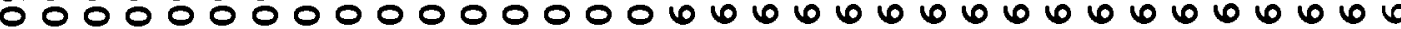

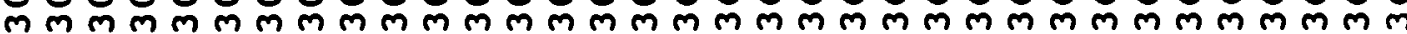




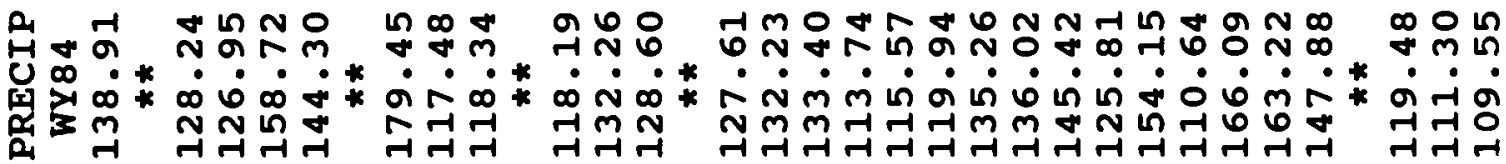

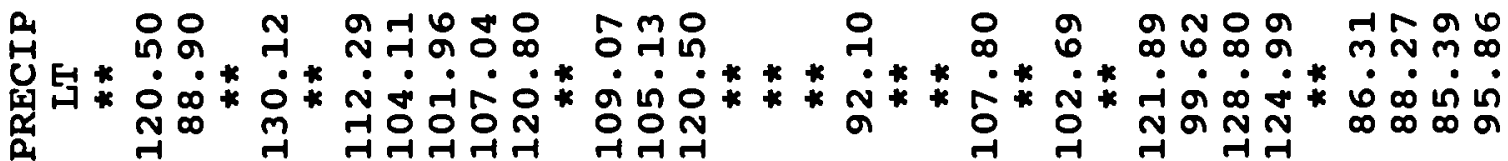

2

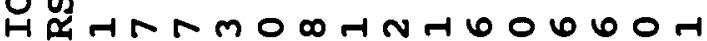

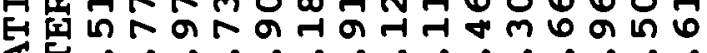

4 :

$>$ \{

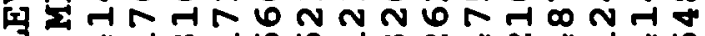

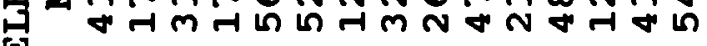

○

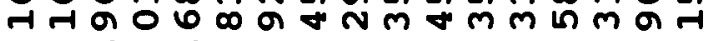
$\cdot \cdot \cdot \cdot \cdot \cdot \cdot \cdot \cdot \cdot \cdot \cdot \cdot \cdot \cdot \cdot \cdot \cdot$ 1 0 in

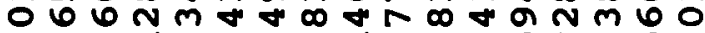

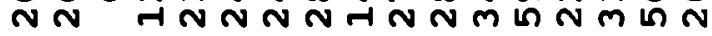

$m m m R 0 \infty N a+n+\infty$

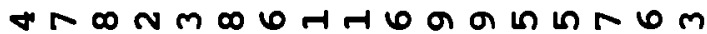

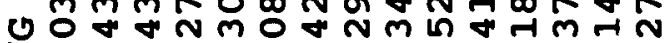

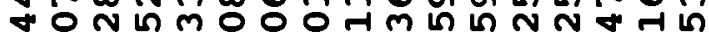

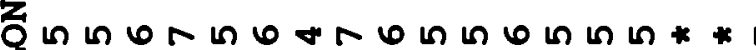

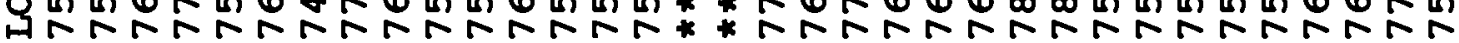
m E

ONO 幽

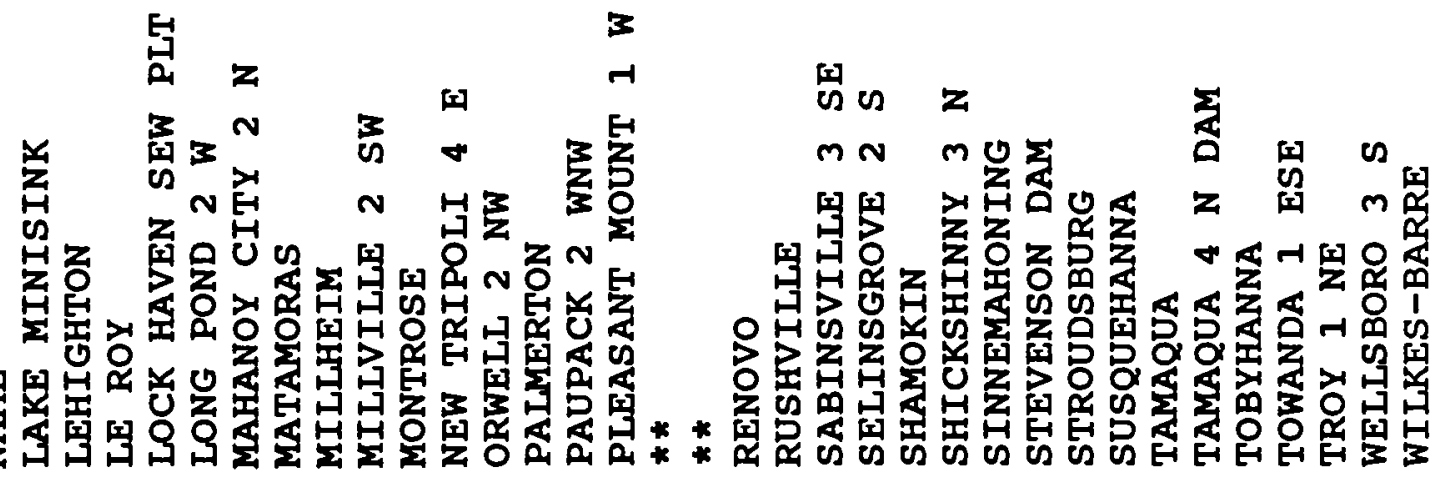

N + N NmNOW Q

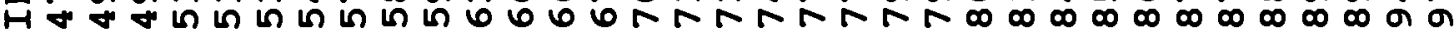

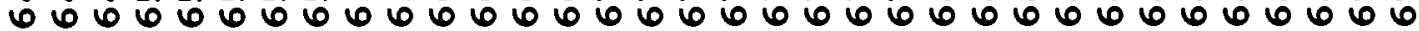
$m m m m m m m m m m m m m m m m m m m m m m m m m m m m m m m m m m$ 
P. N⿴囗十

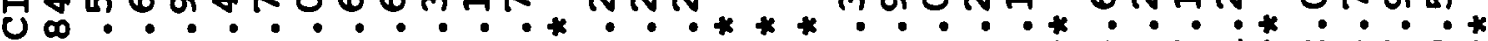
G

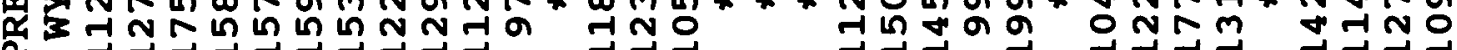

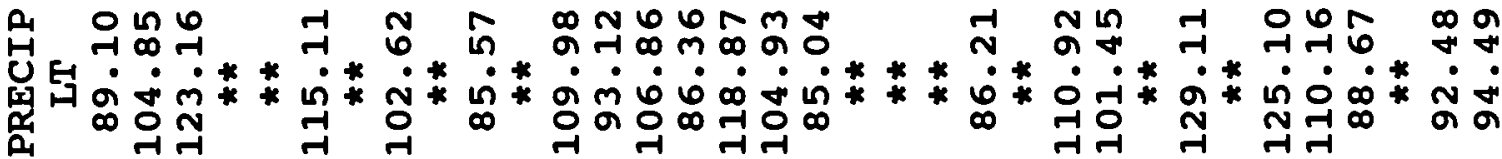

2

H E以

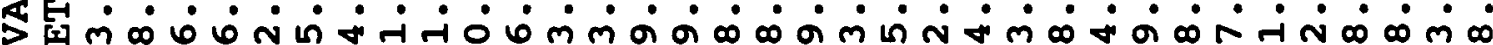

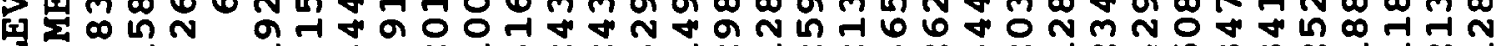

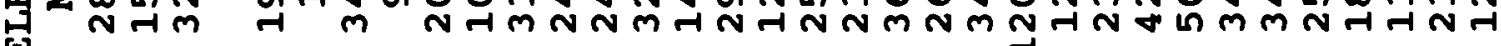

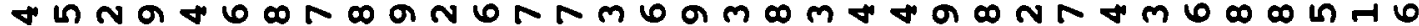
Uึ z

Q

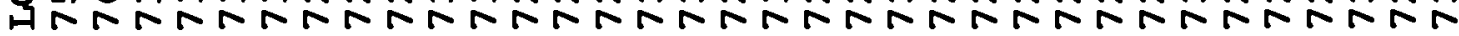

O E.

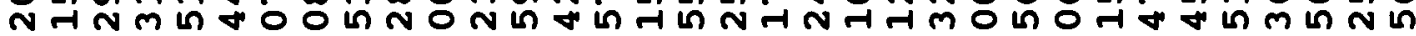
at

H

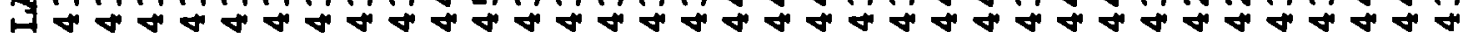

4

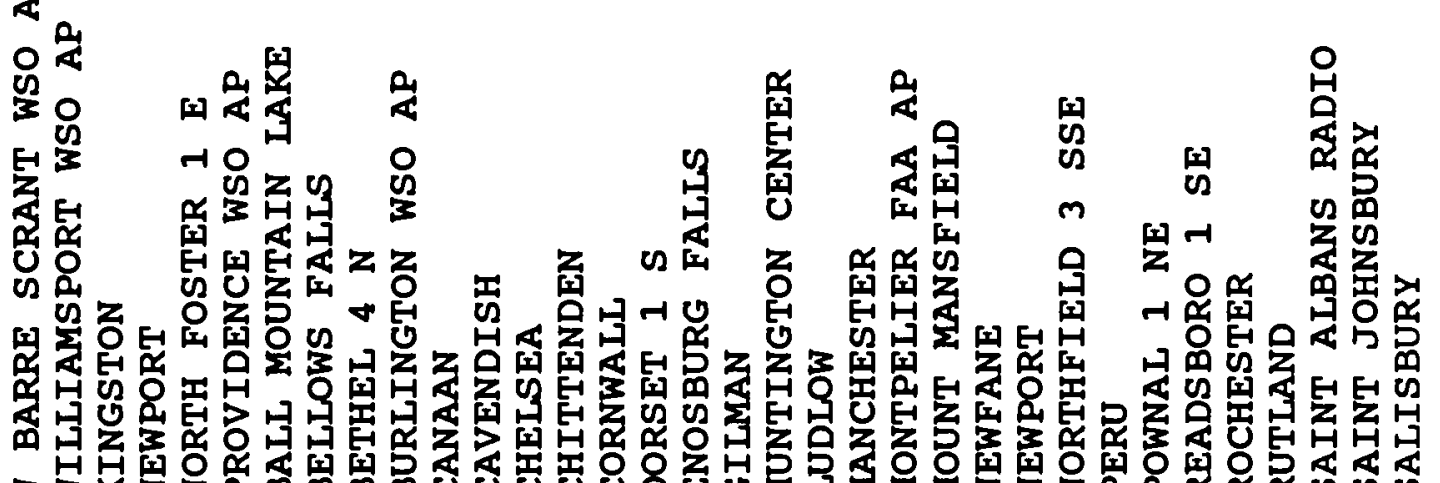

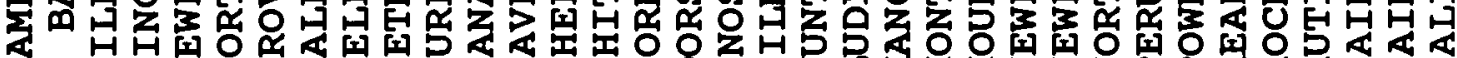

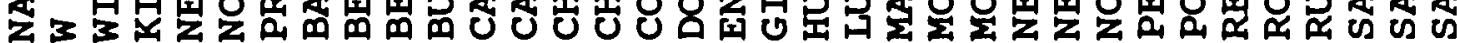

n

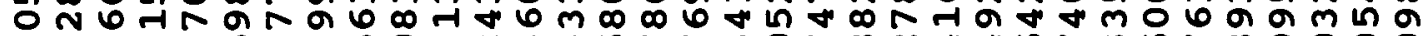

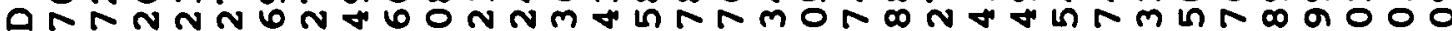
Ho $9+$ in

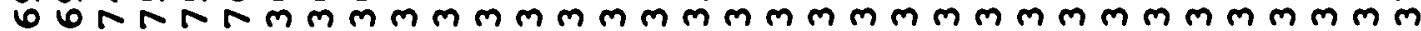
m mmmm m 


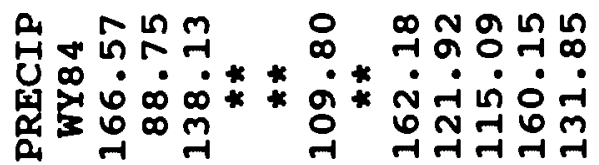

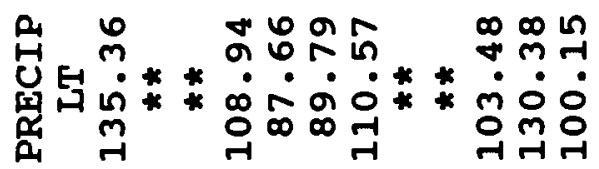

증 ข

H

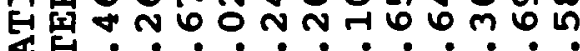

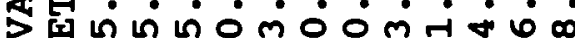

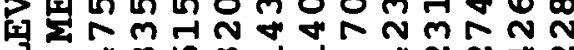
回

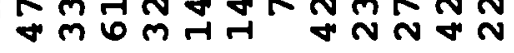

n $\infty \infty$ a เ ט z

dumnnNnNNNGnN

banknknankana

ํำ 루요

$N \rightarrow \infty m N m+\infty N m$

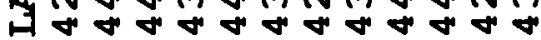

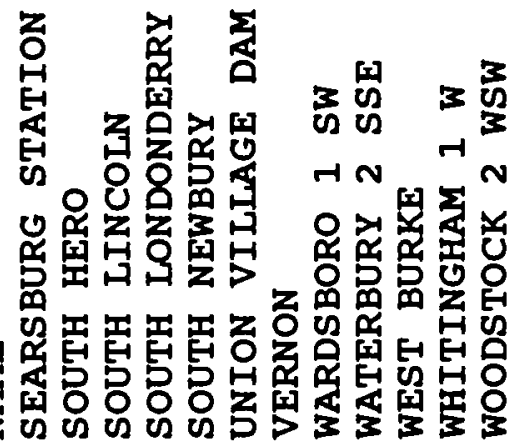

NกNN in 0 न

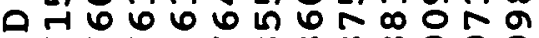
HNRNR⿻ $\infty$ in a a $m m m m m m m m m m$

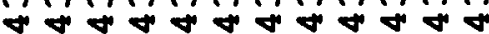




\section{APPENDIX C}

ESTIMATED AND GAGED RUNOFF

FOR THE WITHHELD USGS GAGE SITES 
4 a

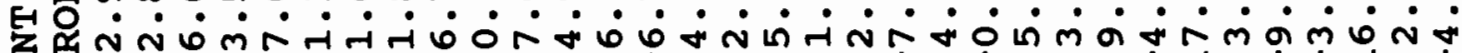

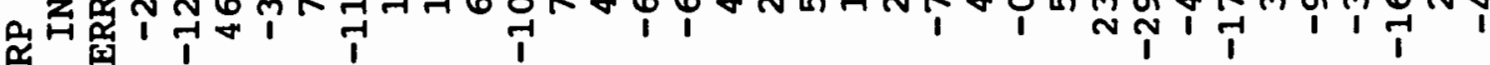

Lumm

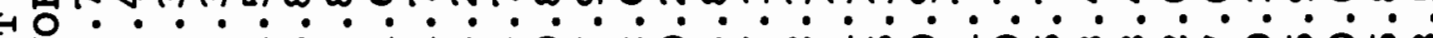
U f

g

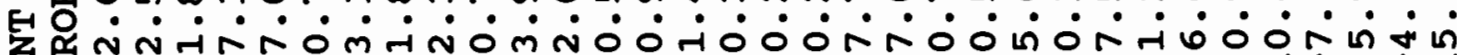

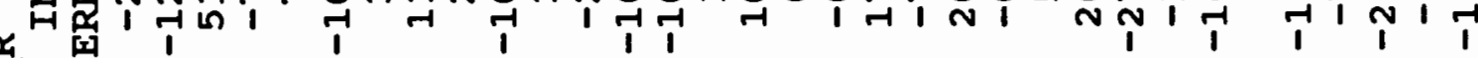

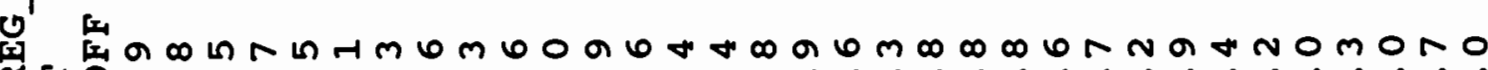
E

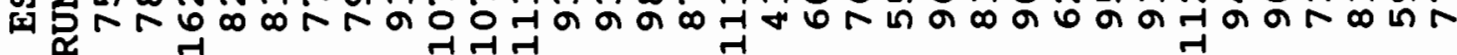

m E $\dot{0} \dot{0} \dot{0} \dot{0} \dot{0} \dot{0} \dot{0} \dot{0} \dot{0} \dot{0} \dot{0} \dot{0} \dot{0} \dot{0} \dot{0} \dot{0} \dot{0} \dot{0} \dot{0} \dot{0} \dot{0} \dot{0}$

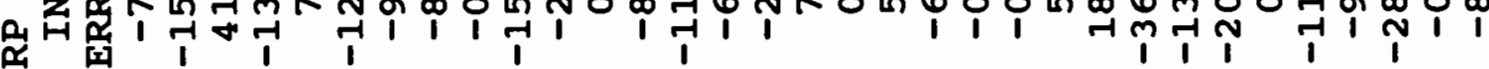

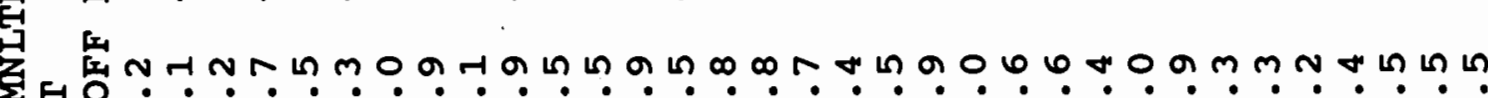

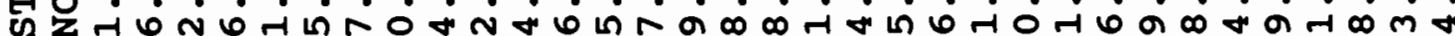

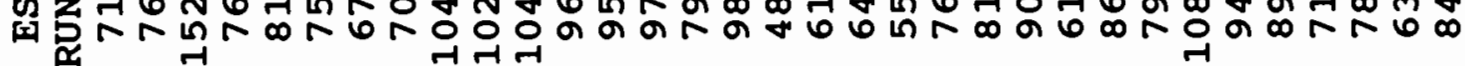

缌的 E

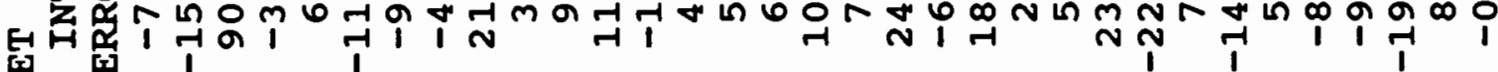
悹

[LIn H म

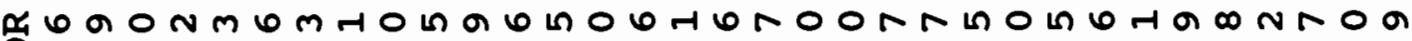

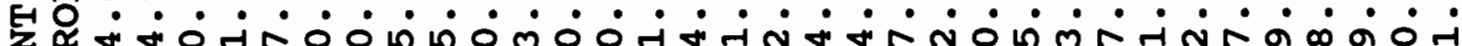
舟留 1 作 dु

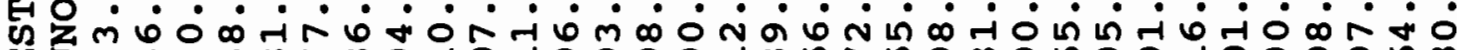

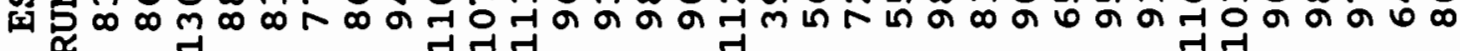

[r

D孯

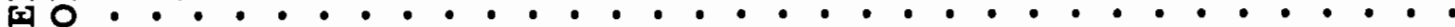

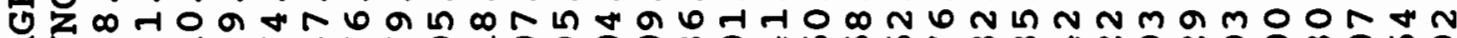

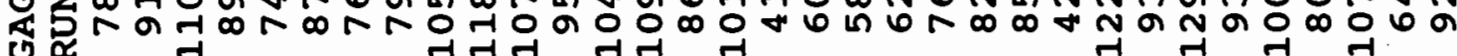

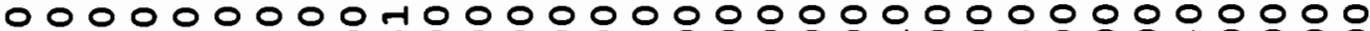

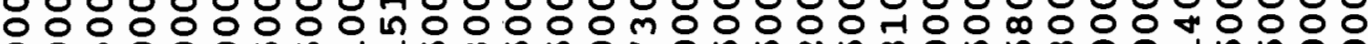

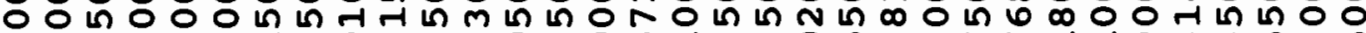
न시에

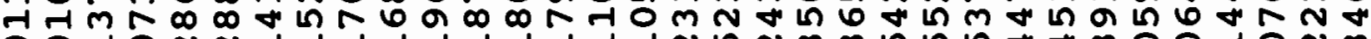

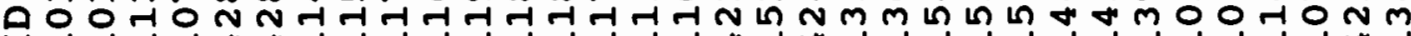

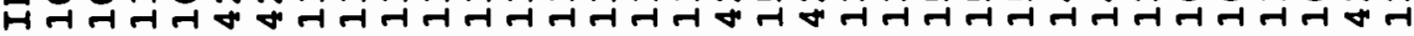


从

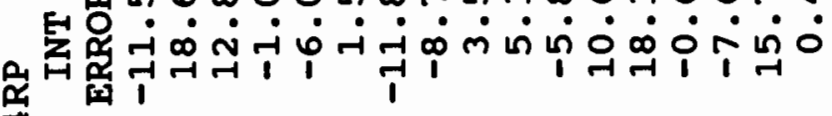

$\infty$

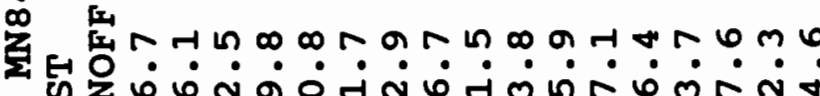

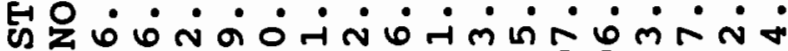
प

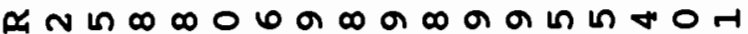

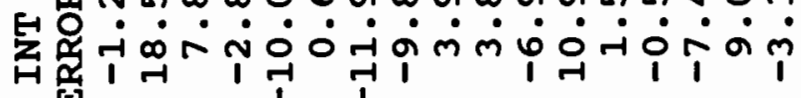
ar |r

宦

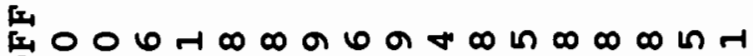

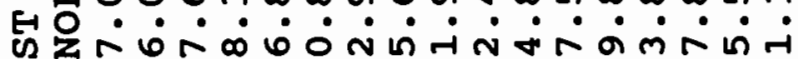
पy

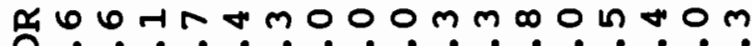

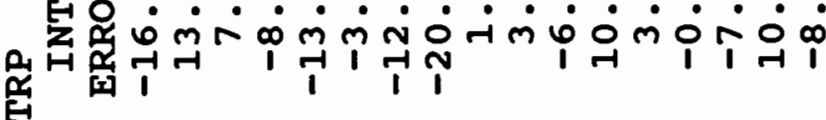

宸

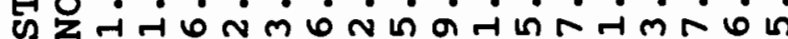

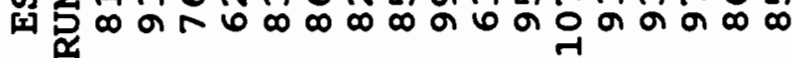

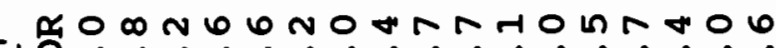

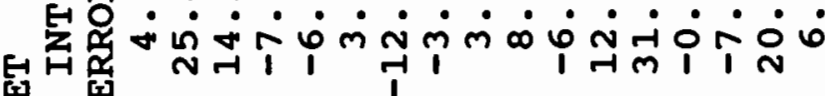

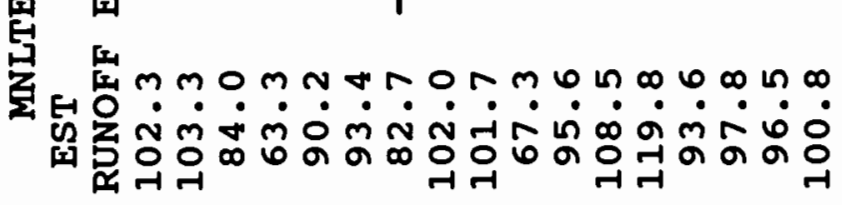
r

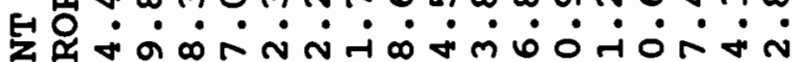
舟出 N 起

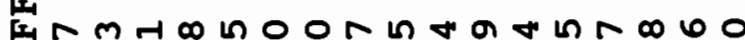
E 0 i $\dot{0} \dot{0} \dot{0} \dot{0} \dot{0} \dot{0} \dot{0} \dot{0}$

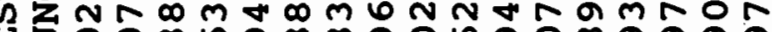

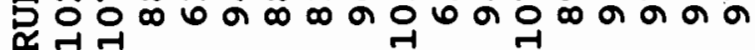

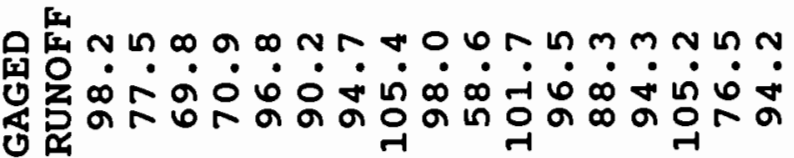

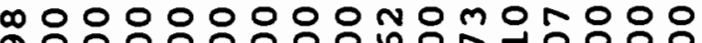

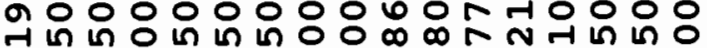

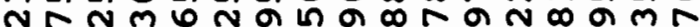

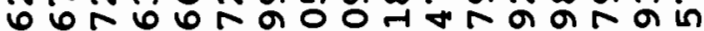

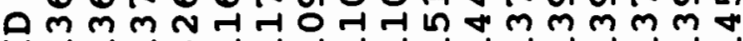

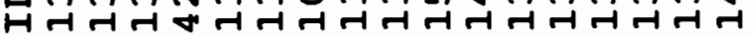

